Universidade de Brasília

Instituto de Ciências Humanas

Departamento de Geografia

Programa de Pós-Graduação em Geografia

PROPOSIÇÃO E AVALIAÇÃO DE UMA ABORDAGEM METODOLÓGICA

PARA O ESTUDO DA VARIABILIDADE ESPAÇO-TEMPORAL DA

PRECIPITAÇÃO NO BRASIL

Raquel Fetter

Tese de Doutorado

Brasília-DF: dezembro/2016 
Universidade de Brasília

Instituto de Ciências Humanas

Departamento de Geografia

Programa de Pós-Graduação em Geografia

\title{
PROPOSIÇÃO E AVALIAÇÃO DE UMA ABORDAGEM METODOLÓGICA PARA O ESTUDO DA VARIABILIDADE ESPAÇO-TEMPORAL DA PRECIPITAÇÃO NO BRASIL
}

\author{
Raquel Fetter
}

Orientadora: Ercília Torres Steinke

Tese de Doutorado

Brasília-DF: dezembro/2016 


\title{
PROPOSIÇÃO E AVALIAÇÃO DE UMA ABORDAGEM METODOLÓGICA PARA O ESTUDO DA VARIABILIDADE ESPAÇO-TEMPORAL DA PRECIPITAÇÃO NO BRASIL
}

\author{
Raquel Fetter
}

Tese de Doutorado submetida ao Departamento de Geografia da Universidade de Brasília, como parte dos requisitos necessários para a obtenção do Grau de Doutor em Geografia, área de concentração Representação Espacial da Dinâmica Territorial e Ambiental.

Aprovado por:

Ercília Torres Steinke, Doutora, Universidade de Brasília (Orientadora)

Rogério Uagoda, Doutor, Universidade de Brasília

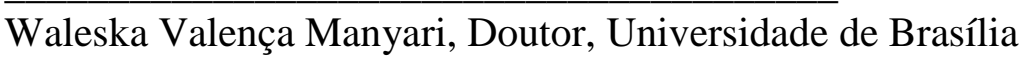

Edilson de Souza Bias, Doutor, Universidade de Brasília

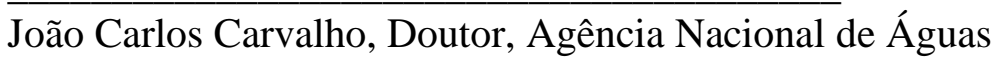


Universidade de Brasília

Instituto de Ciências Humanas

Departamento de Geografia

Programa de Pós-Graduação em Geografia

FETTER, RAQUEL

Proposição e avaliação de uma abordagem metodológica para o estudo da variabilidade espaço-temporal da precipitação no Brasil. 2016. 151 p. (GEA/IH/UnB, Doutorado, Geografia - Representação Espacial da Dinâmica Territorial e Ambiental, 2016).

Tese de Doutorado - Universidade de Brasília. Programa de Pós-Graduação em Geografia.

1. Variabilidade pluviométrica

2. Escala espaço-temporal

3. Efeito orográfico

4. Tendência espaço-temporal

É concedida à Universidade de Brasília permissão para reproduzir cópias desta Tese e emprestar ou vender tais cópias somente para propósitos acadêmicos e científicos. O autor reserva outros direitos de publicação e nenhuma parte desta Tese de Doutorado pode ser reproduzida sem a autorização por escrito do autor.

Raquel Fetter 


\section{AGRADECIMENTO}

Ao meu esposo Carlos, que atuou ativamente em todas as etapas deste trabalho, nas quais obtive um aprendizado enorme e pelo auxílio no desenvolvimento de algoritmos estatísticos e scripts, sem os quais a análise do extenso conjunto de dados seria inviável. Pelo grande incentivo diante das minhas dificuldades, compreensão pelas minhas faltas e angústias, além da disponibilidade para assumir alguns compromissos, dos quais precisei me ausentar.

Ao meu filho Heitor pela felicidade infinita que me proporciona com a sua existência, do qual muitas vezes privei-me do convívio em função de compromissos atrelados ao desenvolvimento das atividades desta tese.

A minha orientadora, Dr. Ercília Torres Steike, pela oportunidade de orientação, confiança, paciência diante das minhas dificuldades e pelas sugestões voltadas ao aperfeiçoamento do trabalho.

Ao professor Raul Yikihiro Matsushita, do Departamento de Estatística da Universidade de Brasília, pelas orientações nas análises estatísticas, as quais foram fundamentais para a definição da abordagem metodológica utilizada.

Ao Laboratório de Ecologia Aplicada, do Departamento de Ecologia, da Universidade de Brasília, pela disponibilidade de um computador servidor com o qual foi obtido o conjunto de dados utilizados e no qual foi desenvolvida a etapa de consolidação do Banco de Dados.

A Comissão de Aperfeiçoamento e Pesquisa (CAPES), pelo apoio financeiro concedido na forma de bolsa.

Ao Programa de Pós-Graduação em Geografia pela disponibilidade de recursos financeiros para a participação em Eventos Científicos.

Aos queridos amigos Suéle e Alan, por se disponibilizarem a tomar conta do meu filho Heitor nos finais de semana próximos à conclusão desta tese.

Ao amigo Romero pelo fundamental auxílio no uso do SIG Quantum Gis 2.12.3 (Lyon) para o qual decidi migrar nas vésperas de finalizar a tese.

Ao amigo Everaldo pela disponibilidade de tomar conta do meu filho Heitor durante a defesa desta tese. 


\section{RESUMO}

O regime pluviométrico no Brasil apresenta significativas variações no espaço e no tempo e a compreensão dos mecanismos que contribuem para essa variabilidade torna-se mais complexa ao migrar para escalas de maior detalhe. Assim, este trabalho propõe uma abordagem metodológica para o tratamento e estudo da variabilidade pluviométrica no Brasil, por meio de informações espaço-temporais de pluviosidade (1888-2010), direção e velocidade do vento (2012-2015) e do Modelo Digital de Elevação $\left(0.025^{\circ}\right)$. O Índice de Proporção de Escalas (IPE) proposto descreve a contribuição relativa da heterogeneidade do espaço e do tempo na variabilidade do regime pluviométrico; o teste de Mann-Kendall identifica tendências espaço-temporais na variabilidade pluviométrica e o Potencial Orográfico de Chuvas descreve o potencial de o relevo brasileiro influenciar a distribuição espaço-temporal da pluviosidade. Foram identificados 5 padrões de IPE, dos quais, A, B e C indicam uma alta variabilidade das chuvas em função do espaço, numa região circular entorno do Brasil central, mais evidentes em distintos meses do ano, de acordo com a localização. Os padrões D e E, no Brasil central e extremo sul do país, correspondem à alta variabilidade temporal das chuvas, que se mantém elevada praticamente o ano todo. Pela análise multiescalar de tendências, percebe-se um incremento significativo de tendências com maiores generalizações temporais. As tendências positivas (TP) aumentam em quantidade e se fortalecem, enquanto que as tendências negativas (TN) aumentam em quantidade e enfraquecem nos locais onde foram originalmente identificadas. Com o aumento da generalização espacial ocorre a diminuição nas ocorrências quando associadas a pequenas generalizações temporais. O principal efeito da generalização espacial é de homogeneização da distribuição de tendências temporais que, quanto mais pontuais e esparsamente distribuídas no espaço, são suavizadas e até eliminadas, enquanto as TN fracas se fortalecem e, as TP fortes enfraquecem. De modo geral, a maior parte do Brasil apresenta POCs muito próximos a 0 (nulo), indicando a ortogonalidade do vento em relação ao relevo e/ou o caráter plano do mesmo. A exceção é o extremo norte do país, com grandes elevações localizadas, e a porção leste do Brasil, caracterizando esses locais como os mais propícios para a ocorrência de chuvas orográficas $(\mathrm{POC}+)$ e o efeito de sombra de chuva (POC-). O POC apresenta grande congruência com a literatura sobre chuvas orográficas e alerta sobre locais e períodos do ano para os quais necessitam de maiores esforços de investigação, como os meses entre maio e outubro, quando o POC se eleva da 
costa ao interior do continente nas regiões sudeste e nordeste, e do extremo norte do Brasil, onde a quantidade de estudos foi inferior de ao restante do país. Na calibração do POC pelo IPE por meio da análise de correlação linear, os maiores $\mathrm{R}^{2}$ mensais ocorrem para $\mathrm{PO}+$ (formação de chuvas orográficas), principalmente em junho, onde $25 \%$ da variabilidade espaço-temporal do efeito orográfico é explicação pelo POC. O caráter ideográfico e nomotético da abordagem proposta possibilitam análises singulares e de caráter genérico da variabilidade pluviométrica, visando o aperfeiçoamento da análise regional, como sugerido para a disciplina geográfica. 


\begin{abstract}
The rainfall in Brazil presents significant variations in space and time and understanding the mechanisms that contribute to this variability becomes more complex when migrating to scales of greater detail. Thus, this study proposes a methodological approach for the treatment and study of rainfall variability in Brazil, through space-temporal rainfall information (18882010), direction and speed of the wind (2012-2015) and the Digital Elevation Model $\left(0.025^{\circ}\right)$. The Scale Proportion Index (IPE) proposed describes the relative contribution of the heterogeneity of space and time in the rainfall variability; The Mann-Kendall test identifies temporal trends in rainfall and the Orografic Potential of Rainfall (POC) describes the potential of the brazilian relief to influence the spatial and temporal distribution of rainfall. We identified 5 patterns of IPE. The patterns called A, B and C indicate a high variability of rainfall in function of space and draw a circular region around the central Brazil, more evident in some months, according to the location. The patterns D and E, in central Brazil and the southern extreme of the country, show a high temporal variability of rainfall, which remains high almost all the year. The multi-scalar trends analysis shows a significant increase of trends with greater temporal generalizations. Along multiple scales, positive trends increase in quantity and become stronger, while negative tendencies also increase in quantity, but became weaker in the places where they were originally identified. As space generalization increases occurs a decreasing on trend occurrences when associated with small temporal generalizations. The main effect of spatial generalization is the homogeneity for temporal trends. As more punctual and sparsely distributed in space, more smoothed. Along scale increasing, the weak negative tendencies on original scale (detail) turns more strengthened for broad scales. Otherwise, the strong positive tendencies become more and more weak. In general, the greater part of Brazil presents POCs very close to 0 (zero), indicating the orthogonality of the wind in relation to the relief and/or the plane and flat terrain. The exception was the extreme north of the country, with a more complex relief, as well the east Brazilian coast, characterizing the more propitious condition for the orographic rainfall (POC+) and the rain shadows (POC-). The POC presents congruence with the literature on orographic rainfall, but also indicates places and times of seasonal cycle that require future research intensification, specifically the months between May and October, when the POC rises from the coast to the interior of the continent on southeast and northeast regions, as well in the north of Brazil with a lower research effort. The calibration of the POC based on IPE
\end{abstract}


values was carried using a linear regression model. The largest $\mathrm{R}^{2}$ values occur for POC+ (orographic rainfall), especially in June, where $25 \%$ of the space-time variability (IPE) was promoted by orographic effect (POC+ variability). The ideographic and nomothetic approach adopted provides generic and singular analysis of rainfall variability, aiming at the improvement of the regional analysis, as suggested for the Geography discipline. 


\section{SUMÁRIO}

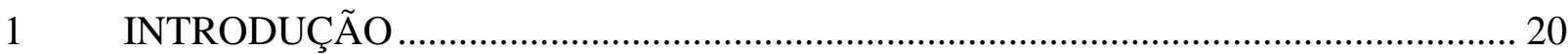

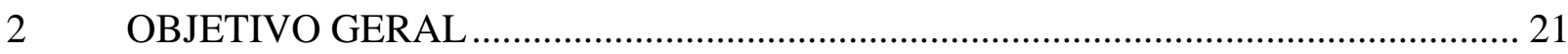

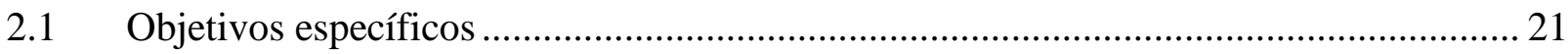

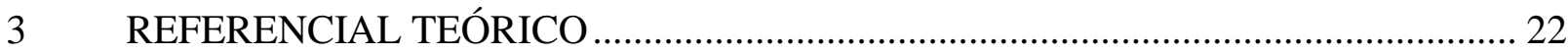

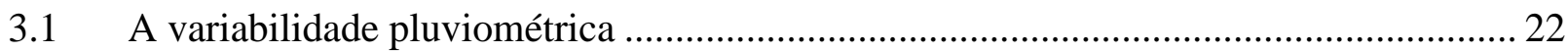

3.2 Sistemas meteorológicos que afetam o tempo no Brasil ............................................. 30

3.2.1 Zona de Convergência Intertropical do Atlântico ........................................................ 30

3.2.2 Zona de Convergência do Atlântico Sul ..................................................................... 31

3.2.3 Vórtices Ciclônicos de altos níveis .................................................................................. 33

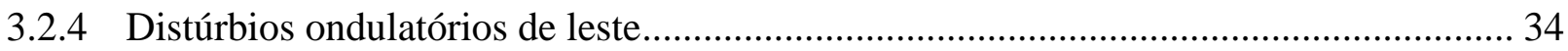

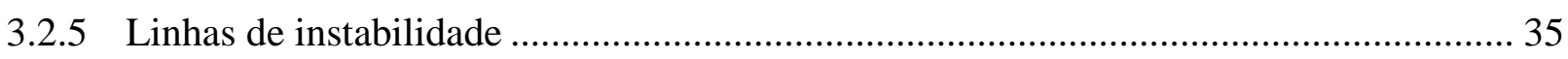

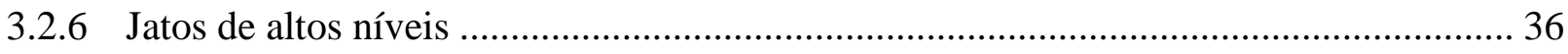

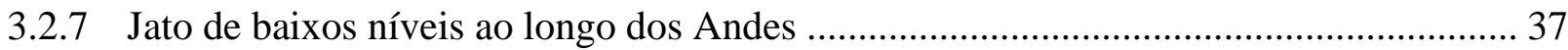

3.2.8 Complexos convectivos de mesoescada na América do Sul (CCM) ............................. 38

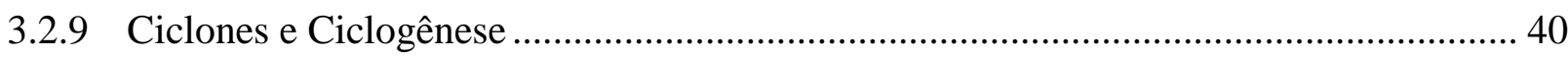

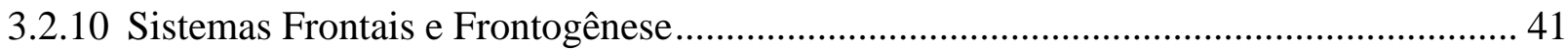

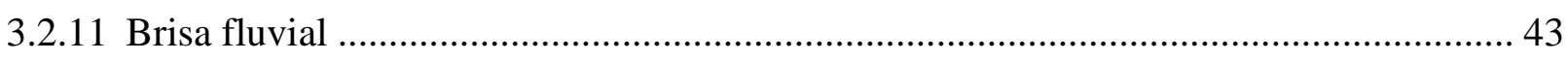

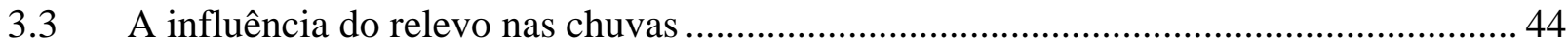

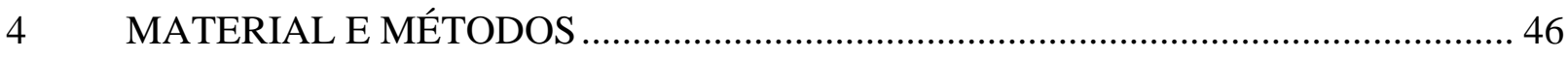

4.1 Estruturação de dados e automatização de processos ............................................... 46

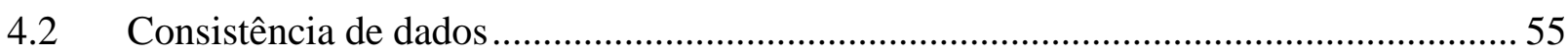

4.2.1 Identificação e eliminação de inconsistências .............................................................. 55

4.2.2 Análise da distribuição espacial dos dados .................................................................. 56

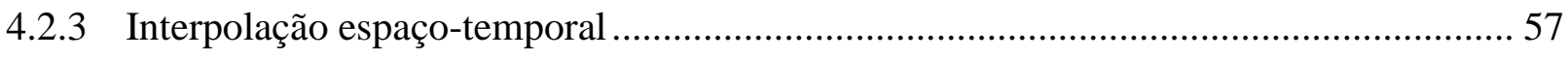

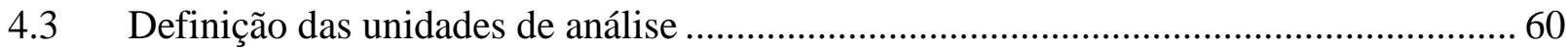

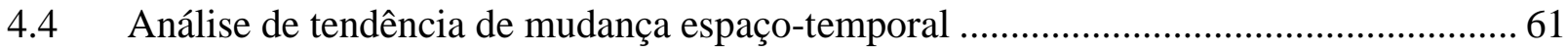

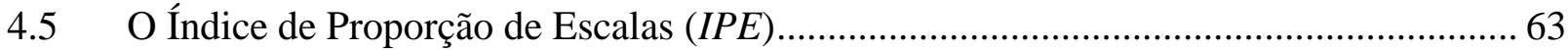

4.6 O potencial para ocorrência de chuvas orográficas no Brasil (POC) ............................ 67

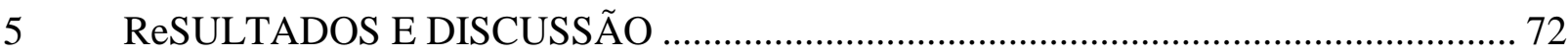


5.1 Características gerais dos dados e sua consistência.................................................... 72

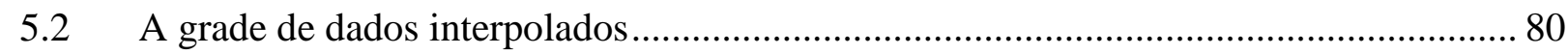

5.3 O Índice de Proporção de Escalas - IPE ................................................................. 93

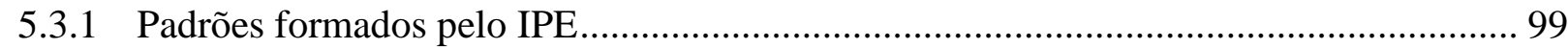

5.3.2 Os sistemas de tempo local formados pelos drivers de escala sinótica ....................... 105

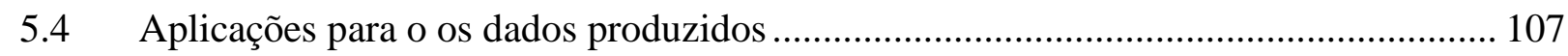

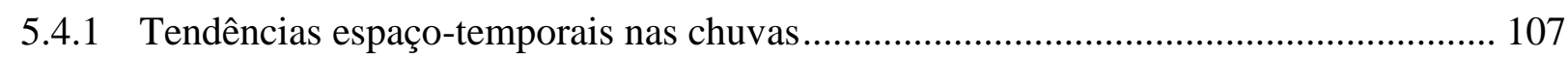

5.4.2 O Potencial orográfico para Chuvas (POC) e o Índice de Proporção de Escalas (IPE) 115

5.5 Apontamentos e reflexões acerca das possibilidades de aplicações futuras ................. 133

5.5.1 Contribuições para o planejamento da rede de estações pluviométricas ...................... 133

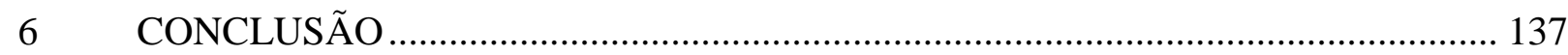

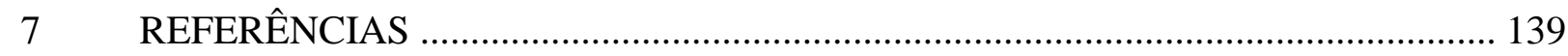




\section{LISTA DE FIGURAS}

Figura 1: Representação de diferentes processos que conduzem ao aumento do volume pluviométrico em função do fluxo de ar sobre uma montanha: a) mecanismo semeadoralimentador, b) condensação pelo fluxo forçado na subida, c) desencadeamento ascendente da convecção, d) formação de nuvem resultante do bloqueio do fluxo orográfico ou propagação de ondas de gravidade, e) disparo térmico por uma fonte de calor elevada, f) convergência a sotavento devido ao fluxo entorno da montanha, g) reforço da precipitação a sotavento por ondas de gravidade induzidas pela montanha. Fonte: AUSTIN e DIRKS (2005). 46

Figura 2: Sobreposição da localização das 10.939 Estações Meteorológicas, vinculadas a Agência Nacional de Águas - ANA e utilizadas neste estudo, cujos registros não são, necessariamente, simultâneos ao longo da série de 1888-2010

Figura 3: Distribuição espacial das 704 estações meteorológicas automáticas do INMET, utilizadas para o cálculo de direção e velocidade do vento para os 809 quadrantes, na resolução de $1^{\circ}$ de arco de latitude e longitude

Figura 4: Modelo Digital de Elevação do Brasil, reamostrado da resolução de 0,002778 para 10 " de arco de latitude e longitude ( $30 \mathrm{~m})$ utilizado para a derivação da clinografia e direção das vertentes para os 809 quadrante. Fonte: TOPODATA/INPE. Nota: Reamostrado pelo autor.

Figura 5: Apresentação da interface de armazenamento e manipulação do Banco de Dados, contendo um total de 56 tabelas.

Figura 6: Modelo Entidade-relacionamento do Banco de Dados. As entidades (retângulos) representam as relações ou tabelas cujo conteúdo mantém relação com as demais por meio de atributo chaves, representados pelos círculos azuis. Os losangos indicam o tipo de relacionamentos entre as entidades. 53 
Figura 7: Exemplo de um script em linguagem PHP, desenvolvido para a criação, manipulação e manutenção do banco de dados por proporcionar uma ampla gama de possibilidades de gerenciamento de Sistemas de Gerenciamento de Bancos de Dados em $S Q L$ e análises diversas.

Figura 8: Distribuição espacial das 704 estações meteorológicas automáticas do INMET, utilizadas para o cálculo de direção e velocidade do vento para os 809 quadrantes, na resolução de $1^{\circ}$ de arco de latitude e longitude.

Figura 9: Clinografia do relevo brasileiro, obtido do Modelo Digital de Elevação, na resolução de $0.025^{\circ}$ de latitude e longitude.

Figura 10: Direção de vertentes do relevo brasileiro, obtido do Modelo Digital de Elevação, na resolução de $0.025^{\circ}$ de latitude e longitude. 68

Figura 11: Linha do tempo apresentando os registros das 10.939 estações meteorológicas no Brasil, mostrando o início e o final de operação de cada estação (organizadas sequencialmente ao longo do eixo das ordenadas), bem como as interrupções (faixas claras ao longo do eixo das abcissas) e a quantidade de estações meteorológicas funcionando simultaneamente (vermelho). 73

Figura 12: Linha do tempo apresentando os registros das meteorológicas nos estados brasileiros, mostrando o início e o final de operação de cada estação (organizadas sequencialmente ao longo do eixo das ordenadas), bem como as interrupções (faixas claras ao longo do eixo das abcissas) e a quantidade de estações meteorológicas funcionando simultaneamente (vermelho). 78

Figura 13: Quantidade de estações meteorológicas em funcionamento e valores anuais de índice do vizinho mais próximo $(\mathrm{NNI})$. Valores de NNI próximos a 1,0 indicam tendência à distribuição espacial aleatória das estações; conforme os valores diminuem, indica-se a tendência à distribuição agregada; conforme os valores ultrapassam 1,0 (condição não existente nos dados presentes), indica-se uma distribuição uniforme. 
Figura 14: Disponibilidade de dados pluviométricos das estações meteorológicas administradas pela ANA (Agência Nacional de Águas), nas Unidades da Federação, referente ao período de 1888 a 2010 (consulta realizada em abril de 2011). Dados originais: Agência Nacional de Águas. Organização: Fetter (2016).

Figura 15: Disponibilidade de dados pluviométricos das estações meteorológicas administradas pela ANA (Agência Nacional de Águas), nas Unidades da Federação, referente ao período de 1888 a 2010 (consulta realizada em abril de 2011). Dados originais: Agência Nacional de Águas. Organização: Fetter (2016). 80

Figura 16: Quantidade de estações meteorológicas com precipitação superior a $350 \mathrm{~mm}$, por Unidades da Federação, nos dados disponibilizados pela ANA (Agência Nacional de Águas, referente ao período de 1888 a 2010 - consulta realizada em abril de 2011). Dados originais: Agência Nacional de Águas. Organização: Fetter (2016). 81

Figura 17: Casos de precipitação diária acima de $350 \mathrm{~mm}$ por Unidades da Federação nos dados disponibilizados pela ANA (Agência Nacional de Águas, referente ao período de 1888 a 2010 - consulta realizada em abril de 2011). Dados originais: Agência Nacional de Águas. Organização: Fetter (2016). 82

Figura 18: Percentual de dados válidos após a interpolação espacial da série pluviométrica de 1888 a 2010 e disponíveis para uso. O eixo x apresenta a série temporal, na unidade de resolução mensal ( 1.476 casos $=123$ anos $x 12$ meses), cada uma contendo 809 interpolações $(1.194 .084=809 \times 123 \times 12)$, das quais $27.88 \%$ (332.615) permaneceram nulas e 5,33\% (45.916) foram eliminados devido à ocorrência de efeito pepita. 83

Figura 19: Sucesso da interpolação, apresentado em intervalos de décadas, na forma de percentual de quadrantes com casos não nulos entre 1888 e 1950m após a interpolação 84

Figura 20: Pluviosidade média mensal e anual no Brasil, na série de 1975 a 2010. 86

Figura 21: Desvio padrão da pluviosidade mensal e anual no Brasil, na série de 1975 a 2010. 
Figura 22: Coeficiente de variação da pluviosidade mensal e anual no Brasil, na série de 1975 a 2010.

Figura 23 Precipitação pluviométrica anual no Brasil, segundo distintas fontes. Alguns dados são apresentados em médias diárias ( $\mathrm{mm} / \mathrm{dia})$, outros em totais acumulados ( $\mathrm{mm} / \mathrm{ano})$. 90

Figura 24: Direção e velocidade média do vento nos meses de janeiro a junho para os 809 quadrantes sobre o Brasil (continua).

Figura 25: Direção e velocidade do vento para os meses de julho a dezembro para os 809 quadrantes sobre o Brasil.

Figura 26: Pluviosidade média diária, desvios no tempo (Dt), desvios no espaço (De) e IPE para a série pluviométrica de 1975 a 2010, no Brasil, na escala 3M x 3Q.

Figura 27: Precipitação média diária, Média do Módulo dos Desvios no tempo (Dt - desvios em função do tempo) e Média do Módulo dos Desvios no espaço (De - desvios em função do espaço) e Índice de Proporção de Escalas (IPE) para a série pluviométrica de 1975 a 2010, para o ciclo anual e meses separadamente, na escala $3 \mathrm{M} \times 3 \mathrm{Q}$ 97

Figura 28: Precipitação média diária, Média do Módulo dos Desvios no tempo (Dt - desvios no tempo) e Média do Módulo dos Desvios no espaço (De - desvios no espaço) e Índice de Proporção de Escalas (IPE) para a série pluviométrica de 1975 a 2010, para o ciclo anual e meses separadamente, na escala $3 \mathrm{M} \times 3 \mathrm{Q}$ 98

Figura 29: Padrões (de A até E) identificados com base no Índice de Proporção de Escalas (IPE) (a) e os principais sistemas de tempo meteorológicos que atuam sobre a variabilidade espaço-temporal das chuvas no Brasil (IPE - b). ASPS: Anticiclone Semipermanente do Pacífico Sul; ASAS: Anticiclone Semipermanete do Atlântico Sul; ZCIT: Zona de Convergência Intertopical; ZCAS: Zona de Convergência do Atlântico Sul; CCM: Complexos Convectivos de Mesoescala; JBN: Jatos de Baixos Níveis; FF: Frente Fria; LI: Linhas de Instabilidade; APA: Anticilone Polar Atlântico. 100 
Figura 30: Ocorrências de tendências pluviométricas (teste de Mann-kendall) positivas e negativas nos meses do ano no Brasil, na série de 1975 a 2010, na escala de 1M e 1Q. Os números expressam a quantidade de quadrantes, de um total de 809.

Figura 31: Distribuição espaço-temporal de tendências pluviométricas (teste de Mannkendall) mensais e anual no Brasil, na série de 1975 a 2010, na escala de 1M e 1Q. 108

Figura 32: Distribuição espacial de tendências (teste de Mann-kendall) anuais positivas e negativas na precipitação do Brasil, para a série pluviométrica de 1975 a 2010. O efeito da generalização espacial na distribuição de tendências é observado ao efetuar a leitura da figura na vertical, de cima para baixo; para observar o efeito da generalização temporal é preciso que a escala espacial esteja constante, efetuando a leitura da figura na horizontal, da esquerda para a direita; o efeito do aumento de ambas as escalas é identificado pela leitura da figura na diagonal.

Figura 33: Distribuição multiescalar de tendências anuais na precipitação do Brasil, para a série pluviométrica de 1975 a 2010.

Figura 34: Distribuição multiescalar de tendências anuais negativas na precipitação do Brasil, para a série pluviométrica de 1975 a 2010.

Figura 35: Distribuição de tendências anuais positivas na precipitação do Brasil, para a série pluviométrica de 1975 a 2010.

Figura 36: Distribuição espacial do POC anual e para distintos meses e para o ano. 117

Figura 37: Distribuição dos estudos sobre a influência do relevo nas chuvas no Brasil, indicados pelos respectivos retângulos envolventes (com labels pretos). No caso de estudos locais, são indicados pontos (com labels vermelhos) e a área fica limitada a $0 \mathrm{~km}^{2}$.

Figura 38: Coeficientes de determinação $\left(\mathrm{R}^{2}\right)$ para o modelo linear de correlação entre IPE e POC para a escala de $3 \mathrm{M}$ e $3 \mathrm{Q}$, para os distintos meses do ano. 
Figura 39: Resíduos mensais e anual da correlação entre IPE e POC+ (formação de chuvas orográficas)

Figura 40: Resíduos mensais e anual da correlação entre IPE e POC- (formação de sombra de chuvas)

Figura 41: Representação da necessidade de adensamento de estações meteorológicas em função de altos e baixos valores de IPE.

Figura 42: Representação gráfica simplificada de um modelo linear para cálculo do adensamento de estações pluviométricas em um local participante de uma rede regional de estações meteorológicas, dado um valor local de IPE e com base no conhecimento prévio de valores mínimos, máximos e médios da densidade planejada de estações e do IPE 136 


\section{LISTA DE TABELAS}

Tabela 1: Escalas espaço-temporais propostas para o estudo da variabilidade pluviométrica no Brasil (36 escalas). Os números no centro da tabela indicam o produto entre o tamanho das janelas temporais e espaciais, portanto, o número de itens utilizados para compor cada média móvel.

Tabela 2: Classificação dos valores de POC de acordo com a clinografia, velocidade do vento e o alinhamento entre direção do vento e direção da vertente 67

Tabela 3: Coeficientes de Pearson (r) para correlação linear entre valores de PLSD, desvios no tempo (Dt), desvios no espaço (De) e Índice de proporção entre escalas (IPE) ( $\mathrm{n}=12$ meses $\mathrm{x}$ 809 quadrantes $=9708$ )

Tabela 4: Coeficientes de Pearson para correlação linear entre valores médios mensais $(n=12)$ de PLSD, desvios no tempo (Dt), desvios no espaço (De) e Índice de proporção entre escalas (IPE) 


\section{LISTA DE ABREVIATURAS E SIGLAS}

\begin{tabular}{|c|c|}
\hline $\mathrm{AB}$ & Alta da Bolívia \\
\hline ANA & Agência Nacional de Águas \\
\hline $\mathrm{BC}$ & Baixa do Chaco \\
\hline $\mathrm{BD}$ & Banco de Dados \\
\hline $\mathrm{CCM}$ & Complexos Convectivos de Mesoescala \\
\hline $\mathrm{CV}$ & Coeficiente de variação \\
\hline De & Média dos módulos dos desvios devido ao espaço (desvios no espaço) \\
\hline DOL & Distúrbios Ondulatórios de Leste \\
\hline DP & Desvio padrão \\
\hline $\mathrm{Dt}$ & Média dos módulos dos desvios devido ao tempo (desvios no tempo) \\
\hline FDE & Fator Direcional Específico \\
\hline FDEQ & Fator Direcional Específico do Quadrante \\
\hline FPA & Frente Polar Atlântica \\
\hline FPP & Frente Polar Pacífica \\
\hline $\mathrm{HN}$ & Hemisfério Norte \\
\hline HS & Hemisfério Sul \\
\hline INMET & Instituto nacional de Meteorologia \\
\hline IPE & Índice de Proporção de escalas \\
\hline JBN & Jatos de Baixos Níveis \\
\hline JP & Jato Polar \\
\hline JST & Jato Subtropical \\
\hline M & Mês \\
\hline MDE & Modelo Digital de Elevação \\
\hline MySQL & Gerenciador de Banco de Dados que utiliza a linguagem SQL \\
\hline NNI & Nearest Neighbor Index \\
\hline OMM & Organização Meteorológica Mundial \\
\hline PHP & Hypertext Preprocessor ou Personal Home-Page Language \\
\hline PLSD & Pluviosidade \\
\hline POC & Potencial Orográfico de chuvas \\
\hline
\end{tabular}


POC- Potencial Orográfico para a inibição de chuvas

POC+ $\quad$ Potencial Orográfico para o aumento de chuvas

POOQ Potencial Orográfico Omnidirecional do Quadrante q

Q Quadrante

SGBD Sistema de Gerenciamento de Banco de Dados

SQL Structured Query Language - Linguagem de Consulta Estruturada

TP Tendência Positiva

TN Tendência Negativa

ZCAS Zona de Convergência do Atlântico Sul

ZCIT Zona de Convergência Intertropical 


\section{INTRODUÇÃO}

O regime pluviométrico no Brasil apresenta significativas variações no espaço e no tempo e a compreensão dos mecanismos que contribuem para essa variabilidade torna-se mais complexa ao migrar para escalas de maior detalhe, onde é identificado maior número de fatores e de interações que modulam a precipitação. Esse tema permite inúmeras possibilidades de abordagens analíticas, as quais vêm sendo aplicadas e descrevem a influência de fatores espaciais e temporais, como por exemplo, da topografia, do tipo de vegetação, de ilhas de calor urbanas, desmatamento, variabilidade de sistemas atmosféricos, etc. No entanto, a dificuldade de identificar os limites na manifestação dos fenômenos na escala espaço-temporal decorre não somente da complexa interação entre os mesmos, mas também pelas diferenças metodológicas que cada escala exige, como pela preferência de autores em determinadas abordagens metodológicas, que dificultam aproximações mais precisas do conjunto desses estudos. Além disso, é comum cada abordagem demandar adequações nos bancos de dados, visto a necessidade de correspondência escalar, eliminação de inconsistências e de preenchimento de falhas.

Com a tecnologia de banco de dados relacional tem sido possível integrar conjuntos de dados de diversas naturezas e, para o estudo de natureza climatológica, não é diferente. É provável que parte das questões citadas acima fosse esclarecida, caso houvesse pareamento entre os resultados de diferentes estudos. Para que os bancos de dados deem suporte a elevado volume de informações, na perspectiva de manter o pareamento entre essas, é inevitável o desenvolvimento de habilidades como o domínio de procedimentos estatísticos e linguagens computacionais para o desenvolvimento de algoritmos de análise, além do domínio das propriedades do fenômeno estudado visando à identificação de tratamentos estatísticos e abordagens metodológicas apropriadas.

A interpretação dos padrões espaciais resultantes da interação entre a sociedade e os fenômenos climáticos, constitui o foco de estudo da Climatologia Geográfica, muito mais do que a análise da física e microfísica relacionada aos processos (da qual é fundamental ter o domínio). Assim, este trabalho propõe uma abordagem metodológica para o tratamento e estudo da variabilidade pluviométrica, com a hipótese de que a consolidação de banco de dados relacional, com a incorporação de grande volume de dados, submetido a procedimentos 
analíticos sistemáticos, por meio de algoritmos estatísticos construídos em linguagem de programação para a automação de análises multiescalares, constitui uma abordagem promissora para o avanço científico da Climatologia Geográfica no Brasil. Assim, as questões abordadas neste trabalho, voltadas à averiguação da hipótese, estiveram relacionadas a possibilidade de identificar o papel da variação espacial e temporal na distribuição de tendências nos dados pluviométricos; a possibilidade de medir a parcela da variabilidade em função da heterogeneidade temporal e espacial; e a possibilidade de descrever o potencial de o relevo brasileiro influenciar o regime pluviométrico do Brasil, diante da sazonalidade do vento.

\section{OBJETIVO GERAL}

Propor, avaliar e demonstrar a potencialidade de uma abordagem metodológica para o estudo sistemático da variabilidade pluviométrica no Brasil, por meio da consistência de um banco de dados pluviométrico, eólico e topográfico.

\subsection{Objetivos específicos}

- Consolidar um banco de dados para o estudo da variabilidade pluviométrica no Brasil, por meio da estruturação e adequação de informações espaço-temporais de pluviosidade e vento;

- Avaliar a contribuição relativa da heterogeneidade do espaço e do tempo na variabilidade do regime pluviométrico;

- Analisar a distribuição multiescalar de tendências espaço-temporais na variabilidade pluviométrica em uma rede sistematizada de dados;

- Avaliar o potencial de o relevo brasileiro influenciar a distribuição espaçotemporal da pluviosidade;

- Propor a adequação de redes de pluviômetros ao longo do território brasileiro. 


\subsection{A variabilidade pluviométrica}

Diversos fatores geográficos contribuem para a distribuição e variabilidade das chuvas no Brasil, como a grande extensão territorial e configuração geográfica, com a maior parte do território contida na zona tropical, extensas áreas litorâneas e áreas afastadas do litoral, características topográficas diversificada, com cotas altimétricas que variam do nível do mar a cotas superiores a 2.000 metros, a disposição dos compartimentos de serras, planaltos e planícies, que atuam como barreiras e corredores atmosféricos, os diferentes tipos de vegetação, das quais, as florestas contribuem de forma significativa com o fornecimento de água para a atmosfera pela evapotranspiração (MENDONÇA e DANNI-OLIVEIRA, 2007).

A pluviosidade nos trópicos origina-se principalmente pela convecção e tende a ser mais localizada em sua distribuição espacial. Com exceção de algumas áreas, principalmente em torno da zona equatorial, onde as chuvas são bem distribuídas ao longo do ano, as chuvas são na sua maioria sazonais e essa sazonalidade torna-se cada vez mais pronunciada com o crescente afastamento da fonte de suprimento de umidade. Ao contrário dos trópicos, nas regiões temperadas ocorre a passagem de maior número de massas de ar, com características contrastantes de temperatura e umidade, que originam depressões frontais com distintas sequências de tipos de tempo. As estações nessa região são determinadas mais pela temperatura do ar do que pelo volume de chuvas, como acontece nos trópicos, e as quais são dominantemente ciclônicas e tendem a ser distribuídas mais igualmente durante o ano, exceto no interior do continente (AYOADE, 2012).

A Massa Equatorial Norte (mEn) originada no anticiclone do Atlântico Norte (AAN), a Massa Equatorial Atlântica (mEa) originada no anticiclone semifixo do Atlântico Sul (ASAS) fornecem umidade e calor para a atmosfera, principalmente das regiões norte e nordeste do país. Também nessa região, as chuvas são influenciadas pela proximidade do cavado equatorial, onde se localiza a Zona de Convergência Intertropical, uma área de elevada convergência de umidade que atinge latitudes entorno de $5^{\circ} \mathrm{S}$ em março e $10^{\circ} \mathrm{N}$ em setembro, determinando a quantidade de chuva das regiões onde se estabelece. A Massa Equatorial Continental $(\mathrm{mEc})$ originada na planície Amazônica, além atuar localmente, fornece umidade 
e calor para as regiões centro-sul do país. A alta pressão associada ao ASAS gera a Massa Tropical Atlântica (mTa) que se estende sobre o país nos meses de inverno, entorno da latitude de $30^{\circ}$, na qual também se localiza a depressão do Chaco, uma região de baixa pressão que gera a Massa Tropical Continental (mTc) sobre o altiplano Boliviano. Ambas são mais pronunciadas no verão, no entanto, enquanto a mTa proporciona a elevação dos totais pluviométricos a mTc reduz a umidade em curtos períodos de tempo na região. Na porção central do país ocorre convergência de umidade proveniente do encontro de massas de ar quente e úmida da Amazônia e do Atlântico Sul e que origina a Zona de convergência do Atlântico Sul (ZCAS). O anticiclone migratório polar gera a Massa Polar Atlântica (mPa), a qual caracteriza a estação de inverno nos climas brasileiros, cuja superfície frontal atua constantememente na porção centro-sul e interfere nos climas das porções centro-nortenordeste particularmente em parte do outono, inverno e primavera onde boa parte das chuvas tem origem nos processos frontogenéticos (MENDONÇA e DANNI-OLIVEIRA, 2007).

Aliado a esses fatores naturais, estão às modificações decorrentes do uso do espaço pela sociedade que, ora aumenta, ora reduz a heterogeneidade espacial e causam alterações no balanço de radiação na superfície e que são citados na literatura pela sua capacidade em alterar o regime de precipitação. Na região metropolitana de São Paulo VEMADO e PEREIRA FILHO (2016) descreveram a combinação do efeito de ilha de calor local com as brisas marinhas comuns na região. Os resultados são episódios intensos de chuva logo após a passagem da frente da brisa marinha sobre a região, os quais podem chegar a máximos acumulados de 600 milímetros ou cerca de quatro vezes mais do que em áreas rurais ou menos urbanizadas no seu entorno, quando em condições de temperaturas do ar e ponto de orvalho acima $30 \circ \mathrm{C}$ e $20 \circ \mathrm{C}$, respectivamente. LIU et al. (2016) identificaram que a poluição urbana de Manaus é transportada pelos ventos para oeste de 100 a $300 \mathrm{~km}$ e interferem nos mecanismos de oxidação dos compostos orgânicos voláteis emitidos pela floresta, como o isopreno, interferindo nos processos de formação e crescimento das gotas de chuva. Como resultado são formadas grandes quantidades de partículas menores que demoram mais pra crescer e evolui, diminuindo o potencial dessas nuvens formarem chuva. Quando a atmosfera está limpa de poluição, ARTAXO et al. (2005) salienta que os compostos orgânicos voláteis da região Amazônica, disputam menos por água, crescem rápido e o resultado são nuvens baixas que precipitam, devolvendo os núcleos de condensação para o local. Em casos de atmosfera poluída, como ocorre, por exemplo, na estação seca devido ao aumento das 
queimadas, aumenta a quantidade de núcleos de condensação, os quais disputam mais por água e as gotas crescem pouco e devagar enquanto a nuvem vai crescendo. Pode ocorrer de as gotas evaporarem e não retornarem ao chão, ou das gotas crescerem demais, subirem, congelarem, gerando nuvens altas e profundas, as quais podem crescer tanto a ponto de serem transportadas para outros locais levando consigo a água e os núcleos de condensação.

A representação da distribuição das chuvas tanto no espaço como no tempo é essencial para determinar a influência da precipitação no ciclo hidrológico e em diversas atividades humanas (KOUTSOYIANNIS, 2006). No entanto, a mensuração das inúmeras variáveis que determinam a variabilidade em diferentes escalas de tempo e de espaço é considerada uma tarefa difícil (HARRIS e GEORGIOU, 2001) diante da complexidade inerente aos processos (BARROS e LETTENMAIER, 1994). Inclusive, tem sido frequente a estratégia de analisar os fenômenos, separadamente, no tempo e no espaço (WU, 1999).

Dentre as questões fundamentais para o estudo da Climatologia Geográfica está o questionamento de como lidar com a inconsistência de dados nas séries temporais, visto a frequente ocorrência das mesmas e o obstáculo que constituem para o estudo da variabilidade da precipitação, podendo gerar resultados tendenciosos (ZAVATTINI e BOIN, 2013).

Segundo o Manual de orientações para consistência de dados pluviométricos da Agência Nacional de Águas (ANA, 2012) a análise de consistência tem como objetivo identificar, corrigir e preencher as falhas nos registros pluviométricos diários das estações meteorológicas e ressalta a necessidade de analisar registros de estações próximas. No entanto, considerando que a pluviosidade é influenciada por diversos fatores físicogeográficos espera-se que, em grandes distâncias, o regime não seja muito homogêneo (KELLER FILHO, ASSAD e LIMA, 2005), dificultando o preenchimento das falhas diárias das estações (BERTONI e TUCCI, 2001). Além disso, quanto mais longo for o período de observação, mais precisa é a imagem da variação ao longo do tempo (KOUTSOYIANNIS, 2006).

Assim, o conhecimento dos fatores que influenciam a precipitação de uma região é critério importante no processo de análise já que diferenças entre registros de estações próximas podem ocorrer tanto por mudanças relacionadas ao clima como a ocupação do espaço por atividades humanas, as quais podem produzir resultados similares e gerar incertezas quando necessárias ao processo de gestão (ANA, 2012). 
A densidade e a distribuição dos pluviômetros também é altamente determinante da exatidão da precipitação sobre uma região (ANDERS et al., 2006; CHENG, LIN e LIOU, 2008; VILLARINI et al., 2008; MISHRA, 2013; JUNG et al., 2014). A representatividade espacial de uma estação meteorológica varia de acordo com a complexidade espacial, onde uma estação localizada em uma paisagem mais homogênea pode ser mais representativa das condições de tempo numa grande extensão dessa paisagem, enquanto que uma estação localizada em uma paisagem mais heterogênea pode representar as condições de tempo apenas numa pequena extensão dessa. Merece menção o fato de a localização das estações meteorológicas no Brasil estar fortemente relacionada ao processo de ocupação territorial, podendo apresentar maior ou menor grau de agregação no espaço e no tempo e não representar a variação espacial real da precipitação (ZAVATTINI e BOIN, 2013).

Os processos de estimativa de dados pluviométricos, por vários anos, foram obtidos por técnicas de regressão e modelos de séries temporais. Atualmente, diversas abordagens matemáticas, estatísticas e geoestatísticas, estão sendo usadas para a interpolação de dados de precipitação (BARGAOUI e CHEBBI, 2009). A utilização da geoestatística como método de interpolação, para regiões que apresentam falhas, vem mostrando resultados satisfatórios no que concerne a variáveis regionalizadas como a precipitação (HABERLANDT, 2007). Vários métodos são utilizados para obter o volume de precipitação e limitações ocorrem em todos os casos. HEIL e FOLEY (1998) analisaram a precipitação sobre a região a amazônica de diferentes formas, utilizando dados originais de estações meteorológicas, imagens de satélite e modelagens e diferentes tamanhos de séries. Eles concluíram que é preciso ter cautela na utilização de dados de satélite e modelados, pois encontraram diferenças em cada compilação do banco de dados. Por isso, hoje em dia tem-se usado dados de satélite ajustados por dados de estações meteorológicas locais (LIEBMANN e ALLURED, 2005). NEGRI, ANAGNOSTOU e ADLER (2000) identificaram áreas ao longo a Cordilheira dos Andes onde uma superfície fria persistente faz a recuperação de precipitação por imagens de satélite, não confiável.

Se mensurar as causas da variabilidade da precipitação é considerada uma tarefa difícil, então a identificação do fator que estaria causando uma suposta mudança observada na pluviosidade é uma tarefa tão grande quanto e, atualmente, tem gerado muita discussão e divergências, devido mjuitas evidências serem construídas pela percepção em determinadas escalas. 
Séries temporais geralmente são decompostas em componentes formadoras da série, como a tendência, a sazonalidade e o ciclo. A "sazonalidade" ocorre quando a série é influenciada por fatores bimestre, trimestre, semestre ou anuais, por exemplo, ou seja, que imprimem uma característica padrão a variável. O "ciclo" ocorre quando os dados exibem variações crescentes ou decrescentes em períodos não fixados e, geralmente, apresentam períodos maiores que a sazonalidade (HYNDMAN e ATHANASOPOULOS, 2016). A "tendência" existe quando há um acréscimo ou decréscimo em longo prazo no nível da série e, sua ocorrência é definida quando há uma mudança sistemática e contínua em qualquer parâmetro de uma dada amostra, excluindo-se mudanças periódicas ou quase periódicas (YEVJEVICH, 1972).

No entanto, BACK (2001) ressalta que a dificuldade no estabelecimento de existência de tendências significativas se deve à grande variabilidade natural (incluindo as não linearidades) dos dados meteorológicos. Além disso, BUISHAND (1982) ressalta que não é óbvia a diferença entre uma mudança real e flutuações aleatórias de uma variável climática. Mesmo quando os testes indicam tendência significativa, os resultados podem ocorrer devido a mudanças com causas antropogênicas, mudanças naturais das bacias, variabilidade climática, mudanças climáticas ou problemas com os dados. Nesse sentido, CONRAD (1944) definiu homogeneidade relativa, indicando que as variações climáticas têm tendências semelhantes em regiões bastante grandes. Portanto, as estações vizinhas devem ter o mesmo padrão de mudança da precipitação, sendo muito improvável que mudanças artificiais ocorram ao mesmo tempo para a maioria dos sensores (MARTÍNEZ et al., 2010).

No entanto, vários estudos sugerem algum grau de influência humana, como o trabalho de RYBSKI et al. (2006) que estudaram a persistência a longo prazo do aquecimento global e argumentaram, que pelo menos parte do aquecimento recente da atmosfera do planeta não pode estar unicamente relacionada a fatores naturais. No Brasil muitos trabalhos analisam ocorrência de tendências na precipitação, em diversas escalas temporais (diária, mensal, sazonal, anual, decadal, etc) e espaciais (pontuais sobre estações (PINHEIRO, GRACIANO e SEVERO, 2013), municípios (ELY, 2013), estados (SANSIGOLO e KAYANO, 2010), no país (OBREGÓN e MARENGO, 2007), báscias hidrográficas, numa dimensão continenal (HAYLOCK et al., 2006), etc, fazendo relação com as possíveis causas dessas tendências, as quais refeltem a ocupação do espaço por atividades humanas, quanto mais localizadas forem as análises. 
KOUTSOYIANNIS ( 2006) mostra como a interpretação das tendências que os dados seguem depende da janela temporal em que se realiza a análise, ou seja, os dados observados podem ser apenas uma pequena porção de um longo ciclo, cujas características podem ser difíceis de inferir com base nas observações disponíveis. Essas janelas correspondem a generalizações que RUAS e LAGRANGE (1995) definem como um processo que possibilita alterações no nível de percepção dos dados geográficos. Informações em escalas amplas, seja por generalizações ou não, são úteis para capturar padrões que não são evidentes nas observações numa escala precisa, e desenvolver estratégias para traduzir informações de local para escalas regionais e globais. Um dos motivos para isso é que, a maioria, se não todos os problemas de gestão ambiental só podem ser tratadas eficazmente nas escalas em que eles ocorrem. Além disso, a fim de compreender como a natureza funciona, os processos e os padrões em larga escala precisam ser relacionados com padrões de escalas de maior detalhe (WU, 1999).

Com o aumento da escala espacial, a escala de tempo dos processos importantes também aumenta porque os processos operam em taxas mais lentas e os efeitos indiretos se tornam cada vez mais importantes (DELCOURT, DELCOURT e WEBB, 1983; CLARK, 1985). Assim, GUERRERO et al. (2013) enfatiza a importância da definição de escalas ser o menos arbitrária possível. Como observou GREIG-SMITH (1979), há um elemento de subjetividade no processo de amostragem porque os limites dentro dos quais um conjunto de amostras é tomado são fixados com base em seu julgamento do que pode ser descrito como uma unidade para o propósito em questão. A arbitrariedade na definição de unidades de área pode afetar os resultados de uma série de análises estatísticas (JELINSKI e J., 1996).

Devido à existência de inícios e extinções dos fenômenos é impossível encontrar um sistema geral do espaço que respeite os limites de cada ordem desses fenômenos (BERTRAND, 2004). O'NEILL et al. (1986) enfatiza que mais importante do que escolher a escala correta de estudo, é reconhecer que os processos e a interação entre os fenômenos estão ocorrendo em muitas escalas ao mesmo tempo. A mesma ideia é enfatizada por LEVIN (1992) quando fala que nenhum mecanismo explica um padrão em todas as escalas. Sendo assim, em lugar de impor categorias pré-estabelecidas, o ideal seria pesquisar as descontinuidades objetivas da paisagem. No entanto, essas descontinuidades ou heterogeneidade espacial podem variar de forma não linear em função da escala e assim, condicionar os limites para a generalização das informações. Por isso, TURNER, DALE e 
GARDNER (1989) consideram necessário o desenvolvimento de métodos para a transferência de informação entre escalas que preservem informações ou que quantifiquem a perda de informações nesse processo.

Com base em vários estudos, WIENS (1989) fala que a escala de investigação pode ter profundos efeitos sobre os padrões dos fenômenos, ou seja, dependência de escala e, nesse caso, determinados padrões e processos podem ser mais previsíveis ou serem encontrados diferentes fatores que os influenciam de acordo com a escala. O ponto importante é que diferentes padrões emergiriam em diferentes escalas de investigação de praticamente qualquer aspecto de qualquer sistema. GREIG-SMITH (1979) e WOODWARD (1987) exemplificam esse fato com as relações entre clima e vegetação que são evidentes em escalas amplas, mas podem desaparecer em escalas mais finas, sobrepostos aos efeitos, por exemplo, da competição e outros processos biológicos já que interações biológicas locais podem ocasionar defasagens temporais ou espaciais na dinâmica do sistema, direta ou indiretamente. Em escalas mais amplas, segundo LEVIN (1992), os processos físicos podem dominar ou dissipar estes efeitos biológicos, no entanto, há exceções em que a distribuição de plantas em escalas finas pode ser controlada por fatores edáficos ou microtopográficas e a vegetação pode influenciar o clima em escalas regionais. Outro exemplo é a temperatura do ar em áreas não urbanizadas, que é regida principalmente pela topografia em escala local, porém mais fortemente determinada pela latitude numa escala continental.

TURNER, DALE e GARDNER (1989) apresentaram um conceito de escala que considera as dimensões espaciais e temporais de padrões ou processos e que caracteriza-se por grão e extensão, sendo o grão, a resolução das observações no tempo ou no espaço, ou seja, o tamanho da menor unidade de análise e, a extensão, a área total ou o período de tempo considerado no estudo. Juntos, esses conceitos definem os limites superior e inferior de resolução de um estudo, que são análogos aos do tamanho de uma peneira e o tamanho da sua malha. Dessa forma, qualquer inferência sobre dependência de escala em um sistema seria limitada pela extensão e pelo grão de investigação, onde a ampliação da extensão, normalmente implicaria também a ampliação do grão, ou seja, a maior capacidade de detectar padrões de grande escala levaria ao custo de uma perda de resolução dos detalhes em escala fina. Dessa forma, se poderia dizer que quando a escala de medição de uma variável é alterada também ocorreria alteração na variância dessa variável, ou seja, mantendo a extensão constante, um aumento do grão de medida geralmente diminuiria a variação espacial ao passo 
que, mantendo constante o grão, um aumento na extensão incorporaria uma maior heterogeneidade espacial de elementos na área de estudo e a variação entre grãos.

Para WIENS (1989), estudos realizados em várias escalas ou em que grão e extensão variem sistematicamente de forma independente uma da outra proporcionariam uma melhor resolução de domínios, de padrões e seus determinantes, e das inter-relações entre as escalas. Salienta a necessidade do desenvolvimento de teorias de escala capazes de gerar hipóteses testáveis, principalmente sobre as ligações entre domínios de escala, a final, a nossa capacidade de organizar escalas em hierarquias não significa que entendamos como traduzir as relações de padrões e processos através dos espaços não lineares entre os domínios de escala, ainda que reconheçamos essas ligações. $\mathrm{O}$ autor julga que talvez haja um pequeno conjunto de algoritmos que possam servir para traduzir através de escalas, mas que descobrilos exigiria primeiro reconhecer que padrões e processos são dependentes da escala, com fronteiras aparentemente caóticas e que uma escolha arbitrária de escalas de investigação contribuiria relativamente pouco para definir essas relações de escala. Segundo LEVIN (1992), "a descrição do padrão é a descrição da variação e a quantificação da variação requer a determinação de escalas".

A integração de bases de dados de diferentes origens normalmente requer a generalização de algumas partes. Análises espaciais conduzidas sobre dados com resoluções espaciais diferentes também envolve o conceito de generalização porque depende de métodos que possibilitem a abstração e o entendimento das relações entre os dados espaciais (SESTER, 2005). O processo de generalização pode auxiliar a derivação de bases de dados através da manutenção das conexões entre os dados originais e suas versões simplificadas (LAGRANGE e RUAS, 1994). No entanto, uma questão importante relacionada à multiescalaridade na análise geográfica é a homogeneização excessiva que, em alguns casos, pode levar a informações contraditórias sobre os fenômenos analisados, os quais podem levam à propagação de erros e resultados controversos. O processo de extrapolação ou tradução de informações de uma escala para outra, sem dúvida, é um desafio fundamental na teoria e na prática em todas as ciências da terra (WU, 1999). 


\subsection{Sistemas meteorológicos que afetam o tempo no Brasil}

\subsubsection{Zona de Convergência Intertropical do Atlântico}

A convergência dos ventos alísios no HN e HS, na região equatorial, resulta numa descontinuidade térmica denominada Zona de Convergência Intertropical (ZCIT), onde a ascensão conjunta do ar dessa região produz uma zona de aguaceiros e trovoadas (NIMER, 1979). A ZCIT é caracterizada por um conjunto de variáveis meteorológicas que atuam próximas à faixa equatorial dos oceanos, como a zona de confluência dos Alísios, a região do cavado equatorial, as áreas de máxima temperatura da superfície do mar, de máxima convergência de massas e a região de maior cobertura de nuvens convectivas que aumentam o transporte de umidade e a convecção no norte da América do sul em especial no Nordeste brasileiro, com máximos de precipitação entre março e abril (MELO, CAVALCANTI e SOUZA, 2009).

A posição da ZCIT varia com o movimento geral do sol na eclíptica. Como o HN possui maior área continental em relação ao HS, é em média mais quente e, por isso, ela permanece na maior parte do ano sobre o HN. Suas posições extremas se dão no fim do verão e fim no inverno, quando é maior a diferença de temperatura entre os hemisférios. Sua posição também é modulada pela posição dos anticiclones semifixos do Atlântico sul (ASAS) e dos Açores (ASAN) e, na maior parte do ano, mantém orientação zonal (E-W). Entretanto, de janeiro a abril, em virtude do traçado dos continentes, o ASAS fica muito a leste do núcleo do ASAN o que força a ZCIT a um movimento de rotação que a orienta no sentido NE-SW, conferindo pequenos totais pluviométricos do sertão do nordeste, no fim do verão e princípio de outono (NIMER, 1979).

Na região do Atlântico Equatorial, a ZCIT migra sazonalmente para posições em torno de $14^{\circ}$ na região Norte durante agosto-setembro e $2^{\circ}$ na região Sul durante março-abril em anos considerados normais. No entanto, como a sua configuração é inerente a circulação geral da atmosfera, sua posição é condicionada ao fortalecimento ou o enfraquecimento dos alísios de nordeste e sudeste. Costuma afetar a costa norte do Brasil, do Rio Grande do Norte ao Amapá, de janeiro a junho. No verão e outono, no hemisfério Sul, há um deslocamento da ZCIT para o Sul e no inverno e na primavera, para o Norte. Portanto, num ano considerado 
chuvoso no Nordeste brasileiro esse deslocamento para o sul é maior que num ano normal enquanto que num ano seco se deve pelo seu posicionamento mais ao norte nesse mesmo período (MELO, CAVALCANTI e SOUZA, 2009).

O posicionamento da ZCIT é influenciado principalmente pelo perfil norte-sul da temperatura da superfície do mar do Atlântico Tropical e a máxima cobertura de nuvens localizam-se sobre ou muito próxima à região de águas superficiais mais quentes. Anomalias na circulação atmosférica podem causar anomalias do gradiente meridional de TSM forçando a ZCIT a se deslocar para águas mais quentes. O El Niño-oscilação Sul influencia o dipolo de TSM do atlântico tropical norte e sul e, portanto, a chuva no Nordeste brasileiro (MELO, CAVALCANTI e SOUZA, 2009).

\subsubsection{Zona de Convergência do Atlântico Sul}

É caracterizada por uma banda de nebulosidade e chuvas associada a um escoamento convergente de umidade na baixa troposfera com orientação noroeste-sudeste, que se estende desde a Amazônia até o sudeste do Brasil e, frequentemente sobre o oceano atlântico subtropical. Em todos os verões, importantes variações ocorrem na sua organização espacial, na intensidade das chuvas e na circulação CARVALHO e OYAMA (2013)

A intensidade da ZCAS pode ser considerada independente de sua extensão sobre o oceano, isto é, pode-se observar intensa e persistente atividade convectiva sobre o continente, sem necessariamente haver uma correspondente alta atividade convectiva sobre o oceano. $\mathrm{O}$ oposto também ocorre (CARVALHO e OYAMA, 2013)

A atividade convectiva intensa sobre o oceano ocorre em associação com a propagação de trens de ondas de latitudes médias ligados a distúrbios intrassazonais tropicais. Quando a convecção é intensa sobre o continente, mas não sobre o oceano não se observa uma relação clara com a propagação de trens de ondas em latitudes médias no hemisfério sul, sugerindo que outros fatores locais ou remotos, ao ocorrer nos trópicos, possam contribuir para essa variabilidade (CARVALHO e OYAMA, 2013).

Outra coisa é que as anomalias de precipitação no sudeste do Brasil associadas as anomalias de sinal oposto sobre o sul do Brasil, Uruguai e Norte da Argentina é muito mais 
evidente quando a atividade convectiva é intensa sobre o oceano, o que sugere o importante papel dos trens de ondas de latitudes médias para modular esse padrão de anomalias (CARVALHO e OYAMA, 2013)

A persistência da ZCAS também parece depender de fatores atuantes em diversas escalas espaço-temporais. Em escala sinótica, nota-se que a incursão de frentes frias sobre a Argentina e o Sul do Brasil até as latitudes mais baixas é acompanhada de um reforço da atividade convectiva no oeste-sudeste da Amazônia, estendendo-se sobre a ZCAS (CARVALHO et al., 2009).

Em geral, a ZCAS localiza-se na sua posição mais a leste em dezembro, enquanto que no mês de janeiro, posiciona-se mais a oeste. A presença de topografia (Andes) tende a reforçar a ZCAS, intensificar e reposicionar o máximo de precipitação na Amazônia. Sinais com escalas interanuais e decenais na TSM no atlântico sul modulam mudanças na intensidade e deslocamentos da ZCAS em direção a águas mais quentes (CARVALHO e OYAMA, 2013).

Variações com períodos mais curtos que 90 dias mostram máxima variância sobre a ZCAS e a região central da América do Sul, e mínima sobre a região Amazônica, onde a convecção, em média, é mais intensa. Flutuações de 30-60 dias grande parte da variabilidade é associada a propagações para leste da Oscilação de Madden-Julian (OMJ) que é o modo mais importante da variabilidade tropical intrassazonal. As atividades convectivas com períodos mais curtos (2-30 dias) são associadas a propagações de ondas de Rossby provenientes das latitudes médias do HS e que atingem a região da ZCAS. Em escalas de tempo interanuais, o fenômeno El Niño exerce um papel importantíssimo na variabilidade da ZCAS, em que o deslocamento da convecção na Indonésia e no Pacífico Oeste associado ao El Niño modula a variabilidade no padrão de gangorra na precipitação da América do Sul (CARVALHO e OYAMA, 2013).

Como consequência da intensificação do jato subtropical de altos níveis sobre o oceano atlântico durante fases quentes do El Niño, há um aumento de aproximadamente duas vezes na frequência de ocorrência de ZCAS com intensa atividade sobre o oceano (CARVALHO e OYAMA, 2013). 


\subsubsection{Vórtices Ciclônicos de altos níveis}

São sistemas meteorológicos caracterizados por centros de pressão relativamente baixa que se originam na alta troposfera e se estendem até os níveis médios, dependendo da instabilidade atmosférica. Eles se desprendem do escoamento atmosférico associado, são quase estacionários, mas podem deslocar-se lentamente tanto para leste quanto para oeste e possuem um tempo de vida de vários dias. Apresentam um centro relativamente frio, convergência de massa, movimentos verticais subsidentes no seu centro e ascendentes na periferia, e nebulosidade mais intensa principalmente na direção de seu deslocamento (FERREIRA, RAMIREZ e GAN, 2009).

No Brasil os VCANs de origem tropical atuam com mais frequência entre dezembro e fevereiro, com um tempo de vida médio entre 4 a 11 dias. Os efeitos sobre a precipitação do NEB são bastante evidentes, principalmente quando os VCANs se originam sobre o continente. Nesse contexto, o NEB experimenta nebulosidade e chuva do VCANs, e parte apresenta céu claro decorrente dos movimentos verticais subsidentes existente no centro do mesmo (FERREIRA, RAMIREZ e GAN, 2009).

A interação dos VCANs com a Alta da Bolívia (AB) e a ZCAS é fundamental para a compreensão do papel desses vórtices no regime pluviométrico do nordeste e parte do norte do Brasil. A AB é uma circulação ciclônica de grande escala que ocorre na troposfera superior, centrada, em média, no platô Boliviano e contribui para as chuvas que ocorrem nas regiões norte, nordeste e centro-oeste do Brasil. atinge maior intensidade nos meses de dezembro a fevereiro, enfraquecendo nos meses de abril a maio. Sua manutenção está associada ao aquecimento continental (calor latente oriundo da convecção da Amazônia, Andes Central e ZCAS) e ao escoamento nos baixos níveis. O sistema AB/VCANs é mantido pela fonte de calor dessa região e também por fontes remotas de calor na África (FERREIRA, RAMIREZ e GAN, 2009).

$\mathrm{Na}$ maioria dos casos os VCANs formam-se devido à intensificação da crista (alta pressão) associada à $\mathrm{AB}$, decorrente do avanço de sistemas frontais para latitudes baixas, gerando grande advecção de ar quente e úmido desenvolvendo-se uma convecção profunda. Forma-se assim, um vórtice nos altos níveis da atmosfera. Sua formação também pode ocorrer pela intensificação da atividade convectiva da ZCAS, e a forte liberação de calor latente de 
condensação gera uma circulação anticiclônica na alta troposfera do atlântico sudoeste. (FERREIRA, RAMIREZ e GAN, 2009).

\subsubsection{Distúrbios ondulatórios de leste}

Ondas de leste são perturbações de escala sinótica nos alísios da região tropical do Atlântico e do Pacífico, nos campos de vento e pressão, que modulam a convecção na ZCIT e são assim denominadas por se moverem para oeste com os alísios (SERRA e HOUZE, 2002). Estes distúrbios são responsáveis por grande quantidade de precipitação em áreas que geralmente são secas ao longo da região dos alísios não perturbados (TORRES, 2008).

Segundo RIEHL (1954), as ondas de leste são oscilações no campo de pressão e vento, que se encontra em fase na superfície. O eixo do cavado inclina-se na mesma direção de propagação dos distúrbios, ou seja, a orientação do cavado (baixa pressão) é de nordestesudoeste no Hemisfério Norte (HN) e noroeste-sudeste no Hemisfério Sul (HS), inclinando-se para leste com a altura. Isso se deve ao sistema de ventos dominantes nessa região. $\mathrm{Na}$ dianteira do cavado, há divergência e movimento subsidente nos baixos níveis, com características de tempo bom; e na retaguarda há convergência nos baixos níveis com predominância de forte movimento ascendente e convecção profunda (TORRES, 2008).

No Brasil, esses distúrbio estão relacionados com um reforço de ar nos alísios de sudeste, com anticiclone polar de posição marítima. Ocorrem no seio dos anticiclones tropicais sob a forma de pseudofrentes, sobre as quais desaparece a inversão térmica superior, o que permite uma mistura de ar das duas camadas horizontais dos alísios e, consequentemente, chuvas mais abundantes anunciam sua passagem (NIMER, 1979).

A formação de DOLs é geralmente originada por pequenos vórtices que se deslocam com os alísios. A origem desses vórtices pode ser atribuída a restos de depressão de latitudes médias que se movem em direção ao equador ou, segundo MACHADO et al. (2009), são consequência da instabilidade barotrópica e baroclínica do jato, correspondendo ao cisalhamento horizontal e vertical do vento. No hemisfério sul propagam-se desde o oeste da África até o atlântico tropical (TORRES, 2008; MACHADO et al., 2009) e sua atividade máxima (maior comprimento de onda e velocidade de propagação) ocorre no inverno austral. O comprimento de onda gira em torno de 2.000 a $3.500 \mathrm{~km}$, persistem por um período de 3 a 
5 dias e a sua propagação para oeste está em torno de $8 \mathrm{~m} / \mathrm{s}$, no entanto outros estudos demonstram valores superiores de comprimento de onda e velocidade de propagação (MACHADO et al., 2009).

Os DOLs são de extrema importância, por provocarem alterações bruscas das condições sinóticas, principalmente na componente meridional do vento, tendo, como consequência, uma umidificação da camada, aumento de nebulosidade e precipitação. Além disso, os sistemas DOLs podem intensificar os sistemas meteorológicos de perturbação convectiva (BARBOSA, 2005), tais como as Linhas de Instabilidades que se propagam para o interior da Amazônia ou ainda associar-se com a ocorrência de tempestades tropicais ou mesmo furações na parte norte do Atlântico Equatorial (COUTINHO e FISCH, 2007).

Sua atividade máxima ocorre no inverno e correspondem à situação de chegada de frente fria ao trópico, sendo que os respectivos movimentos para oeste acompanham os avanços SW-NE da frente fria sem ramo interior, e não ultrapassam o meridiano $40^{\circ}$ (oeste de Pernambuco). Movem-se, porém, para leste sob a ação de uma frente fria que avança pelo interior até o Mato Grosso, e o centro de ação (alto tropical) se afasta para o oceano. No Brasil esse fenômeno ocorre do Rio Grande do Norte ao norte do Rio de Janeiro, sendo mais frequente na zona da Mata de Pernambuco e zona Cacaueira da Bahia. As precipitações devidas a esses distúrbios diminuem bruscamente para oeste, raramente ultrapassando as escarpas da Borborema e da Diamantina. É mais frequente no inverno e secundariamente no outono (NIMER, 1979).

\subsubsection{Linhas de instabilidade}

A linha de instabilidade é uma zona de instabilidade, que se forma principalmente em regiões quentes, onde inúmeras células convectivas de curta duração se dispões de forma alinhada. Desenvolvem-se frequentemente na costa norte-nordeste da América do sul e podem se propagar para o interior do continente, causando quantidades consideráveis de precipitação. Essas linhas foram associadas à circulação da brisa marítima e, portanto, apresenta uma escala temporal associada à variabilidade diurna (aquecimento terrestre). A máxima atividade convectiva é identificada no final da tarde (COHEN, SILVA DIAS e NOBRE, 1989). 
Apresentam variabilidade na sua posição de acordo com a época do ano e seu desenvolvimento na costa acompanha o deslocamento sazonal da ZCIT. Podem ser observadas durante todo o ano, com maior frequência entre os meses de abril e agosto e o seu ciclo de vida está em torno de 9, 12 e 16 horas, de acordo com as maiores distância que alcançam. As LI fortes ocorrem no começo do ano até meados de março. A partir de abril predominam as LI de média intensidade e, depois de setembro, as LI fracas. Tudo isso de acordo com a movimentação da ZCIT. As LI ficam mais extensas entre fevereiro e junho, atingindo seu maior valor no mês de abril, e menos extensas a partir de julho até janeiro. Ou seja, o período em que as LI possuem maior comprimento coincide com o período em que a ZCIT está mais bem definida na sua posição Sul. Os sistemas convectivos associados são classificados de acordo com a distância que alcançam ao se deslocarem continente adentro, em até $170 \mathrm{~km}$, entre 170 e $400 \mathrm{~km}$ e acima de $400 \mathrm{~km}$ (COHEN et al., 2009).

Nos períodos de inverno e primavera, seu desenvolvimento ocorre em latitudes mais a oeste, ao longo da costa, ao norte do equador; e nos períodos de verão e outono, ocorre mais a leste, ao longo da costa, ao sul do equador. Na costa norte-nordeste do Brasil, há grande frequência de LI de janeiro a maio, e no período de junho a dezembro, essa região não apresenta atividade convectiva, mesmo com a entrada de brisa (COHEN et al., 2009).

As linhas de instabilidade também parecem estar relacionadas ao movimento ondulatório que se verifica na frente polar ao contato com o ar quente da zona tropical (em direção a Amazônia). A partir dessas ondulações formam-se, ao norte da frente polar, uma ou mais linhas de instabilidade sobre o continente. Depois de formadas, elas se deslocam com extrema mobilidade até $60 \mathrm{~km} / \mathrm{h}$, embora elas possam, por vezes, permanecer semiestacionárias. À medida que a frente polar caminha para o equador, as linhas de instabilidade se deslocam para $\mathrm{E}$, ou mais comumente para SE, anunciando com nuvens pesadas e em geral chuvas tipicamente tropicais a chegada da frente polar (NIMER, 1979).

\subsubsection{Jatos de altos níveis}

A corrente de jato é uma corrente de ar em forma de um estreito cano ou conduto, quase horizontal, geralmente próximo da tropopausa, cujo eixo localiza-se ao longo de uma linha de velocidade máxima e de fortes cisalhamentos horizontais e verticais. Localiza-se 
entre 9.000 e 13.000 metros de altitude, geralmente tem vários milhares de quilômetros de comprimento, centenas de quilômetros de largura e vários quilômetros de espessura. $\mathrm{O}$ cisalhamento vertical no jato oscila entre 20 e $40 \mathrm{~km} / \mathrm{h}$ por quilômetros de altura e o cisalhamento horizontal é aproximadamente de $20 \mathrm{~km}$ para cada 100 quilômetros. A velocidade do vento ao longo do eixo principal da corrente de jato é de aproximadamente 140 $\mathrm{km} / \mathrm{h}$, mas podendo superar os $300 \mathrm{~km} / \mathrm{h}$ (ESCOBAR, 2009).

Existem dois tipos de correntes de jato. O Jato Polar (JP) e o Jato Subtropical (JST). JP é altamente variável em sua posição dia a dia sobre uma ampla faixa de latitudes médias e subtropicais, pois depende da posição dos sistemas frontais. Encontra-se entre 8.000 e 10.000 metros de altitude, oscilando entre $30^{\circ}$ e $70^{\circ} \mathrm{S}$, podendo alcançar latitudes mais baixas. O JST é relativamente constante em sua posição em determinada estação do ano, e predomina nos campos médios sazonais do vento. NO HS, o JST aparece geralmente acima dos 13.000 metros, na faixa de latitude que vai de $20^{\circ}$ a $40^{\circ} \mathrm{S}$, podendo atingir latitudes mais baixas, mas, nesses casos, sempre aparecerá acoplado ao JP, que está associado aos sistemas transientes. A altura do jato dependerá da intensidade da massa de ar, onde quanto mais fria, mais baixo será o jato (ESCOBAR, 2009).

O JP exerce influência direta ou indireta sobre as mudanças do tempo. Quando o JP se desloca para o norte, seus movimentos são seguidos em superfície pelos sistemas e alta e baixa pressão e pelas frentes frias e quentes. $\mathrm{O}$ cano ou conduto da corrente de JP encontra-se atrás do sistema de nuvens e por cima da superfície frontal e, na maioria das vezes se localiza na direção oeste-leste (ESCOBAR, 2009).

\subsubsection{Jato de baixos níveis ao longo dos Andes}

São ventos que ocorrem na baixa atmosfera com máxima velocidade em torno de 2.000 metros. Esses jatos ocorrem no lado leste de uma topografia elevada e são associados a movimentos de grande escala que cobrem extensas áreas, como os Andes na América do Sul, as quais estendem-se das regiões tropicais até as altas latitudes, bloqueando a circulação em baixos níveis no sentido zonal e provocando uma canalização do vento. Os JBN um componente do sistema de monção da América do Sul, que transporta umidade da bacia Amazônica para a bacia Paraná-Prata, afetando o tempo e o clima da região leste dos Andes. 
Podem influenciar por meio de variações no transporte de umidade, as condições de tempo severas associadas às grandes nuvens convectivas na região de saída do jato, que podem gerar fortes tempestades e enchentes (MARENGO, 2004).

A origem dos ventos associados ao jato está nos ventos alísios vindos do oceano atlântico tropical, que invadem o território brasileiro pela ponta superior da região nordeste. Quando passam pela Amazônia, absorvem muito vapor d'água liberado pela evapotranspiração da floresta. Os Andes funcionam como um acelerador e como uma barreira, pois aumentam a velocidade de circulação do jato e o desvia rumo ao sul (sul/sudeste do Brasil e norte da Argentina). Ao chegarem à bacia do Paraná-Prata, interagem com o relevo e frentes frias geradas em latitudes mais altas, e com as massas de ar oriundas do atlântico sul, produzindo chuvas intensas em poucas horas na região de saída do jato (MARENGO, 2004).

No verão, a umidade que vai para a bacia do Paraná-Prata é, em sua maior parte, oriunda da região Amazônica, enquanto no inverno, ainda que possa haver transporte da umidade da Amazônia, observa-se o transporte de origem oceânica associado ao ciclo anual da Alta Subtropical do Atlântico Sul. Episódios de jatos podem acontecer durante todo o ano, porém são detectados com maior frequência entre os meses de dezembro até fevereiro. No inverno o fluxo se caracteriza pelo enfraquecimento dos alísios e pela intensificação do fluxo associado a Alta Subtropical do Atlântico Sul (MARENGO, 2004).

\subsubsection{Complexos convectivos de mesoescada na América do Sul (CCM)}

Os CCMs juntamente com as linhas de instabilidade correspondem à categoria extrema dos sistemas convectivos de mesoescala responsáveis pela maior parte da precipitação nos trópicos e em várias localidades de latitudes médias durante a estação quente. Os critérios originais de classificação desses sistemas consideram uma cobertura de nuvens com temperaturas menores que $-32^{\circ} \mathrm{C}$ e com área de $100.000 \mathrm{~km} 2$, sendo que a região mais interna da nuvem deve apresentar temperatura menor que $-52^{\circ} \mathrm{C}$ com área de $50.000 \mathrm{~km} 2$. O sistema deve ter formato circular com excentricidade maior que 0,7 . O tempo de vida á caracterizado quando as duas condições descritas ocorrem por um período superior a seis horas (SILVA DIAS e DA SILVA, 2009). 
Sua formação ocorre geralmente no final da tarde, quando as primeiras células convectivas se desenvolvem e onde os efeitos de escalas locais, como a topografia e fonte de calor localizada, podem exercer importante papel. À noite, quando a atmosfera em baixos níveis encontra-se mais estável, o fluxo de calor e umidade provenientes da região amazônica passa a fornecer condições necessárias para que esses sistemas cresçam. O estágio maduro geralmente ocorre durante a madrugada, coincidindo com o horário de máxima intensidade do jato de baixos níveis. O sistema continua a crescer e a principal condição de tempo passa a ser fortes chuvas localizadas. Durante o estágio de dissipação, por volta das 12:00 UTC o fluxo de calor e umidade é reduzido interrompendo a convecção intensa. A região sudeste da América do sul, onde fica a bacia do prata, é apontada como tendo os CCMs mais intensos do globo (SILVA DIAS e DA SILVA, 2009).

A alta da Bolívia e a baixa do Chaco atuam para gerar convergência, movimentos ascendentes e aquecimento em baixos níveis, condições propícias para a convecção. O escoamento, quando canalizado para leste dos Andes, dependendo do cisalhamento vertical e da intensidade do vento meridional, é classificado como jato de baixos níveis, o qual representa um dos mecanismos dinâmicos responsáveis pelo transporte de calor e umidade da região amazônica para regiões preferenciais de formação dos CCMs (bacia do rio da Prata) (SILVA DIAS e DA SILVA, 2009).

O ciclo de vida dos complexos pode ser explicado principalmente pela associação de dois mecanismos: o ciclo diurno do jato de baixos níveis e o escoamento catabático. A umidade, associada aos ventos catabáticos que descem a cordilheira dos Andes e sofrem ascensão no vale, é o principal combustível necessário para a convecção (SILVA DIAS e DA SILVA, 2009).

Estudos já demonstraram que a atividade convectiva sobre o norte da Argentina, Paraguai e sul/sudeste do Brasil apresenta uma correlação negativa com a convecção associada a ZCAS. Em situações em que a ZCAS estava ausente, observa-se que o jato de baixos níveis se intensifica, enquanto que na presença da ZCAS a circulação predominante era de noroeste/sudeste, inibindo o fornecimento de calor e umidade para os CCMs (SILVA DIAS e DA SILVA, 2009).

Uma justificativa para o hábito noturno dos CCMs é que a precipitação nas proximidades da cordilheira dos Andes no final do dia faz com que a superfície resfrie-se mais rapidamente durante a madrugada e o ar mais denso desce as encostas, propiciando 
movimentos ascendentes na região da planície. Esse mecanismo, associado à oscilação inercial, contribui para a intensificação do jato de baixos níveis, favorecendo a ocorrência de convecção intensa sobre o vale (SILVA DIAS e DA SILVA, 2009).

\subsubsection{Ciclones e Ciclogênese}

Ciclogênese é o processo de abaixamento da pressão atmosférica de superfície com consequente formação de circulação ciclônica. Muitas vezes pode ser disparada por vórtices ciclônicos de altos níveis. Ciclones extratropicais originam-se quase que exclusivamente fora das regiões tropicais em de massas de ar de origem não tropical. Obtêm sua energia por métodos diferentes daqueles usados por outros fenômenos ciclônicos e são classificados como sistemas de núcleo frio. Formam-se em massas atmosféricas com alta instabilidade meteorológica e perdem a sua força quando se tornam barotrópicos, ou seja, quando as diferenças de temperatura ocorrem juntamente com as diferenças de pressão $\mathrm{O}$ ciclone tropical é caracterizado por ser uma região onde a pressão atmosférica é significativamente menor, com grande diferença de pressão atmosférica entre o centro e suas vizinhanças, possui uma circulação fechada de ventos e a temperatura é ligeiramente maior do que suas vizinhanças. Possui um núcleo quente e um centro bastante definido. É formado nos arredores da linha do equador e é movido pela energia térmica liberada quando ar úmido sobe para camadas mais altas da atmosfera e o vapor d'água associado se condensa (SELUCHI, CALBETE e ROZANTE, 2001).

A costa leste da América do Sul é uma das regiões do globo onde ciclones preferencialmente ocorrem (MENDES et al., 2007). GAN e RAO (1991) descobriram que há duas regiões ciclogenéticas na América do Sul, um próximo do Golfo de San Matias, na Argentina, com pico máximo no verão, relacionado com o processo de instabilidade baroclínica na corrente dos ventos de ajudados pelo contraste continente-oceano. A outra região de ciclogênese é localizada próxima do Uruguai, com sua máxima no inverno, relacionada a instabilidade baroclínica e ao efeito montanha. SINCLAIR (1994) observaram uma terceira região ciclogenética sobre a costa sul do Brasil, em torno de $25^{\circ} \mathrm{S}$, com pico máximo nos meses de verão (GAN e SELUCHI, 2009; ROSA et al., 2013). 
Ao longo da costa sul do Brasil os fatores que podem contribuir para a ciclogênese é a presença de um cavado em níveis altos da troposfera a presença de um sistema frontal, o transporte de umidade para a costa sudeste/sul do Brasil gerada por Alta Pressão do Atlântico Sul subtropical e da Amazônia, a convergência gerada pelo movimento da alta subtropical (SELUCHI, CALBETE e ROZANTE, 2001).

O pico de ciclogênese na América do Sul acontece em maio e o mínimo em dezembro; os máximos de frequência ocorrem nos meses de inverno e, os mínimos, nos meses de verão. No inverno o principal processo de desenvolvimento de ciclones é a conversão de energia do estado básico para a perturbação (instabilidade baroclínica), enquanto que no verão estes sistemas dependem de instabilidade hidrodinâmica (GAN e SELUCHI, 2009).

A ligação entre ciclogênese e precipitação consiste em suprimento de umidade (da região amazônica ou mesmo de regiões marítimas), o qual possui grande importância na própria dinâmica da ciclogênese. Sobre a costa sul do Brasil ocorrem com frequência durante o inverno e, especialmente quando gera um ciclone sobre o continente, é responsável por situações de tempo severo (ROSA et al., 2013).

\subsubsection{Sistemas Frontais e Frontogênese}

As frentes são caracterizadas por linhas de contato entre duas massas de temperatura e componentes diferentes em que forma-se uma superfície de descontinuidade térmica. As frentes frias correspondem aos casos em que o ar frio substitui o ar quente, ao passo que nos casos em que o ar quente substitui o ar frio correspondem às frentes quentes. No HS, geralmente, as frentes se estendem na direção noroeste-sudeste e ao longo delas, formam-se cicloness que se deslocam na mesma direção, no seio dos quais existem acentuada mudança do vento, chuva forte, nuvens baixas e escuras, visibilidade reduzida, forte turbulência e possibilidade de formação de granizo. São seguidas por chuvas finas e contínuas, para finalmente, sob o domínio do anticiclone polar, o céu se torna limpo com declínio acentuado da temperatura. Próximo ao topo da cúpula de ar frio, o ar quente pode deslizar para baixo, o que além de produzir um aquecimento adiabático, torna a atmosfera mais seca (NIMER, 1979). 
As massas que deixam o continente antártico penetram nos oceanos onde se aquecem e umedecem rapidamente. Com o desaparecimento da subsidência, elas se tornam instáveis e, com tal estrutura, invadem o continente sul americano com sua direção condicionada a orografia. Uma parte da massa polar segue para oeste da Cordilheira dos Andes e seus ventos frios se encontram com os ventos quentes da massa tropical pacífica constituindo uma zona de frontogênese denominada de frente polar pacífica. No verão essa trajetória é muito comum, pois com o enfraquecimento do anticiclone do pacífico e o afastamento inicial da FPP do continente americano, o ar polar encontra menor resistência em sua marcha para o norte. Já no inverno, com o anticiclone do pacífico avançando para o litoral e a FPP sendo muito mais ativa, as massas frias percorrem de preferência as zonas a leste da cordilheira, depois de transpô-la em sua extremidade meridional, seguindo novo percurso. Do encontro do ar frio com o ar quente do sistema tropical origina-se a frente polar atlântica que, condicionada pelo contraste térmico continente-oceano e pela orografia divide-se em dois ramos. O primeiro segue para a depressão geográfica continental (Chaco) e o do oceano atlântico (NIMER, 1979).

No ramo marítimo, a FPA se desloca para nordeste com ondulações ciclônicas sobre o litoral, sobretudo no mar. Dependendo da época do ano, atingem determinadas latitudes (em média $15^{\circ} \mathrm{S}$ ), onde entram em contato com os alísios de SE e perdem sua nitidez por incorporar esse anticiclone semifixo do atlântico (NIMER, 1979).

No inverno, em virtude do forte gradiente térmico equador-polo, a circulação secundária é muito mais vigorosa e, assim, as massas frias atingem mais facilmente os alísios de SE podendo alcançar latitudes mais baixas, inclusive, ultrapassando o trópico. $\mathrm{Na}$ primavera, atingem geralmente o trópico de capricórnio. No verão, o forte aquecimento do continente (região do Chaco) impede geralmente a passagem de ar polar para as latitudes mais baixas. Sendo assim, a energia frontal geralmente é muito fraca e o ramo marítimo da frente toma, via de regra, uma orientação NE-SW sobre o oceano, raramente ultrapassando o trópico. No outono as condições de frontogênese já são mais favoráveis e a FPA normalmente ultrapassa aquele paralelo. No entanto a ZCIT, impelida para o HS nesta época do ano, impede um maior avanço da FPA para as latitudes mais baixas. No inverno, quando as condições de frontogênese são mais acentuadas, e a FPA alcança latitudes inferiores a $10^{\circ} \mathrm{S}$ com casos excepcionais de grande intensidade, provocam a chamada friagem. Enquanto a FPA é impedida se seguir o caminho da depressão geográfica do Chaco, seu ramo marítimo 
prossegue no percurso para o norte até o paralelo de $22^{\circ}$ aproximadamente. Aí estaciona em média uns dois dias para, em seguida, sofrer frontólise e recuar como frente quente, provocando chuvas persistentes no sudeste do Brasil, até desaparecer no oceano (NIMER, 1979).

No HS, as frentes frias afetam o tempo da América do sul durante todo o ano, porém são mais frequentes de maio a setembro e menos frequentes de dezembro a fevereiro, principalmente nas latitudes ao norte de $20^{\circ} \mathrm{S}$. Entre uma e cinco frentes frias chegam ao oeste da Amazônia a cada ano, com aproximadamente três frentes alcançando o equador. Ao longo da costa leste do Brasil, entre cinco e 10 frentes chegam até $15^{\circ} \mathrm{S}$ a cada ano. No sul do Brasil as frentes ocorrem todo o ano, principalmente de junho a setembro (CAVALCANTI e KOUSKY, 2009).

\subsubsection{Brisa fluvial}

A brisa fluvial é um mecanismo físico no qual o ar, devido ao contraste térmico entre água-terra, move-se em direção a superfície terrestre adjacente durante o dia e vice-versa à noite. Imagens de satélites mostram que as nuvens formam-se preferencialmente sobre o continente durante o dia, com movimentos de subsidência na área dos rios, OLIVEIRA e FITZJARRALD (1993) comprovam a existência desta circulação fluvial nos baixos níveis (até 1500-2000 m), possuindo o sentido floresta/rio durante à noite e início da manhã, revertendo o sentido (rio/floresta) durante a tarde e início da noite. É provável que esse efeito seja mais intenso nas regiões em que a largura do rio é considerável, como próximo à Manaus (confluência os Rios Negro e Solimões), Santarém (Rios Tapajós e Amazonas) e Belém (Rios Tocantins e parte sul da Foz do Rio Amazonas). As brisas fluviais são mais atuantes durante os meses de cheias dos grandes rios (julho-agosto) e, segundo MOLION e DALLAROSA (1990), tendem a diminuir os totais pluviométricos próximos aos rios e aumentá-los a cerca de 20-30 km de distância. 


\subsection{A influência do relevo nas chuvas}

A configuração do relevo, principalmente pelas características de posição das feições, orientação das vertentes e a declividade, conduzem a inúmeras modificações nos padrões de ventos da baixa atmosfera podendo influenciar as chuvas de um local de diferentes formas (AUSTIN e DIRKS, 2005; ROTUNNO e HOUZE, 2007). Especialmente nas latitudes subtropicais, a orientação do relevo define as vertentes mais aquecidas e secas, e as mais frias e úmidas, enquanto que a declividade modifica a quantidade de radiação que chega a superfície, de acordo com o ângulo de incidência dos raios solares (MENDONÇA e DANNIOLIVEIRA, 2007). No entanto, essa influência não depende somente das características da topografia isoladas, mas também, de outros fatores como a estabilidade e a umidade do ar e da direção e velocidade do vento (FREI e SCHAR, 1998; KLIMOWSKI et al., 1998; AUSTIN e DIRKS, 2005; BARRY e CHORLEY, 2010). O efeito da interação desses fatores pode desencadear redistribuir ou modificar a quantidade de precipitação que ocorreria na presença de um terreno menos complexo AUSTIN e DIRKS (2005). Esses processos podem ocorrer tanto em grande escala, por exemplo, a indução da ciclogênese ou alteração no comportamento de ciclones, como também em pequena escala, por exemplo, alterando a velocidade e a direção do fluxo local que chega a um terreno montanhoso e, consequentemente, a velocidade vertical ao longo da inclinação desse terreno (BUZZI e FOSCHINI, 2000).

Uma das formas mais marcantes de influência do relevo no tempo meteorológico está no forte controle local da distribuição espacial das chuvas, e que frequentemente resulta em maiores volumes de precipitação nas vertentes a barlavento do que no sotavento, que caracteriza o efeito de sombra de chuva. Também são observados volumes significativamente mais elevados no topo das montanhas em relação aos vales circundantes (SMITH, 1979). Em alguns casos, a topografia pode resultar em circulações de mesoescala devido às propriedades térmicas modificadas ou a inclinação da camada limite, as quais podem desencadear os processos de convecção, precipitação ao longo da encosta, ou novos sistemas de mesoescala, como as depressões a sotavento (Figura 1).

A principal influência sobre a pluviosidade é a ascensão do ar úmido e quente que, ao elevar-se sobre a barreira orográfica, sofre expansão e resfriamento adiabático devido à descompressão ocasionada pela menor densidade do ar nos níveis mais elevados. O 
resfriamento conduz a parcela de ar ao ponto de saturação de vapor, ocorrendo assim a formação das nuvens que originam as precipitação (ROE, 2005; MENDONÇA e DANNIOLIVEIRA, 2007; SELUCHI, CHOU e GRAMANI, 2011). Após passar as montanhas, já desprovido de umidade, o ar desce e aquece adiabaticamente (LIEBMANN et al., 2011).

Uma característica comum dos mecanismos de precipitação orográfica é a sensível interdependência dos fluxos dinâmicos induzidos e a microfísica associada à formação de nuvens. Os efeitos microfísicos são profundos em regiões de terreno complexo, pois influencia na velocidade de formação e no tamanho das gotas e na velocidade de queda das gotas, a qual pode ser mais ou menos influenciada pelo vento (ROTUNNO e HOUZE, 2007).

Esses processos caracterizam alguns mecanismos orográficos, os quais podem ocorrer individualmente ou em conjunto para a geração de chuvas. SMITH (1979) descreve esses mecanismos como autoconvecção, o mecanismo seeder-feeder e a convecção disparada. A autoconvecção ocorre por condensação e coalescência resultante da ascensão do ar em grande escala pela encosta, independente de chuvas pré-existente. É um processo típico de vento fraco e de grande escala em que as chuvas apresentam uma sequência temporal muito uniforme em qualquer ponto a barlavento da montanha. No mecanismo seeder-feeder as chuvas caem de nuvens mais altas, sejam elas frontais ou orográficas, e alimentam com gotículas as nuvens mais baixas mantidas pela ascensão de ar úmido através da encosta da montanha. Nesse caso se observa que a taxa de chuva aumenta a partir dos níveis inferiores a barlavento, chegando ao máximo no topo da montanha, sendo que a nuvem semeadora pode precipitar também a sotavento. Na convecção disparada, ocorre a formação de nuvens cumulonimbus no lado da montanha iluminado pelo sol, em uma massa de ar instável que, dependendo da quantidade de energia, umidade e vento podem ou não apresentarem maior desenvolvimento chegando a precipitar em sotavento.

Um mecanismo também associado aos padrões de chuva observados em pequenas serras é a redistribuição da precipitação, em que pode ocorrer um déficit de precipitação a barlavento e, excesso, a sotavento, inconsistentes com os mecanismos acima mencionados. Neste caso, pode não ocorrer qualquer aumento na precipitação, e sim, uma redistribuição de precipitação como resultado de perturbações na trajetória das gotas de chuva devido a uma distorção do fluxo de vento (AUSTIN e DIRKS (2005). 


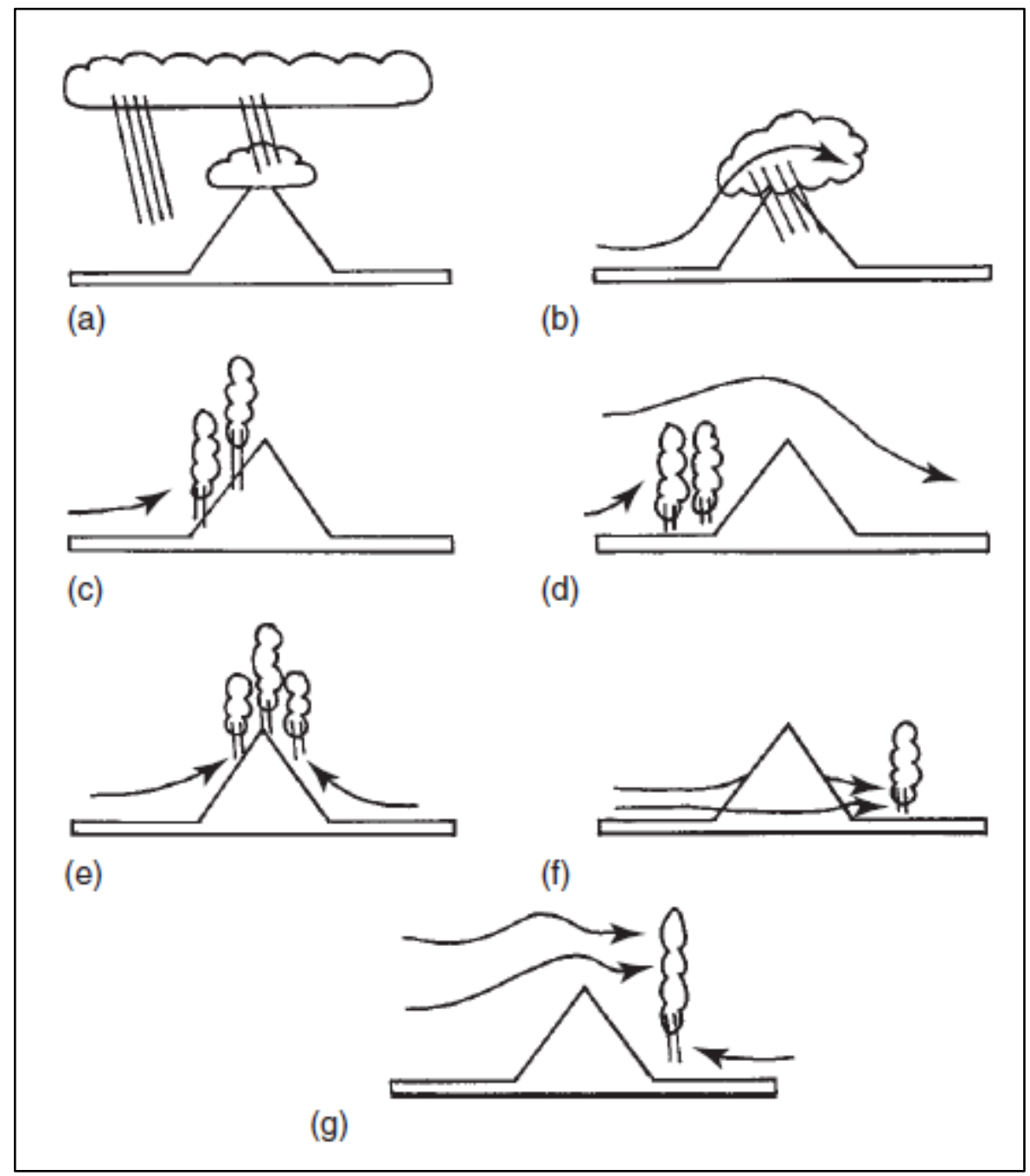

Figura 1: Representação de diferentes processos que conduzem ao aumento do volume pluviométrico em função do fluxo de ar sobre uma montanha: a) mecanismo semeador-alimentador, b) condensação pelo fluxo forçado na subida, c) desencadeamento ascendente da convecção, d) formação de nuvem resultante do bloqueio do fluxo orográfico ou propagação de ondas de gravidade, e) disparo térmico por uma fonte de calor elevada, f) convergência a sotavento devido ao fluxo entorno da montanha, g) reforço da precipitação a sotavento por ondas de gravidade induzidas pela montanha. Fonte: AUSTIN e DIRKS (2005).

\section{MATERIAL E MÉTODOS}

\subsection{Estruturação de dados e automatização de processos}

Foram utilizados registros pluviométricos, de direção e velocidade do vento e o Modelo Digital de Elevação do Brasil, os quais foram obtidos de fontes distintas. Os registros 
pluviométricos foram obtidos do Sistema de Informações Hidrológicas (HIDROWEB) da Agência Nacional de Águas (ANA), na resolução diária, para o período de 1888 a 2010 (Figura 2). Os registros de direção e velocidade de ventos foram obtidos do Banco de Dados Meteorológicos para Ensino e Pesquisa (BDMEP), do Instituto Nacional de Meteorologia (INMET), para os anos entre 2012 e 2015, de 702 estações meteorológicas disponíveis, coletados em regime horário (Figura 3). O Modelo Digital de Elevação (MDE) foi obtido do Banco de Dados Geomorfométricos do Brasil (TOPODATA), criado pelo Instituto de Pesquisas Espaciais (INPE), na resolução de $0,002778^{\circ}$ de arco de latitude e longitude (Figura $4)$.

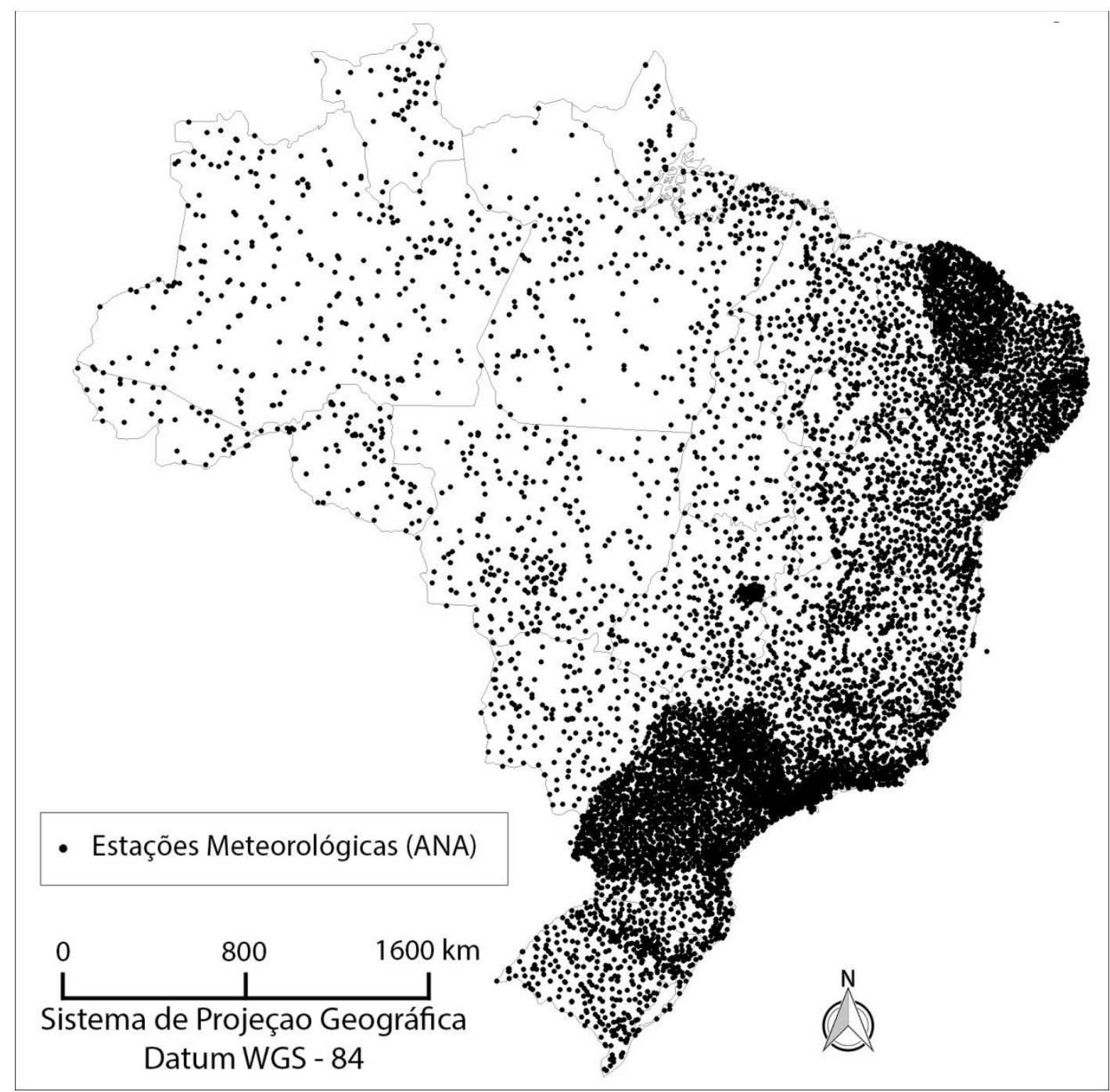

Figura 2: Sobreposição da localização das 10.939 Estações Meteorológicas, vinculadas a Agência Nacional de Águas - ANA e utilizadas neste estudo, cujos registros não são, necessariamente, simultâneos ao longo da série de 1888-2010. 


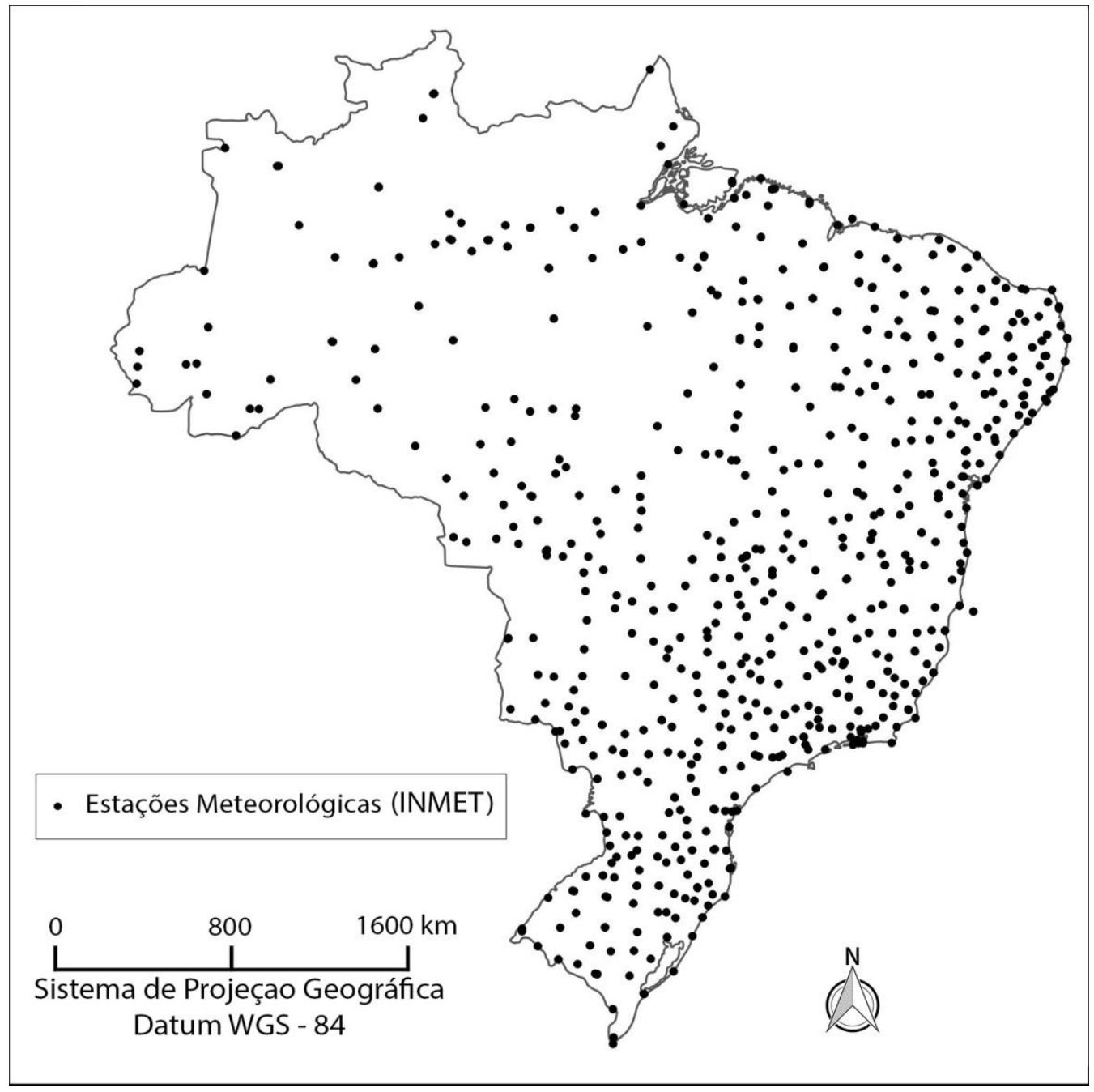

Figura 3: Distribuição espacial das 704 estações meteorológicas automáticas do INMET, utilizadas para o cálculo de direção e velocidade do vento para os 809 quadrantes, na resolução de $1^{\circ}$ de arco de latitude e longitude. 


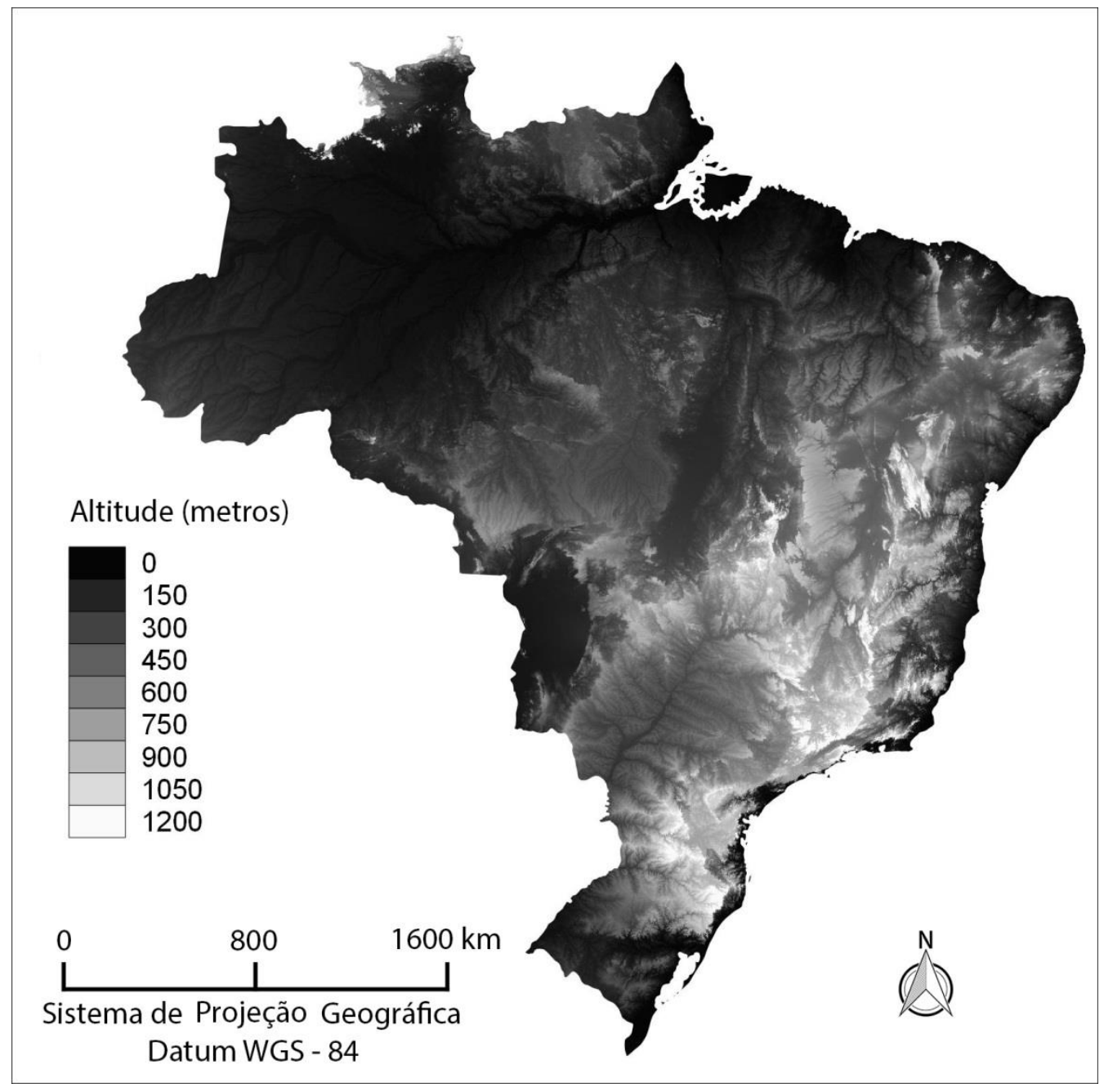

Figura 4: Modelo Digital de Elevação do Brasil, reamostrado da resolução de $0,002778^{\circ}$ para 10 " de arco de latitude e longitude $(\sim 30 \mathrm{~m})$ utilizado para a derivação da clinografia e direção das vertentes para os 809 quadrante. Fonte: TOPODATA/INPE. Nota: Reamostrado pelo autor.

O trabalho teve como premissas: (a) a possibilidade de adequações e consistência dos dados, (b) a possibilidade de armazenamento em um sistema local para o (c) processamento de grande volume de dados, (d) a utilização dos mesmos para análises sistemáticas e (e) multiescalares mediante a (f) utilização de diferentes métodos, bem como (g) a possibilidade de comparação entre resultados e a (h) integração e utilização de informações complementares ao estudo da variabilidade pluviométrica. Além disso, buscou-se manter o alinhamento da metodologia aos princípios geográficos de localização, extensão, causalidade, correlação, atividade e analogia. 
Para que parte dessas premissas fosse atendida, optou-se pelo gerenciamento dos registros em Bancos de Dados relacional (Figura 5), os quais representam conjuntos logicamente coerentes de dados relacionados (DATE, 2003; ELMASRI e NAVATHE, 2011), mantidos por um conjunto de softwares que compõe um Sistema Gerenciador de Banco de dados (SGBD) (DATE, 2003). Esses sistemas que proporcionam um ambiente conveniente e eficiente para a recuperação e armazenamento de informações (SILBERSCHATZ, KORTH e SUDARSHAN, 1999) e, cujos recursos disponíveis permitem definir, construir, manipular, compartilhar, proteger e manter banco de dados (ELMASRI e NAVATHE, 2011). Nesse contexto, os dados permanecem em um único local, proporcionando o controle de redundâncias e desperdício de espaço de armazenamento, pois os dados são armazenados apenas uma vez e podem ser compartilhados por diversos usuários. Além disso, devido à centralização dos dados em BD, torna-se mais propício instituir padrões de nomenclatura e documentação que facilitam o acesso à informação.

Nesse trabalho foi utilizada a plataforma MySQL, um SGBD, que utiliza a tecnologia SQL (Structured Query Language) como interface, por meio da qual os usuários obtêm informações do banco de dados (SILBERSCHATZ, KORTH e SUDARSHAN, 1999), cuja versatilidade, visa evitar a limitação no volume de dados, permitindo volumes da ordem de 108 (cem milhões), mantendo a estrutura, a integridade e facilitando a manipulação dos dados. É baseado no modelo relacional de dados que se fundamenta em conceitos da matemática, como a teoria dos conjuntos e a lógica de predicado (ELMASRI e NAVATHE, 2011), a qual é mantida por três aspectos principais dos dados: a estrutura, a integridade e a manipulação (DATE, 2003). A estrutura é mantida por uma nomenclatura e significado lógico que garantem a integridade e manipulação, onde uma tabela é considerada uma relação, as linhas ou tuplas contém os valores individualizados, as colunas contêm os atributos vinculados ao dado, às classes dos atributos representam o domínio desse atributo e, o número de atributos vinculados a um dado representa o grau de relação desse dado no banco de dados. A identidade é baseada no conceito de chaves, as quais são estabelecidas de modo que cada linha de uma tabela faça referência a uma linha de outra tabela por meio de atributos (atributos chave) (SILBERSCHATZ, KORTH e SUDARSHAN, 1999). Assim, uma forma de expressar a inteireza da proposta de um banco de dados relacional pode se fazer com a afirmação de que uma relação é matematicamente definida como um subconjunto do conjunto 
de todas as combinações possíveis de valores, ou seja, entre todos os domínios de todos os atributos (ELMASRI e NAVATHE, 2011) (Figura 6).

A manipulação em BD realizada por linguagens computacionais específicas padronizadas para expressar comandos. Nesse trabalho, a obtenção dos dados e a execução das análises geoestatísticas foram conduzidas por meio de scripts em PHP (Hypertext Preprocessor, inicialmente conhecido como Personal Home-Page Language), uma linguagem orientada a objeto, que se diferencia pela rapidez, agilidade e facilidade, em lidar com bancos de dados e de executar tarefas em taxas consideravelmente mais elevadas que os procedimentos manuais. Os scripts foram baseados na estruturação de bibliotecas de funções geográficas e estatísticas, numa estrutura flexível, que permite melhorar e incluir novas funcionalidades paulatinamente e sob demanda. A Figura 7 apresenta um exemplo de script.

Para a espacialização dos resultados foi utilizado o Sistema de Informação Geográfica livre, Quantum Gis 2.12.3 (Lyon). 
PAMA localhost/ localhost/met... $\times+$

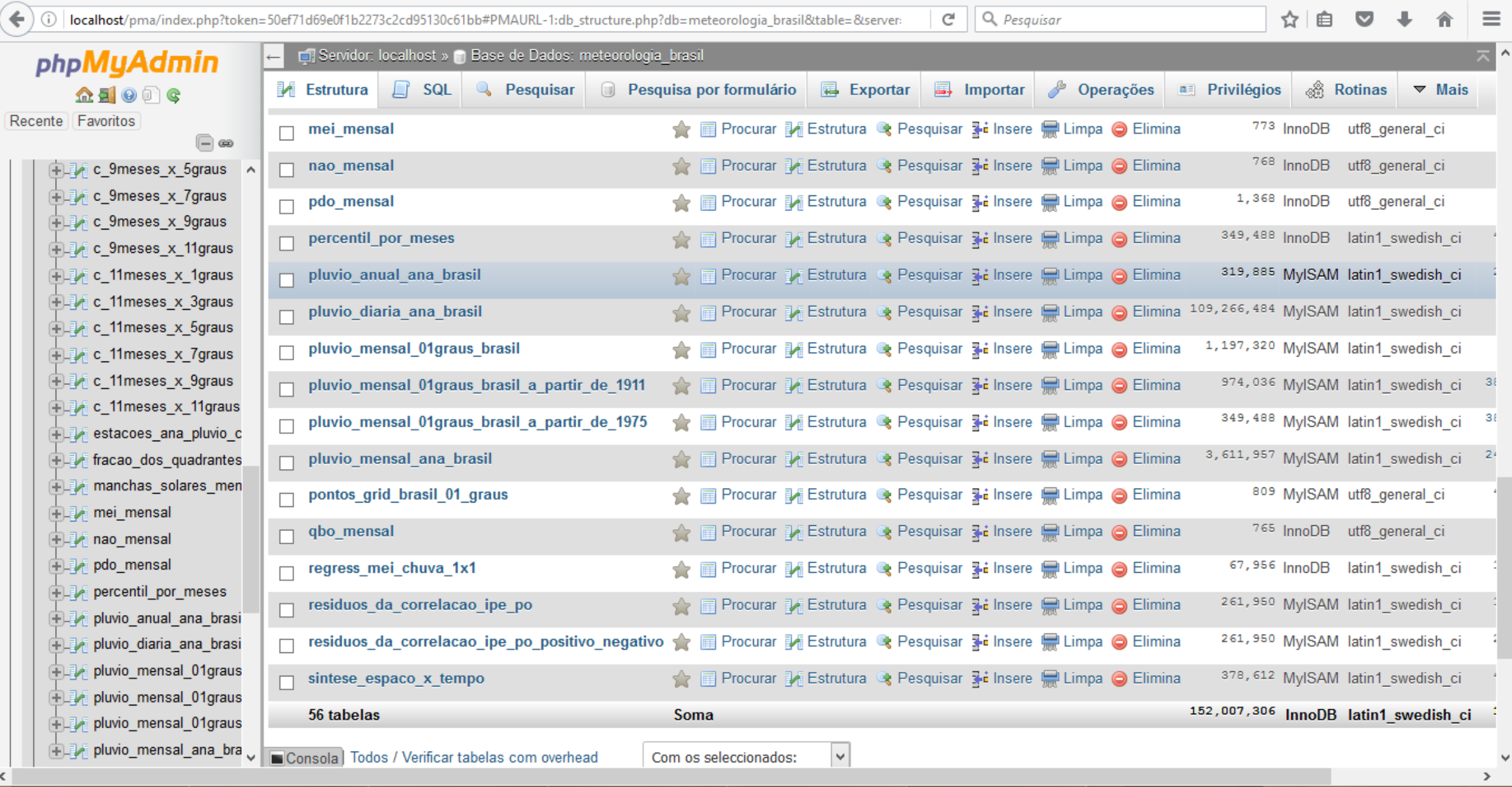

Figura 5: Apresentação da interface de armazenamento e manipulação do Banco de Dados, contendo um total de 56 tabelas. 


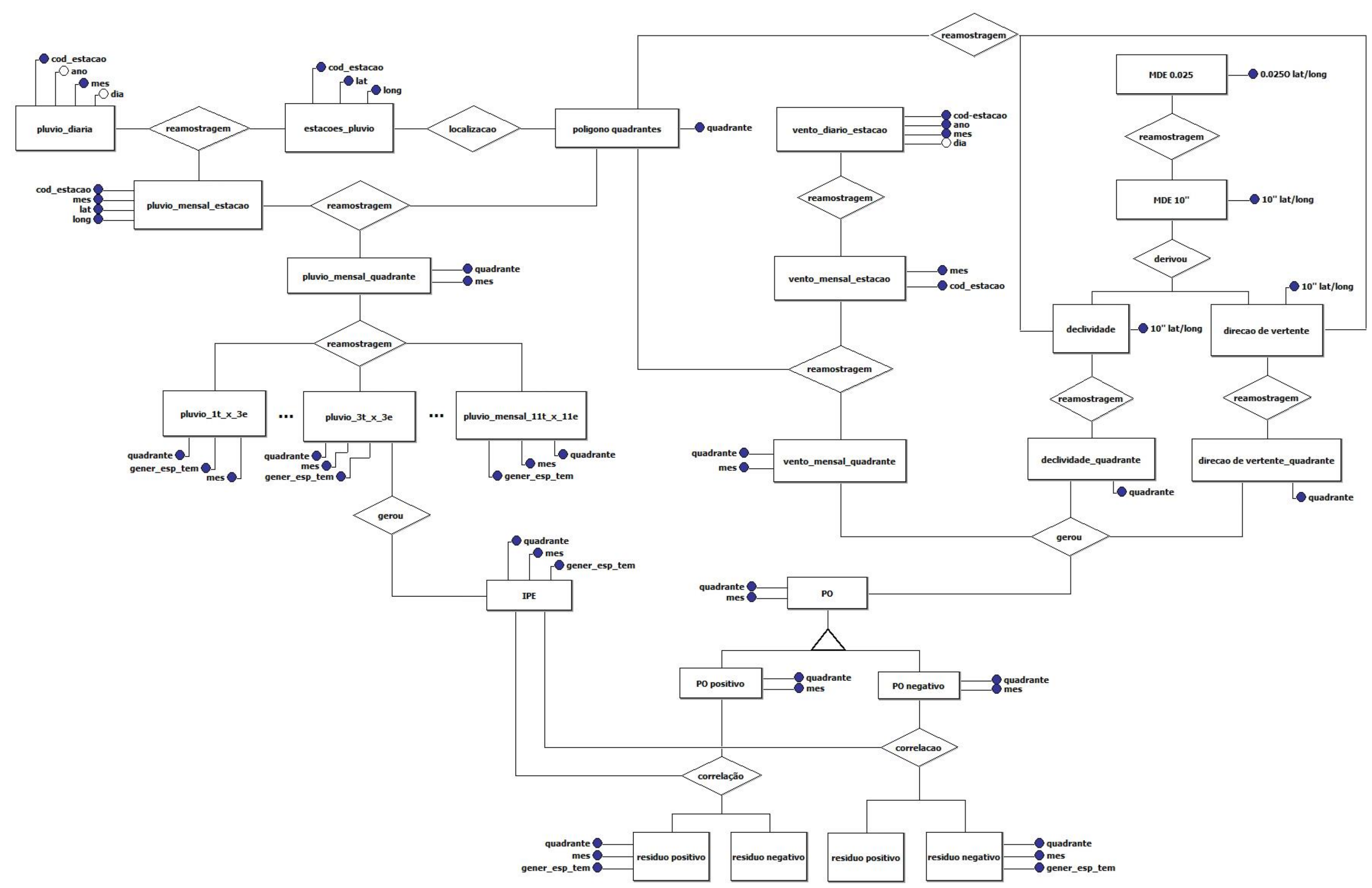

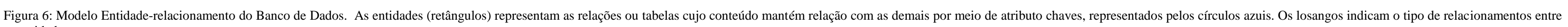
as entidades. 


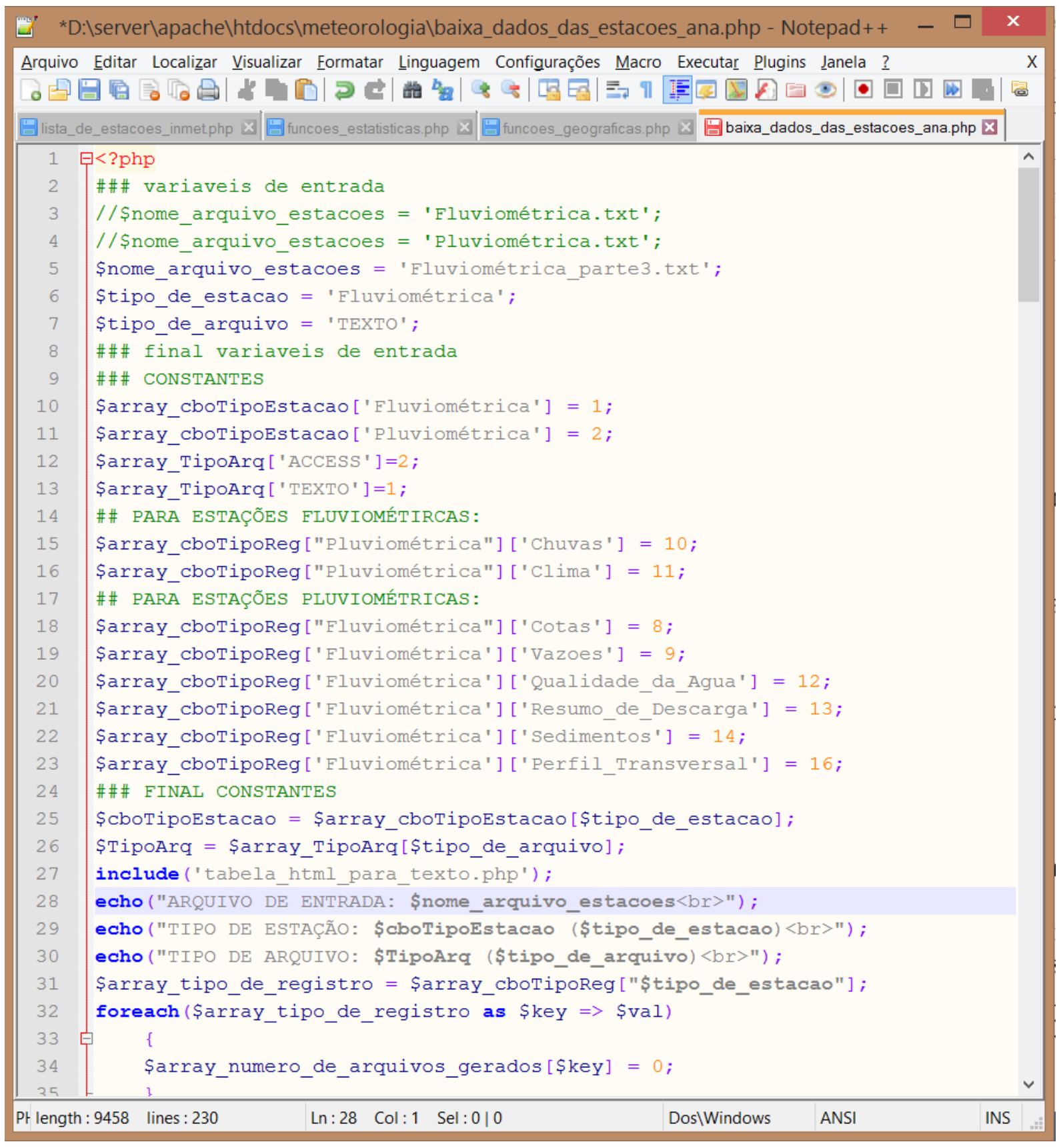

Figura 7: Exemplo de um script em linguagem $P H P$, desenvolvido para a criação, manipulação e manutenção do banco de dados por proporcionar uma ampla gama de possibilidades de gerenciamento de Sistemas de Gerenciamento de Bancos de Dados em $S Q L$ e análises diversas. 


\subsection{Consistência de dados}

O registro de dados é susceptível a erros sejam eles de ordem técnica, falhas de leitura, aquisição, coleta ou de digitação, dentre outros. Assim, demanda-se de auditorias criteriosas para a identificação de inconsistências, bem como o preenchimento de falhas. A consistência de dados representa um conjunto de procedimentos que visa tornar os dados adequados para uso posterior (ANA, 2005). Neste caso, a consistência foi conduzida em duas etapas: a) a identificação e eliminação de inconsistências, e b) a interpolação espaço-temporal para registros mensais numa grade regular de $1^{\circ}$ de arco de latitude e longitude, com 809 quadrantes recobrindo o país.

\subsubsection{Identificação e eliminação de inconsistências}

Muitos métodos de consistência de dados pluviométricos são utilizados atualmente, os quais se baseiam principalmente em informações de estações próximas. Dentre eles destaca-se o método de "ponderação regional" (RHA, 2009); os métodos de "regressão linear simples" ou "múltipla" (BERTONI e TUCCI, 2001); o método de "dupla massa" (SEARCY, 1960); o método do "vetor regional" (HIEZ (1977); o "modelo multivariado sazonal mensal auto regressivo de ordem 1" (RHA, 2009); o método de "redes neurais artificiais". Adicionalmente destacam-se as técnicas de "agrupamento" e a técnica de "Componentes Principais". Não obstante ao valor individual de cada técnica, os seus usos são mais frequentemente orientados à interpolação temporal, notoriamente votadas ao preenchimento de falhas em uma única estação ou localidade.

O método adotado para a identificação de inconsistências foi desenvolvido por FETTER et al. (2016) e baseia-se na análise dos recordes históricos de chuvas no Brasil, permitindo estabelecer os limites inferiores e superiores para os dados considerados consistentes, inconsistentes e duvidosos. A escolha pelo método justifica-se pela preferência pelo método de krigagem Ordinária para a interpolação dos dados. Assim, valores inferiores a $100 \mathrm{~mm}(99,9 \%$ ou 109.157.230 - limite inferior) foram considerados consistentes, pois são de ocorrência comum em todo o Brasil. Valores superiores a $350 \mathrm{~mm}(0,003 \%$ ou 3.584 - 
limite superior) foram considerados inconsistentes, já que registros históricos demonstram poucas ocorrências com esses valores elevados de chuva diária. Os registros em posição intermediária (100-349) foram tratados como suspeitos e tiveram sua consistência avaliada separadamente. Estes limites foram arbitrados incluindo uma análise da probabilidade de caracteres acidentalmente repetidos ou adicionados (para o limite inferior) durante a digitação e a análise dos recordes históricos de chuvas no Brasil e no mundo (para o limite superior). A auditoria prévia realizada nos dados também mostrou que caracteres repetidos são típicos de registros com mais de dois algarismos significativos (registros iguais ou superiores a 100 mm), não sendo próprios dos registros com dois algarismos significativos (de 10 a 99 mm). Um exemplo seria o registro de " $122 \mathrm{~mm}$ ”, que levantaria a suspeita de repetição involuntária do algarismo " 2 " pelo digitador. Outro exemplo seria o valor de "156 mm", que levantaria a suspeita da inclusão involuntária do algarismo " 5 " ou “6”, visto que são números vizinhos no teclado. Diante da existência de registros suspeitos, a análise de consistência prosseguiu considerando os registros pluviométricos nas 10 estações meteorológicas mais próximas, sob três preceitos: 1) de que os mesmos erros de digitação não se repetem em estações diferentes, mesmo que próximas, visto que são dados independentemente registrados, coletados e digitados; 2) de que o dado suspeito, mesmo que correto, difere dos dados das estações vizinhas por uma questão de heterogeneidade espacial; e 3) de que o dado suspeito, para que seja consistente, não deveria diferir demasiadamente dos dados das estações vizinhas devido ao princípio geográfico da correlação espacial (áreas próximas tendem a ser parecidas). Desta forma, foram considerados inconsistentes aqueles dados suspeitos, entre 100 e $350 \mathrm{~mm}$, que diferiram em mais de dez vezes (acima ou abaixo) da média pluviométrica das dez estações mais próximas $(0.097 \%)$. Finalmente, foram eliminados todos os meses com registros inferiores a 28 dias. As implicações destas escolhas também foram discutidas.

\subsubsection{Análise da distribuição espacial dos dados}

A avaliação da distribuição espacial das séries temporais é fundamental para uma análise que vise à incorporação do espaço. Em alguns casos, o maior problema não é exatamente a escassez de dados ou o pequeno volume destes, mas a existência de uma distribuição espacial inadequada, para fins de análises climatológicas. Assim, num dado momento ou intervalo de tempo, a existência de dados concentrados em algumas regiões 
específicas, em detrimento de outras regiões com ausência ou insuficiência de dados, pode representar limitações significativas às análises.

O padrão de distribuição espacial das estações pluviométricas foi obtido ano a ano pelo Índice do Vizinho mais Próximo, NNI (Nearest Neighbor Index), Equação 1, desenvolvido por CLARK e EVANS (1954), baseado na relação entre a distância de um ponto específico para o seu vizinho mais próximo e a distância média de todos os pontos do conjunto de dados. O cálculo de NNI foi aplicado anualmente, formando uma série temporal, considerando-se somente as estações com dados disponíveis para cada ano de referência. $\mathrm{O}$ valor do índice permite a organização espacial do conjunto de casos nas classes de dados agregados, dados uniformes ou dados aleatórios.

$$
N N I=\sum_{i=l}^{N}\left(\frac{\operatorname{Min}\left(d_{i j}\right)}{N}\right)
$$

Equação 1

Onde: $\operatorname{Min}\left(d_{i j}\right)=$ distância entre cada ponto $(i)$ e o seu vizinho mais próximo $(j)$; e $N=$ número de pontos na distribuição.

\subsubsection{Interpolação espaço-temporal}

Foi realizado um planejamento para análises a serem implementadas à posteriori, o qual exigiria a disposição dos dados numa malha espacial regular, de modo que cada nó desta malha possuísse sua própria série temporal. O método empregado consistiu numa interpolação baseada em krigagem ordinária e que consiste em fornecer estimadores não tendenciosos e variância mínima para estimar o valor de um atributo, em uma posição não amostrada, a partir de um conjunto de amostras vizinhas, levando-se em consideração, no modelo, a estrutura de variação espacial (KRIGE, 1951), o que pressupõe a existência de correlação entre os dados (ISAAKS e SRIVASTAVA, 1989).

A krigagem ordinária é reconhecida por mostrar resultados mais realistas, para a utilização em dados pluviométricos, quando comparada a outras técnicas (REINSTORF et al., 2005). Um dos principais motivos do seu destaque, segundo (BARGAOUI e CHEBBI, 2009) é a construção 
do semivariograma para expressar à dependência espacial através da medida da variância dos valores amostrais, separados por uma distância h (Equação 2).

$$
y(h) \frac{1}{2 N(h)}=\sum_{i=1}^{N(h)}[Z(x i)-Z(x i+h)]^{2}
$$

Equação 2

Onde: $N(h)=$ número de pares de valores amostrados $[Z(x i)-Z(x i+h)]$ separados pelo vetor $h$.

Verificada a dependência espacial, a krigagem utiliza as informações do semivariograma para encontrar pesos a serem associados às amostras com valores conhecidos, para estimar o valor de pluviosidade para os pontos desconhecidos, nesse caso, o centro dos quadrantes. A estimativa por krigagem ordinária busca por um conjunto de ponderadores que minimize a variância do erro da estimativa (LANDIM, 2006) (Equação 3)

$$
K \cdot \lambda=k \rightarrow \lambda=k \cdot K^{-1}
$$

Equação 3

Onde: $K$ e $\lambda$ são matrizes das covariâncias e $k$ o vetor dos pesos. Os pesos são atribuídos arbitrariamente (Equação 4)

$$
Z(x i)=f(x i)+e(x i), \quad i=1,2, \ldots, n
$$

Equação 4

Onde: $f(x i)=$ função aleatória $F$ num ponto $x i$;

(xi) são realizações médias de zero e erros. A correlação espacial entre os pontos de medida pode ser quantificada por meio da função de variância (Equação 5)

$$
y=(x, h) \frac{1}{2} \operatorname{var}[F(x)-F(x+h)]
$$

Equação 5

Onde: $h$ é a distância euclidiana entre dois pontos e que a tendência é constante, e $y(x, h)$ são independentes de $x$. Uma função paramétrica é usada para modelar a variância para valores diferentes de $h$. 
Os dados foram interpolados em registros mensais para um sistema de quadrantes de $1^{\mathrm{o}} \times 1^{\mathrm{o}}$ de arco de latitude e longitude, que resultou em 809 quadrantes (Figura 8), representados por 809 pontos equivalentes aos seus centroides, facilitando a manipulação de um grande volume de dados e também para a estimação de valores de chuva em regiões com menor densidade de registros, como é o caso da região Amazônica. Cada krigagem considerou uma quantidade máxima de 20 referências (estações contendo dados), com máxima uniformidade possível na sua distribuição no entorno do ponto alvo (cinco referências em cada quadrante, sendo estes N, S, E e W), e que estivessem a uma distância de no máximo 500 quilômetros do ponto alvo da interpolação. $\mathrm{O}$ dado estimado foi acompanhado do erro de estimação, ou seja, um valor máximo de erro esperado para um intervalo de confiança de $95 \%$. Assim, tem-se uma probabilidade de $95 \%$ de que o dado real esteja entre X-ERRO e X+ERRO, onde X é a média da estimação e ERRO é o erro da estimação.

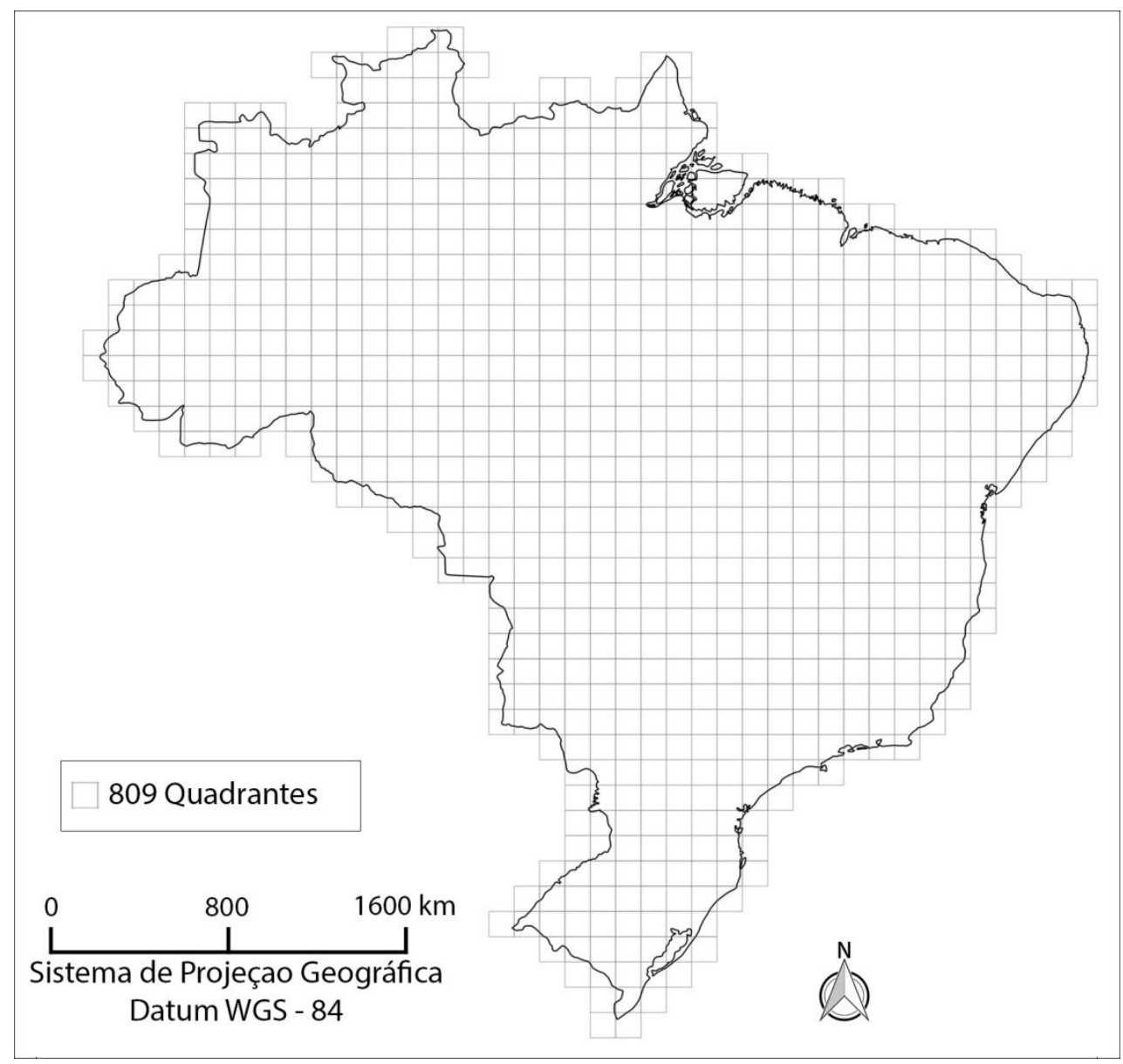

Figura 8: Distribuição espacial das 704 estações meteorológicas automáticas do INMET, utilizadas para o cálculo de direção e velocidade do vento para os 809 quadrantes, na resolução de $1^{\circ}$ de arco de latitude e longitude. 


\subsection{Definição das unidades de análise}

A definição do grão temporal (mês) e espacial (quadrante) decorreu da análise de consistência, estabelecendo uma malha de $1^{\circ}$ de arco de latitude e longitude, representado a resolução original do dado utilizado nesse trabalho. Como dentre os objetivos propostos está a estruturação dos dados visando o desenvolvimento de estudos multiescalares, que permitam o pareamento de resultados, a partir da resolução original foram derivadas 35 escalas com pluviosidade média em função do tempo e do espaço (Tabela 1), as quais foram genericamente denominadas "MxQ" (M meses e Q quadrantes). A Equação 6 apresenta o procedimento empregado para a definição das escalas, baseado no uso de janelas móveis (moving windows, filtros ou Kernels), matematicamente caracterizada como um tipo de convolução, um exemplo de filtro passa-baixa usado no processamento de sinais (SKRØVSETH, BELLIKA e GODTLIEBSEN, 2012) em que o valor central (tempo = unidimensional; espaço = bidimensional) é uma média aritmética simples dos valores vizinhos da janela espaço-temporal.

A técnica é comumente usada com dados de séries temporais para suavizar flutuações de curto prazo e destacar tendências ou ciclos de longo prazo (ESCÁRIA, 1995; PIRES e PEREIRA, 2015). O limiar entre curto e longo prazo depende da aplicação, e os parâmetros da média móvel serão ajustados em conformidade com o fenômeno que se deseja indentificar. Também é utilizada na identificação de padrões e tendências espaciais, produzindo uma superfície menos descontínua, permitindo fazer indicações de locais de transição entre regimes espaciais (QUEIROZ, 2003).

$$
x_{((t, e),(M, Q))}=\frac{1}{M \times Q}\left(\sum_{t=M_{1}}^{M_{M}}\left(\sum_{e=Q_{1}}^{Q_{Q}} x_{(t, e)}\right)\right)
$$

Equação 6

Onde: $x_{(t, e),(M, Q)}$ : precipitação para o mês $t$ e quadrante $e$, na escala de $M$ meses e $Q$ quadrantes $(M \times Q)$

$x_{(t, e)}$ : precipitação o mês $t$ e quadrante $e$, na escala inicial $(1 \mathrm{x} 1)$

$M$ : escala temporal (número de meses) 

$Q$ : escala espacial (número de quadrante)
$M_{1}$ : primeiro mês da janela temporal
$M_{M}$ : último mês da janela temporal
$Q_{1}$ : primeiro quadrante da janela espacial
$Q_{Q}:$ último quadrante da janela espacial

Tabela 1: Escalas espaço-temporais propostas para o estudo da variabilidade pluviométrica no Brasil (36 escalas). Os números no centro da tabela indicam o produto entre o tamanho das janelas temporais e espaciais, portanto, o número de itens utilizados para compor cada média móvel.

\begin{tabular}{c|c|cccccc}
\hline \multicolumn{2}{c|}{} & \multicolumn{5}{c}{ Tamanho da janela temporal (Quantidade de } \\
meses - M)
\end{tabular}

\subsection{Análise de tendência de mudança espaço-temporal}

A análise de tendência correspondeu a aplicação do teste de Mann-Kendall (MANN, 1945; KENDALL, 1975) as 36 escalas espaço-temporais definidas no item anterior. Consiste no teste não paramétrico, dentre os mais utilizados para detectar tendências naturais que se distanciam da distribuição normal, como a precipitação (HAMED, 2009) e tem sido é indicado pela Organização Meteorológica Mundial. Testes não paramétricos são considerados mais robustos e não necessitam da especificação do modelo distributivo da população, sendo formulados com base nas características da amostra (XU, TAKEUCHIA e ISHIDAIRAA, 2003). A exigência é que os dados sejam independentes (a distribuição de probabilidade deve permanecer sempre a mesma), uma vez que a correlação serial positiva entre as observações aumentaria a chance de resposta significativa, mesmo na ausência de uma tendência (COX e STUART, 1955), apesar da distribuição de $S$ tender à distribuição Normal para Grande $\mathrm{n}$ 
quando os dados são independentes. Por tratar-se de um método baseado na ordem dos registros, é menos sensível a outliers (KENDALL, 1975).

O teste se baseia na correlação entre as classificações de uma série temporal e sua ordem temporal. Para uma série temporal $\mathrm{X}=(\mathrm{x} 1, \mathrm{x} 2, \ldots, \mathrm{xn})$, a estatística de teste é dada pela Equação 7:

$$
S=\sum_{k=l}^{n-1} \sum_{j=k+1}^{n} \operatorname{sinal}\left(x_{j}-x_{k}\right)
$$

Equação 7

onde: $S=$ coeficiente de correlação de Mann-Kendall;

$x_{j}-x_{k}=$ os dados estimados da sequência de valores;

$n=$ número de elementos da série temporal;

$$
\begin{aligned}
\operatorname{sinal}\left(x_{j}-x_{k}\right) & =1 \text { se } x_{j}-x_{k}>0 ; \\
& =0 \text { se } x_{j}-x_{k}=0 ; \\
& =-1 \text { se } x_{j}-x_{k}<0 .
\end{aligned}
$$

Um valor positivo muito elevado de $S$ é um indicador de uma tendência crescente, e um valor negativo muito baixo indica uma tendência decrescente. Na prática, a estatística mede a diferença entre a frequência relativa dos aumentos e a frequência relativa das diminuições. No entanto, é necessário calcular a probabilidade associada a $S$ e o tamanho da amostra, $n$, para quantificar estatisticamente a significância da tendência (Equação 8).

$$
\operatorname{VAR}(S)=\frac{1}{18}=\left\{n(n-1)(2 n+5)-\sum_{p=1}^{g} t_{p}\left(t_{p}-1\right)\left(2 t_{p}+5\right)\right\}
$$

Equação 8

Onde: $\operatorname{VAR}(S)=$ variância

$$
\begin{aligned}
& S=\text { coeficiente de correlação de Mann-Kendall } \\
& n=\text { número de elementos da série temporal } \\
& g=\text { conjunto de dados da amostra com o mesmo valor } \\
& t_{p}=\text { número de elementos da série temporal no grupo } \mathrm{p}^{\text {th }}
\end{aligned}
$$


A tendência é indicada pelo valor de $Z$ (Equação 9), a ser empregado junto a um teste inferencial estatístico $Z$ e sob uma distribuição normal, cujo sinal positivo significa uma tendência crescente e um valor negativo indica uma tendência decrescente.

$$
Z=\frac{S-1}{\sqrt{\operatorname{VAR}(S)}} \text {, se } S>0 \quad Z=0 \text {, para } S=0 \quad Z=\frac{S+1}{\sqrt{\operatorname{VAR}(S)}} \text {, se } S<0
$$

Equação 9

Se a probabilidade $(p)$ para o teste de Mann-Kendall for menor que o nível de significância $\alpha$, uma tendência estatisticamente significante existe, enquanto que um valor de $p$ maior que $\alpha$ confirma uma tendência insignificante. Para amostras onde não há tendência, $o$ valor de Z é próximo de 0 e o valor de $p$ é próximo de $\alpha$.

\subsection{O Índice de Proporção de Escalas (IPE)}

A fim de medir a variação pluviométrica proporcionalmente atribuída aos fatores espaço e tempo, é proposto o "Índice de Proporção de Escalas" (IPE), o qual demanda de um conjunto $X$ de dados de precipitação numa escala espaço-temporal $M \times Q$, onde $M>1$ e $Q>1$. A medida de dispersão mais básica possível e que seja baseada na totalidade dos dados do conjunto $X$ pode ser obtida pela análise dos desvios da média, ou simplesmente desvios. Considerando que, invariavelmente, a média dos desvios é zero, visto que a soma dos desvios é zero, torna-se fundamental analisar os desvios em termos de seu módulo (ausência de sinal), de forma que desvios negativos e positivos não se anulem e que os resíduos possam ser computados integralmente e linearmente, enquanto expressão da variação dos dados. Assim, a Equação 10 apresenta o cálculo para a obtenção da Média dos Módulos dos Desvios em função do tempo para a escala de $M$ meses e $Q$ quadrantes e, de forma análoga, para análise da dispersão promovida pelo espaço, assume-se a Equação 11. 


$$
D t_{(M, Q)}=\frac{1}{M} \sum_{t=M_{1}}^{M_{M}}\left|\bar{x}_{Q}-x_{t, Q}\right|
$$

Equação 10

Onde: $D t_{(M, Q)}$ : Média dos módulos dos desvios devido ao tempo para escala de $M$ meses e $Q$ quadrantes

$\bar{x}_{Q}$ : Média de pluviosidade para os $M$ meses e na escala espacial de $Q$ quadrantes

$x_{(t, Q)}$ : pluviosidade para o tempo $t$ e escala espacial $Q$

$M$ : escala temporal (número de meses)

$Q:$ escala espacial (número de escala)

$M_{1}$ : primeiro mês da janela temporal

$M_{M}$ : último mês da janela temporal

$$
D e_{(M, Q)}=\frac{1}{Q} \sum_{e=Q_{1}}^{Q_{Q}}\left|\bar{x}_{M}-x_{M, e}\right|
$$

Equação 11

Onde: $D e_{(M, Q)}$ : Média dos módulos dos desvios devido ao espaço para a escala de $M$ meses e $Q$ quadrantes.

$\bar{x}_{M}$ : Média de pluviosidade para as $Q$ quadrantes na escala temporal de $M$ meses

$x_{(M, e)}$ : pluviosidade para o mês $M$ e escala espacial $e$

$M$ : escala temporal (número de meses)

$Q$ : escala espacial (número de quadrantes)

$Q_{1}$ : primeira quadrante da janela espacial

$Q_{Q}$ : última quadrante da janela espacial 
O IPE é obtido pela média do módulo dos desvios no tempo para a escala de $M$ meses e $Q$ quadrantes $(D t)$, dividida pela soma de ambas as médias do $S$ desvios, ou seja, aquela devida ao tempo e a devida ao espaço (De) (Equação 12)

$$
I P E_{(M, Q)}=\frac{D t_{(M, Q)}}{D t_{(M, Q)}+D e_{(M, Q)}}
$$

Equação 12

Onde: IPE: índice de proporção de escalas

$$
\begin{aligned}
& 0<\mathrm{IPE}<1 \\
& \mathrm{IPE} \rightarrow 0 \text { se De é maior que Dt } \\
& \mathrm{IPE} \rightarrow 1 \text { se De é menor que Dt } \\
& \mathrm{IPE}=0,5 \text { se } \mathrm{De}=\mathrm{Dt}
\end{aligned}
$$

Assim:

- Um IPE próximo a 0 ocorre quando $D e$ é maior que $D t$, indicando que a variação na quantidade de chuva se deve mais à heterogeneidade no espaço que no tempo;

- Um IPE próximo a $l$ ocorre quando $D t$ é maior que $D e$, indicando que a variação na quantidade de chuva se deve mais a heterogeneidade no tempo que no espaço;

- Um IPE em torno de 0,5 ocorre quando $D t$ e $D e$ são muito semelhantes, indicando que a variação na quantidade de chuva se deve, de forma similar, a heterogeneidade no espaço e no tempo.

Por exemplo, um $I P E$ de valor 0,3 indica que a variação na quantidade de chuva é uma consequência maior da heterogeneidade espacial, ou seja, do conjunto das variáveis com uma marcante estruturação espacial, como é o caso da vegetação, do relevo, proximidade do mar, etc., obviamente, com a contribuição de variáveis estruturadas no tempo, como a dinâmica das massas de ar, os sistemas de tempo frontais, convergências, etc. Assim, o uso do IPE tem finalidade de comparação entre as escalas, portanto é um indicador relativo. O entendimento do IPE como indicador absoluto necessitaria uma discussão sobre a validade de se estabelecer equivalência entre espaço e tempo, algo que está fora do propósito deste trabalho. 
Provavelmente, demandaria a compreensão física da interação entre os diferentes fatores envolvidos em cada episódio de precipitação e condição de ausência da mesma num determinado local, diante de uma determinada escala de espaço e tempo.

O IPE é fundamentado em alguns aspectos da análise de "variância (ANOVA) dois fatores" havendo, contudo, duas diferenças principais. Em primeiro lugar, a ANOVA considera o quadrado dos desvios que, por si só, já elimina os valores negativos e exerce a mesma função do módulo usado no IPE. O quadrado dos desvios para todos os fatores numa ANOVA possibilita encontrar o resíduo (ou erro), que é parcela da variância não explicada pelos fatores explícitos e, consequentemente, a variância total, dada pela soma da variância dos fatores e do resíduo. A segunda diferença se dá na análise da proporção, que no caso de uma ANOVA, é a razão entre a variância de um fator e a variância do resíduo (e não entre distintos fatores, como no caso do IPE). Considerando que haja condições adequadas de distribuição dos dados, tal razão constitui o valor de $F$, que pode ser comparada à distribuição de $F$ de Fisher para um determinado grau de liberdade, para fins inferenciais. No caso do IPE, embora seja uma estatística por indicar o estado dos dados, não há uma proposta inferencial, sobretudo devido aos pré-requisitos frequentemente exigidos na ANOVA e outras estatísticas inferenciais, tais como normalidade, mesocurtose, homocedasticidade e coeficiente de variação baixo (ZAR, 2010).

O valor do IPE é calculado para uma dimensão espaço-temporal de $Q$ quadrantes e $M$ meses, contudo é um indicador exclusivo para uma janela cujo centro é representado pelo quadrante $q$ e o mês $m$. Assim, um valor específico de IPE pode ser identificado por $I P E_{(M, Q, m, q)}$ e uma coleção destes elementos representa uma série espaço-temporal que, portanto, pode ser analisada segundo suas estatísticas de tendência central e dispersão.

Os valores de IPE na escala anual foram obtidos pela análise de série temporal total, enquanto que, para análise por mês, considerou-se uma janela restrita a 3 meses. Da mesma forma, a escala espacial considerou uma janela de 3 quadrantes e correspondeu a conjuntos de 9 quadrantes. 


\subsection{O potencial para ocorrência de chuvas orográficas no Brasil (POC)}

Para fins de análise da influência do relevo na precipitação, é proposto um índice denominado Potencial Orográfico de Chuvas (POC) baseado nas características topográficas e na sazonalidade do vento no Brasil. O Modelo Digital de Elevação (MDE) do Brasil foi reamostrado da resolução de $0,002778^{\circ}$ de arco de latitude e longitude ( 300 metros) para a resolução de 10" de arco de latitude e longitude ( 30 metros) e utilizado para a derivação da clinografia (Figura 9) e direção das vertentes para os 809 quadrantes (Figura 10).

O POC considera que, num dado local, o vento pode fluir em todas as direções e que distintos lugares possuem discretos valores para clinografia e direção de vertentes, de acordo com a generalização de escala utilizada, a qual corresponde a uma determinada quantidade de pixels da imagem em um ambiente SIG (Sistema de Informação Geográfica). Assim, a formulação do índice contempla distintas direções potenciais de vento, sob distintas velocidades, operando sobre um relevo com distintas direções de vertentes e distintas clinografias, que podem resultar num potencial positivo, nulo ou negativo de influência na pluviosidade (Tabela 2).

Tabela 2: Classificação dos valores de POC de acordo com a clinografia, velocidade do vento e o alinhamento entre direção do vento e direção da vertente.

\begin{tabular}{|c|c|c|c|}
\hline Alto POC (+) & $\begin{array}{l}\text { Elevada } \\
\text { Clinografia }\end{array}$ & $\begin{array}{l}\text { Elevada Velocidade } \\
\text { do Vento }\end{array}$ & $\begin{array}{l}\text { Coincidência entre direção do } \\
\text { vento e direção da vertente }\end{array}$ \\
\hline POC nulo & & & $\begin{array}{l}\text { Direção de vento ortogonal à da } \\
\text { vertente }\left(90^{\circ} \text { ou } 270^{\circ}\right)\end{array}$ \\
\hline Baixo POC (-) & $\begin{array}{l}\text { Elevada } \\
\text { Clinografia }\end{array}$ & $\begin{array}{l}\text { Elevada Velocidade } \\
\text { do Vento }\end{array}$ & $\begin{array}{l}\text { Direção do vento se opõe à da } \\
\text { vertente }\left(180^{\circ}\right)\end{array}$ \\
\hline
\end{tabular}




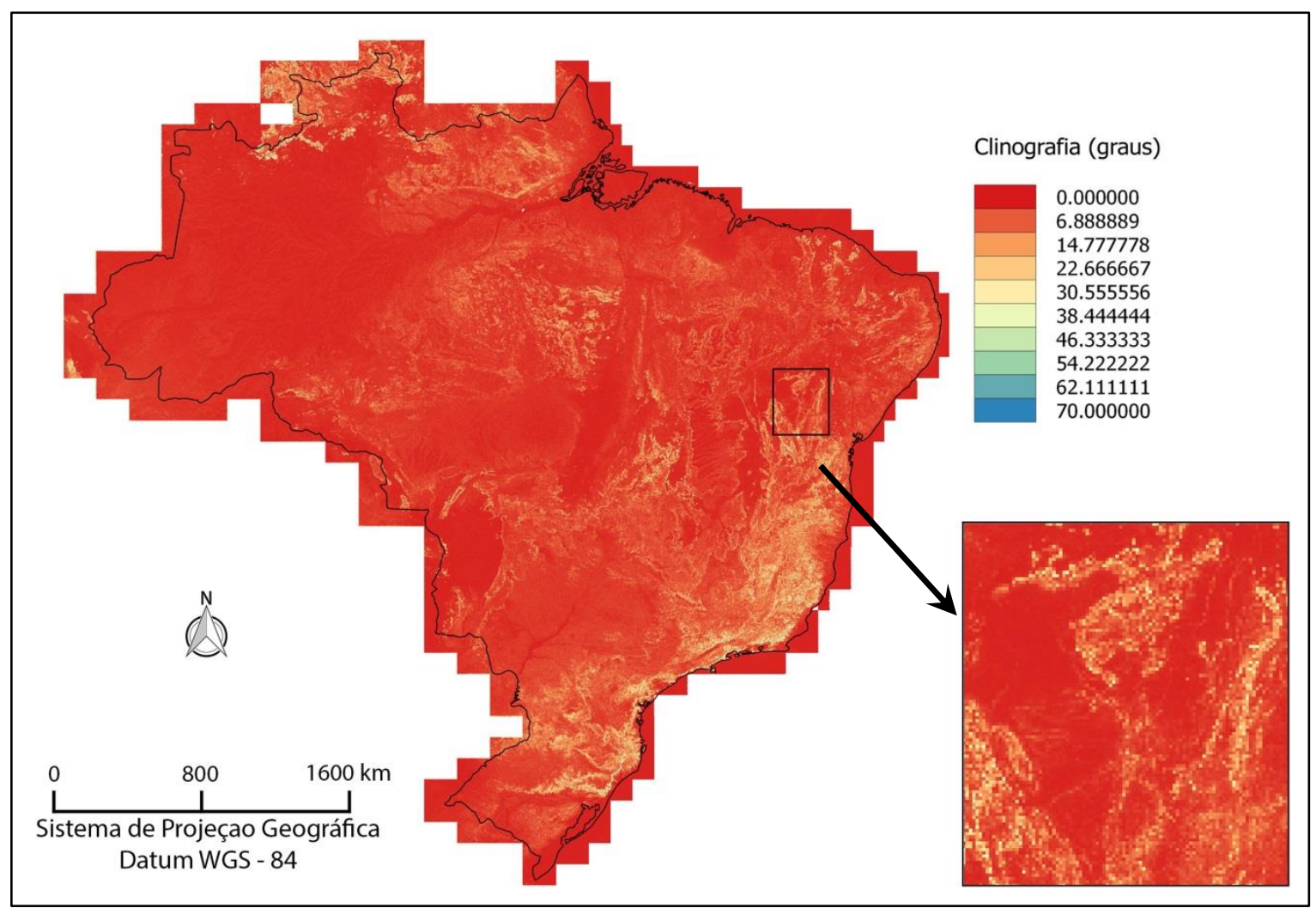

Figura 9: Clinografia do relevo brasileiro, obtido do Modelo Digital de Elevação, na resolução de $0.025^{\circ}$ de latitude e longitude.

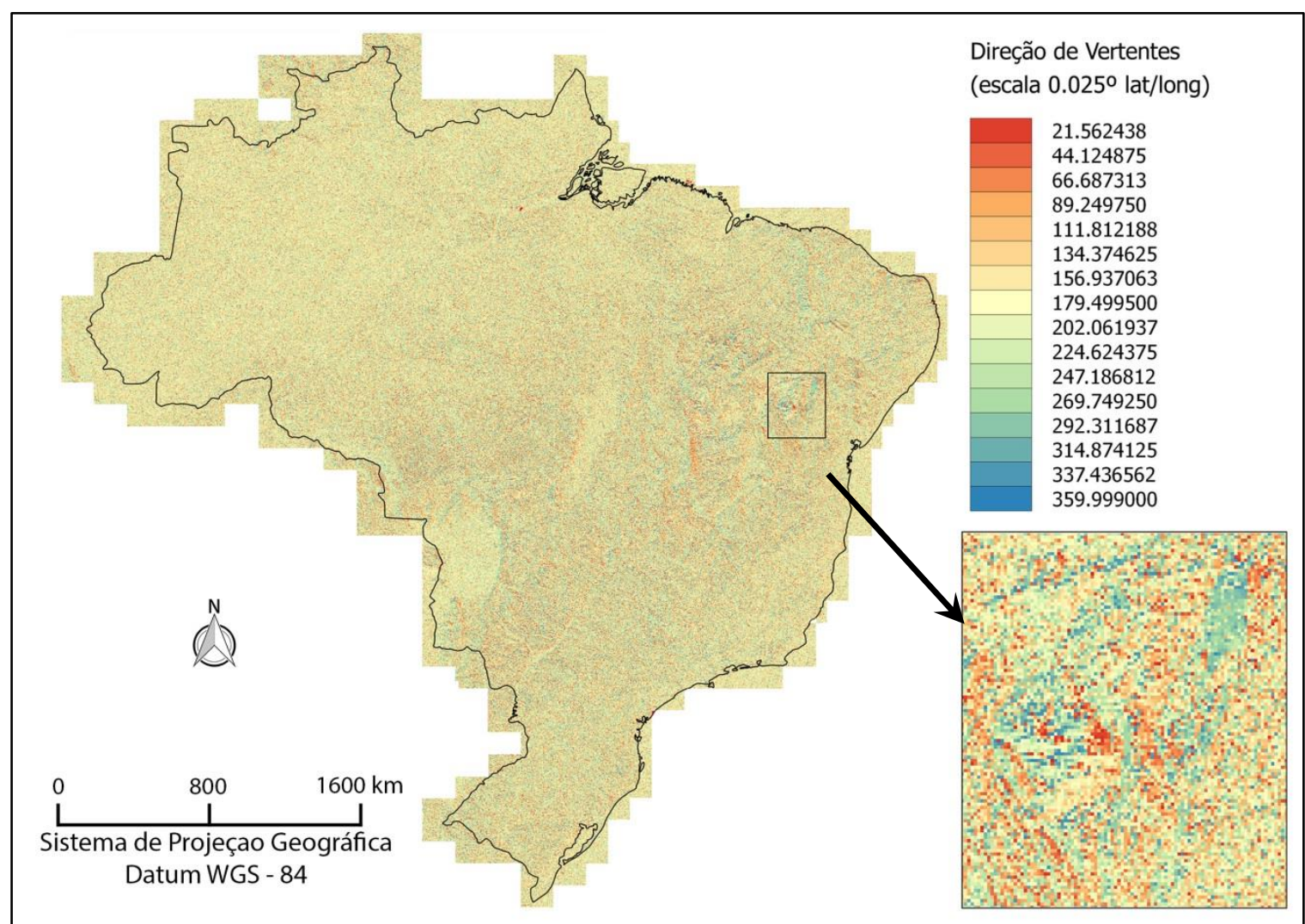

Figura 10: Direção de vertentes do relevo brasileiro, obtido do Modelo Digital de Elevação, na resolução de $0.025^{\circ}$ de latitude e longitude. 
O POC segue a Lei dos Cossenos, sendo proporcional 1) ao cosseno do ângulo formado entre os azimutes da direção do vento e o da direção da vertente, 2) à clinografia e, 3) à velocidade do vento. Para isso, os dados de direção do vento e direção de vertente foram organizados em 16 classes de direção, representando todos os pontos cardeais, colaterais e subcolaterais, com intervalos de $22.5^{\circ}(0.0,22.5,45.0,67.5,90.0,112.5,135.0,157.5,180.0$, 202.5, 225.0, 247.5, 270.0, 292.5, 315.0 e 337.5 graus) (Equação 13).

$$
p=\frac{360}{c}
$$

Equação 13

Onde: $p=$ intervalo de passo (neste estudo, $360^{\circ} \div 16$ classes de direção $=22.5^{\circ}$ )

$c=$ número de classes de direção (neste estudo 16)

O cálculo do POC iniciou com a determinação do Fator Direcional Específico (FDE), o qual é o resultado da multiplicação entre a clinografia e o cosseno da diferença entre a direção da vertente e uma outra direção arbitrada. Este valor é obtido na instância do pixel, que possui somente um valor de clinografia $(\alpha)$ e direção de vertente $(\gamma)$, mas que pode ser calculado para qualquer direção $(\omega)$ específica (de vento, no caso), resultando em 16 imagens, com resolução de 10'” de arco de lat/long (Equação 14).

$$
F D E_{(x, y, \omega)}=\alpha_{(x, y)} \times \cos \left(\gamma_{(x, y)}-\omega\right)
$$

Equação 14

Onde: $F D E_{(x, y, \omega)}=$ fator direcional específico para a direção do vento $\omega$ em um pixel de coordenadas $x$ e $y$.

$\alpha=$ Clinografia do pixel de coordenadas $x$ e $y$

$\gamma=$ Direção da vertente do pixel de coordenadas $x$ e $y$

$\omega=$ Direção específica, para a qual se pretende calcular o valor de FDE. Neste estudo, foram calculados FDE para todas as direções relacionadas aos pontos cardeais, colaterais e subcolaterais, os quais correspondem às distintas direções do vento.

O Fator Direcional Específico foi generalizado para todos os pixels de um quadrante $q$, resultando no FDEQ, possibilitando a adequação do dado para a escala espacial do 
quadrante ( $1^{\circ}$ de arco de latitude e longitude) (Equação 15), resultando em 16 arquivos de valor de atributo, com 12.944 registros (809 x 16 direções).

$$
F D E Q_{(q, \omega)}=\frac{1}{N} \times \sum_{x=1}^{i}\left(\sum_{y=1}^{j}\left(F D E_{x, y, \omega}\right)\right)
$$

Equação 15

Onde: $F D E Q_{(q, \omega)}=$ fator direcional para a direção de vento $\omega$ no quadrante $q$

$i=$ número de pixels ao longo de uma linha no eixo $x$ para o quadrante $q$

$j=$ número de pixels ao longo de uma coluna no eixo $y$ para o quadrante $q$

$N=$ número de pixels no quadrante $q$. Se o quadrante for perfeitamente retangular, então $N=i^{2}$

Na sequência foi calculado o Potencial Orográfico Específico em um Quadrante $q$ (POEQ), também direcional, relacionado à velocidade $(V)$ do vento e ao FDEQ, os quais são ponderados pela frequência $(F)$ do vento em cada classe de direção (Equação 16). Como resultado obteve-se 155.328 registros mensais de $V_{\omega}$ e $F_{\omega}(809$ quadrantes x 16 direções x 12 meses), 12.944 registros anuais de $V_{\omega}$ e $F_{\omega}$ (809 quadrantes x 16 direções) e 12.944 registros anuais de $\operatorname{POEQ}_{(q, \omega)}(809$ quadrantes x 16 direções).

$$
. P O E Q_{(q, \omega)}=\operatorname{FDEQ}_{(q, \omega)} \times V_{\omega} \times F_{\omega}
$$

Equação 16

Onde: $P O E Q_{(q, \omega)}=$ Potencial Orográfico Específico do quadrante $q$, para a direção $\omega$,

$V_{\omega}=$ velocidade do vento na direção $\omega$,

$F_{\omega}=$ frequência de vento na direção $\omega$, sendo que a soma de todos os $F_{\omega}$ resulta em 1 .

Num determinado quadrante ocorre, potencialmente, vertentes e ventos em todas as direções. Assim, o Potencial Orográfico Omnidirecional do Quadrante (POOQ), ou simplesmente Potencial Orográfico de Chuvas (POC) é representado pela média aritmética de todos os potenciais orográficos específicos $(P O E Q)$, calculados para as $c$ direções, iniciadas em $0^{\circ}$, seguindo passos de $p^{\circ}$, até completar um giro de $360^{\circ}$ (limite não incluso) (Equação 17), resultando em 9.708 registros mensais ( 809 quadrantes x 12 meses) e 809 registros anuais (809 quadrantes). 


$$
\operatorname{POC}_{(q)}=\frac{1}{c} \times \sum_{\substack{\omega=0, \omega=\omega+p}}^{\lim 360}\left(\operatorname{POEQ}_{(q, \omega)}\right)
$$

Equação 17

Onde: $P O C_{(q)}=$ Potencial Orográfico Omnidirecional do Quadrante $q$,

$c=$ número de classes, neste estudo 16,

$p=$ passo de classe, neste caso $22.5^{\circ}$ (considerando todos os pontos cardeais, colaterais e subcolaterais),

$\omega=$ Direção específica da vertente de relevo, entre 0 e $360^{\circ}$ (não incluso), condicionada a cada passo $p$ de cálculo.

O POC possibilita a análise integrada de processos orográficos em distintas direções representando, portanto, um índice omnidirecional, visto que contempla ventos e vertentes em todas as direções simultaneamente.

É importante notar que a Equação 17 não realiza sozinha todas as 256 interações possíveis, ou seja, o produto das 16 classes para fatores topográficos (FDE) e 16 classes para fatores eólicos $(V$ e $F)$. Tal interação somente é notada ao se analisar combinadamente as equações anteriores. Enquanto a Equação 15 incorpora as 16 classes de direção de vento a Equação 17 incorpora as 16 classes de direção de vertente, respeitando-se as proporções de ocorrência das classes de direção dentro de um quadrante e as diferenças de ângulo entre vertente e vento e a clinografia (Equação 14). Assim resultam 256 interações possíveis, ponderadas pelas características de vento (direção e velocidade) e relevo (orientação de vertente e inclinação).

A validação do POC foi realizada pela comparação de dos resultados com 34 estudos realizados sobre chuvas orográficas no Brasil obtidos nas bases de dados do Portal Capes e Google Acadêmico. Cada estudo foi inserido em ambiente SIG visando avaliar a distribuição e concentração dos locais estudados. Ferramentas de geoprocessamento ajudaram a análise dos dados. A validação também contou com a análise dos dados de vento e dos mecanismos meteorológicos conhecidos. O processo de validação ocorreu de forma imersiva, onde dados de $P O C$ foram confrontados aos estudos, simultaneamente a análise das cartas de vento e mecanismos formadores do tempo meteorológico. 


\section{RESULTADOS E DISCUSSÃO}

Os resultados são apresentados em duas partes. Uma parte inicial trata da apresentação dos dados derivados do processamento que estruturou tabelas específicas do banco de dados. A segunda parte apresenta possíveis desdobramentos do uso destes dados, enquanto aplicações concretas para a compreensão das chuvas no Brasil, bem como apontamentos e reflexões acerca das possibilidades de aplicações futuras.

\subsection{Características gerais dos dados e sua consistência}

Foram obtidos 109.266.484 registros diários de precipitação pluviométrica da Agência Nacional de Águas (ANA) para o período de 1888 a 2010 (123 anos). Estes estiveram organizados em um total de 10.939 estações meteorológicas (Figura 2), contudo nem todas com operações simultâneas. Utilizando a data do primeiro e do último registro de cada estação meteorológica e as interrupções nas séries de dados obteve-se uma representação gráfica dos registros simultâneos no tempo e dos momentos mais críticos de escassez de dados (Figura 11 e Figura 17). A Figura 18 apresenta os valores do NNI (Índice do Vizinho mais próximo) que caracterizam a distribuição espacial dos registros pluviométricos simultâneos da série temporal de dados 


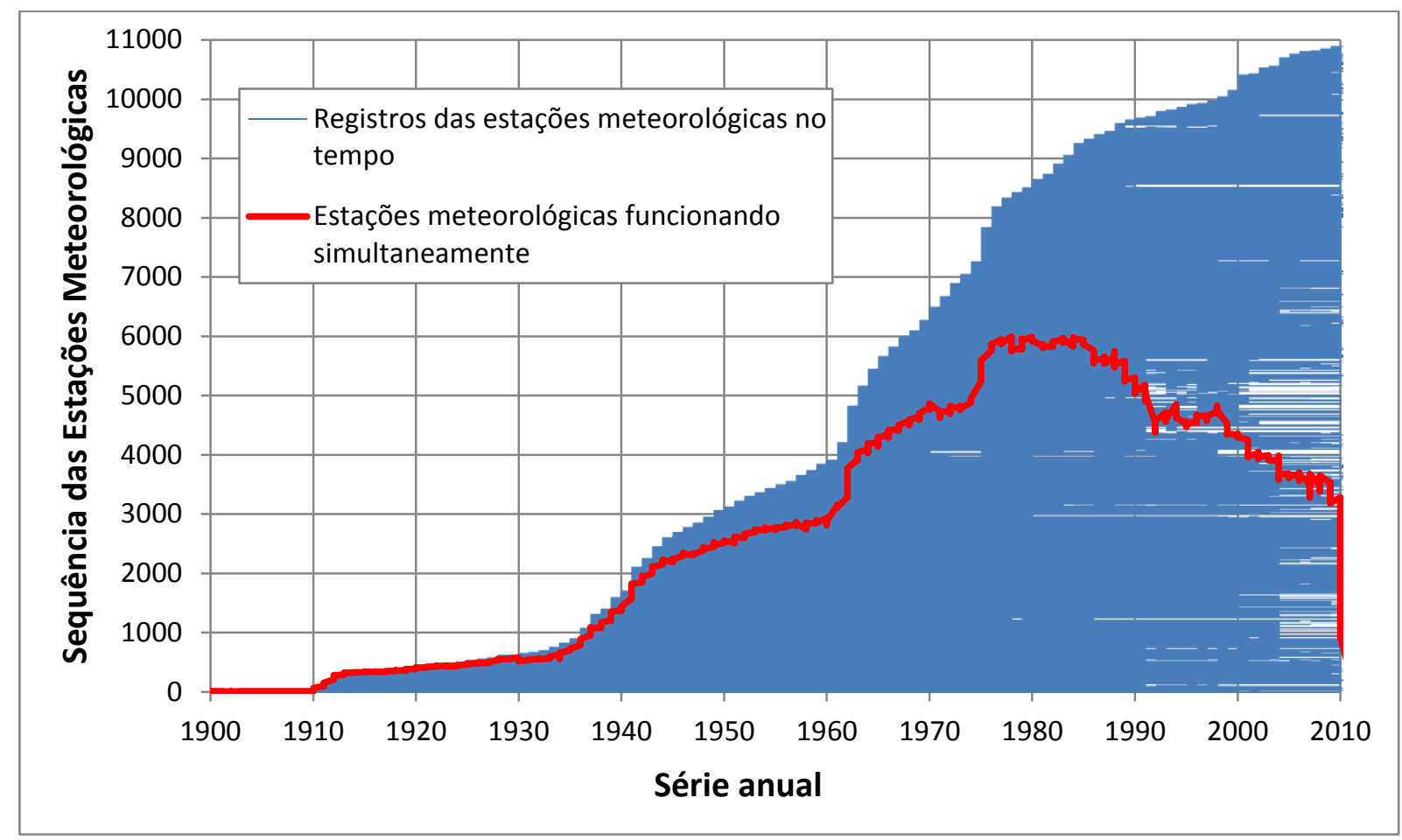

Figura 11: Linha do tempo apresentando os registros das 10.939 estações meteorológicas no Brasil, mostrando o início e o final de operação de cada estação (organizadas sequencialmente ao longo do eixo das ordenadas), bem como as interrupções (faixas claras ao longo do eixo das abcissas) e a quantidade de estações meteorológicas funcionando simultaneamente (vermelho).
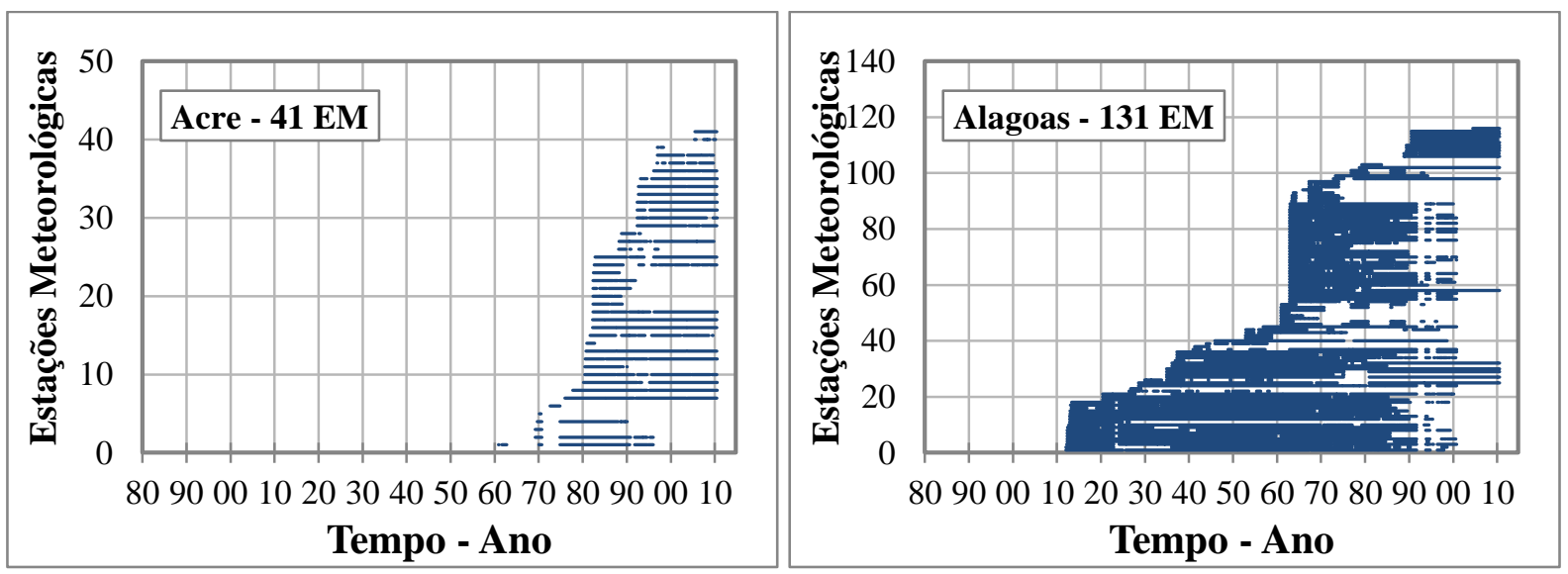

Figura 12: Linha do tempo apresentando os registros das meteorológicas nos estados brasileiros, mostrando o início e o final de operação de cada estação (organizadas sequencialmente ao longo do eixo das ordenadas), bem como as interrupções (faixas claras ao longo do eixo das abcissas). Continua.. 

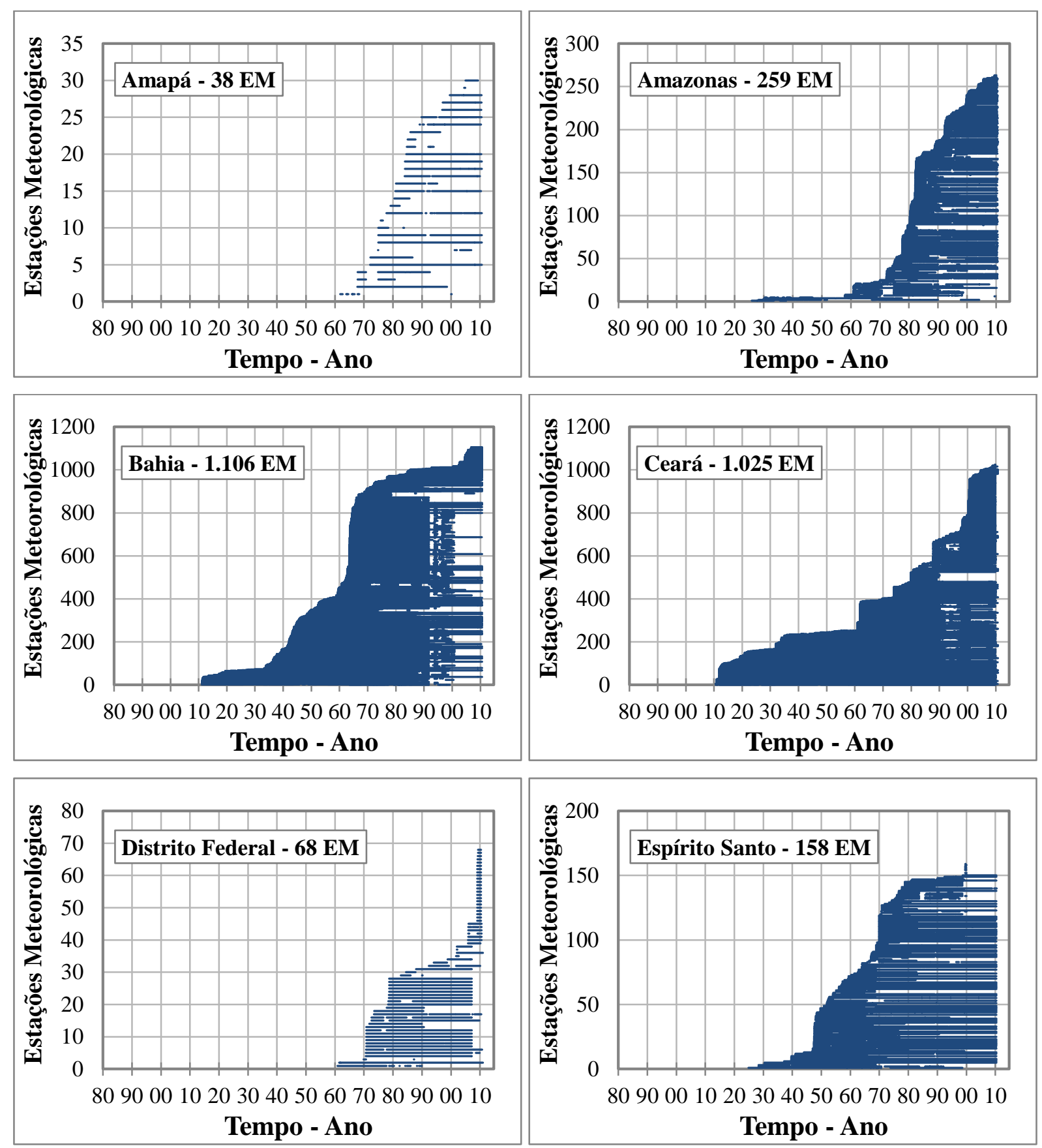

Figura 13: Linha do tempo apresentando os registros das meteorológicas nos estados brasileiros, mostrando o início e o final de operação de cada estação (organizadas sequencialmente ao longo do eixo das ordenadas), bem como as interrupções (faixas claras ao longo do eixo das abcissas). Continua.. 

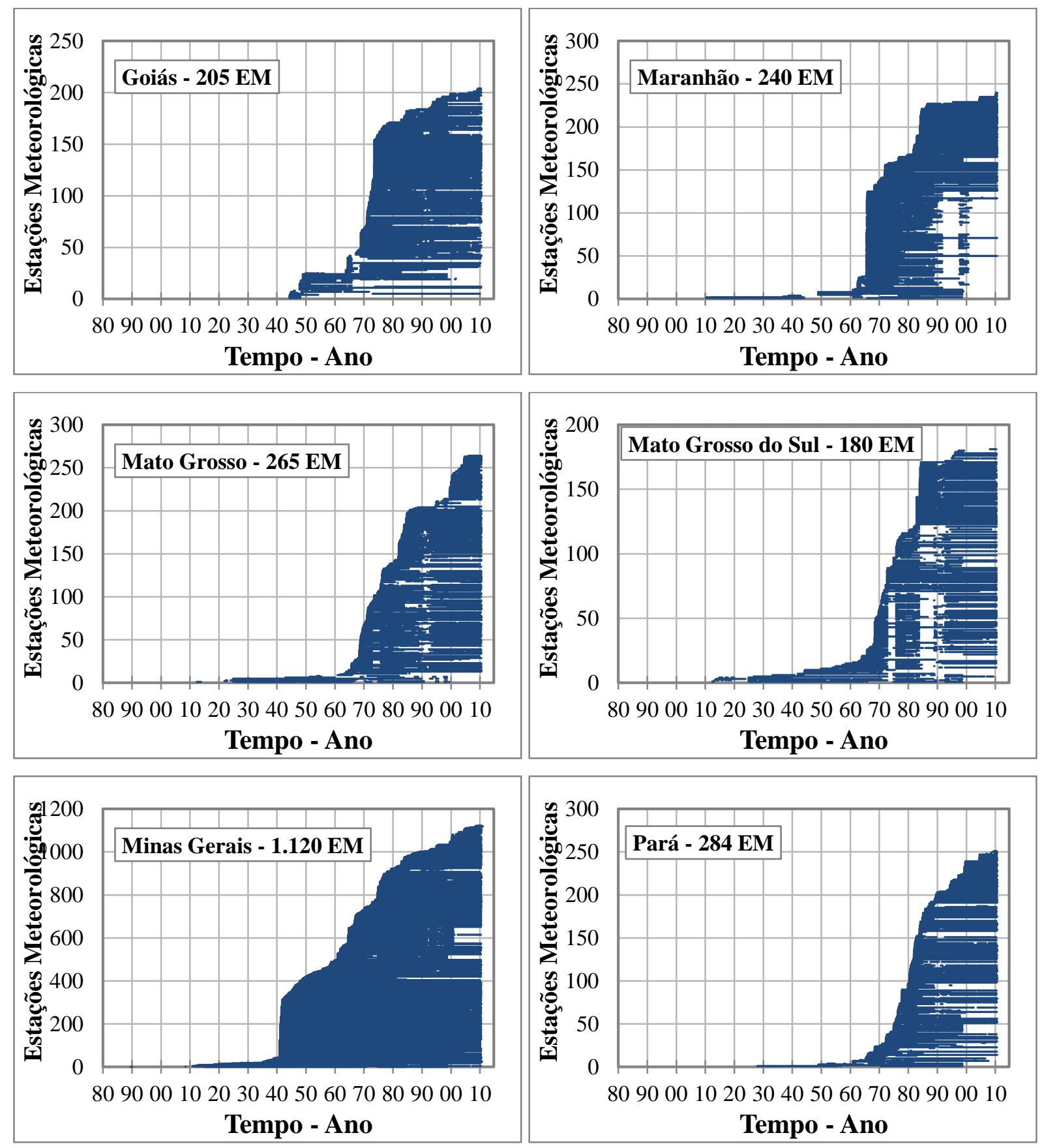

Figura 14: Linha do tempo apresentando os registros das meteorológicas nos estados brasileiros, mostrando o início e o final de operação de cada estação (organizadas sequencialmente ao longo do eixo das ordenadas), bem como as interrupções (faixas claras ao longo do eixo das abcissas). Continua.. 

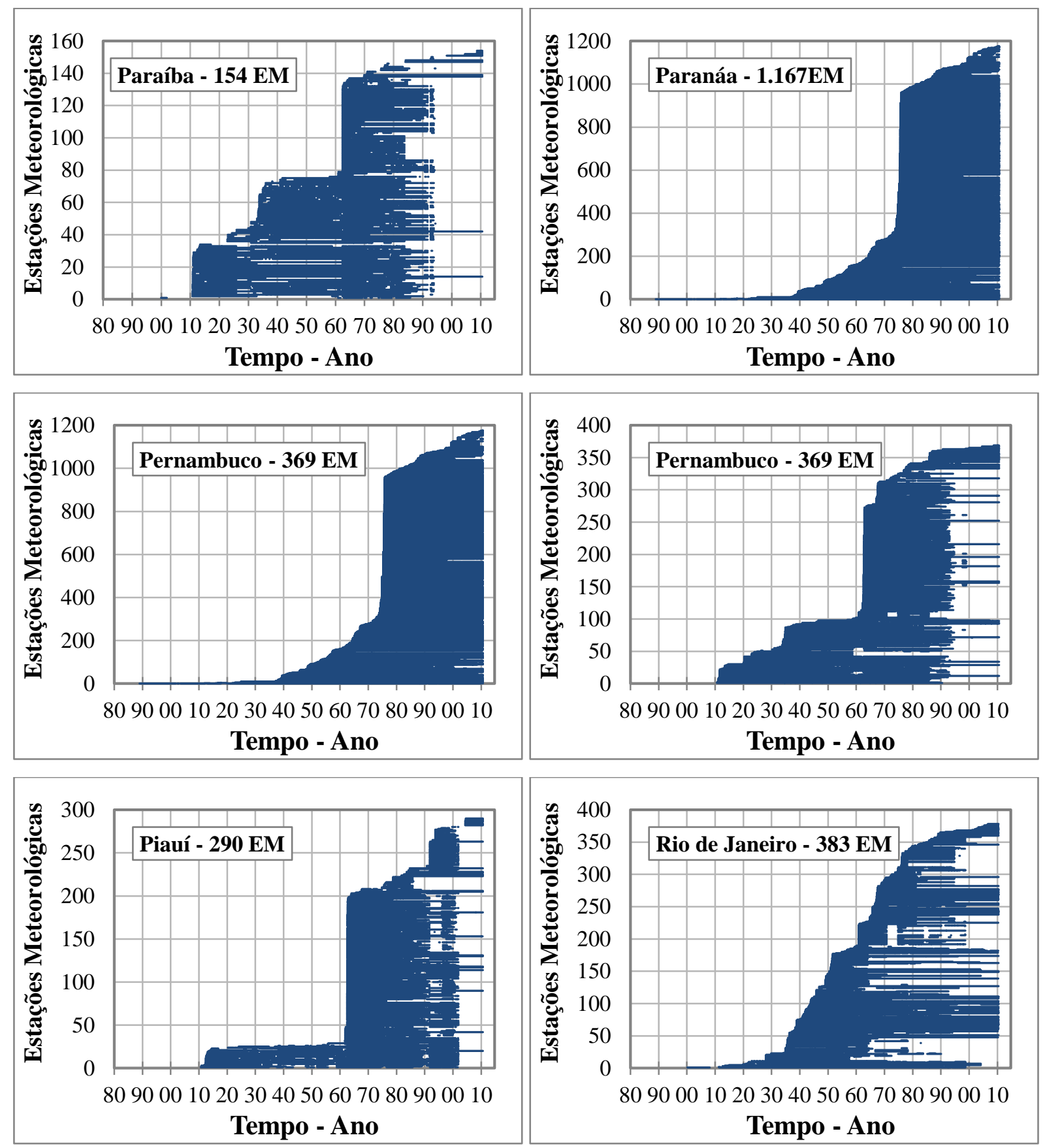

Figura 15: Linha do tempo apresentando os registros das meteorológicas nos estados brasileiros, mostrando o início e o final de operação de cada estação (organizadas sequencialmente ao longo do eixo das ordenadas), bem como as interrupções (faixas claras ao longo do eixo das abcissas). Continua.. 

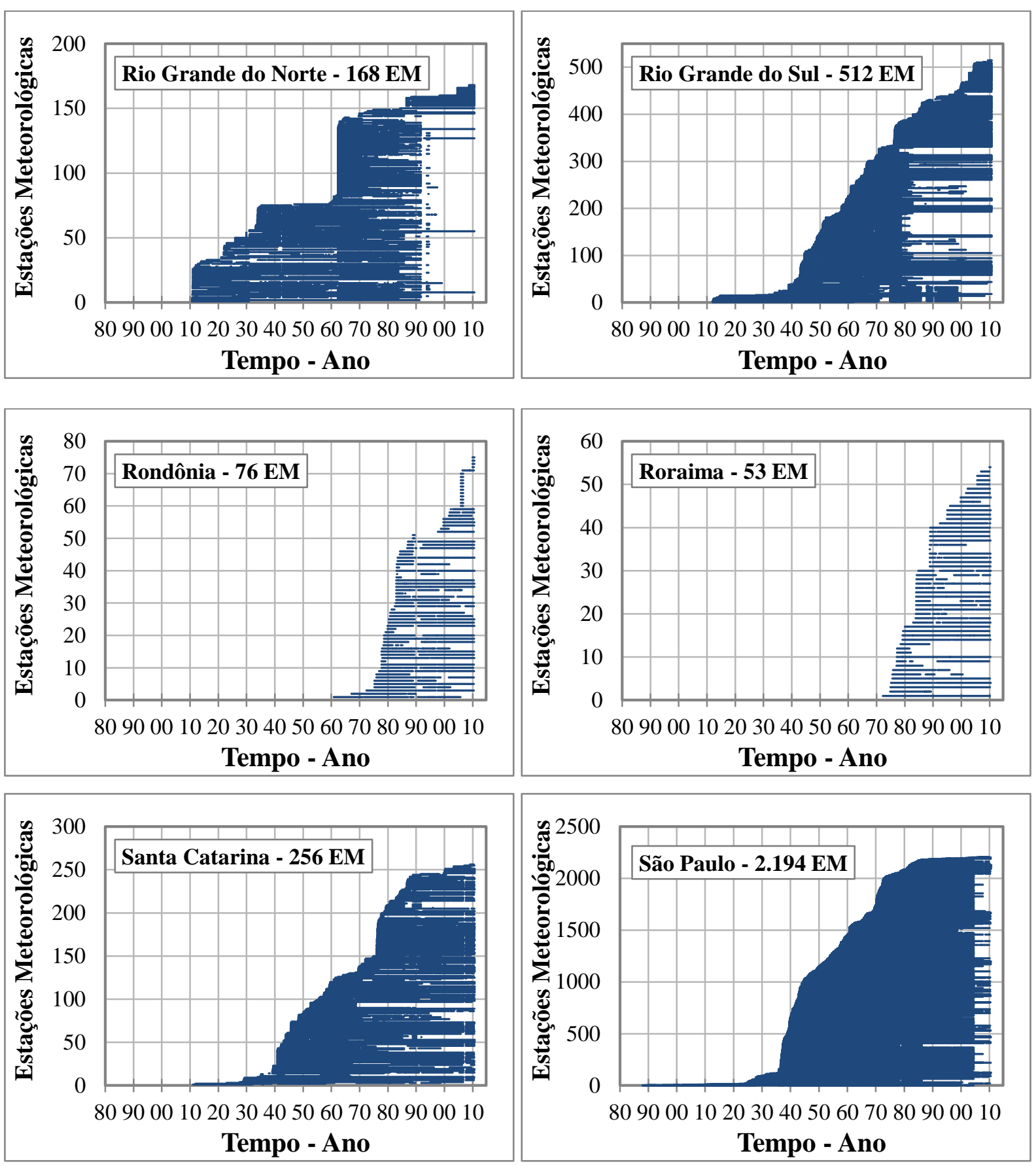

Figura 16: Linha do tempo apresentando os registros das meteorológicas nos estados brasileiros, mostrando o início e o final de operação de cada estação (organizadas sequencialmente ao longo do eixo das ordenadas), bem como as interrupções (faixas claras ao longo do eixo das abcissas). Continua.. 

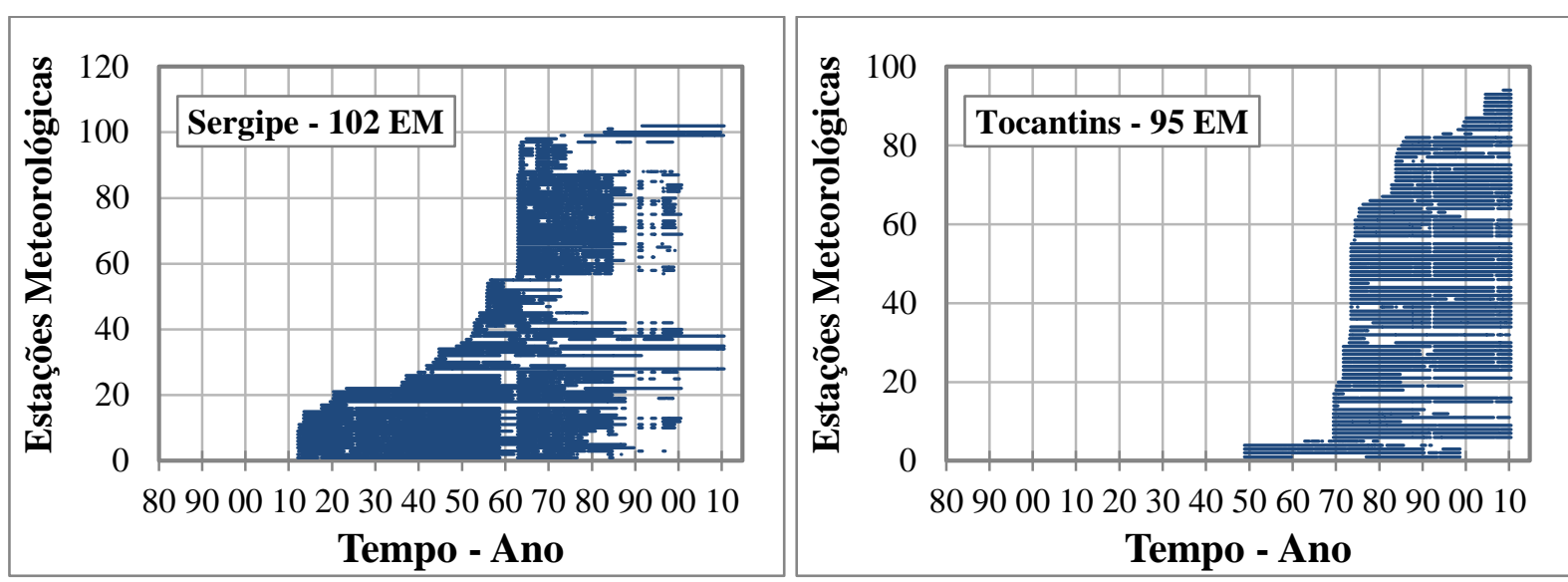

Figura 17: Linha do tempo apresentando os registros das meteorológicas nos estados brasileiros, mostrando o início e o final de operação de cada estação (organizadas sequencialmente ao longo do eixo das ordenadas).

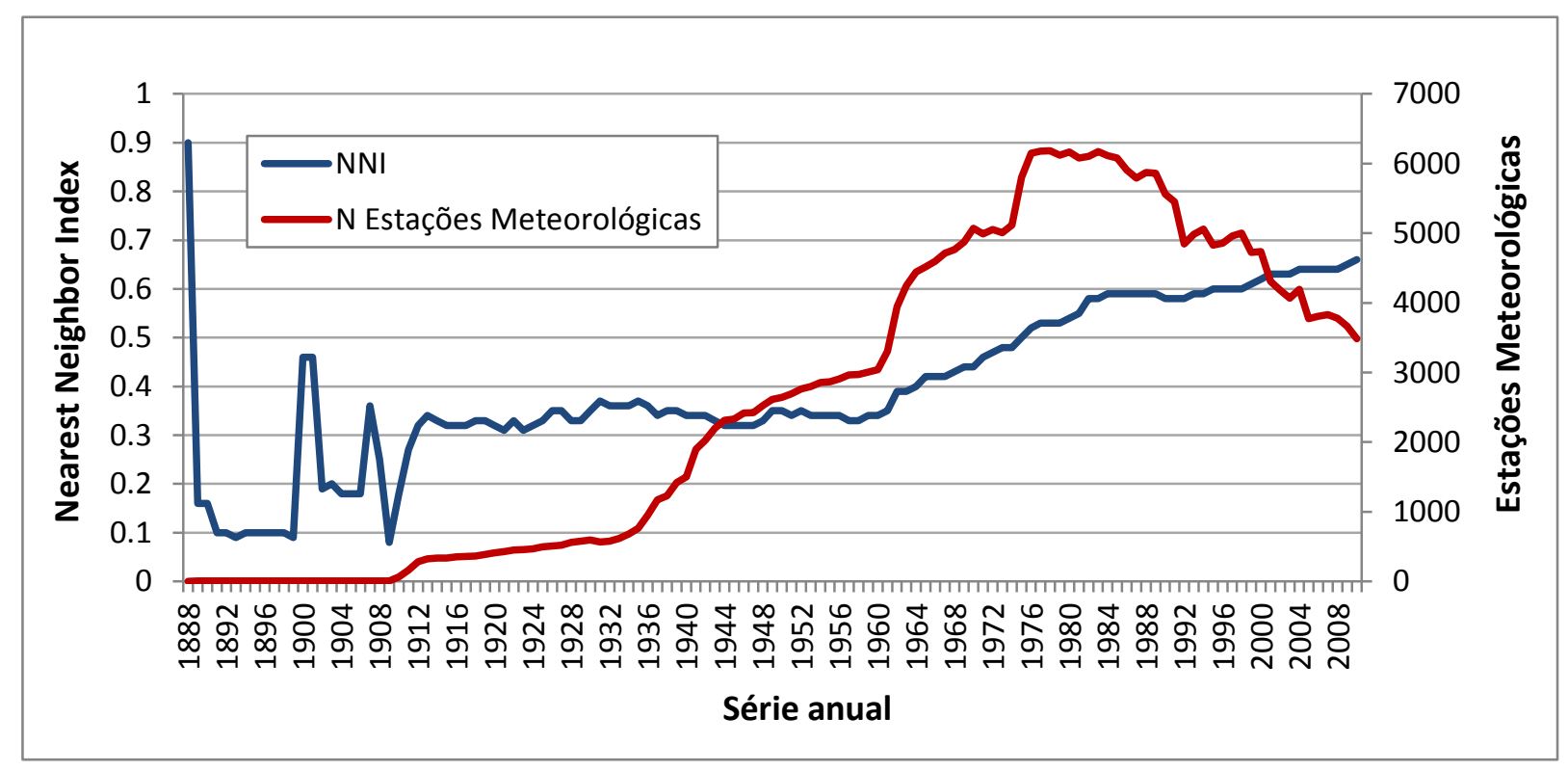

Figura 18: Quantidade de estações meteorológicas em funcionamento e valores anuais de índice do vizinho mais próximo (NNI). Valores de NNI próximos a 1,0 indicam tendência à distribuição espacial aleatória das estações; conforme os valores diminuem, indica-se a tendência à distribuição agregada; conforme os valores ultrapassam 1,0 (condição não existente nos dados presentes), indica-se uma distribuição uniforme.

Até meados da década de 1930, cerca de 550 estações meteorológicas operavam simultaneamente, sendo que períodos de aumentos significativos ocorreram em torno de 1940, 1962 e 1975, com a quantidade máxima de 5.993 estações no ano de 1980. Ao final da década de 1980, apesar de novas estações iniciarem as operações, a quantidade de estações em funcionamento simultâneo decresceu (Figura 19). Ao analisar as Unidades da Federação 
separadamente (Figura 20) observa-se que os estados amazônicos apresentam falhas mais notáveis, em alguns casos beirando um terço da série temporal total adotada (1888 a 2010). Provavelmente isso está relacionado à indisponibilidade de dados históricos em áreas mais longínquas, bem como um descompasso entre a disponibilização dos dados no site da ANA e a obtenção dos mesmos no início do ano de 2011. A partir da década de 1960 o aumento na quantidade de estações esteve fortemente associado a uma distribuição espaço-temporal menos agregada (Figura 18). Esta tendência à aleatorização espacial dos dados (ou diminuição da agregação espacial) progrediu mesmo com o declínio no número de estações em funcionamento sincrônico, que ocorreu a partir do final da década de 1980 (Figura 11). Isso tem implicações positivas no emprego dos dados mais recentes para as análises subsequentes, pois mostra uma maior disponibilidade de dados de áreas longínquas, produzindo uma distribuição espaço-temporal mais adequada para fins de análises climatológicas na escala (extensão) do território nacional.

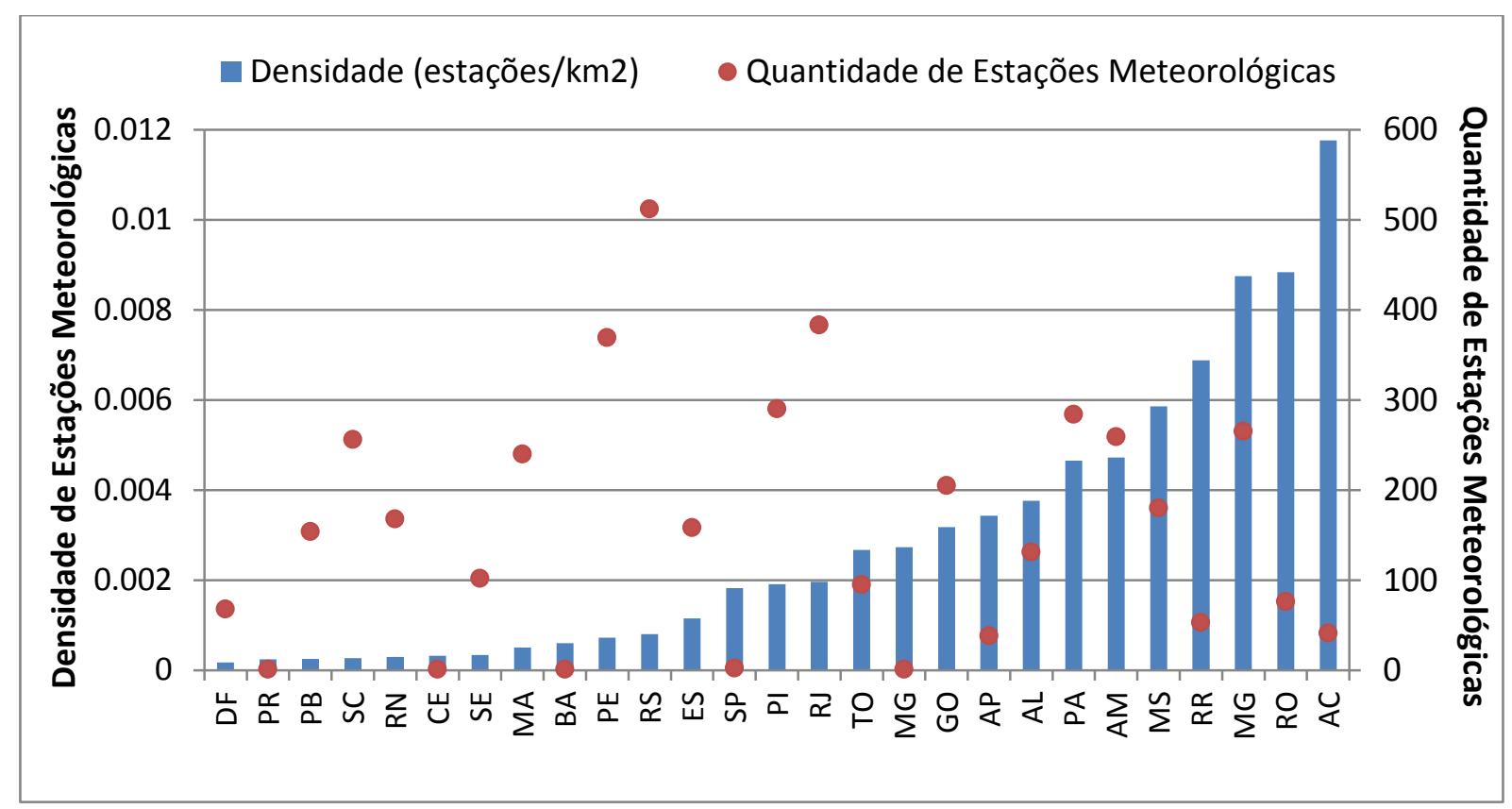

Figura 19: Disponibilidade de dados pluviométricos das estações meteorológicas administradas pela ANA (Agência Nacional de Águas), nas Unidades da Federação, referente ao período de 1888 a 2010 (consulta realizada em abril de 2011). Dados originais: Agência Nacional de Águas. Organização: Fetter (2016). 


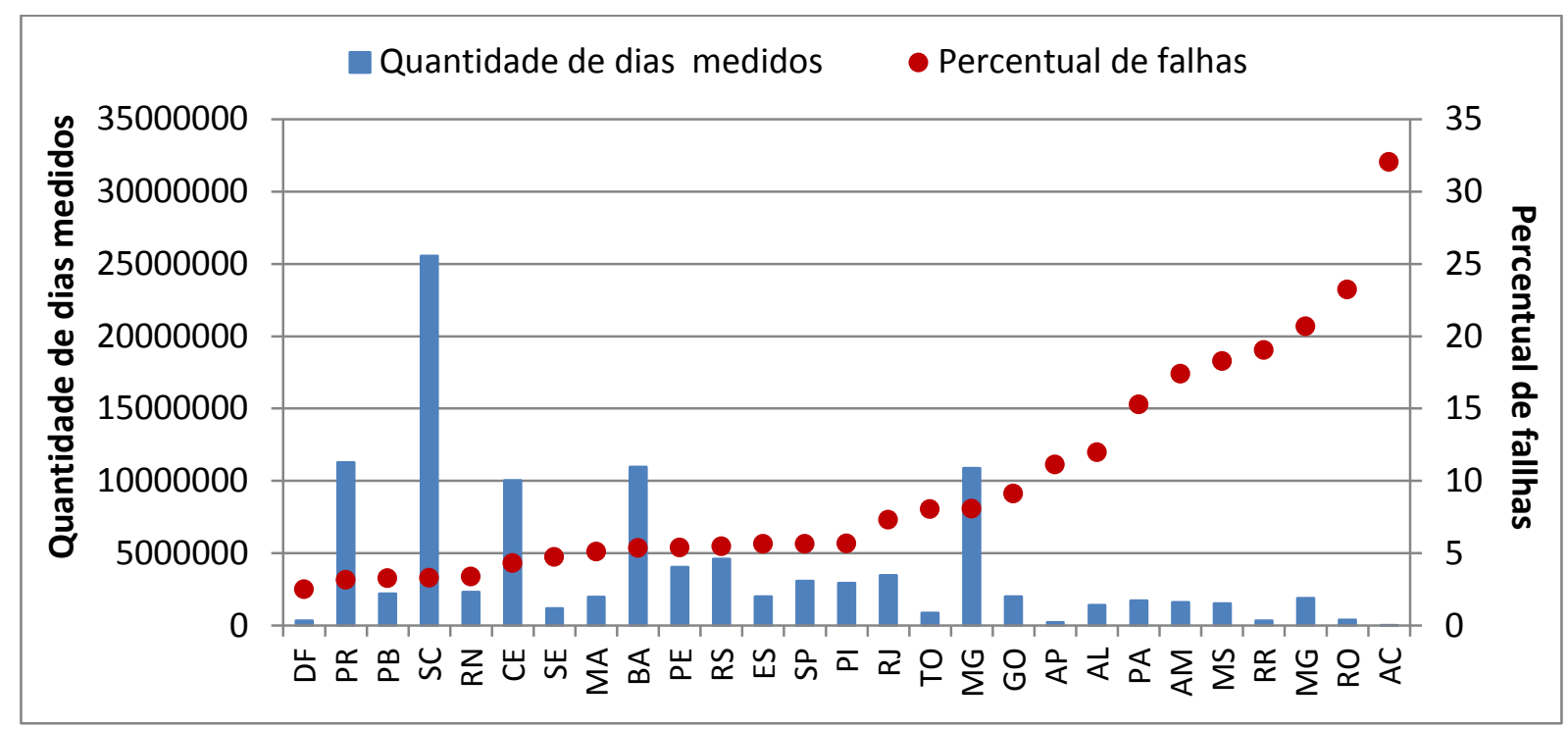

Figura 20: Disponibilidade de dados pluviométricos das estações meteorológicas administradas pela ANA (Agência Nacional de Águas), nas Unidades da Federação, referente ao período de 1888 a 2010 (consulta realizada em abril de 2011). Dados originais: Agência Nacional de Águas. Organização: Fetter (2016).

\subsection{A grade de dados interpolados}

De um total de 109.266.484 registros no banco de dados diário de precipitação, 29607 foram considerados inconsistentes, equivalendo a $0.0271 \%$ (271 ppm) do total, e não foram contemplados na interpolação subsequente. Foram os casos de valores notoriamente incorretos, como os negativos e os da ordem de milhares de milímetros para regiões semiáridas, bem como aqueles casos que, inicialmente suspeitos, diferiram mais de dez vezes da média dos registros das dez estações mais próximas. A Figura 21 discrimina, por Unidades da Federação, a quantidade de estações com precipitação superior a $350 \mathrm{~mm}$ e, a Figura 22 os casos de valores pluviométricos diários acima de $350 \mathrm{~mm}$, que foram limitados a 3604 casos, equivalendo a uma fração de $32,9 \mathrm{ppm}$ dos casos totais. Estes dados mostram que a arbitrariedade na escolha do valor limite $(350 \mathrm{~mm} / \mathrm{dia})$, não impacta qualquer análise subsequente, visto que o total acumulado nestes cortes são inexpressivos, a ponto de serem mensurados em partes por milhão ( $\mathrm{ppm})$, representando quantis igualmente inexpressivos mesmo em análises de severidade e extremos de eventos climáticos.

Ao mesmo tempo em que a análise de consistência inicial sugere uma notável qualidade dos dados disponibilizados pela ANA, descreve cenários que merecem investigação futura aprofundada. Particularmente, os estados de São Paulo e Paraná apresentaram os maiores percentuais de valores elevados (> $350 \mathrm{~mm}$ ) (Figura 22). O primeiro retêm 65,23\% 
dos casos julgados inconsistentes por ultrapassar o limite, representando uma desproporcionalidade em relação ao total de dados coletados para o estado, sobretudo em comparação com outros estados, como o de Santa Catarina, com maior número e registros, porém com apenas $1 \%$ do total de dados inconsistentes por exceder o limite. Isso sugere que deva haver maiores esforços para consistir dados de algumas agências locais ou estaduais que subsidiam a ANA por meio da cessão de dados.

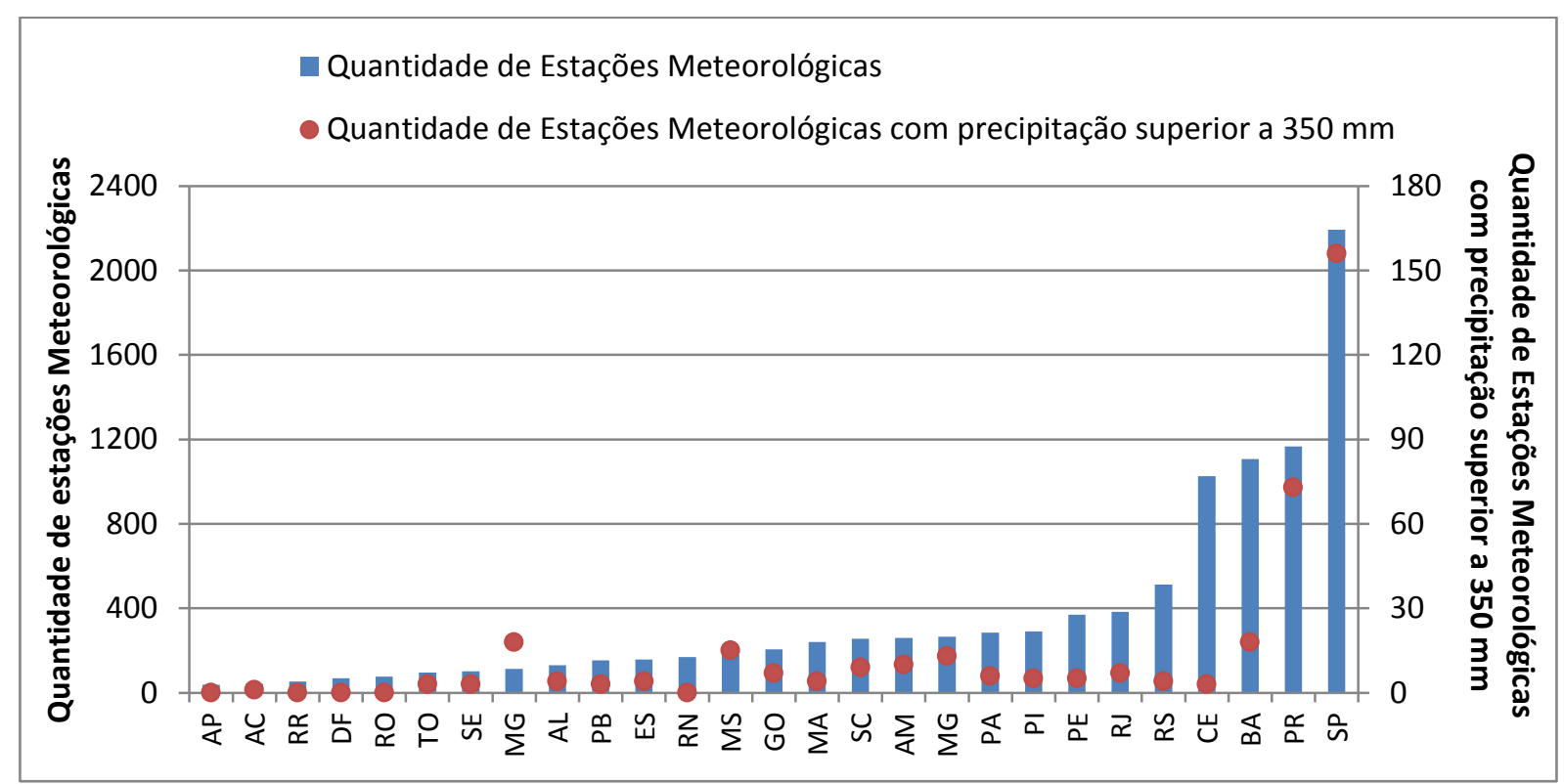

Figura 21: Quantidade de estações meteorológicas com precipitação superior a $350 \mathrm{~mm}$, por Unidades da Federação, nos dados disponibilizados pela ANA (Agência Nacional de Águas, referente ao período de 1888 a 2010 - consulta realizada em abril de 2011). Dados originais: Agência Nacional de Águas. Organização: Fetter (2016). 


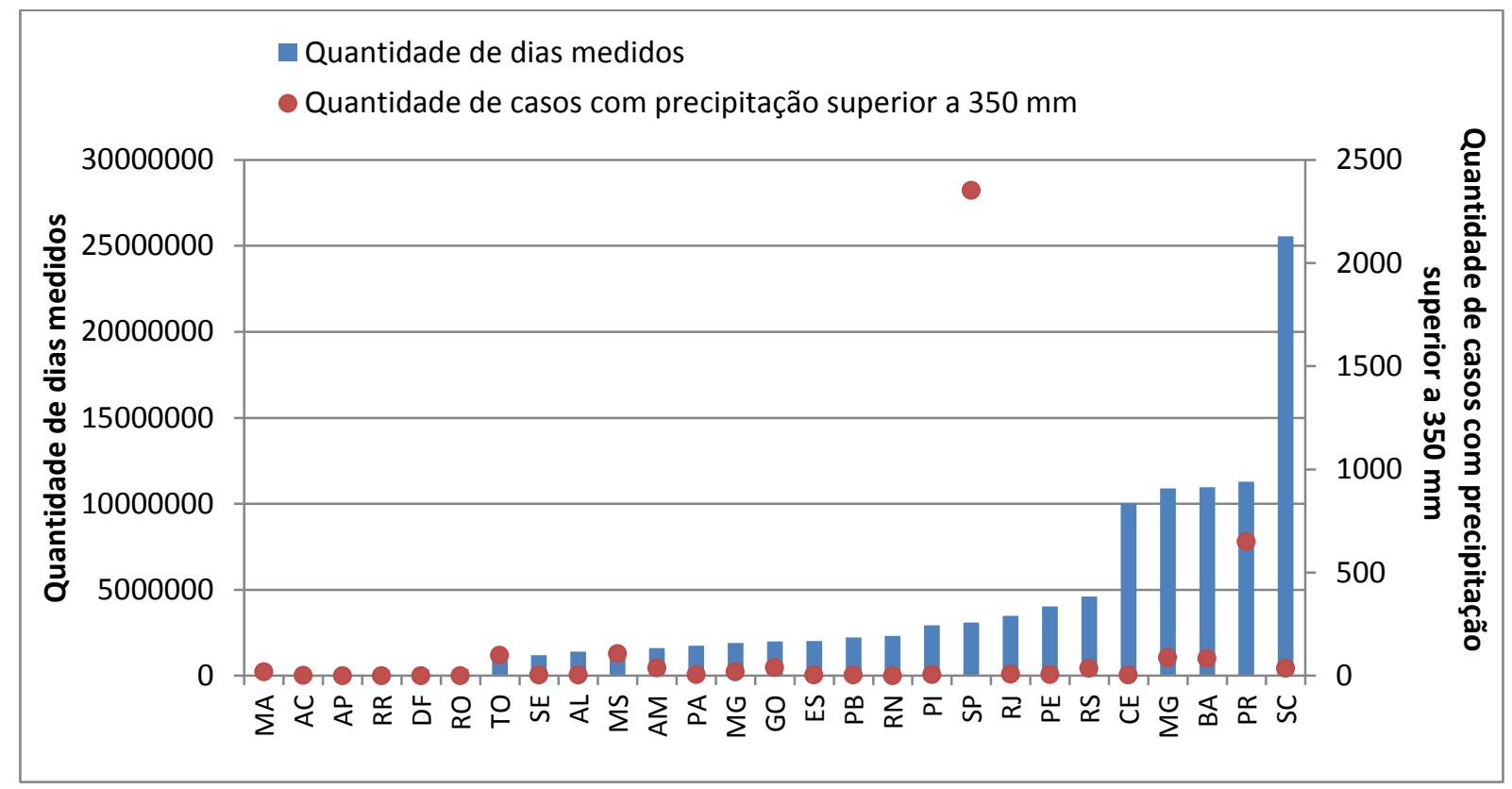

Figura 22: Casos de precipitação diária acima de $350 \mathrm{~mm}$ por Unidades da Federação nos dados disponibilizados pela ANA (Agência Nacional de Águas, referente ao período de 1888 a 2010 - consulta realizada em abril de 2011). Dados originais: Agência Nacional de Águas. Organização: Fetter (2016).

O uso da interpolação aqui empregada tem como base o fato da krigagem proporcionar resultados mais realistas que os demais métodos, sobretudo quando se trata de variáveis regionalizadas, como a precipitação (VEER et al., 2009). Basicamente, a técnica utiliza regressão linear generalizada para minimizar a variância de estimação a partir de um modelo de covariância e identificar a existência de dependência espacial.

No presente estudo, a krigagem não foi usada para o preenchimento de falhas, mas para a construção de uma grade regular de dados interpolados. Partiu-se, portanto, de dados oriundos de 10.939 estações meteorológicas, para atingir uma rede com apenas 809 pontos. Para isso, 1.194.084 interpolações foram executadas, (produto de 809 quadrantes, 123 anos e 12 meses). A Figura 18 apresenta a evolução, por década, do sucesso na interpolação espacial. Os insucessos de interpolação se deram em função de dois fatores:

a) inexistência de volume mínimo de dados devido à falta de estações com dados no entorno do centroide do quadrante, inclusive pela alta agregação das estações com dados disponíveis, promovendo abundância de dados em determinados locais em detrimento de outros, Este fator foi responsável por $27.88 \%$ (332.615) de insucessos e; 
b) efeito pepita, caracterizado pela ruptura na dependência espacial, seja por micro oscilações nos dados ou por falhas de medida, situação na qual não houve aumento da variância com o aumento da distância; Este fator foi responsável por 5,33\% (45.916) de insucessos.

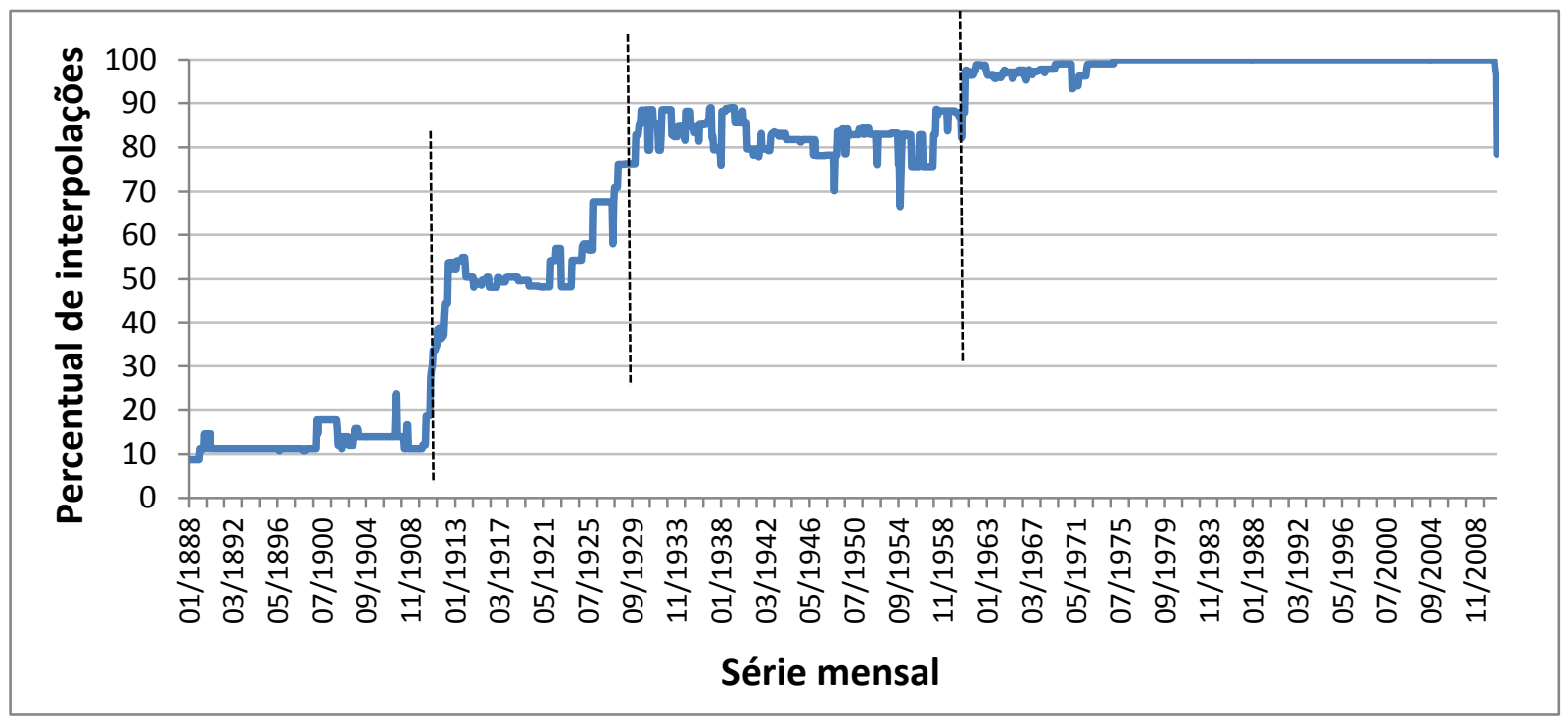

Figura 23: Percentual de dados válidos após a interpolação espacial da série pluviométrica de 1888 a 2010 e disponíveis para uso. $\mathrm{O}$ eixo $\mathrm{x}$ apresenta a série temporal, na unidade de resolução mensal $(1.476$ casos $=123$ anos x 12 meses), cada uma contendo 809 interpolações $(1.194 .084=809$ x 123 x 12), das quais $27.88 \%$ (332.615) permaneceram nulas e 5,33\% (45.916) foram eliminados devido à ocorrência de efeito pepita.

Um padrão geral mostra que o insucesso decorrente da inexistência de volume mínimo de dados ocorreu principalmente no início da série, até 1925. A partir deste ano, continuou-se a notar problemas de disponibilidade de dados, mas iniciou-se um período marcante (de 1926 a 1977) em que o efeito pepita mostrou-se mais evidente que no início da série, representando entre 1 e 2 casos por ano. Este padrão temporal de sucessos/insucessos também tem uma representação espacial no território brasileiro. Na Figura 24 é possível distinguir pelo menos quatro fases que caracterizam o sucesso da interpolação diante da disponibilidade de dados. Entre 1888 a 1910 (23 anos) a quantidade de quadrantes interpolados foi inferior a $30 \%$ dos casos e compreendeu principalmente os estados da região Nordeste, Sudeste e parte da região Sul e, respectivamente os biomas Caatinga, Mata Atlântica, com pequenas porções dos biomas Cerrado e Amazônia. De 1911 a 1928 (18 anos) houve um aumento dos casos interpolados, porém cerca da metade dos quadrantes foram interpolados menos de $70 \%$. Neste 
período iniciou a operação de estações na Amazônia e alguns quadrantes no estado do Amazonas e Pará foram interpolados, mas em menos de 28\%. O bioma Pampa foi interpolado em praticamente todo o período. Nos 32 nos seguintes (1929 a 1960), ocorreu um significativo aumento das interpolações na região amazônica, porém, de forma menos significativa nas regiões fronteiriças do país, nos estados do Acre, Manaus, Roraima e Amapá e na divisa do estado do Pará com Mato Grosso. Somente a partir de 1961 todos os quadrantes foram mais de $90 \%$ interpolados e, a partir de 1975 o sucesso de interpolação foi de 100\% para todos os quadrantes.

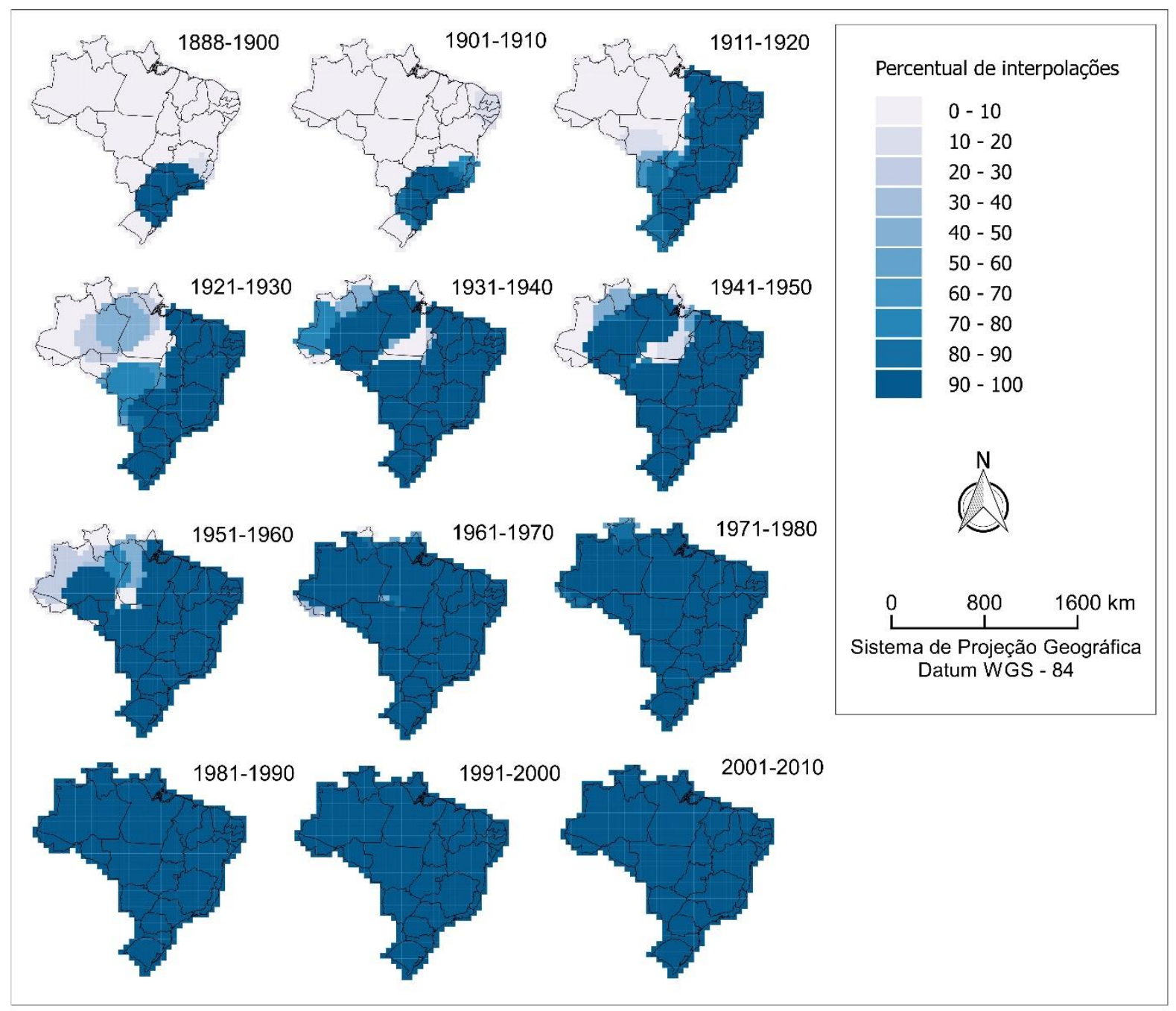

Figura 24: Sucesso da interpolação, apresentado em intervalos de décadas, na forma de percentual de quadrantes com casos não nulos entre 1888 e 1950 m após a interpolação. 
O completo sucesso das interpolações a partir de 1975 não se deve exatamente à disponibilidade de dados. A inexistência de efeito pepita parece mais associado a uma melhoria nos dados (eliminação falhas de medida, coleta e digitação), mas sobretudo a uma distribuição menos agregada das estações em operação simultânea, ou seja, um aumento dos valores do Índice do Vizinho mais Próximo (NNI), como mostrado na Figura 18. O efeito da distribuição espacial mais uniforme foi tão importante, que nem a redução no número de estações em operação a partir de 1980 afetou em insucessos na interpolação.

Tal constatação evidencia a melhoria nos dados históricos mais recentes disponibilizados pela ANA, sobretudo por ampliar o leque de possibilidades em termos de analises climáticas nos últimos 40 anos. Porém, também são patentes as implicações da qualidade dos dados sobre as múltiplas aplicações possíveis, sobretudo aquelas de caráter regional. Assim, um estudo que tenha foco no sul ou no sudeste brasileiro, terá uma série temporal de elevada qualidade a partir da década de 1930. Porém, aquele estudo que voltar-se à Amazônia terá uma série bem mais curta, notoriamente, a partir de 1975. Desta forma, o presente estudo, que visa uma escala nacional para o estudo da precipitação pluviométrica, tem sua série temporal limitada a período posterior a 1975 (este incluso), podendo, entretanto buscar séries maiores para atender a nuances ou incursões de caráter mais regional, se necessário, possível ou aplicável.

Como uma etapa final da consistência de dados, foi realizada uma rápida e visual validação dos dados aqui produzidos, dispostos na forma de médias de precipitação obtidas para o Brasil (Figura 25), os desvios padrões (Figura 26) e coeficientes de variação (Figura 27). Embora o propósito aqui não seja a descrição exaustiva dos dados produzidos, tampouco a comparação profunda com outras fontes clássicas, vale ressaltar a grande similaridade entre os dados e os divulgados pela ANA (2005), BRASIL (1993), OBREGÓN e MARENGO (2007), INMET (2014), CPRM (2014), SHI et al. (2000), NIMER (1979), MARENGO e HASTERNRATH (1993) e RAO e HADA (1990), alguns destes apresentados na Figura 28. Assim, o propósito central é o da apresentação dos dados devidamente estruturados numa malha homogênea, a qual representa a base para as análises subsequentes.

A malha de dados de direção e velocidade dos ventos entre 2012 e 2015 é mostrada nas Figura 29 e 25. Os mapas mostram grande congruência àqueles apresentados no Atlas do Potencial Eólico Brasileiro (AMARANTE, ZACK e SÁ, 2001).

O Regime pluviométrico no Brasil apresenta grande variabilidade espacial e temporal, tanto para a escala anual como para a mensal, como pode ser observado nas (Figura 25). Os 
volumes mais elevados ocorrem na região norte, notadamente sobre o litoral dos estados do Amapá e Pará e ao noroeste de Manaus, onde é frequente ultrapassar a faixa de $3.000 \mathrm{~mm}$, e de onde o volume decresce para o interior da região, a qual também se encontra entre os núcleos mais chuvosos. Os volumes decrescem ao estado de Roraima, às maiores latitudes e ao nordeste brasileiro, cuja porção semiárida, principalmente na divisa entre os estados da Bahia, Pernambuco e Piauí, o volume anual poder ser inferior a $800 \mathrm{~mm}$.

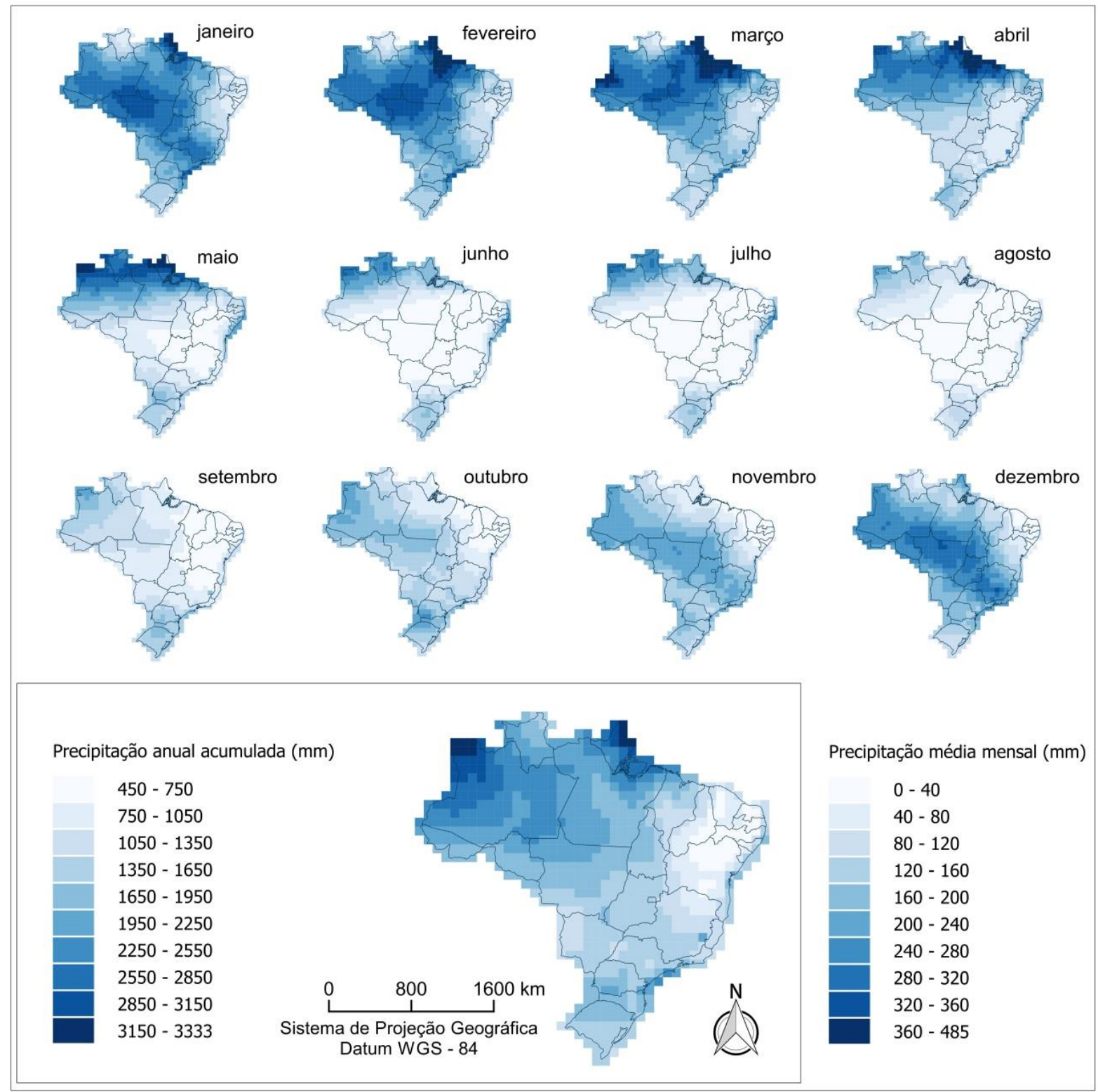

Figura 25: Pluviosidade média mensal e anual no Brasil, na série de 1975 a 2010. 
De modo geral, os maiores desvios padrões (DP) ocorrem nos locais mais chuvosos, porém, sua relação com o volume pluviométrico não é tão linear, visto haver uma relação com a constância dos mecanismos que causam a precipitação ao longo do ano (Figura 26). Isso é identificado pela comparação entre o noroeste do Amazonas e as regiões nordeste e sul do país, cujos baixos DP estão associados ora a volumes elevados, ora a volumes baixos, ora a volumes intermediários. Os baixos DP na região nordeste são uma forte correspondência ao baixo volume; o decréscimo dos DP do litoral norte ao noroeste do Amazonas provavelmente estão relacionados a baixa variabilidade de radiação de ondas longas sobre a região, que BERNARDO e MOLION (2004) sugerem ser responsável por manter constante a cobertura de nuvens e movimentos convectivos ao longo do ano e que acarreta em pequenas variações sazonais. Na região sul os baixos DP também estão relacionados ao caráter da constância do fator gerador de chuva, pois sua localização garante frequentes invasões da frente polar atlântica ao longo do ano, definindo grande homogeneidade anual da precipitação, dificultando a definição de período seco e chuvoso, quanto mais alta fora altitude.

Os altos DP sobre o litoral do Amapá e norte do Pará, estão relacionados a grande heterogeneidade da precipitação anual, causadas pelas oscilações no posicionamento da Zona de Convergência Intertropical (ZCIT), principal responsável pelos elevados volumes anuais. O mesmo ocorre com os altos DP na faixa noroeste-sudeste sobre o país, pela sazonalidade na atuação da ZCAS.

A partir da compreensão dos mecanismos que definem a dinâmica da variabilidade, é possível utilizar os coeficientes de variação para descrever a variabilidade relativa da precipitação de forma comparativa entre diferentes locais, sem comprometimento da sua interpretação (Figura 27). Ou seja, os locais com menores volumes acumulados no ano possuem maiores coeficientes de variação $(\mathrm{CV})$, pois apesar dos baixos DP, esses são proporcionalmente altos em relação à média de precipitação. Assim, os CV vão sucessivamente diminuindo em direção aos locais mais chuvosos e, a partir de um determinado ponto os baixos DP da precipitação ganham mais significado para determinar os locais de menores $\mathrm{CV}$. 


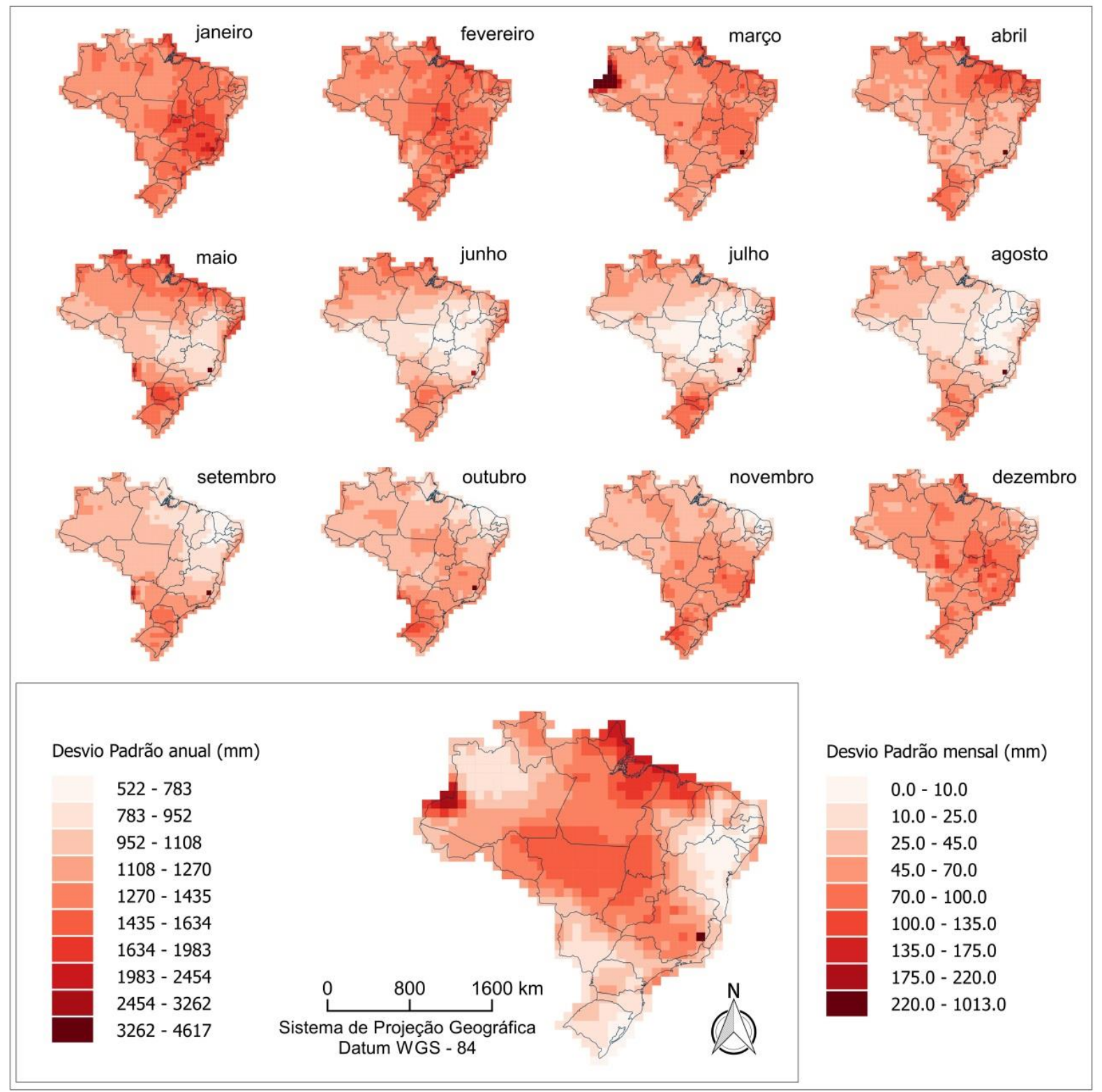

Figura 26: Desvio padrão da pluviosidade mensal e anual no Brasil, na série de 1975 a 2010. 


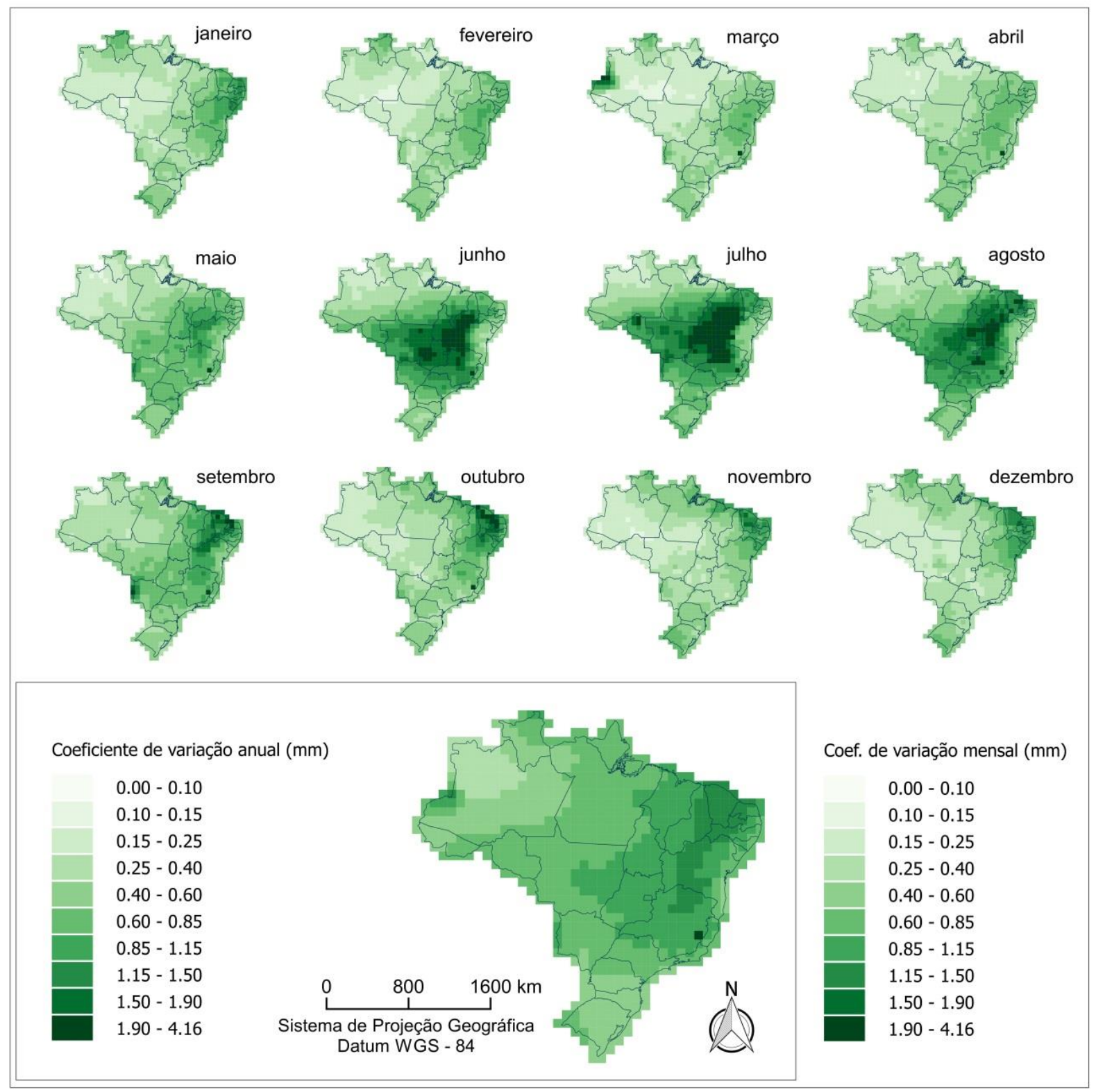

Figura 27: Coeficiente de variação da pluviosidade mensal e anual no Brasil, na série de 1975 a 2010. 


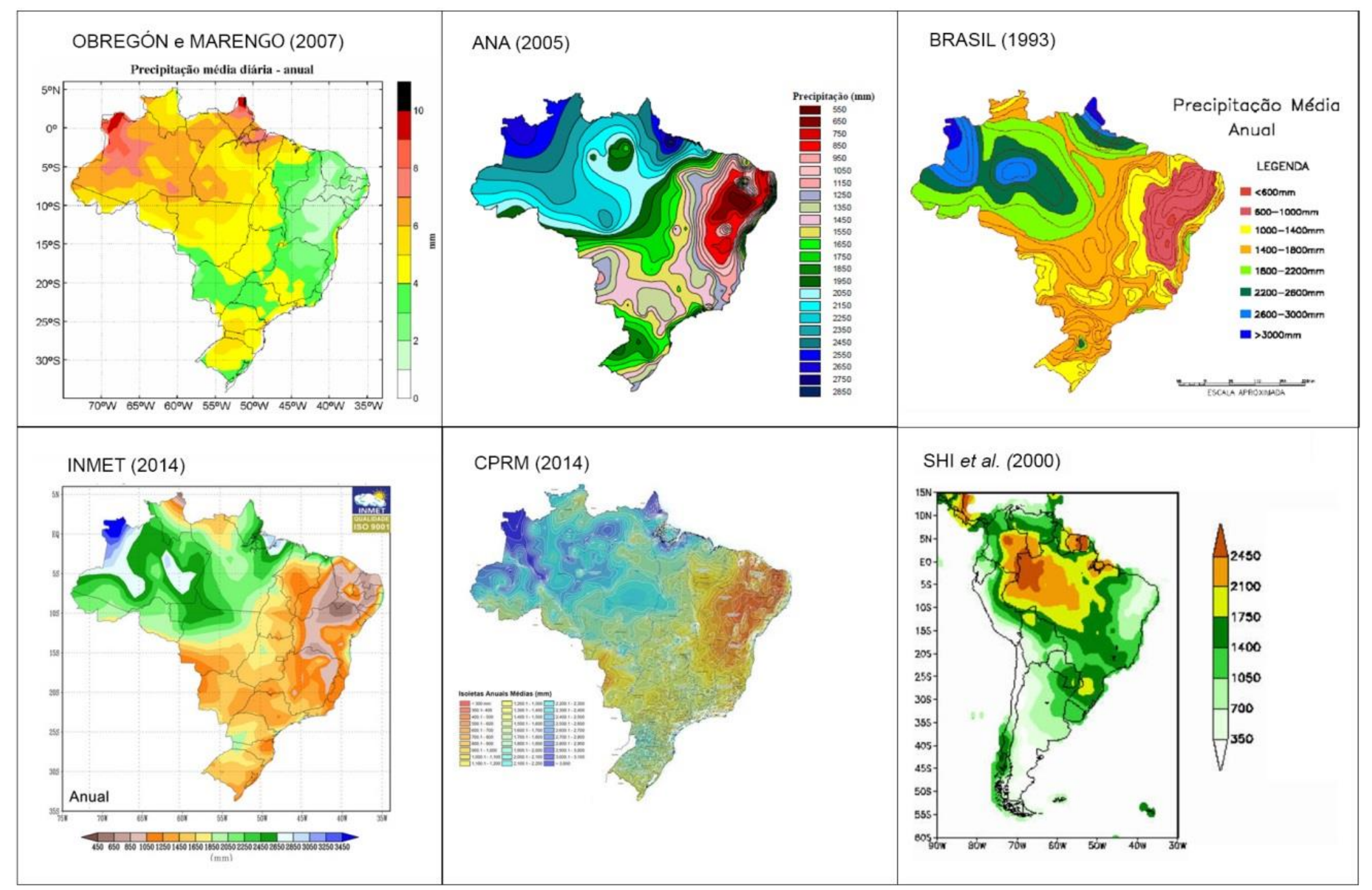

Figura 28 Precipitação pluviométrica anual no Brasil, segundo distintas fontes. Alguns dados são apresentados em médias diárias (mm/dia), outros em totais acumulados (mm/ano). 


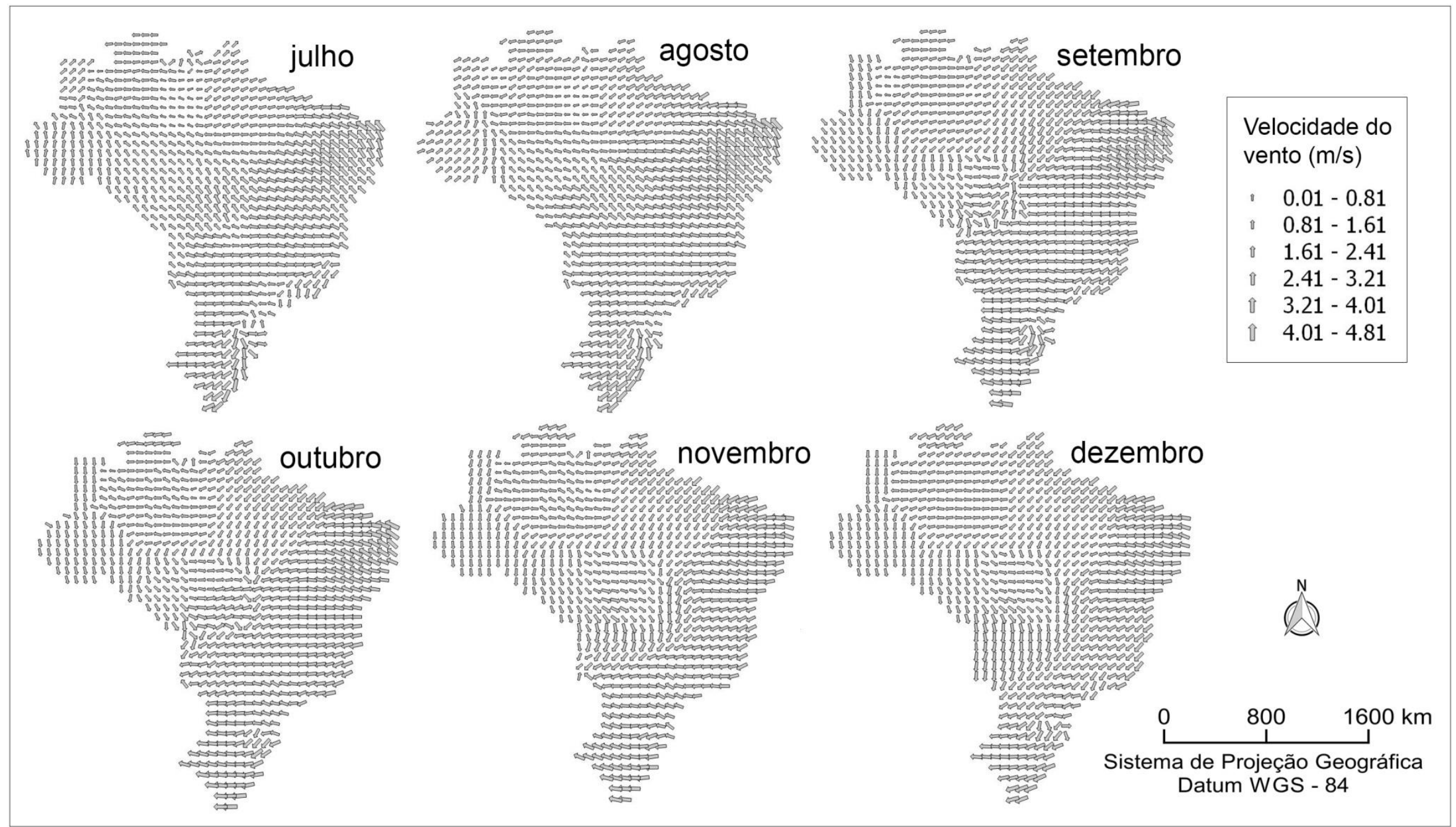

Figura 29: Direção e velocidade média do vento nos meses de janeiro a junho para os 809 quadrantes sobre o Brasil (continua). 


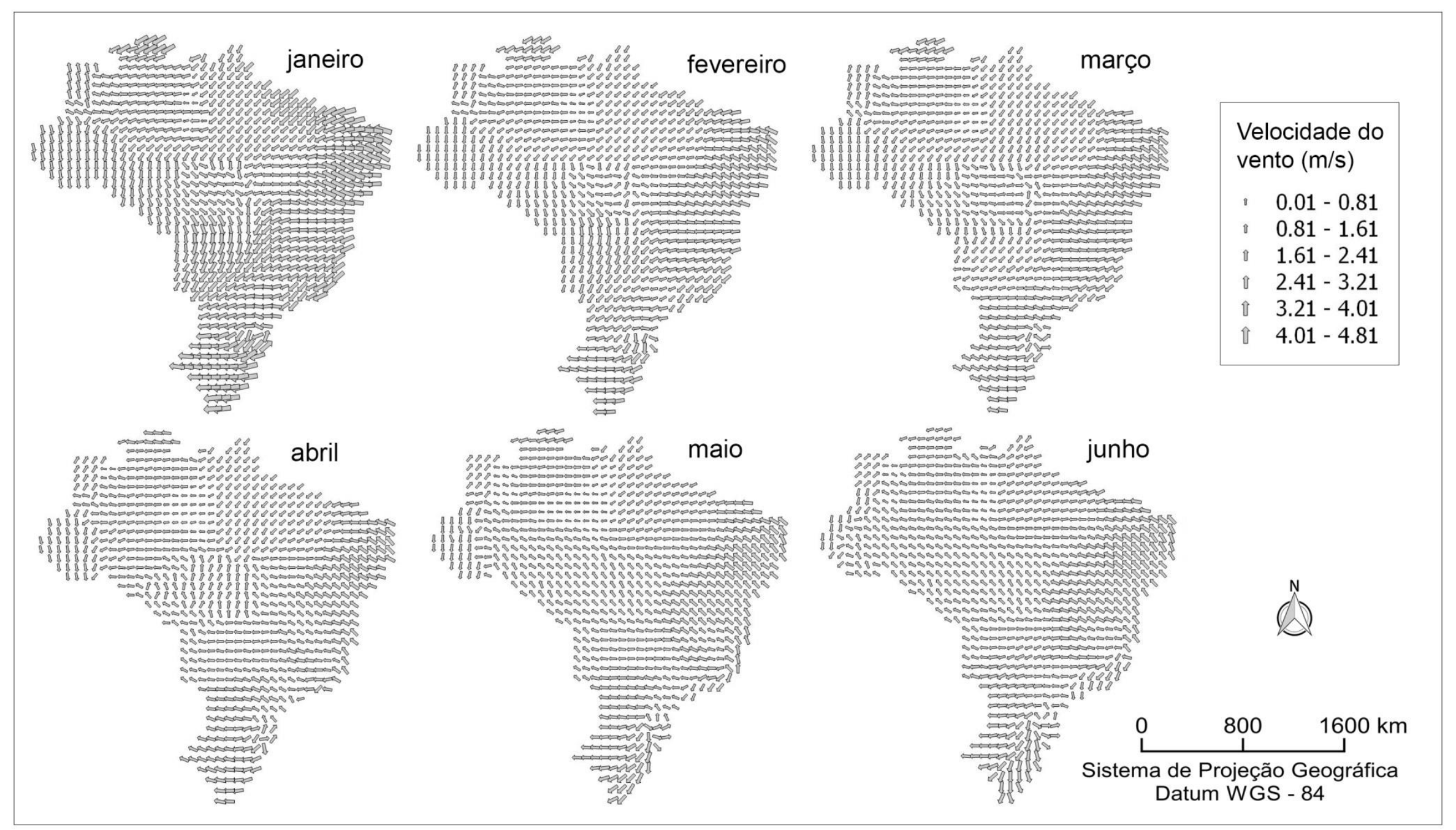

Figura 30: Direção e velocidade do vento para os meses de julho a dezembro para os 809 quadrantes sobre o Brasil. 


\subsection{O Índice de Proporção de Escalas - IPE}

O IPE é um índice proposto para representar de forma sintética a variabilidade espaçotemporal da precipitação. Sua concepção, explicada tão somente pelas relações algébricas fundamentais da Equação 12, torna implícita a existência de correlações positivas com a variabilidade temporal (altos valores de IPE) e negativas com a variabilidade espacial (baixos valores de IPE). Também fica implícita uma possível correlação entre pluviosidade (PLSD) e o IPE, visto que é comum a existência de maior variabilidade temporal (desvios padrões) em situações (locais ou épocas) de maior precipitação. Porém um possível efeito do volume pluviométrico sobre a variabilidade espacial não é óbvio, sendo necessário analisar os padrões paralelamente aos valores de originais de pluviosidade, bem como da Média dos Módulos dos Desvios no tempo e no espaço (tratados a partir de agora como "desvios no tempo" - Dt e “desvios no espaço" - De).

A Tabela 3 mostra a correlação entre estas variáveis, confirmando a aderência estatística entre IPE e Dt $(r=0,50344)$ e entre IPE e De $(r=-0,46719)$, o que é esperado já que o índice é composto por estes desvios. Porém, a maior correlação entre IPE e Dt indica que, de modo geral, a variabilidade na distribuição das chuvas no Brasil é maior em função do tempo, inclusive ocorrendo casos em que, apesar das chuvas apresentarem grandes desvios no espaço, os Dt promovem maior dispersão nas chuvas e, portanto maiores IPEs. Um significado climatológico mais importante está na correlação entre IPE e PLSD ( $r=0,069932)$ que, mesmo sendo baixíssima, possui significância estatística confirmada em decorrência do elevado grau de liberdade nos dados não agregados ( $\mathrm{n}=9708=12$ meses x 809 quadrantes), indicando que os altos IPEs tendem a ocorrer em condições de maior volume pluviométrico. Porém, a melhor compreensão da significância estatística entre IPE e PLSD, se dá pelas altas e significativas correlações positivas entre PLSD e Dt $(r=0.53365)$ e PLSD e De $(r=$ 0.45129), que merecem atenção, pois confirmam o esperado efeito do volume pluviométrico sobre a variabilidade no tempo, mas também confirmam o insuspeito efeito do volume pluviométrico sobre a variabilidade no espaço. Sendo estas duas correlações positivas e significativas, tem-se consequentemente correlação positiva entre Dt e De ( $r=0,40929)$, indicando que, até certo ponto, as condições de maiores desvios no tempo correspondem às condições de maiores desvios no espaço e vice-e-versa. A fraca correlação entre IPE e PLSD não representa limitações para a utilização do índice, ao contrário. O IPE representa 
justamente os resíduos da regressão linear (validada estatisticamente) entre a variabilidade espacial e temporal das chuvas, muito mais que pelo volume em si. Em outras palavras, o IPE é um indicador de falta de aderência e correlação do modelo de regressão, onde existem outliers, os quais são mais importantes que as fortes e significativas correlações.

Tabela 3: Coeficientes de Pearson (r) para correlação linear entre valores de PLSD, desvios no tempo (Dt), desvios no espaço (De) e Índice de proporção entre escalas (IPE) $(n=12$ meses $\times 809$ quadrantes $=9708)$.

\begin{tabular}{c|cccc}
\hline & PLSD & Dt & Ds & IPE \\
\hline PLSD & 1.00 & & & \\
Dt & $0.53365^{(*)}$ & 1.00 & & \\
Ds & $0.45129^{(*)}$ & $0.40929^{(*)}$ & 1.00 & \\
IPE & $0.069932^{(*)}$ & $0.50344^{(*)}$ & $-0.46719^{(*)}$ & 1.00 \\
\hline
\end{tabular}

$(*) \mathrm{p}<0.05$

Quando realizada a mesma análise para os dados agregados espacialmente no Brasil, discriminados apenas pelos 12 meses do ano $(\mathrm{n}=12)$ (Tabela 4), as conclusões são análogas. As correlações continuam fortes e significativas, existem fortes associações entre volume pluviométrico e variabilidade espacial e temporal, sendo o IPE o fator com menor correlação com volumes pluviométricos. Também se mantém as fortes correlações entre variabilidade no espaço e no tempo. A única diferença está na fraca e não significativa correlação entre IPE e De $(r=0,0096692)$, nesse caso explicada pela generalização espacial (809 quadrantes foram agregados em um único). Novamente, os dados sugerem que o IPE é um indicador de condições (locacionais ou temporais) de falta de aderência (resíduos) de um modelo linear de dependência espaço-temporal, porém sem expressivo (e significativo) efeito do volume pluviométrico $(\mathrm{r}=0.13919)$.

A Figura 31 apresenta os dados de Dt, De e IPE discriminados por meses, permitindo visualizar que a fraca correlação entre PLSD e IPE, destacada anteriormente, se dá pelo fato dos altos valores de IPE serem mais frequentes nos meses de transição entre o período mais úmido (verão austral) e o período mais seco (inverno austral) e, os menores valores de IPE serem mais frequentes, exatamente, nesses períodos. 
Tabela 4: Coeficientes de Pearson para correlação linear entre valores médios mensais ( $\mathrm{n}=12$ ) de PLSD, desvios no tempo (Dt), desvios no espaço (De) e Índice de proporção entre escalas (IPE).

\begin{tabular}{c|cccc}
\hline & PLSD & Dt & De & IPE \\
\hline PLSD & 1.00 & & & \\
Dt & $0.82416^{(*)}$ & 1.00 & & \\
De & $0.87938^{(*)}$ & $0.7833^{(*)}$ & 1.00 & \\
IPE & 0.13919 & $0.59494^{(*)}$ & 0.0096692 & 1.00 \\
\hline
\end{tabular}

$(*) \mathrm{p}<0.05$

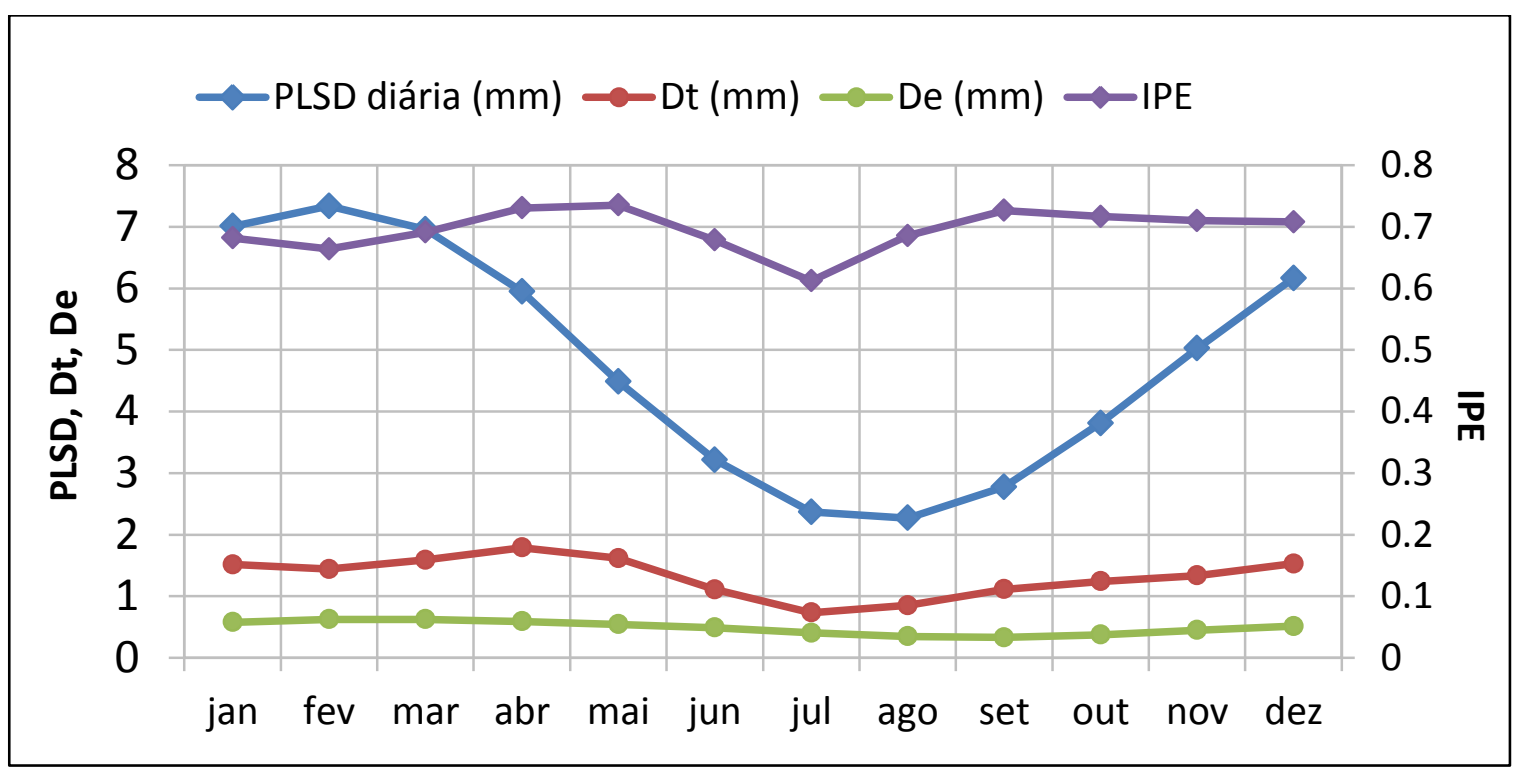

Figura 31: Pluviosidade média diária, desvios no tempo (Dt), desvios no espaço (De) e IPE para a série pluviométrica de 1975 a 2010, no Brasil, na escala 3M x 3Q.

Os dados genericamente analisados para todo o espaço geográfico brasileiro não são totalmente adequados para a efetiva compreensão do IPE e suas peculiaridades, mas contribuem para identificar as especificidades no espaço e no ciclo sazonal. Além disso, sua leitura paralela à distribuição pluviométrica auxilia na interpretação da sua forte correlação com a variabilidade no tempo (Dt, $r=0,82416$, Tabela 4). Por exemplo, nos meses de junho a agosto, os mais secos do ano para a maior parte do Brasil, os valores de Dt são altos apenas no extremo norte do país (Figura 31). Na primavera os Dt aumentam e adquirem uma configuração zonal sobre o centro do país, que se fortalece e se estabelece a sudeste e, a partir 
de dezembro, adquire um sentido meridional até o litoral norte e Roraima. Em março retorna o padrão zonal que migra progressivamente para oeste numa configuração mais meridional até o litoral norte, recolhendo-se novamente para o extremo norte do país a partir de junho.

De modo geral, os Dt estão relacionados ao volume pluviométrico, similarmente a estatística de desvio padrão, onde locais mais úmidos frequentemente estão associados a desvios padrões elevados. Uma das razões pode estar relacionada à afirmação de GONG et al. (2003) sobre o caráter esparso que caracteriza a pluviosidade de origem convectiva nas regiões tropicais, o qual pode apresentar-se extremamente variável, mesmo para intervalos trimestrais. É uma consequência do perfil da precipitação no período de transição entre as estações seca e chuvosa, especialmente nos locais onde o marcante efeito da sazonalidade reduz (aumenta), de forma abrupta o volume pluviométrico, num curto intervalo de tempo.

Apesar do elevado volume pluviométrico da região norte, alguns locais apresentam baixos $D t$, como a porção oeste da Amazônia, que BERNARDO e MOLION (2004) sugerem apresentar uma baixa variabilidade sazonal da precipitação, em função da baixa variabilidade de radiação de ondas longas, responsável pela manutenção da cobertura de nuvens e movimentos convectivos constantes ao longo do ano.

Os baixos Dt na região sul do Brasil, provavelmente estão relacionados à baixa variabilidade intra-anual do regime pluviométrico, em virtude das sucessivas invasões da frente polar atlântica ao longo do ano, cuja pluviosidade associada, possui caráter menos intermitente e de ampla abrangência espacial.

A variação do De (média $=0,48)$ é menor que a variação de Dt (média $=1,32)$, porém, a principal característica do De é a maior expressão em escala espacial mais detalhada. Em outras palavras, o De parece ter um grão espacial menor que o Dt, ou ainda, o De reflete maior heterogeneidade pluviométrica em menores distâncias (Figura 32 e Figura 33). Por outro lado, o Dt parece ter um grão temporal menor, refletindo maior heterogeneidade pluviométrica em curtos períodos de tempo. A princípio isso reflete a propriedade de escala a que são submetidos os fenômenos geográficos, onde o IPE sugere uma importância mais significativa dos componentes físicos da superfície na modulação do volume pluviométrico. 


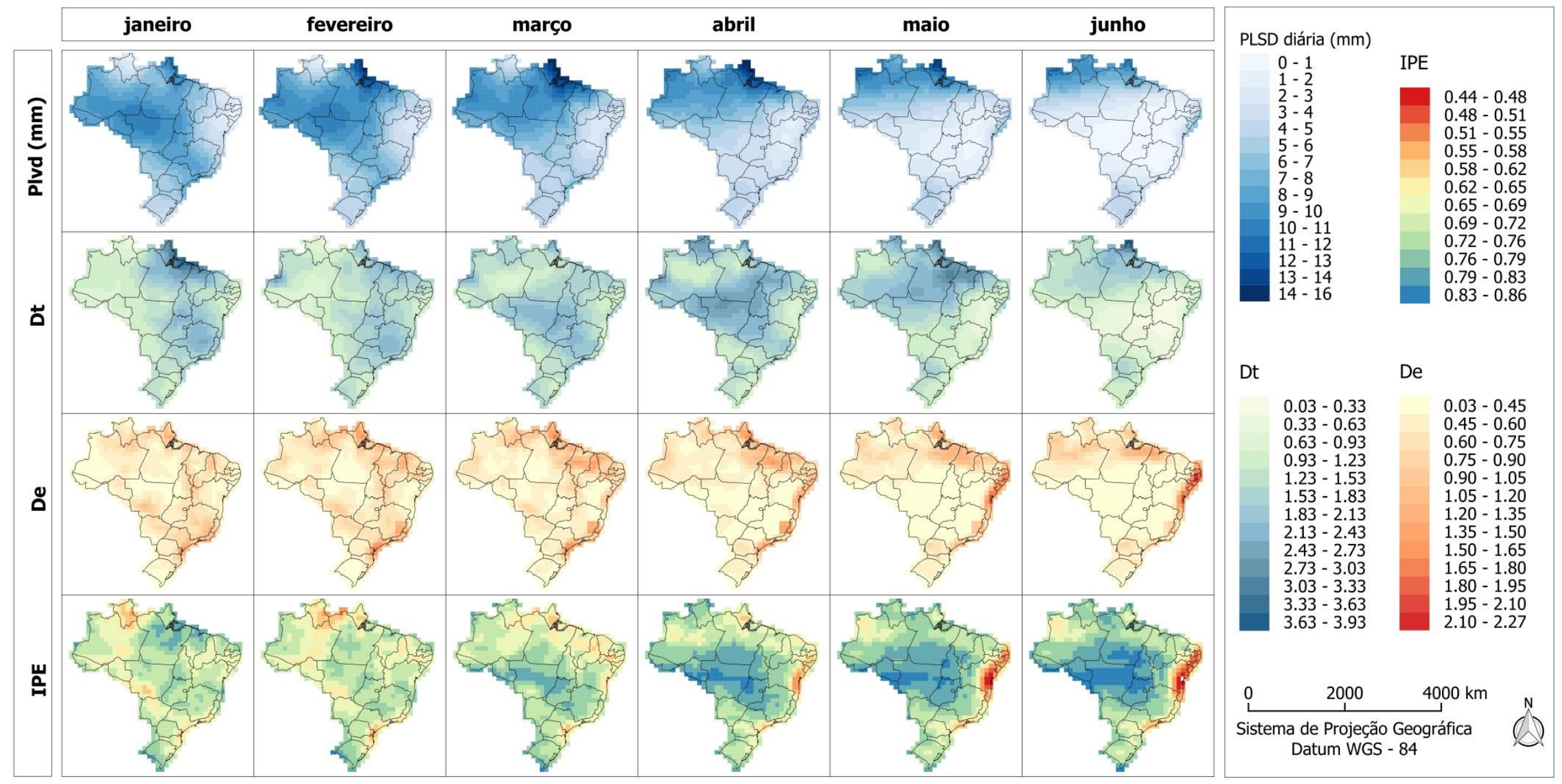

Figura 32: Precipitação média diária, Média do Módulo dos Desvios no tempo (Dt - desvios em função do tempo) e Média do Módulo dos Desvios no espaço (De - desvios em função do espaço) e Índice de Proporção de Escalas (IPE) para a série pluviométrica de 1975 a 2010, para o ciclo anual e meses separadamente, na escala 3M x 3Q. 


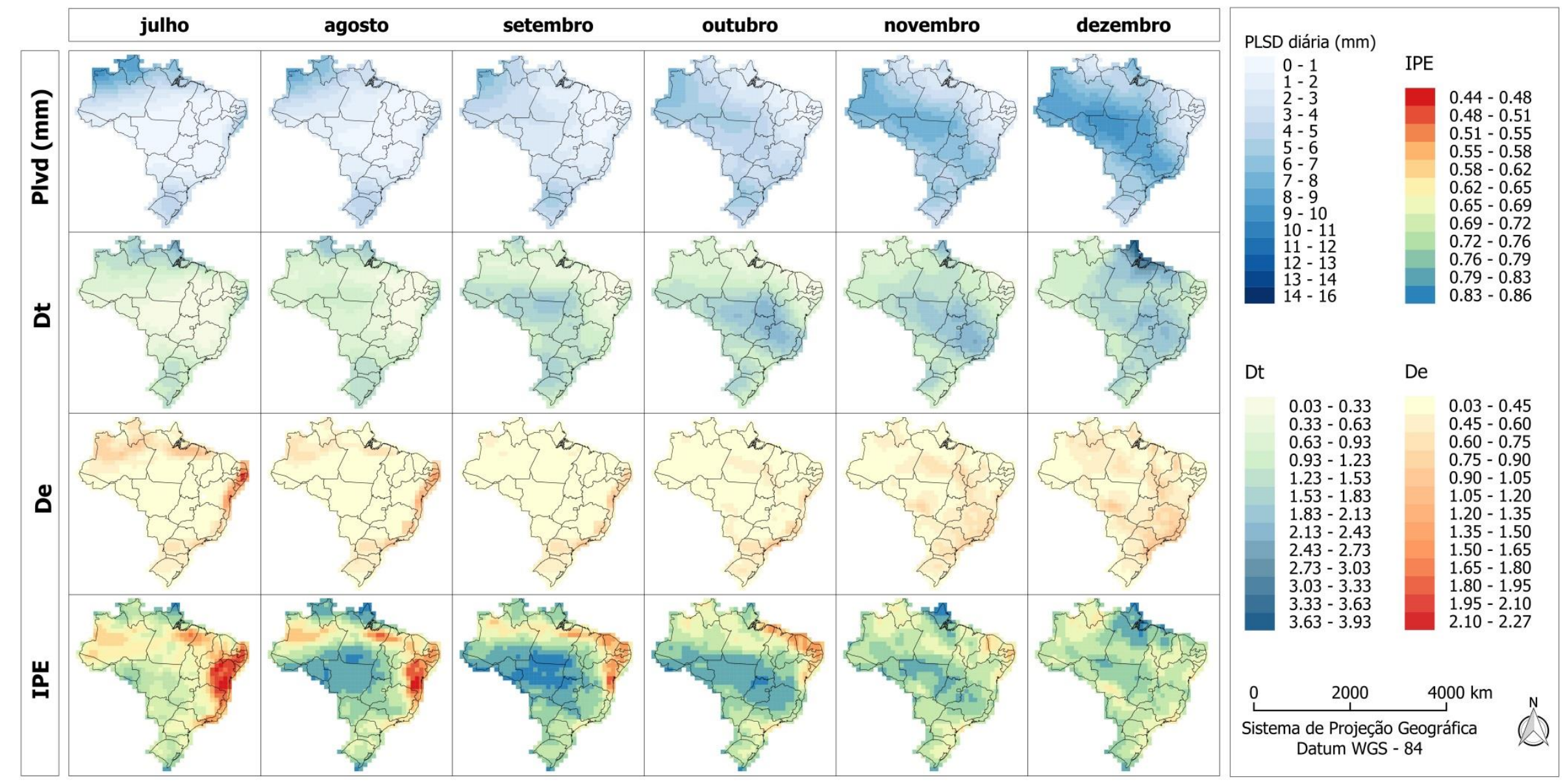

Figura 33: Precipitação média diária, Média do Módulo dos Desvios no tempo (Dt - desvios no tempo) e Média do Módulo dos Desvios no espaço (De - desvios no espaço) e Índice de Proporção de Escalas (IPE) para a série pluviométrica de 1975 a 2010, para o ciclo anual e meses separadamente, na escala 3M x 3Q. 
$\mathrm{Na}$ escala anual, os maiores valores de IPE (entre 0,76 e 0.84 ) ocorrem na porção central do Brasil, cobrindo quase a totalidade de estado do Mato Grosso, Goiás e parte dos estados vizinhos (Tocantins, Rondônia, Pará, Amazonas e Minas Gerais). Outro local de valores altos de IPE está situado no extremo sul do Rio Grande do Sul, atingindo o valor recorde na média anual $(0,93)$. A partir destes locais, o IPE decresce concentricamente, com valores menores $(\sim 0,60)$ no extremo norte do país (Roraima, norte do Amazonas e nordeste do Pará) e por toda a Costa Atlântica, até o norte do Rio Grande do Sul. Nos estados de São Paulo, Paraná e Santa Catarina, os mais baixos valores de IPE adentram o continente pela costa leste em cerca de $400 \mathrm{Km}$, com valores entre 0,59 a 0.67 , enquanto que, nos estados nordestinos, marcadamente na Bahia, em Alagoas e Pernambuco, ocorrem os menores valores do país $(0,41$ a 0,50) alcançando distâncias em torno de $800 \mathrm{~km}$ da costa.

\subsubsection{Padrões formados pelo IPE}

Dada a notável variação sazonal e geográfica dos padrões de IPE, faz-se necessária uma avaliação mais detalhada e que permite identificar, pelo menos, cinco padrões regionais principais, que podem ser descritos paralelamente aos principais sistemas meteorológicos que definem o regime pluviométrico e as peculiaridades locais do relevo (Figura 34). 


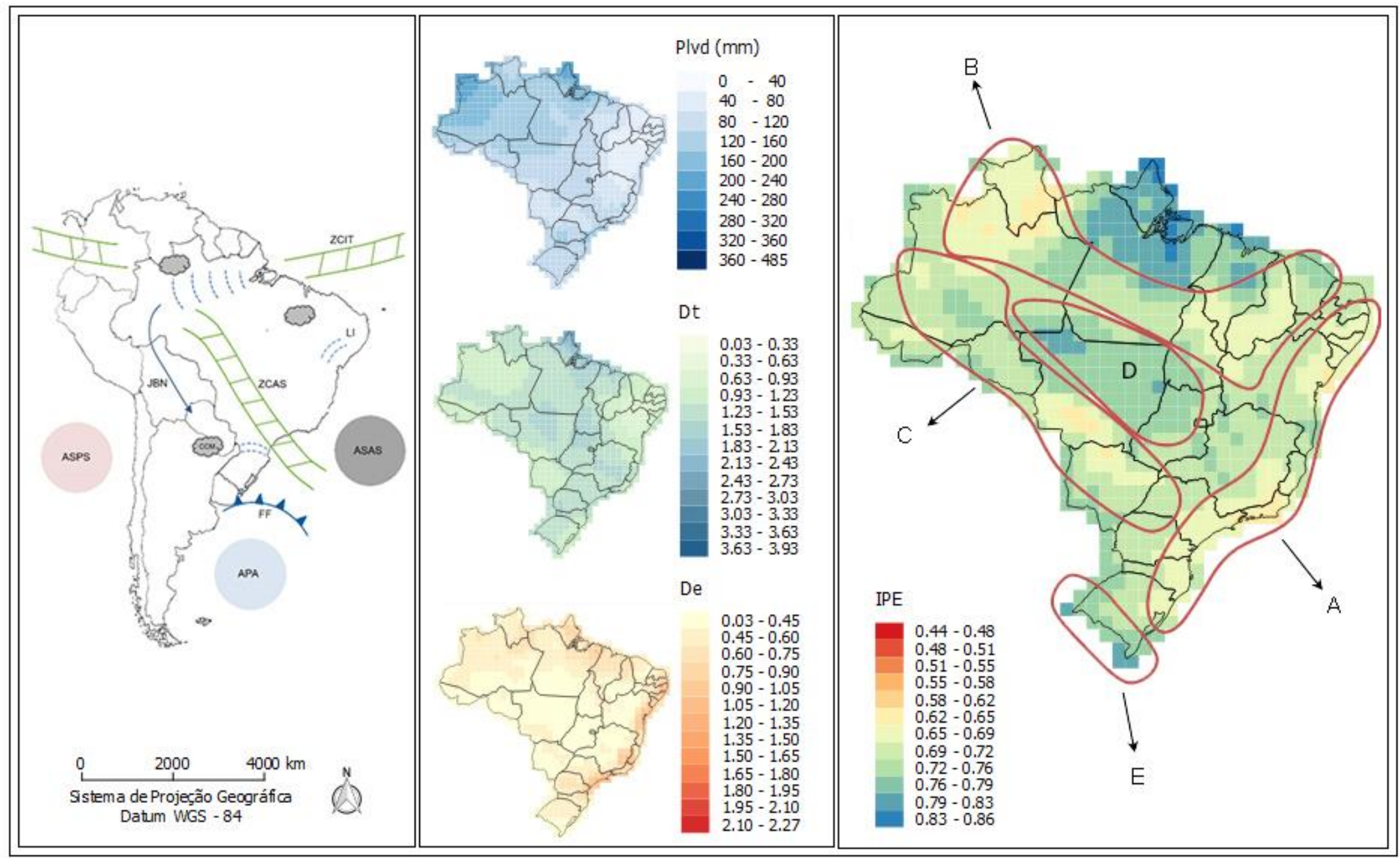

Figura 34: Padrões (de A até E) identificados com base no Índice de Proporç̃o de Escalas (IPE) (a) e os principais sistemas de tempo meteorológicos que atuam sobre a variabilidade espaço-temporal das chuvas no Brasil (IPE - b). ASPS: Anticiclone Semipermanente do Pacífico Sul; ASAS: Anticiclone Semipermanete do Attântico Sul; ZCIT: Zona de Convergência Intertopical; ZCAS: Zona de Convergência do Atlântico Sul; CCM: Complexos Convectivos de Mesoescala; JBN: Jatos de Baixos Níveis; FF: Frente Fria; LI: Linhas de Instabilidade; APA: Anticilone Polar Atlântico. 


\subsubsection{Padrão A}

O Padrão A descreve uma faixa de baixos valores de IPE que se estende do litoral norte gaúcho ao litoral leste do estado do Rio Grande do Norte. De abril a julho, há uma intensificação da influência do espaço na variabilidade pluviométrica, seguindo de uma retração contínua do litoral sudeste ao litoral norte até novembro, onde os baixos IPEs permanecem por mais dois meses. No restante do período (dezembro a março), o padrão de menores IPEs na costa brasileira permanece, porém de forma menos evidente.

O Padrão A corresponde à região mais estudada em termos de interação entre relevo e precipitação no Brasil, devido as suas peculiaridades de altitude, direção de vertentes, posição e configuração espacial, que lhe conferem um caráter complexo quando comparado ao restante do país. Dentre os trabalhos que confirmam essa interação estão (FORGIARINI e VENDRUSCOLO (2013), BARATTO e WOLLMANN (2015) no Rio Grande do Sul, RODRIGUES (2015) e HAAS (2002) em Santa Catarina, (CORREA (2013) no Paraná, CARVALHO, JONES e LIEBMANN (2002) em São Paulo, BERBERY e COLLINI (2000) na região sudeste do Brasil, SOARES, FRANCISCO e SENNA (2014) no Rio de Janeiro, MELO JÚNIOR et al. (2005) nas serras da Mantiqueira, do Espinhaço, do Gavião e Caparaó, ÁVILA, DE MELLO e VIOLA (2009) na Serra da Canastra, LYRA, OLIVEIRA-JÚNIOR e ZERI (2014). PEREIRA (2013) em Alagoas, SOUZA, ALMEIDA e CORREA (2015) em Pernambuco, SILVA et al. (2006) no Ceará e Rio Grande do Norte, NOBRE, MOURA e SUN (2001) para a região nordeste do Brasil.

Sobre o litoral do Paraná e São Paulo, ao longo da Serra do Mar, ocorrem valores de IPE relativamente baixos o ano todo, principalmente de janeiro a abril, quando os principais mecanismos de precipitação são a zona de convergência de umidade dos alísios de sudeste que originam a Zona de Convergência de Atlântico Sul (ZCAS), além das frequentes passagens de frentes frias, que tanto interagem com a ZCAS, como com as elevações do litoral. Nesse período o efeito topográfico é intensificado pelos ventos de sudeste do Anticiclone Subtropical do Atlântico Sul (ASAS) que sopram alinhados à topografia da Serra do Mar (GRIMM e ZILLI, 2009).

O litoral sudeste apresenta alta sazonalidade pluviométrica devido à atuação e interação de inúmeros sistemas tropicais e intertropicais, responsáveis por uma estação 
chuvosa de verão que constrasta com os baixos volumes da estação seca, em decorrência da subsidência gerada pela proximidade do ASAS, no inverno. No verão é frequente a ocorrência da ZCAS, com sentido noroeste-sudeste sobre a região, além da frequente permanência das frentes polares, em torno da latitude $22^{\circ} \mathrm{S}$, devido a um equilíbrio dinâmico entre o Anticiclone Migratório Polar e o ASAS, cuja estacionaridade do fluxo atmosférico interage com o relevo e influencia a ocorrência de chuvas (GRIMM, PAL e GIORGI, 2007; NUNES, VICENTE e CANDIDO, 2009). A elevada heterogeneidade temporal das chuvas durante o verão mantém os IPEs altos nesse período, apesar de haver uma forte heterogeneidade espacial próxima a costa, nas maiores elevações. A redução da heterogeneidade temporal nos meses mais secos, permite evidenciar o efeito da topografia sobre os baixos valores de IPE.

$\mathrm{Na}$ costa leste do nordeste brasileiro, o máximo volume pluviométrico ocorre de maio a julho e está relacionado, principalmente, à circulação de brisa mais intensa que advecta bandas de nebulosidade média para o continente, a ação das frentes frias remanescentes que se propagam ao longo da costa (KOUSKY, 1979) e perturbações ondulatórias no campo dos alísios, que correspondem à convergência dos ventos de sul, associados aos sistemas frontais, com os ventos de leste (CHAN, 1990). Além disso, de abril a agosto, quando o ASAS está mais próximo à região, se estabelecem ventos de sudeste, perpendiculares a costa (SERVAIN e LUKAS, 1990). Na transição para a estação chuvosa e ao longo dessa, a heterogeneidade temporal aumenta e os ventos passam a soprar do quadrante leste, alinhados à topografia, diminuindo a heterogeneidade espacial das chuvas. É, portanto o período em que o IPE é mais alto em toda a região nordeste.

\subsubsection{2 $\underline{\text { Padrão B }}$}

O Padrão B ocorre do litoral norte do Rio Grande do Norte ao oeste da região amazônica, onde os baixos IPEs são mais evidentes, formando uma faixa contínua, de julho a agosto e, secundariamente entre fevereiro a abril. No primeiro caso, o baixo volume pluviométrico, associado a ausência da Zona de Convergência Intertropical (ZCIT) (KOUSKY, 1979; NOBRE, 1983), reduz a heterogeneidade temporal das chuvas e que é acompanhada de baixos valores de IPEs, os quais aumentam quando a ZCIT inicia seu deslocamento para o sul, sobre a região. Observa-se uma relação mais clara entre o IPE e a 
ZCIT nos meses de fevereiro e março, quando ocorre o chamado "salto", caracterizado como um retorno de aproximadamente $1,5^{\circ}$ da ZCIT para o norte e que é acompanhado da redução do IPE. Na sequencia, quando o deslocamento da ZCIT para o sul é retomando, os valores de IPE se elevam (UVO e NOBRE, 1989).

No final da primavera austral, a ZCIT inicia seu deslocamento para o litoral norte e os alísios de nordeste passam a predominar sobre o estado de Roraima, com altas velocidades devido ao progressivo aquecimento do continente, e os quais sofrem aceleração por efeito de compressão vertical nos Planaltos do Norte da Amazônia, na porção norte do estado e noroeste do Pará (AMARANTE, ZACK e SÁ, 2001). Provavelmente este processo é responsável pela redução do IPE, como já foi evidenciado por NEGRI, ANAGNOSTOU e ADLER (2000).

As chuvas no oeste da Amazônia são bem distribuídas no ano, devido a atuação contínua da massa equatorial continental (MARENGO e HASTERNRATH, 1993) e que mantém uma baixa heterogeneidade temporal das chuvas, permitindo a expressão dos baixos valores de IPE. No inverno austral, devido a redução do fluxo sobre os trópicos, apenas os ventos da porção sudeste amazônica são canalizados como jatos de baixos níveis, para as altas latitudes, os quais seguem preferencialmente para o leste dos Andes, pela depressão do rio Amazonas, e são elevados pela topografia. Ao contrário dos meses de verão, quando os ventos de toda a região são canalizados e transportam umidade para o sul do país (NOBRE, 1983; DA ROCHA et al., 2009). É difícil identificar o que eleva o efeito do espaço nos meses de inverno, porém, (BETTS et al., 2009) salienta que apesar da topografia local não ser muito pronunciada, pequenas diminuições da forçante temporal fazem com que a condição local afete bastante a distribuição das chuvas.

\subsubsection{3 $\underline{\text { Padrão } C}$}

A partir de dezembro surge um terceiro padrão de forte efeito do espaço na variabilidade pluviométrica que se estende da Amazônia central, na direção sudoeste, pelo vale do Rio Madeira até a tríplice fronteira Rondônia-Amazonas-Bolívia, defletindo para o sudeste, sobre a Bacia do Prata até atingir o litoral paulista. Esse padrão é mais bem observado nos meses em que a ZCAS é mais ativa, se estabelecendo nas adjacências da 
região. Nesse período o fluxo sobre os trópicos se intensifica e os jatos de baixos níveis, ao escoarem para o sul fornecem umidade ora para a região da ZCAS, ora para os Complexos Convectivos de Mesoescala (CCM) que se originam sobre o norte da Argentina (MARENGO, 2005).

Sistemas frontais do sul do país também contribuem para a precipitação (SATYAMURTI e RAO, 1988). Em janeiro e fevereiro esse escoamento parece gerar elevada heterogeneidade espacial e baixos IPEs sobre a margem mais larga do Rio Madeira, ao sul do Amazonas e, de novembro a março, sobre o sul do Mato Grosso e norte do Mato Grosso do sul devido a elevada heterogeneidade espacial no relevo do planalto e Chapada dos Parecis e a Serra do Rio Guaporé. No inverno, a localização dos jatos mais ao sul (GUEDES et al., 1994) sugerem uma explicação para os baixos IPEs, que nesta época ali ocorrem.

\subsubsection{4 $\underline{\text { Padrão } D}$}

Os padrões descritos anteriormente articulam-se, formando um arco que se fecha num grande um círculo, composto por baixos valores de IPE. No interior desse círculo distingue-se o padrão D que consiste em altos valores de IPE durante todo o ano, porém, ligeiramente mais elevados na primavera e outono. A região corresponde à área de atuação da ZCAS, considerada um dos principais fenômenos determinantes do regime de chuvas dessas regiões (QUADRO e ABREU, 1994; GRIMM, 2011), cuja atividade convectiva pode ser intensificada pelo fluxo de umidade transportado pelos jatos de baixos níveis que ao escoarem para o sul do continente. Nos meses de inverno, o bloqueio gerado pela alta pressão do ASAS, que se estende sobre o país, inibe a chegada dos sistemas geradores de chuva e a região permanece sob a atuação da massa tropical continental, quente e seca (NIMER, 1979; VIANELLO e ALVES, 1991). Todos estes sistemas de tempo e mecanismos meteorológicos (sistemas frontais, ASAS, ZCAS) que parecem reger o Padrão D são altamente variáveis no tempo, porém notoriamente constantes no espaço, visto que apresentam continuidade em extensões de centenas ou milhares de quilômetros e, portanto, são típicos mecanismos promotores de altos valores de IPE. 


\subsubsection{Padrão E}

O último padrão identificado (E) é representado por uma pequena área no extremo sul do Brasil, com IPEs altos e uma pequena diminuição nos meses de inverno e primavera. A homogeneidade espaço-temporal das chuvas parece ter relação com os baixos contrastes do relevo típicos do extremo sul do Rio Grande do Sul e com a frequente passagem da frente polar (SIQUEIRA e MACHADO, 2004) que mantém os IPEs elevados. Também ocorrem altos valores de IPE no oeste da região durante a primavera, verão e outono, respectivamente, quando é frequente a ocorrência de CCM que se originam sobre o Paraguai e Argentina, se desenvolvem e migram para a bacia do Prata. Desta forma, representa um mecanismo análogo àquele que explica o Padrão D.

\subsubsection{Os sistemas de tempo local formados pelos drivers de escala sinótica}

O conhecimento atual sobre os sistemas de tempo possibilita posicioná-los relativamente uns aos outros dentro de um gradiente de IPE. Por exemplo, sistemas convectivos possuem grande variabilidade diária e, seu desenvolvimento é condicionado ao aquecimento da superfície e presença de umidade do ar, que pode ser tanto associada a fenômenos em escala sinótica (ex. umidade da massa de ar operante) quanto local (ex. evapotranspiração local). Células convectivas individuais podem apresentar escala espacial (extensão) de poucos a dezenas de quilômetros, geralmente com poucas horas entre a formação das primeiras nuvens e a dissipação da energia do sistema, apesar de poderem se organizar em sistemas maiores atingindo centenas de quilômetros. Outro aspecto importante deste sistema, é que nos arredores de uma célula convectiva, criam-se correntes descendentes, que ao se aproximarem do solo, promovem movimentos de advecção, inibindo a ocorrência de chuvas nos arredores da célula. Esse fenômeno é descrito por DAVIDSON et al. (2012) para pequenas áreas desmatadas na Amazônia, onde houve aumento das chuvas sobre as pequenas clareiras e diminuição no entorno florestado e, também por BETTS et al. (2009) que verificou esse mesmo efeito sobre áreas de pastagem desmatadas no estado de Rondônia e, verificou ainda que o fluxo advectado contribuiu para iniciar a auto-organização da convecção nos limites das nuvens precipitantes. Ao longo do dia, os fluxos ascendentes e 
descendentes produzem uma superfície descontínua de precipitação no espaço, porém, novas células convectivas são formadas diariamente, no mesmo local ou nos arredores, de forma que na escala mensal ou trimestral, o conjunto dos processos convectivos conduz a certa homogeneidade temporal e espacial. Os dados produzidos neste estudo, ao menos nas escalas de tempo e espaço consideradas, sugerem que a homogeneidade espacial é maior que a temporal nas condições (regiões e meses) em que sistemas convectivos são mais importantes, em comparação a outros sistemas, por exemplo, de efeito orográfico. Provavelmente isso explicaria valores relativamente altos de IPE sobre o Brasil central e sul da Amazônia, onde processos convectivos são particularmente frequentes. Diante de iniciativas futuras, com uso de escalas espaço-temporais distintas daquelas aqui utilizadas, tais aspectos poderiam ser melhor explorados.

Os sistemas de tempo geradores de precipitação orográfica são análogos aos convectivos por dependerem de mecanismos em distintas escalas. Têm dependência tanto da escala sinótica, como a presença de uma massa de ar relativamente úmida e ventos com direção bem estabelecida, quanto de processos em escala local, dado pela presença de relevo com alta descontinuidade e vertentes voltadas a barlavento (KLIMOWSKI et al., 1998; ROTUNNO e HOUZE, 2007). Os valores de IPE para o Nordeste brasileiro, sobretudo no seu litoral são notavelmente baixos. Isso pode ser explicado por um relevo complexo e ventos úmidos consideravelmente fortes que fornecem condições propícias para a ocorrência de chuvas orográficas e sombras de chuva. Assim, com diminuição relativa da forçante temporal nos locais com relevo mais complexo, nas condições em que o relevo em escala local define uma precipitação local distinta dos arredores, espera-se que ocorram valores baixos de IPE. Basicamente, foi isso que os resultados mostraram.

Sistemas de tempo frontais sejam frentes frias, quentes ou estacionárias, e os sistemas de convergência de massas, como a Convergência Intertropical e a Convergência do Atlântico Sul, ocorrem em escalas de dias ou semanas, sendo que a ampla extensão espacial é que mais se destaca. São sistemas com grão de várias centenas de quilômetros. Tal fato ajuda a definir um valor de IPE alto, algo análogo ao encontrado nos sistemas convectivos. 


\subsection{Aplicações para o os dados produzidos}

Tanto os dados de precipitação quanto os de IPE, estruturados em uma malha espacial homogênea, apresentam múltiplas possibilidades de aplicação. Na sequência, serão abordadas duas aplicações por meio de análises específicas, que não somente revelam padrões e processo velados nos dados, mas também os validam, de forma a cumprir parte dos objetivos desta tese. São elas: 1) identificação de tendências espaço-temporais na série pluviométrica e 2) identificação do potencial efeito orográfico brasileiro na distribuição espaço-temporal da pluviosidade. Porém, não se propõe a abordar tais aplicações de forma exaustiva, dada a complexidade inerente as mesmas, mas sim, abordá-las em termos de perspectivas futuras, bem como reflexões e apontamentos necessários e pertinentes.

\subsubsection{Tendências espaço-temporais nas chuvas}

Para a série de 1975 a 2010, foram identificadas tendências positivas e negativas para os meses do ano (Figura 35 e Figura 36), das quais, as negativas estão presentes em maior número, notadamente nos meses de setembro e outubro, período que caracteriza o início do semestre mais úmido no país. As tendências positivas foram mais frequentes nos meses de janeiro e maio.

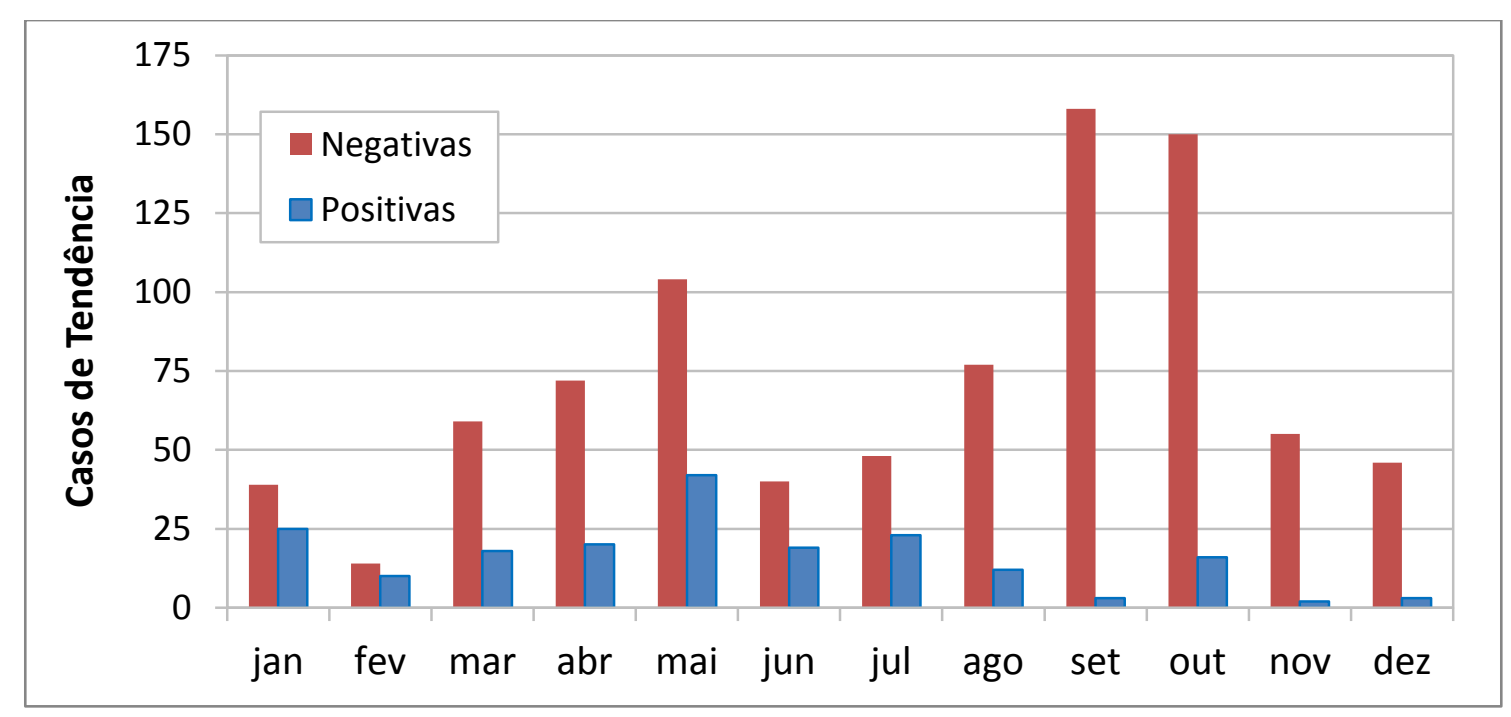

Figura 35: Ocorrências de tendências pluviométricas (teste de Mann-kendall) positivas e negativas nos meses do ano no Brasil, na série de 1975 a 2010, na escala de 1M e 1Q. Os números expressam a quantidade de quadrantes, de um total de 809. 


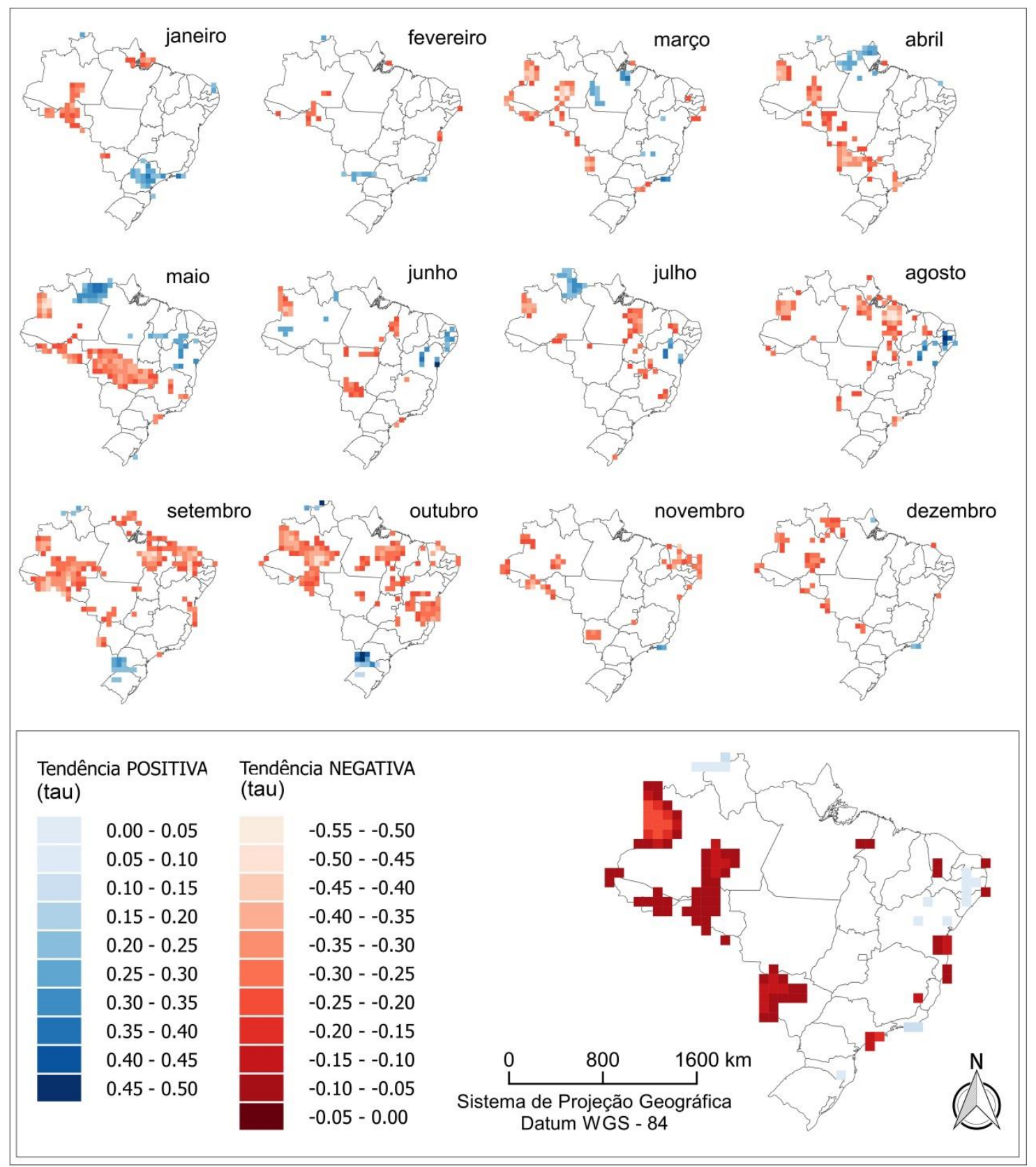

Figura 36: Distribuição espaço-temporal de tendências pluviométricas (teste de Mann-kendall) mensais e anual no Brasil, na série de 1975 a 2010, na escala de 1M e 1Q.

A elevada ocorrência de tendências negativas observadas nos meses de abril e maio ocorre principalmente sobre uma faixa em sentido noroeste-sudeste, do sul da Amazônia em direção ao sudeste, a qual remete a localização da ZCAS. Nos meses de agosto e setembro são mais frequentes sobre o litoral norte e, em setembro e outubro, sobre o sudoeste/noroeste da 
região amazônica e, em outubro, nas fronteiras do nordeste com as regiões sudeste e norte (Figura 36).

No período de março a julho as tendências positivas ocorrem preferencialmente na região norte do país, sendo os meses de abril, maio e julho, nos quais elas apresentam-se mais localizadas, em agrupamento com certa homogeneidade, sobre o Amapá, norte do Pará e Roraima. De maio a agosto as tendências positivas ocorrem preferencialmente sobre a região nordeste, mas de forma relativamente esparsa no espaço. Em setembro e outubro localiza-se um agrupamento de tendências positivas sobre a porção leste da região sul do Brasil e, nos meses de novembro a março, ocorre de forma pontual sobre o estado do Rio de Janeiro.

Da comparação da distribuição das tendências apresentadas mensalmente na Figura 36 e a distribuição da precipitação média mensal apresentada na Figura 25, observa-se que em distintos locais do território brasileiro, é possível contextualizar as tendências em relação às fases do regime pluviométrico anual em que são identificadas, ora em períodos úmidos, secos ou de transição entre períodos úmidos e secos e, que num primeiro momento, são sugestivas de deslocamentos das chuvas ao longo do regime anual.

Na porção central do país, as tendências negativas são mais frequentes em abril e maio, período de transição entre estação chuvosa para a seca na região, o que sugere a antecipação da estação seca. Tendências negativas esparsas ocorrem nos meses de inverno e início da primavera, também sugerindo um possível atraso no início da estação chuvosa.

Na região Amazônica as tendências negativas ocorrem em vários meses, com maior frequência em setembro e outubro, os quais marcam o início das chuvas na região. No mês de fevereiro, o mais chuvoso, é quando estão presentes em menor quantidade. As tendências positivas ocorrem principalmente nos meses de março a julho, no período chuvoso sobre o Amapá, Roraima e norte do Pará.

Na região nordeste, tendências negativas ocorrem durante o período menos chuvoso que, na porção norte corresponde aos meses de agosto a novembro, durante a estação seca quando a ZCIT está distante e, ao sul, corresponde aos meses de setembro e outubro, quando estão iniciando as chuvas. Nos meses de maio a agosto, as tendências positivas ocorrem a partir de maio quando está findando a estação chuvosa, sugerindo um possível prolongamento da estação chuvosa nos locais mais secos do país. No litoral as tendências positivas também estão presentes nos meses de transição para a estação seca. 
No sudeste ocorrem algumas tendências positivas nos meses de verão, com destaque para janeiro em São Paulo, que corresponde ao período mais chuvoso da região. Tendências negativas são mais frequentes nos meses de transição entre estação seca e chuvosa, de abril/maio e outubro, sugerindo um prolongamento da estação seca.

$\mathrm{Na}$ região sul ocorre tendências positivas apenas nos meses de setembro e outubro, no núcleo mais chuvoso da região, ao oeste de Santa Catarina e sudoeste do Paraná.

$\mathrm{Na}$ escala anual (Figura 36) permanecem as tendências negativas sobre o oeste e centro-sul da Amazônia (os quais estão dentre os núcleos mais chuvosos do país), sobre o noroeste do Mato Grosso do Sul que representa um núcleo espacial pouco chuvoso, além de tendências positivas e negativas pontuais, principalmente nas proximidades do litoral leste/nordeste. Muitas tendências observadas na escala mensal não o são na escala anual, provavelmente, a) por tendências não significativas num determinado mês se tornarem significativas quando contabilizadas junto a outras tendências pouco significativas ou b) por tendências significativas desaparecerem quando contabilizadas junto a casos de tendência inexistente, por exemplo.

Os dados submetidos à análise de tendência nas múltiplas escalas definidas no item 4.3, geraram padrões espaciais distintos ao serem visualizados de forma independente entre as generalizações espaciais (6 níveis) e as generalizações temporais (6 níveis) conferindo, de certa forma, um caráter dinâmico à análise (Figura 37). Ocorre o aumento significativo de tendências totais (positivas e negativas) quando os dados são submetidos a generalizações temporais sucessivas, cujos intervalos variam de 1, 3, 5, 7, 9 e 11 meses (Figura 38). As tendências positivas (Figura 40) aumentam em quantidade e se fortalecem, enquanto que as negativas (Figura 39) aumentam em quantidade e enfraquecem nos locais onde foram originalmente identificadas. $O$ que merece atenção é a nítida relação entre a elevada quantidade de tendências negativas nas maiores generalizações temporais, o que também ocorre para as tendências positivas, mas de maneira menos expressiva. Como os meses apresentam distintos padrões de tendências espaciais (Figura 36) é provável que o aumento das tendências negativas seja uma consequência de declinações mais pronunciadas da curva pluviométrica, geradas pela média móvel temporal. 

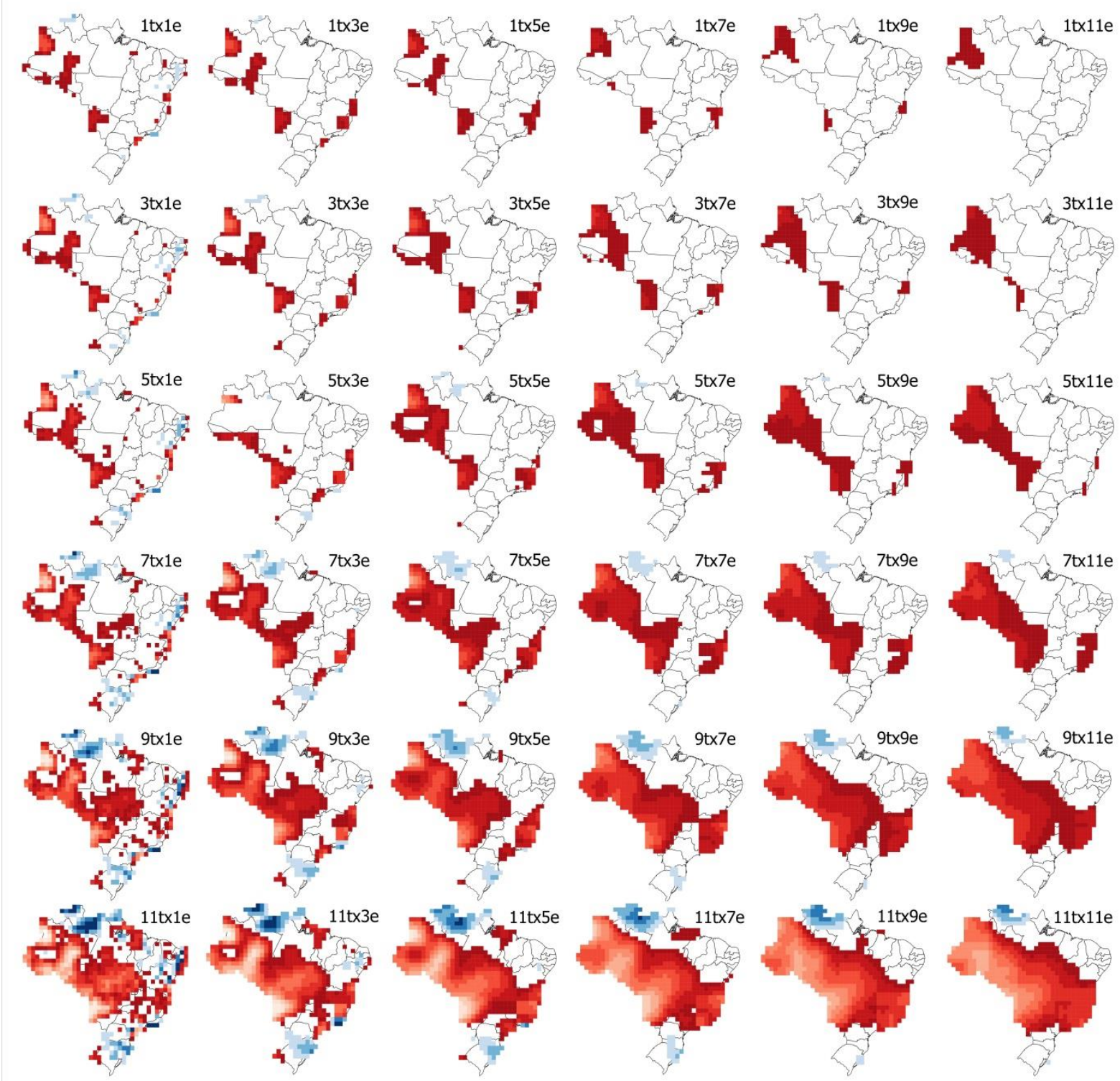
Tendência Anual Positiva
(tau)

Tendência Anual Negativa (tau)

$0.00-0.05$
$0.05-0.10$
$0.10-0.15$
$0.15-0.20$
$0.20-0.60$

$$
\begin{array}{l|l}
-0.55--0.50 & \\
-0.50--0.25--0.20 \\
-0.45--0.40 \\
-0.40--0.35 \\
-0.35--0.30 \\
-0.30--0.25
\end{array}
$$
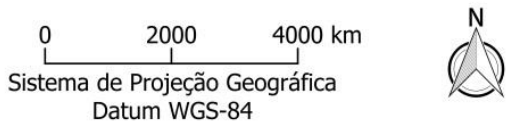

Figura 37: Distribuição espacial de tendências (teste de Mann-kendall) anuais positivas e negativas na precipitação do Brasil, para a série pluviométrica de 1975 a 2010. O efeito da generalização espacial na distribuição de tendências é observado ao efetuar a leitura da figura na vertical, de cima para baixo; para observar o efeito da generalização temporal é preciso que a escala espacial esteja constante, efetuando a leitura da figura na horizontal, da esquerda para a direita; o efeito do aumento de ambas as escalas é identificado pela leitura da figura na diagonal. 
A generalização espacial não possui o mesmo efeito sobre as tendências, havendo diminuição nas ocorrências quando associadas a pequenas generalizações temporais e, praticamente, sem alterar as demais (Figura 37). Com aumento da escala espacial aumenta a quantidade e a intensidade das tendências negativas na porção oeste da região amazônica, porém, é uma exceção. O principal efeito da generalização é de homogeneização da distribuição espacial das tendências temporais que, quanto mais pontuais e esparsamente distribuídas no espaço, são suavizadas e até eliminadas, enquanto as tendências negativas fracas se fortalecem e, as positivas fortes enfraquecem (Figura 39, Figura 40). Teoricamente, isso tem suporte na lei de Tobler, onde espera-se ocorrer um incremento gradual do efeito atenuante da distância, já que feições similares em localização tendem a ser similares, também, em atributos. Esse caráter esparso e pontual das tendências pode ser comparado a ruídos, os quais escondem uma relação espacialmente homogênea em menor grau à medida que a amostra aumenta para zonas que respondem a drivers climáticos diferentes (GONG et al, 2003).

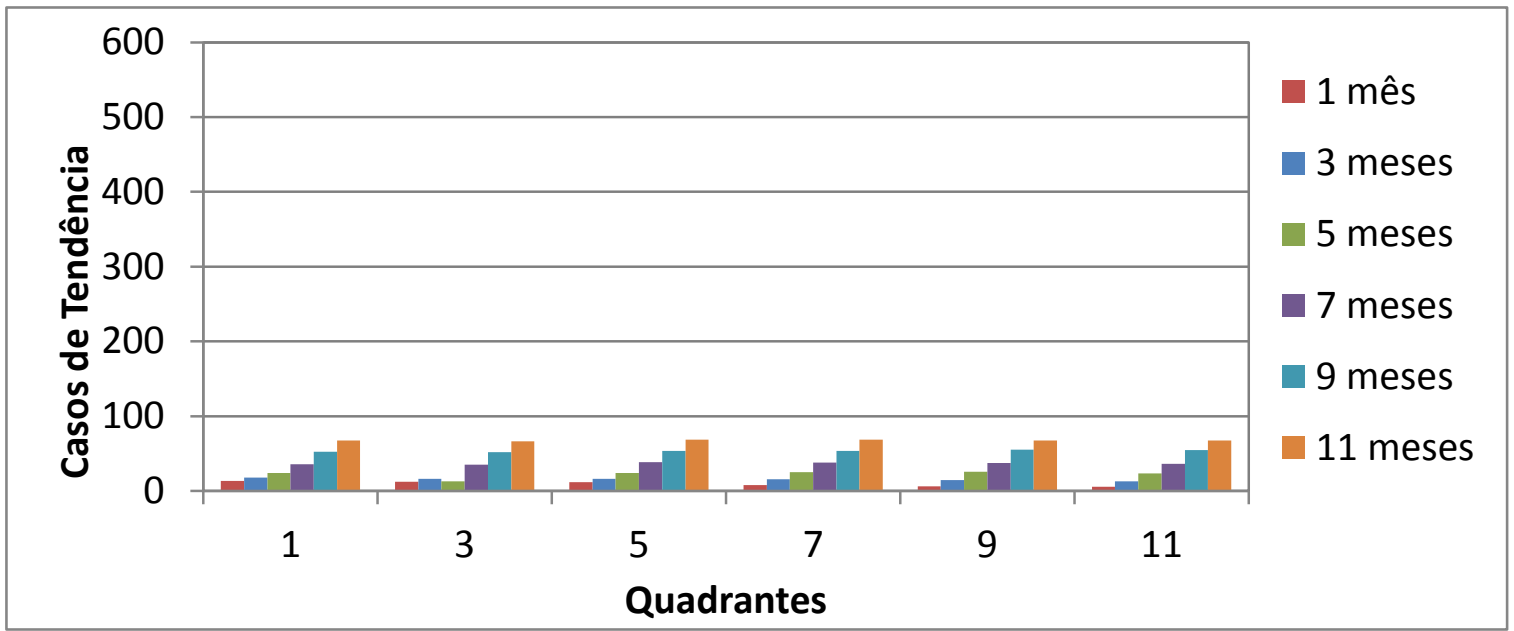

Figura 38: Distribuição multiescalar de tendências anuais na precipitação do Brasil, para a série pluviométrica de 1975 a 2010. 


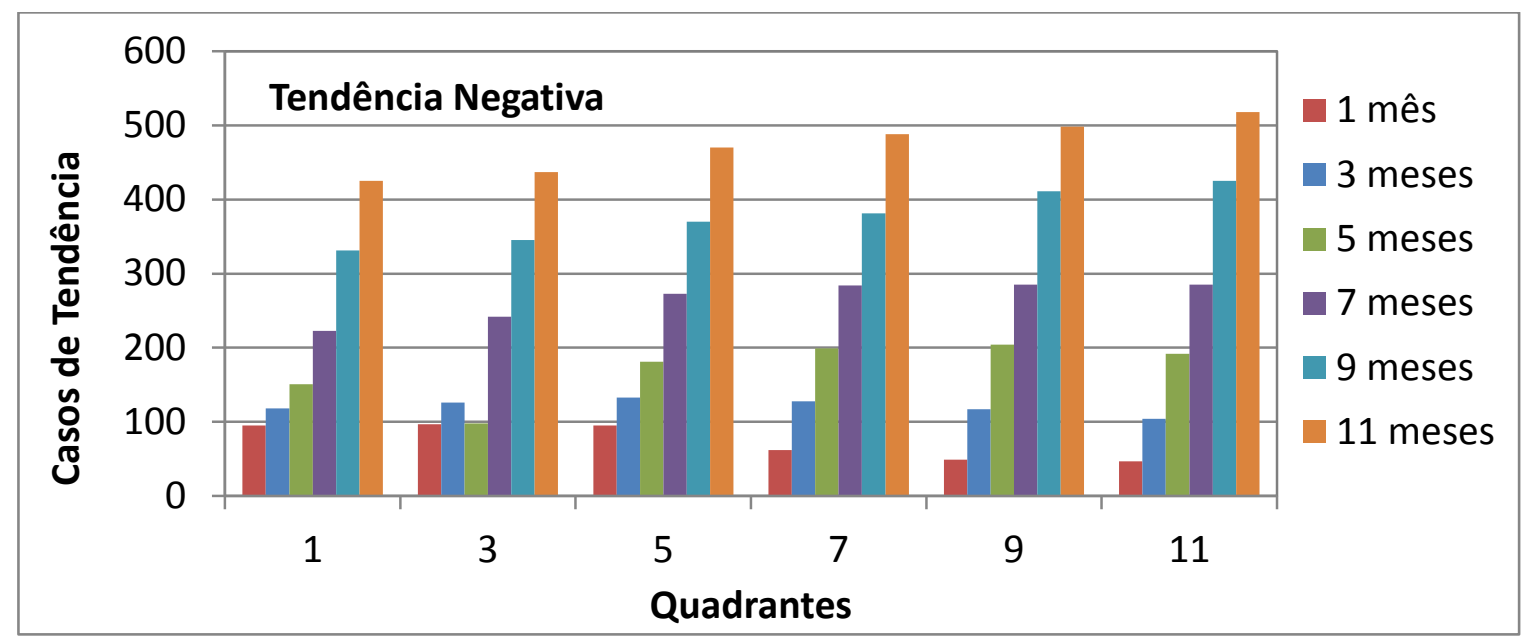

Figura 39: Distribuição multiescalar de tendências anuais negativas na precipitação do Brasil, para a série pluviométrica de 1975 a 2010.

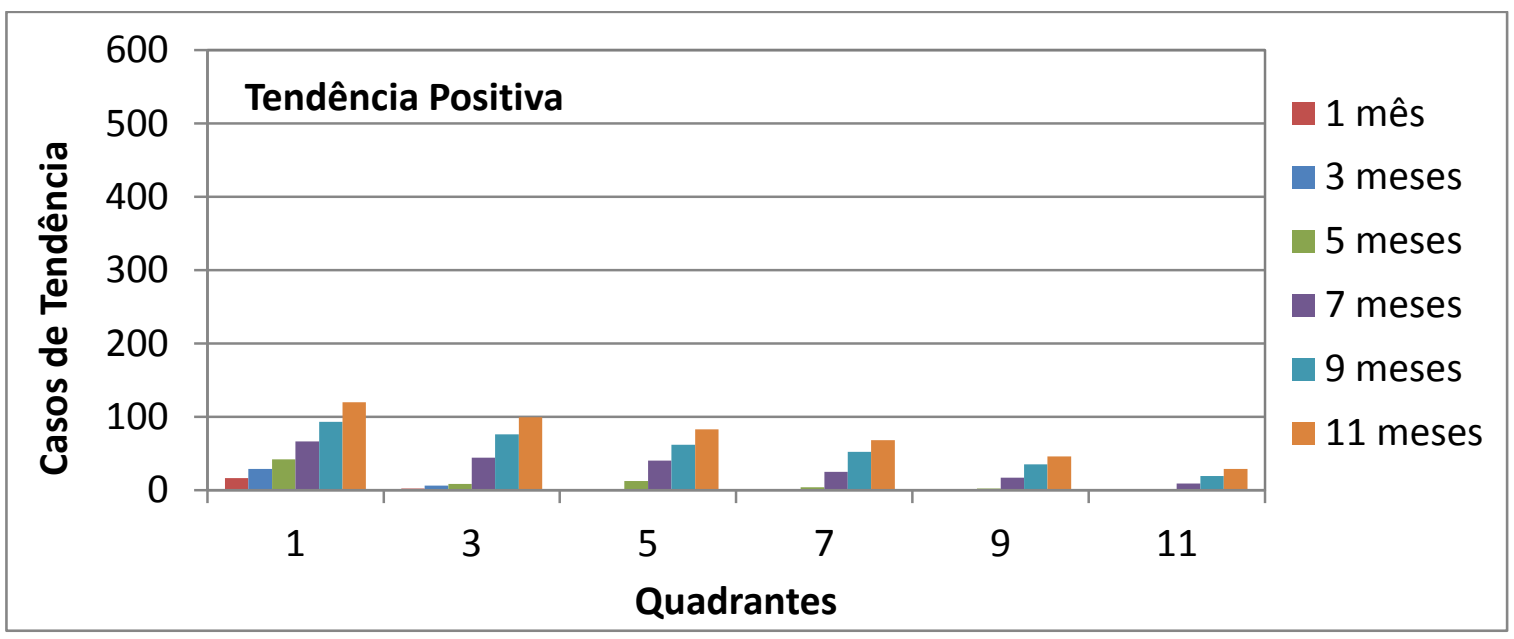

Figura 40: Distribuição de tendências anuais positivas na precipitação do Brasil, para a série pluviométrica de 1975 a 2010.

Apesar da interpretação dos resultados de tendências ser útil para a compreensão das relações físicas subjacentes, seja em escalas de tempo ou em escalas espaciais, uma questão que merece averiguação em algum momento é o efeito da correlação espacial e temporal sobre as tendências. DOUGLAS, VOGEL e KROLL (2000), enfatiza que a presença de correlação espacial nos testes de hipóteses dificulta a derivação analítica de uma distribuição de probabilidade exata para o teste estatístico de Mann-Kendall, o qual, KOUTSOYIANNIS ( 2006) demonstrou ser muito influenciado pelo comportamento de escala. SHAHID et al. (2014) salienta que a identificação de tendências significativas sem considerar a variabilidade climática natural, é uma consequencia inevitável, que resulta do efeito de escala. 
Nesse sentido, é preciso considerar que o método de interpolação utilizado no presente trabalho e a técnica de janelas móveis para derivar as generalizações espaço-temporais da precipitação, correspondem a procedimentos baseados na propriedade de autocorrelação que, teoricamente, está presente no conjunto de dados.

Séries temporais geralmente são decompostas em componentes de tendência, sazonais e cíclicas. A tendência corresponde a um acréscimo ou decréscimo da precipitação a longo prazo. A sazonalidade ocorre quando a série é influenciada por componentes bimestrais, trimestrais, semestrais, anuais, etc., ou seja, períodos fixos que caracterizam o padrão da precipitação. O ciclo corresponde a variações crescentes ou decrescentes em períodos não fixados, porém, maiores que a sazonalidade.

Muitos métodos de previsão são baseados na concepção da existência de um padrão intrínseco no conjunto de dados que podem ser distinguidos dos valores aleatórios com a utilização de técnicas de suavização de dados, visando eliminar a aleatoriedade e projetar valores futuros (HYNDMAN, ATHANASOPOULOS, 2016). No entanto, dentre as críticas às técnicas de correção sazonal, está à inexistência de um modelo estatístico explicativo do comportamento da série, e o relativo atraso introduzido pelas sucessivas suavizações (ESCÁRIA, 1995).

$\mathrm{Na}$ suavização por janela móveis executada ao longo do eixo do tempo, (GODTLIEBSEN et al., 2012) a precisão dos resultados é muito dependente do comprimento da janela definido e, mesmo assim, é muito difícil discriminar variações naturais (climáticas) em relação as artificiais (não climáticas). CONRAD (1944) sugere o termo homogeneidade relativa, para indicar que as variações climáticas possuem tendências semelhantes por extensas áreas, onde é provável que as estações vizinhas, segundo MARTÍNEZ et al. (2010), devem ter o mesmo padrão de mudança, sendo muito improvável, que mudanças artificiais ocorram ao mesmo tempo para muitos pluviômetros, por exemplo. No entanto, não é óbvia a diferença entre uma mudança real e flutuações aleatórias da precipitação e, mesmo que os testes indiquem tendência significante, os resultados podem estar relacionados a várias questões, como causas antropogênicas, mudanças naturais das bacias, variabilidade climática, mudanças climáticas ou problemas com os dados (BUISHAND, 1982).

O teste de Mann-Kendall baseia-se na suposição de que os dados não apresentam correlação temporal. A presença de autocorrelação positiva nos dados aumenta a variância da estatística de Mann-Kendall e, portanto, a probabilidade de rejeição da hipótese nula, mesmo 
na ausência de tendência, com probabilidade maior que o nível de significância fixado pelo pesquisador (STORCH apud ÖNÖZ e BAYAZIT, 2012). Alguns testes foram criados visando levar em consideração a correlação temporal das séries ao realizar testes para detecção de tendências e, uma delas, consiste em aumentar a escala temporal da série. A escala anual reduz a importância da correlação temporal numa série, ou seja, a média anual pode mascarar eventos que ocorrem na escala mensal. Assim, pode ocorrer de tendências observadas na escala mensal desaparecerem quando analisada na escala sazonal. Isso pode acontecer quando a estatística do teste apresenta um p-valor muito próximo do limite da região crítica. A média anual tende a camuflar as tendências que ocorrem na escala mensal, principalmente quando elas possuem sinais opostos, ocorrendo uma espécie de compensação desses valores ao calcular a média.

Apesar de não ser analisada a magnitude das tendências como frequentemente é utilizado, considerações importantes são obtidas pela abordagem multiescalar dos dados, como é o caso da tendência negativa no oeste da região amazônica (Figura 36), a qual se caracteriza como a mais persistente dentre todas, influenciada principalmente pela generalização espacial.

O efeito da escala sobre as tendências pluviométricas deve ser considerado no percurso dos estudos, visto que a ocorrência ou não e a distribuição espacial das tendências, são manifestações características de cada escala, cuja presença ou ausência pode ser manipulada intencionalmente.

\subsubsection{O Potencial orográfico para Chuvas (POC) e o Índice de Proporção de Escalas (IPE)}

A Figura 41 apresenta os valores do potencial para ocorrência de chuvas orográficas (POCs), em escalas mensais e anual para o Brasil, cujos valores oscilam entre -0.140 e 0,22. No geral, grande parte do Brasil apresenta POCs muito próximos a 0 , indicando a ortogonalidade do vento em relação ao relevo e/ou o caráter plano do mesmo. A maior exceção é o extremo norte do país, com grandes elevações localizadas, e a porção leste do Brasil, onde a complexidade do relevo é maior, em termos de posição, extensão, declividade, além de elevações superiores a 2.000 metros, caracterizando esses locais como os mais 
propícios para a ocorrência de chuvas orográficas $(\mathrm{POC}+)$ e o efeito de sombra de chuva (POC-).

Na região litorânea, sob efeito da Serra do Mar e dos ventos alísios de sudeste, também nota-se considerável POC+. De forma geral, toda a porção leste do país, incluindo o nordeste, sudeste e sul, apresenta valores elevados de POCs o ano todo, com valores mais baixos de maio a julho e, cujos valores tornam-se mais próximos à zero (POC nulo) do litoral em direção ao interior do continente.

O relevo é estruturado espacialmente em diversas escalas, podendo apresentar variações notáveis em poucos quilômetros, em termos de altitude, posição e direção de vertentes. Dessa maneira, nota-se que próximo ou logo na sequência de um quadrante com POC+ ocorre um quadrante com POC- (ou POC mais baixo), indicativo do efeito de sombra de chuva e, essa posição entre os quadrantes, observada na Figura 41, é estabelecida de acordo com a direção dos ventos predominantes de cada mês. Ou seja, ventos de norte indicam o efeito de sombra de chuva ao sul dos quadrantes com POC+ (ou POC mais altos), assim como ventos de leste indicam o efeito de sombra de chuva ao oeste dos quadrantes com POC+ (ou POC mais altos), e assim sucessivamente. Tecnicamente, um valor consideravelmente baixo de POC- não apresenta relação nenhuma com um valor consideravelmente alto de $\mathrm{POC}+$ no quadrante precedente, pois considera características individuais de cada quadrante. Este padrão de ocorrência de POC+ e POC- (ou POC alto e baixo) também é observado nas demais porções do território, apesar do caráter plano do terreno, mas é claro, com menor intensidade. 


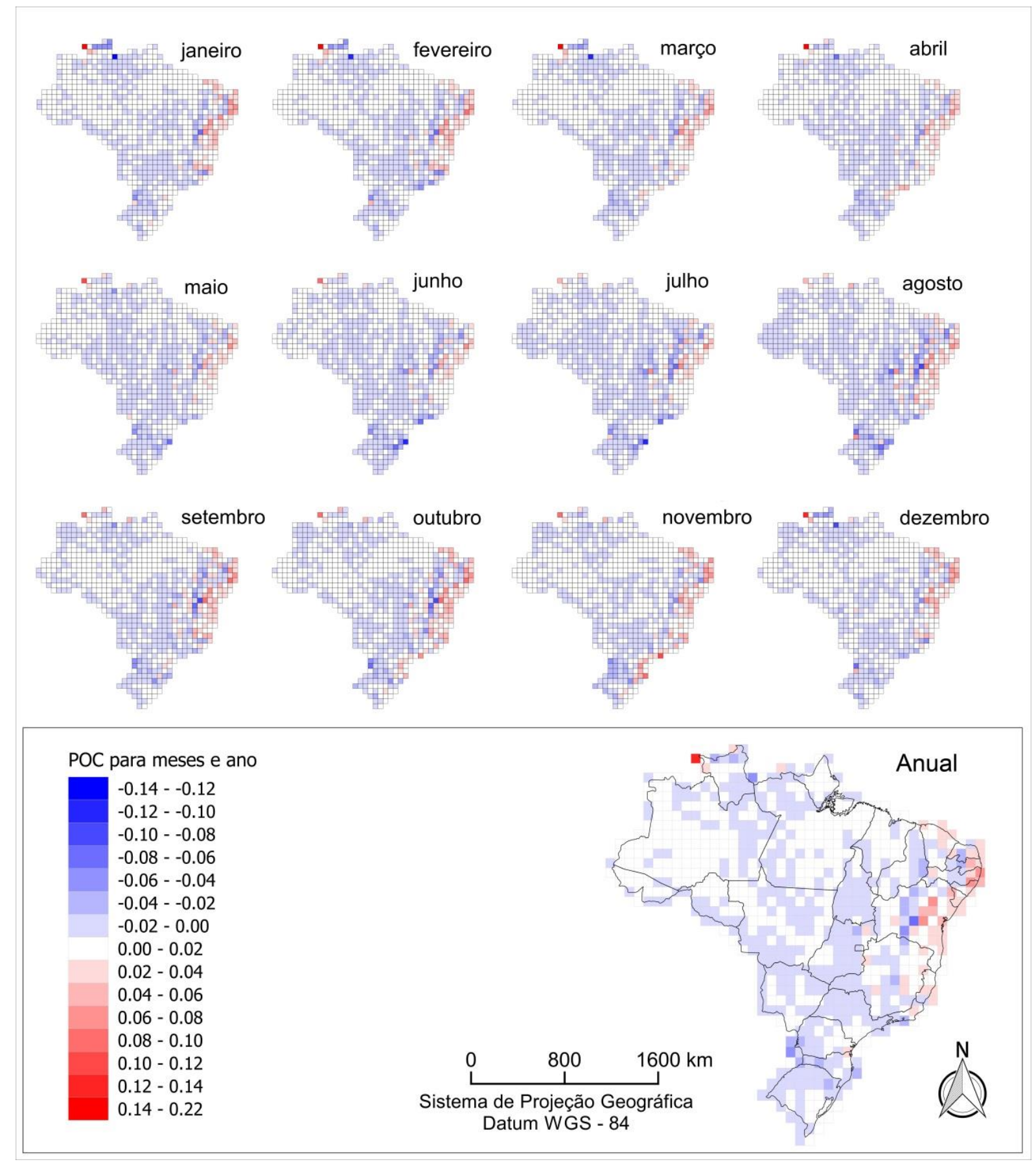

Figura 41: Distribuição espacial do POC anual e para distintos meses e para o ano. 
A localização das áreas de estudo compreendidas pelos trabalhos selecionados, sobre a influência do relevo na pluviosidade do Brasil, para a validação do POC é apresentada na Figura 42. Foram obtidos 34 trabalhos, dos quais, 1 monografia de final de curso de graduação, 2 teses de doutorado, 3 dissertações de mestrado, 25 artigos de periódicos e 3 trabalhos apresentados em eventos. A maioria dos estudos tematizam a região sudeste (19), seguida da região sul (9) e nordeste (7), havendo uma carência de estudos nas regiões centrooeste (2) e norte (1). Alguns estudos apresentam mais de uma área sob investigação e, de modo geral, as dimensões variam entre 24 e $22 \times 10^{6} \mathrm{Km}^{2}$, com média de $900.000 \mathrm{Km}^{2}$. A distribuição é notoriamente assimétrica e a maioria dos estudos tem dimensão inferior a $50.000 \mathrm{~km}^{2}$. Como nem todos os estudos explicitam as dimensões físicas da área de estudo vale-se da dimensão do retângulo envolvente para fins de análise em SIG. 


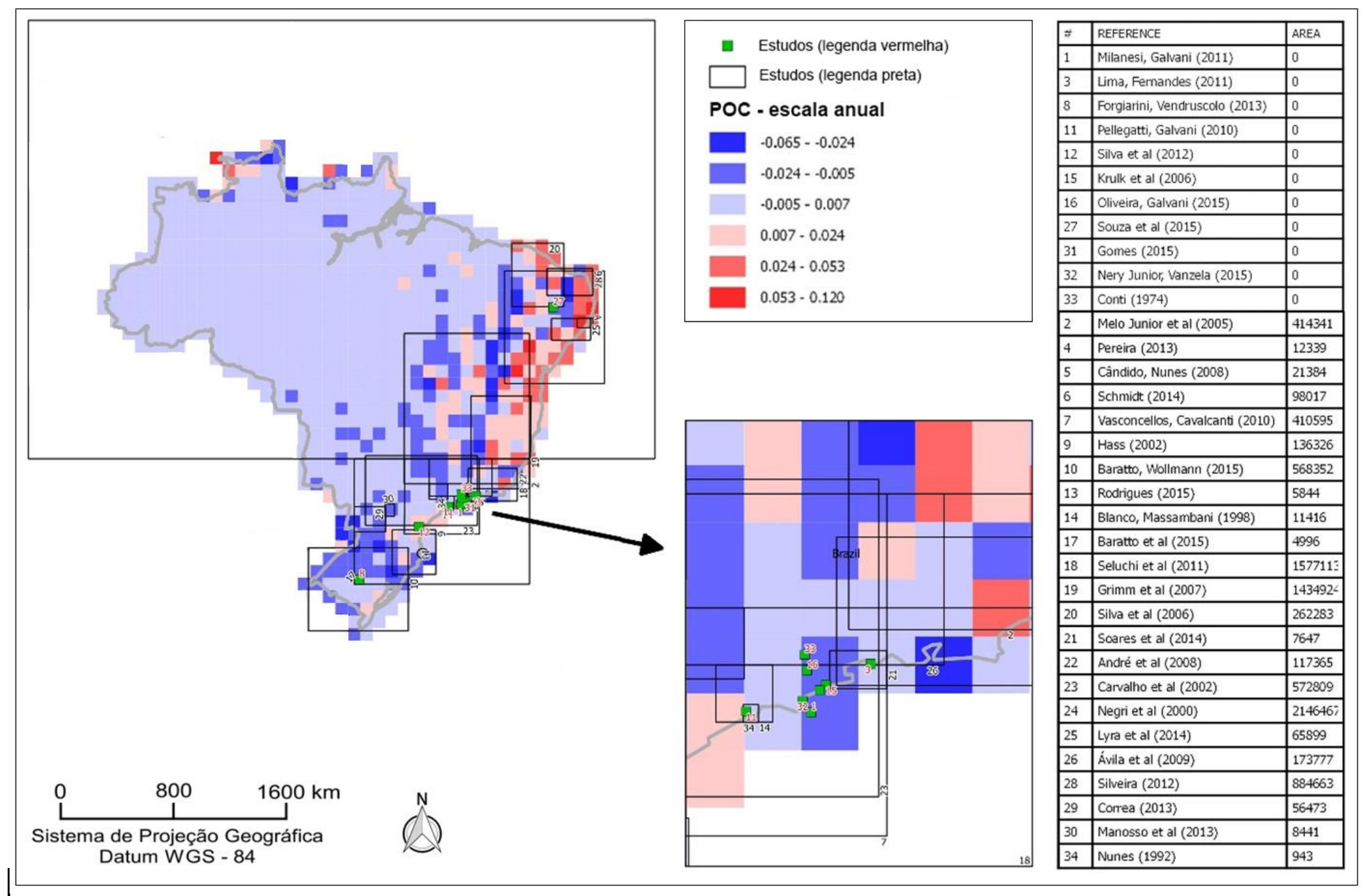

Figura 42: Distribuição dos estudos sobre a influência do relevo nas chuvas no Brasil, indicados pelos respectivos retângulos envolventes (com labels pretos). No caso de estudos locais, são indicados pontos (com labels vermelhos) e a área fica limitada a $0 \mathrm{~km}^{2}$. 
A maioria dos trabalhos avaliados foi desenvolvida da região costeira, em locais que apresentaram os POCs mais elevados. Nesses locais o relevo apresenta propriedades mais complexas quando comparado ao restante do país e, além disso, a proximidade do oceano garante elevado suprimento de umidade, conferindo condições propícias e didáticas para a observação do efeito do relevo na pluviosidade. Os elevados POCs justificam a necessidade de estudos abundantes nessas áreas, mas alerta sobre determinados locais e períodos do ano para os quais não tem sido dada a mesma atenção. É o caso do período entre maio e outubro, quando o POC se eleva da costa ao interior do continente nas regiões sudeste e nordeste e, também é o caso do extremo norte do Brasil, onde a quantidade de estudos foi inferior de ao restante do país.

O estudo de NEGRI, ANAGNOSTOU e ADLER (2000) extrapola os limites nacionais, focando nas florestas tropicais úmidas das Américas com uso de imagens de satélite numa série temporal de 10 anos, no qual identificou-se que, de maio a setembro no extremo norte brasileiro, ocorre a máxima precipitação induzida pela topografia, no período da tarde, principalmente na Serra Pacaraima, próximo de $5^{\circ} \mathrm{N}$ e $63^{\circ} \mathrm{W}$. Destaca-se que os dados de POC (Figura 41) mostram o mesmo padrão, mais precisamente, indicam um POC+ no Monte Roraima e formações associadas. No restante da Bacia Amazônica Ocidental e Central, os autores identificaram que no período da manhã ocorrem eventos de precipitação máxima entre o rio Negro e Orinoco, possivelmente como resultado da circulação valemontanha. Embora os resultados não permitam análise em escala de horas, tal padrão também se revela nas escalas mensal e anual, sobretudo ao sugerir um forte $\mathrm{POC}+$ no Parque Nacional do Pico da Neblina e formações montanhosas associadas. Nesta área encontra-se o maior valor positivo de POC, tanto na escala anual quanto em distintos meses, embora numa pequena área.

Apesar de o relevo apresentar certa homogeneidade na região Norte do Brasil, a validação do POC não deve ser limitada à comparação com a escassa literatura obtida. Mais especificamente, destaca-se que o extremo norte do Brasil possui escarpas e planaltos de altitudes elevadas na fronteira com a Venezuela, onde ocorrem altos POC+ o ano todo, principalmente de dezembro a maio. Nessa região, os ventos mais fortes (Figura 29), provavelmente se devem a altitude entre 1.000 e 2.000 metros e às extensas áreas cobertas por baixa rugosidade de savanas, onde também ocorrem canalizações orográficas em alguns locais. Na Bacia Amazônica Ocidental e Central predominam os alísios de leste (Figura 29), 
bastante reduzidos pelo atrito e longa trajetória sobre florestas densas e pelos gradientes fracos de pressão associados às baixas pressões na região (AMARANTE, ZACK e SÁ, 2001). Esses ventos fracos associados ao terreno plano da região contribuem para os POCs próximos a zero, tanto na Bacia Amazônica Ocidental e Central como na oriental, onde predominam os alísios de leste-nordeste, ao norte, e leste-sudeste, ao sul e, onde a Depressão Equatorial permanece geralmente próxima. O pequeno e generalizado aumento nas velocidades de vento de oeste para leste, na região do Amapá (Figura 29 e Figura 30), são devido ao escoamento predominante de leste percorrer trajetórias gradualmente menores sobre as áreas de vegetação densa e o gradiente de pressão aumentar gradualmente para o leste, devido aos contrastes térmicos mais acentuados entre continente e mar. As máximas velocidades anuais de vento nessa região são encontradas nas porções nordeste e sudeste, onde existem elevações de terreno (Figura 29 e Figura 30) que aceleram os ventos pelo efeito de compressão vertical (AMARANTE, ZACK e SÁ, 2001).

Os demais estudos consultados apresentaram menor extensão geográfica (Figura 42), sendo classificados como estudos regionais ou locais, visto que geralmente não ultrapassam $10 \%$ do território brasileiro. Há casos cuja diminuta extensão, limitada a menos de $500 \mathrm{~km}^{2}$, não permite a delimitação de um polígono visível, sendo representados na forma de pontos (Figura 42). Destaca-se a inexistência de uma padronização na forma de apresentação dos resultados, na estrutura dos dados originais e nos métodos de análise. Por exemplo, os resultados são analisados em escalas temporais distintas, por vezes descrevendo eventos de precipitação orográfica em intervalos de dias ou horas, por vezes mensalmente ou por estações do ano. Há casos em que são utilizados dados de órgãos oficiais, contrastando com estudos que optam pela construção de uma rede ou uma transecção de pluviômetros estrategicamente posicionados. Também há grande heterogeneidade na forma de abordar os mecanismos formadores do tempo meteorológico, desde estudos de descrição da distribuição espacial da precipitação àqueles que relacionam o padrão pluviométrico aos sistemas atmosféricos atuantes, incluindo a identificação dos mecanismos orográficos formadores e intensificadores das chuvas e a microfísica associada. Também existem estudos centrados na modelagem, visando previsões. Porém nem todos os trabalhos utilizam o componente de vento associado ao relevo, sendo essa avaliação feita principalmente em estudos de modelagem. A maioria das publicações analisadas nesse trabalho foi desenvolvida para a porção leste do país, em vista da complexidade do relevo e da elevada umidade atmosférica, 
que caracterizam cenários mais propícios e didáticos para observar a ocorrência de chuvas orográficas. Esta afirmação por si só auxilia na validação do índice proposto, pois os valores de $P O C+$ mostram-se consideravelmente elevados na costa brasileira, sobretudo no litoral dos estados do nordeste. Observa-se um aumento do efeito do relevo (baixos POCs- e altos POCs+) em direção ao Ceará e Rio Grande do Norte, onde os ventos correspondem principalmente aos alísios de leste e brisas terrestres e marinhas. O aumento da velocidade do vento ocorre em direção ao leste à medida que se afastam da Depressão Equatorial, além de passarem por áreas com menores índices de vegetação e umidade do solo que acentuam o contraste de temperaturas terra-mar e as brisas marinhas resultantes. Apesar de ocorrerem áreas de ventos acentuados por bloqueios causados por montanhas na parte continental, o vento anual decresce rapidamente à medida que se desloca da costa para o interior, devido ao aumento de atrito e rugosidade de superfície e ao enfraquecimento das brisas marinhas (AMARANTE, ZACK e SÁ, 2001).

Assim, os valores elevados de $\mathrm{POC}+$ no litoral nordestino tem respaldo na bibliografia. Por exemplo, SILVA et al. (2006) identificaram que a influência combinada de diferentes sistemas atmosféricos e da topografia implicam em grande variabilidade espacial de precipitação no Ceará onde, nas maiores elevações, a Noroeste e Sudeste do estado, ocorrem os mais elevados totais de precipitação durante a estação chuvosa e onde, as altas elevações próximas à costa também estão associadas à elevada precipitação sazonal. Também apresenta dados importantes para a validação dos valores de POC, ao identificar que de novembro a janeiro, na região oeste e porções elevadas da região central do Rio Grande do Norte, é onde há maior ocorrência de chuvas orográficas no estado, sendo também identificadas chuvas orográficas a barlavento da Chapada da Borborema por convecção forçada. Adicionalmente, SILVEIRA (2012) identificaram que as características peculiares do relevo, na porção leste do nordeste brasileiro, resultam em diferenças nas configurações de formação de "complexos convectivos de mesoescala", causadores de grandes tempestades, onde a maioria dos casos possui trajetória ascendente às montanhas na fase de desenvolvimento dos sistemas e trajetórias descendentes na fase de dissipação.

No estado de Alagoas, LYRA, OLIVEIRA-JÚNIOR e ZERI (2014) identificaram que as brisas marinhas, intensificadas no período seco, atuam conjuntamente com os alísios e são canalizados da costa para o sudoeste resultando num transporte de umidade para o continente que, submetido a características orográficas, causam chuvas locais em algumas terras altas, 
inclusive na região semiárida. Identificaram também que a barlavento da Serra da Borborema ocorrem maiores valores de precipitação com a consequente redução desses valores nas regiões áridas devido ao seu efeito de barreira. PEREIRA (2013) concluiu que as maiores médias de precipitação no litoral norte de Alagoas estão localizadas a barlavento dos relevos mais altos, os quais são influenciados diretamente pela direção do vento, que no período seco, quando o efeito do relevo é maior, varia primeiramente de leste e, secundariamente de nordeste.

Na bacia do Riacho do Saco, no sertão central de Pernambuco, SOUZA, ALMEIDA e CORREA (2015), encontraram os maiores índices pluviométricos nas áreas de maior elevação e os menores índices próximos à depressão sertaneja. Porém a relação altitude-precipitação não responde linearmente, devido à topografia irregular da bacia e da ocorrência de diferentes mecanismos formadores de chuva. Este estudo, contudo, é de difícil utilização para fins de validação do indicador POC, dada a escala pontual do estudo frente ao fato de que a região em questão apresenta grande variação de POC, com valores positivos se avizinhando a valores negativos.

Na região sudeste do Brasil os POCs+ são mais baixos em comparação ao nordeste, porém, com maiores ocorrências em direção ao interior do continente. Da zona litorânea do nordeste ao sudeste, as velocidades médias anuais decrescem e permanecem baixas até a costa entre sul do Espírito Santo e nordeste do Rio de Janeiro, por volta de $21^{\circ} \mathrm{S}$ e $41^{\circ} \mathrm{W}$, onde as velocidades aumentam pelo efeito de bloqueio do escoamento leste-nordeste pelas montanhas imediatamente a oeste da costa, causando uma espécie de aceleração por obstáculo. Ao sul dessa região, a costa do Estado do Rio de Janeiro desvia-se para oeste e os ventos passam a ser consideravelmente mais fracos devido ao abrigo das montanhas a norte e a nordeste (AMARANTE, ZACK e SÁ, 2001).

Da costa nordeste-sudeste para o interior do continente os ventos anuais mais intensos são geralmente encontrados nas maiores elevações, onde as maiores velocidades ocorrem em forma localizada, primariamente devido ao efeito de compressão vertical do escoamento predominante em larga escala, que é leste-nordeste, quando ultrapassa a barreira elevada das serras (AMARANTE, ZACK e SÁ, 2001). Alguns desses locais foram considerados nos trabalhos verificados e inclui o trabalho de MELO JÚNIOR et al. (2005) que enfatizam processos orográficos nas serras da Mantiqueira, do Espinhaço, do Gavião e Caparaó e de ÁVILA, DE MELLO e VIOLA (2009) na Serra da Canastra. No presente trabalho nota-se 
maiores POCs a leste e menores valores a oeste de algumas áreas isoladas como a Serra da Canastra e Serra da Mantiqueira. Assim, apesar da dificuldade em comparações decorrentes de grande diferença em escalas geográficas de análise, os resultados de MELO JÚNIOR et al. (2005) e ÁVILA, DE MELLO e VIOLA (2009) também parecem contribuir na validação do indicador. Além de que, o escoamento atmosférico é bastante complexo nessa região, existindo outras características locais com influência adicional, resultantes de uma combinação de fatores relacionados à topografia e ao terreno (AMARANTE, ZACK e SÁ, 2001).

Da mesma forma que ocorre para o litoral do nordeste brasileiro, os estudos que contextualizam a costa das regiões sudeste e sul, onde concentram-se a maioria das pesquisas, os padrões corroboram valores de POC. Contudo, o caráter extremamente localizado das iniciativas dificulta as comparações em recorrência da grande divergência das escalas geográficas. Assim, a validação não se dá exatamente pela correlação espacial entre os dois grupos de dados, POC e revisão bibliográfica. É necessária uma breve discussão do contexto institucional das pesquisas. Por exemplo a Universidade de São Paulo (USP) e o Instituto Nacional de Pesquisas Espaciais (INPE) são duas instituições muito presentes nos estudos avaliados. Destacam-se dois fenômenos básicos: a intensificação de estudos no litoral paulista, e a colaboração destas instituições nos estudos nordestinos via coautoria. Ao mesmo tempo não se constatam estudos vinculados a estas instituições em grande parte do planalto central, mesmo nas proximidades das instituições (ou na região interiorana do estado de São Paulo). Isso denota um menor interesse em estudos sobre precipitação orográfica onde estes são fracos ou não observáveis, basicamente onde encontramos os menores valores de POC. Assim, o grande esforço de pesquisa se dá nas regiões litorâneas paulistas e fluminenses, onde encontramos maiores valores de POC. Por exemplo, MILANESI e GALVANI (2011) afirmam que a orientação do relevo em Ilhabela é mais determinante da quantidade de chuva, do que pela altitude, pois as vertentes a barlavento, úmidas devido aos alísios de sudeste e as brisas marinhas, recebem $20 \%$ a mais de chuvas em relação ao sotavento em qualquer época do ano, apesar da diferença entre as vertentes ser maior no outono, seguido pelo verão, primavera e inverno. Com o aumento da elevação, é observado uma redução no número de eventos de chuva e o aumento da quantidade precipitada e, devido ao efeito de barreira exercido pela ilha, a quantidade precipitada no continente é menor. 
GOMES (2015) também identificou o efeito de sombra de chuva exercido pelo relevo de Ilhabela sobre a zona sul do município de Ubatuba-SP e a importância do efeito orográfico nos maiores totais pluviométricos próximos das encostas da serra do mar, cujas perturbações frontais foram as principais responsáveis pelos totais elevados de precipitação. Conclusões análogas também são encontradas por PELLEGATTI e GALVANI (2010).

BLANCO e MASSAMBANI (1998) avaliaram um evento de chuva forte na Serra do Mar, na Baixada Santista, e identificaram que nos dias após a passagem de uma frente, o máximo de precipitação ocorreu no topo da Serra, seguido pela encosta, litoral e finalmente pelo planalto, com predomínio de ventos perpendiculares à costa, apontando para um fenômeno de intensificação orográfica da precipitação. Também, na porção leste-nordeste de São Paulo, CONTI (1974) avaliou um evento de chuva tipicamente frontal, e identificou que o relevo foi importante como elemento regulador da distribuição regional das chuvas, concluindo que em áreas acidentadas, a quantidade de chuva não depende exclusivamente da posição altimétrica, mas de uma combinação desta com a exposição das vertentes aos fluxos transportadores de umidade.

No setor serrano de Cubatão e Baixada Santista, NUNES (1992) identificou que a altimetria, embora importante, não responde sozinha pela quantidade de chuva mais expressiva, pois um dos postos localizado nas cotas mais altas apresentou os totais mais modestos de chuva por localizar-se no reverso da serra.

No sul do Rio de Janeiro, SOARES, FRANCISCO e SENNA (2014) identificaram que a distância do litoral e a altitude apresentaram fortes correlações com a precipitação anual, sazonal e mensal. A barlavento da Serra do Mar, devido às frentes frias serem barradas pelo relevo, ocorre os valores máximos de precipitação, enquanto que nas vertentes a sotavento ocorrem os menores valores. O planalto, localizado no reverso da Serra do Mar e com altitudes superiores a $1.000 \mathrm{~m}$, também apresenta índices pluviométricos mais modestos, devido ao ar que ali chega já ter perdido grande parte da sua umidade. LIMA e FERNÁNDEZ (2011) também tornam claro os efeitos da temperatura do oceano e do relevo em Angra dos Reis (RJ) e em Ibiraçu (ES).

No litoral sul do Brasil, também são destacados fenômenos orográficos por RODRIGUES (2015), em Santa Catarina, e por HAAS (2002) que realizou simulações de um evento de chuva orográfica prolongada, e identificou que um aumento de resolução de 40 para $10 \mathrm{~km}$ resulta em um maior detalhamento da estrutura espacial da precipitação no litoral sul 
do país, aumentando a intensidade dos máximos de precipitação e as áreas sem precipitação, em acordo com os padrões observados, mostrando que a previsão quantitativa de chuva necessita de tamanhos de grade ainda menores que $10 \mathrm{~km}$.

Por meio de modelagem, NERY JUNIOR e VANZELA (2015) identificaram forte influência do relevo na distribuição das chuvas em Caraguatatuba SP, onde há o incremento de $1 \mathrm{~mm}$ de chuva para cada $1,30 \mathrm{~m}$ de incremento na altitude e que, esse efeito orográfico é maior no período de novembro a abril. Nas simulações de SELUCHI, CHOU e GRAMANI (2011) para um evento atípico de chuva forte de inverno, na serra do Mar, na costa de São Paulo, a condição sinótica gerou ventos quase perpendiculares às montanhas, aumentando a quantidade de chuvas causadas por efeitos orográficos, raros nessa época do ano. Em torno das latitudes $30^{\circ} \mathrm{S}$ a $20^{\circ} \mathrm{S}$ a serra gerou movimentos ascendentes ao longo da costa e movimentos descendentes a sotavento, resultando num grande contraste na quantidade de precipitação acumulada. Também utilizando simulações, KRUK et al. (2006) identificaram uma maior quantidade de precipitação a barlavento, tanto na serra do mar quanto na Serra da Mantiqueira, na Bacia do Rio Grande de Ubatuba, em São Paulo.

No geral, observa-se que as encostas da Serra do Mar apresentam altos índices pluviométricos promovidos por efeito orográfico, seguidos pela Serra da Mantiqueiras, conforme demonstrado por ANDRÉ et al. (2008) e OLIVEIRA e GALVANI (2015). A Serra da Mantiqueira também foi abordada por CARVALHO, JONES e LIEBMANN (2002) que demonstraram uma diminuição das chuvas da costa em direção ao vale do Paraná. Esta transição, indicando processos orográficos de formação/intensificação de chuvas e efeitos de sombra de chuva também foi abordada por CÂNDIDO e NUNES (2008), que mostraram que a maior amplitude nos totais pluviométricos ocorreu nos locais de relevo mais irregular.

As áreas não litorâneas e as transições litoral-interior, também são abordadas em diferentes estudos no estado do Paraná, tanto na bacia do Piquiri (CORREA (2013) quanto na Serra do Cadeado (CORREA (2013) e no Rio Grande do Sul (FORGIARINI e VENDRUSCOLO (2013), onde quando o movimento da massa de ar é na direção sudoestenordeste ocorre maior pluviosidade a barlavento, devido ao choque da massa de ar polar com as formações montanhosas. Quanto o movimento da massa de ar é na direção noroestesudeste, invertem-se as posições barlavento e sotavento, e ocorre o contrário. Ou seja, em qualquer época do ano a vertente a barlavento é a mais úmida, porém, no inverno e outono o efeito da orografia é maior, pois os eventos de chuva são decorrentes de chuvas frontais, que 
são eventos de longa duração, intensificando ainda mais as chuvas. Também no Rio Grande do Sul, BARATTO e WOLLMANN (2015) estudaram a influência orográfica na distribuição espacial da precipitação por meio de transectos norte-sul e oeste-nordeste e concluíram que ocorre efeito orográfico nas chuvas pela alta correlação entre a precipitação e a altimetria. Porém, as duas estações localizadas em maiores altitudes não apresentaram uma correlação significativamente maior que as demais.

Destaca-se, contudo que nos meses de outubro e novembro é quando a região sul do país apresenta os maiores valores de POCs, enquanto que os valores mais baixos ocorrem de junho a agosto. Segundo AMARANTE, ZACK e SÁ (2001), nos Planaltos do Sul o escoamento atmosférico geral é controlado pela Depressão do Nordeste da Argentina, uma área quase permanente de baixas pressões, geralmente estacionária ao leste dos Andes e o Anticiclone Subtropical Atlântico. O gradiente de pressão entre esses sistemas induz um escoamento persistente de nordeste ao longo dessa área, o qual é significativamente influenciado pelo relevo e pela rugosidade do terreno. Ao longo do litoral sul, os ventos predominantes leste-nordeste são acentuados pela persistente ação diurna das brisas marinhas.

Os dados gerados fornecem uma visão geral do potencial de o relevo brasileiro influenciar as chuvas, permitindo identificar onde e quando essa influência é maior (POC+ $e$ POC-) e menor (nulo) e que, pela observação das partes permite identificar os padrões de POCs dentro de áreas de interesse, como regiões hidrográficas, estados e biomas, por exemplo.

Os resultados mostraram um fenômeno espaço-temporal que expressa a maior heterogeneidade espacial do POC quando comparada a temporal, pois os meses não diferem entre si tanto quanto as distinções espaciais encontradas dentro do território brasileiro.

Confrontar um modelo (POC) às publicações científicas produziu um resultado sinérgico de duplo sentido. Por um lado, os resultados dos estudos validaram o modelo (locais destacados na bibliografia pela forte influência no aumento ou na inibição de chuvas apresentam maiores e menores POCs, respectivamente). Por outro lado, o modelo mostra que os diferentes estudos foram direcionados para áreas onde as pesquisas sobre o tema são mais didáticas para o estudo do fenômeno (locais com maiores POCs são preferidos nos estudos). No processo de confronto com a bibliografia, quando houve compatibilidade de escalas, a congruência é notória. Quando os trabalhos usaram escalas mais detalhadas, a ponto de não 
ser possível observar o mesmo padrão, nota-se que o local de estudo está num contexto típico de maior potencial para ocorrência de chuvas orográficas.

\subsubsection{Calibração do Potencial Orográfico para Chuvas (POC) pelo Índice de Proporção de Escalas (IPE)}

Embora validado com base na literatura, o POC não pode ser calibrado com as mesmas bases, visto que a calibração remete a uma análise maia aprofundada, que inclui o pareamento exato dos dados e o emprego de ao menos uma estatística que mostre o grau de aderência entre os POC e dados pluviométricos, ao mesmo tempo em que tal aderência tenha um respaldo dos mecanismos meteorológicos e padrões climáticos conhecidos e plausíveis, ou seja, relação de causa-efeito. Para tanto, é necessária a sua comparação com dados pluviométricos adequados e dispostos na mesma grade, visando o emparelhamento. Para tal fim, o IPE, em escala 3tx3e se mostra adequado. No item 5.3.2 é feita uma breve análise que remete a um baixo valor de IPE nas condições (locais e ocasiões) em que tem-se a atuação de sistemas orográficos de chuva, mas não exclusivamente a esta. Se o POC é capaz de demonstrar onde o efeito do espaço é maior, então se espera que POC+ e POC- ocorram associados a baixos IPEs, enquanto que, os altos IPEs ocorram onde o POC é próximo a zero. Numa breve revisita ao Modelo Digital de Elevação do Brasil (Figura 4) revela-se, mesmo numa análise puramente visual, que um arco de 1 grau de latitude ou longitude (correspondente a 60 milhas náuticas, ou 111,12 km sobre a Linha do Equador), representa uma granulometria que aloja eficazmente grande parte das variações altimétricas, notoriamente coincidindo e abrigando as feições topográficas utilizadas em grande parte das publicações utilizadas na validação do POC (Figura 42), de forma que a resolução original dos dados (1 x 1 grau de lat/long) foi considerada adequada para a calibração do POC com auxílio do IPE.

Assim, foram efetuadas correlações entre o POC- e IPE e entre POC+ e IPE, baseadas no coeficiente de correlação de Pearson. Enquanto o $R$ de Pearson é um indicador da aderência de ambas as variáveis, seguindo um modelo linear, o $R^{2}$ é uma medida da proporção da variabilidade em uma variável que é explicada pela variabilidade da outra, desde que assumida a relação de dependência. Ou seja, o $R^{2}$ mede em que proporções (percentual, se 
multiplicado por 100) a variável dependente (IPE) é explicada pela variável independente (POC).

Para os dados em escala anual para todo o Brasil, o coeficiente de determinação da correlação entre IPE e POC- foi 0.05 (5\%) e entre IPE e POC+ é de 0.14 (14\%), indicando que $5 \%$ da variabilidade do IPE é explicada pela variabilidade do POC- e que $14 \%$ da variabilidade do IPE é explicada pela variabilidade do POC+. Ou seja, os processos formadores de chuva explicam mais os valores de IPE que o efeito de sombra de chuva. A Figura 43 discrimina os valores de determinação do modelo para distintos meses do ano e, da mesma forma de análise em resolução anual, mostra que as correlações para POC+ são maiores que para POC-, ou seja, que o POC se mostra mais eficaz para indicar formação de chuva que sombra de chuvas. Os meses de abril a novembro, ou seja, aqueles que destoam do verão austral são os que mostram maiores valores de $\mathrm{R}^{2}$ para a formação de chuvas orográficas, atingindo mais de $15 \%$ de explicação do IPE. Em junho é explicado mais de $25 \%$ da variabilidade espaço-temporal do efeito orográfico, e em maio e setembro, explica-se mais de 20\%. Para sombras de chuva (POC-), os meses de inverno austral também são os mais importantes (Figura 43).

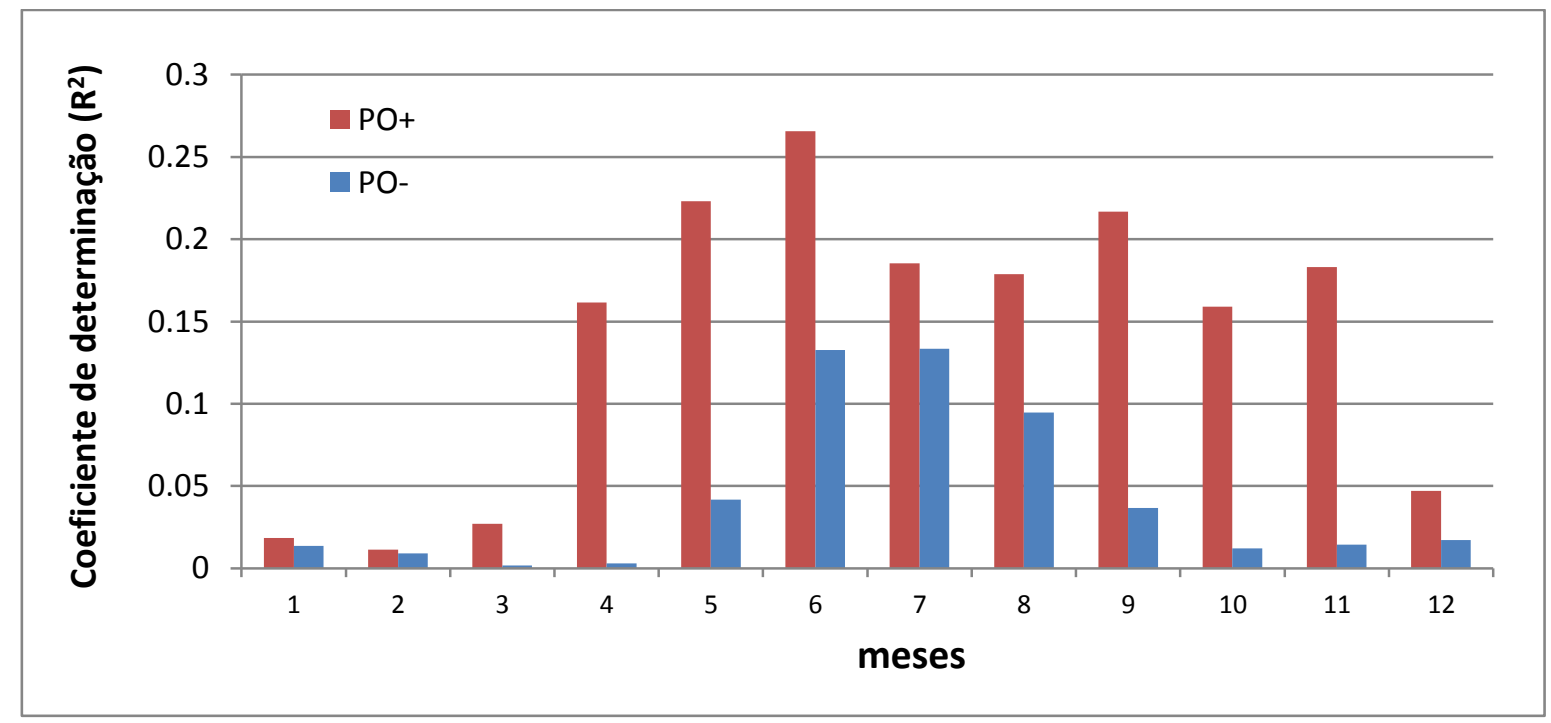

Figura 43: Coeficientes de determinação $\left(\mathrm{R}^{2}\right)$ para o modelo linear de correlação entre IPE e POC para a escala de $3 \mathrm{M}$ e $3 \mathrm{Q}$, para os distintos meses do ano. 
O resíduo da correlação entre POC e IPE permite identificar onde o modelo subestimou ou superestimou a influência do espaço e do tempo nas chuvas (Figura 44 e Figura 45). Quanto mais positivo for o resíduo (IPE real é maior que o modelado), mais o modelo superestima a importância do espaço, subestimando a real importância do tempo naquele quadrante. Quanto mais negativo for o resíduo (IPE real é menor que o modelado), mais o modelo superestima a importância do tempo subestimando a real importância do espaço.

Ou seja, para os locais com maior influência temporal na distribuição das chuvas, o modelo atribui maior importância ao espaço e para os locais com maior influência espacial o modelo atribui maior importância ao tempo. Assim, ao observar os mapas temáticos (Figura 43), os locais com os resíduos mais baixos possuem, na verdade, uma influência espacial um pouco menor, enquanto que os locais de maior resíduo possuem, na verdade, uma influência espacial um pouco maior.

Assim, o POC proposto aqui é um modelo que explica relativamente bem os efeitos orográficos, mas não na sua totalidade. A calibração proposta foi realizada por um modelo linear, mas há indícios suficientes para a proposição de modelos lineares melhorados, porém regionalizados para áreas mais propensas a esses efeitos (ex. Serra do Mar, Monte Roraima, etc), ou pela adoção de modelos não lineares, o que exigiria uma justificativa mais aprofundada. 


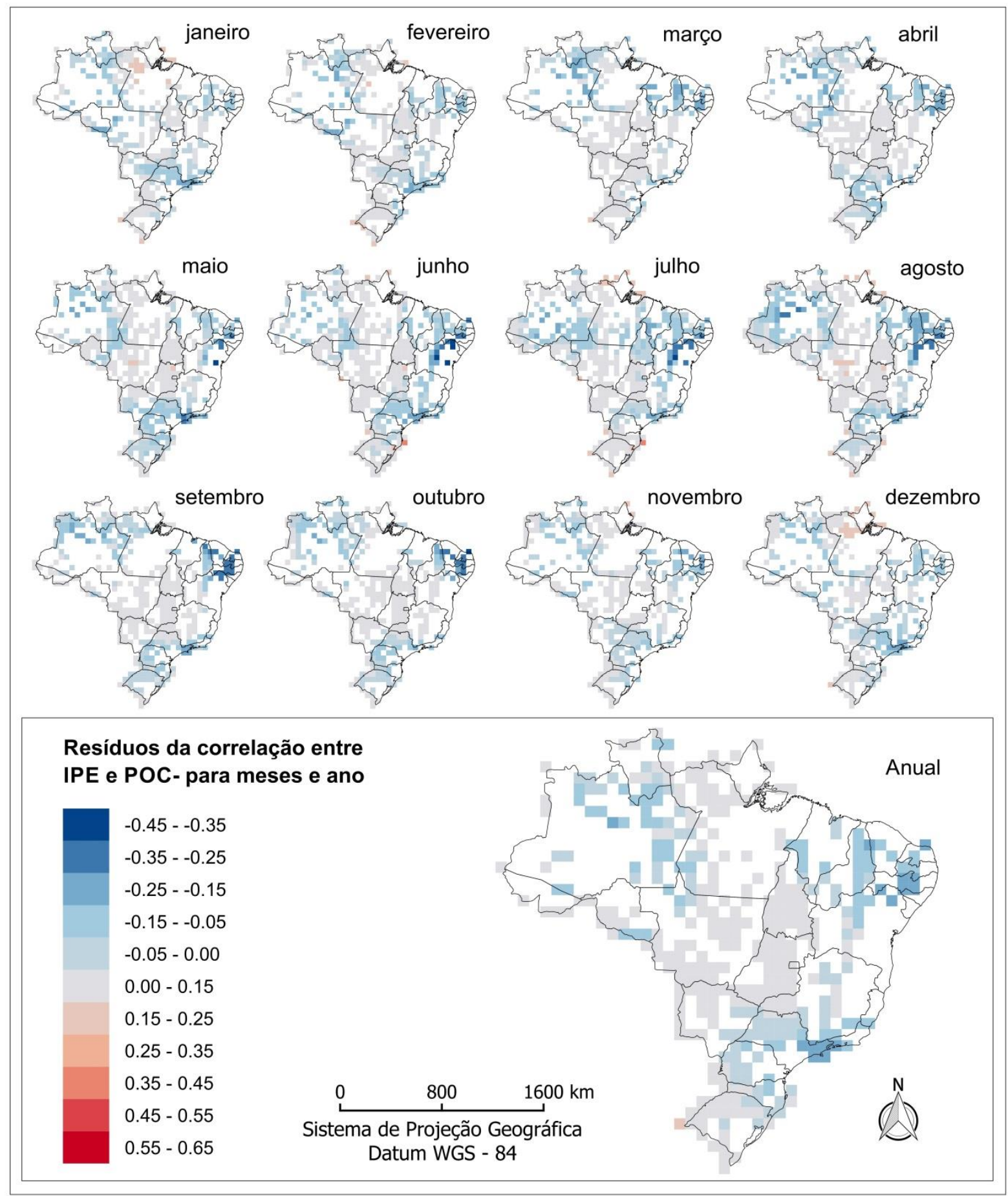

Figura 44: Resíduos mensais e anual da correlação entre IPE e POC+ (formação de chuvas orográficas). 


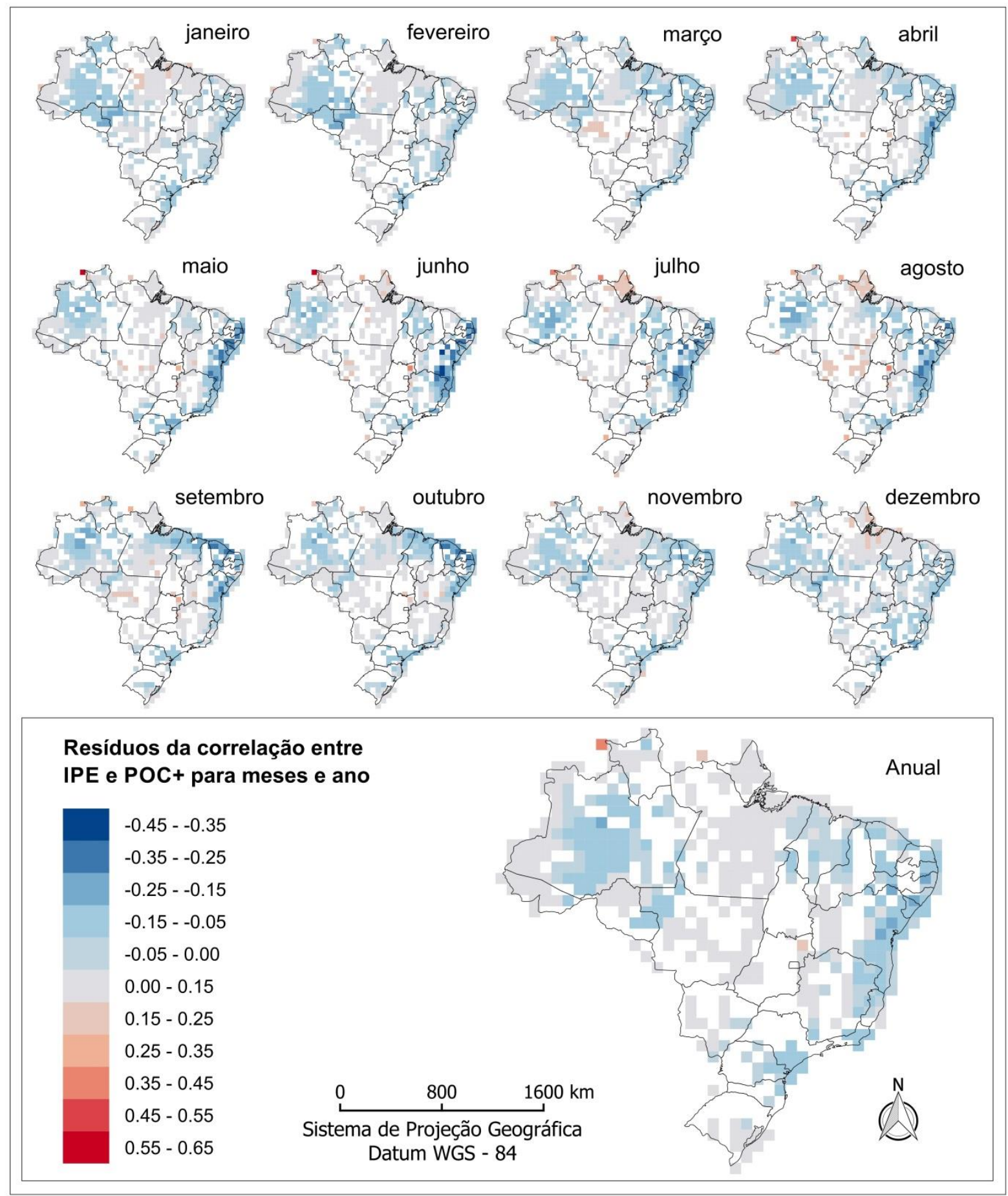

Figura 45: Resíduos mensais e anual da correlação entre IPE e POC- (formação de sombra de chuvas). 


\subsection{Apontamentos e reflexões acerca das possibilidades de aplicações futuras}

O IPE não se propõe a ser um indicador absoluto, ou mesmo inferencial, em termos estatísticos, sendo sua interpretação baseada nas variações dos valores dentro de um contexto de observações vizinhas no espaço e no tempo. À rigor, constitui um índice com potencial para a explicação dos efeitos dos sistemas de tempo meteorológico sobre a variabilidade espaço-temporal das chuvas (numa perspectiva mais meteorológica), ou mesmo a pura descrição da espacialidade das forçantes que o compõem (numa perspectiva da climatologia geográfica), como feito no item anterior. Contudo, uma análise mais cuidadosa permite evidenciar aplicações distintas para o IPE. Destacamos aqui duas aplicações, uma relacionada ao planejamento de redes de postos pluviométricos, e outra voltada à análise dos efeitos adversos, no espaço e no tempo, de mudanças, variabilidade e oscilações climáticas.

\subsubsection{Contribuições para o planejamento da rede de estações pluviométricas}

Devido a precipitação ser um parâmetro extremamente variável no espaço e no tempo, o nível de exatidão, confiabilidade e aplicabilidade dos estudos é altamente dependente da densidade e da distribuição dos pluviômetros sobre uma região (ANDERS et al., 2006; CHENG, LIN e LIOU, 2008; VILLARINI et al., 2008; MISHRA, 2013; JUNG et al., 2014). Ao considerar que a representatividade espacial de uma estação meteorológica varia de acordo com a complexidade espacial, uma estação localizada em um ambiente mais homogêneo pode ser mais representativa das condições de tempo numa grande extensão desse, enquanto que uma estação localizada em um ambiente mais heterogênea pode representar as condições de tempo apenas numa pequena extensão.

Nesses termos, o IPE poderia integrar um método para a indicação do adensamento de estações meteorológica no espaço. Enquanto baixos valores de IPE indicam a necessidade de um grande adensamento de estações, altos IPEs indicam a necessidade de um adensamento relativamente menor, porém, onde a ocorrência de falhas nas séries temporais seria mais comprometedora (Figura 46). 


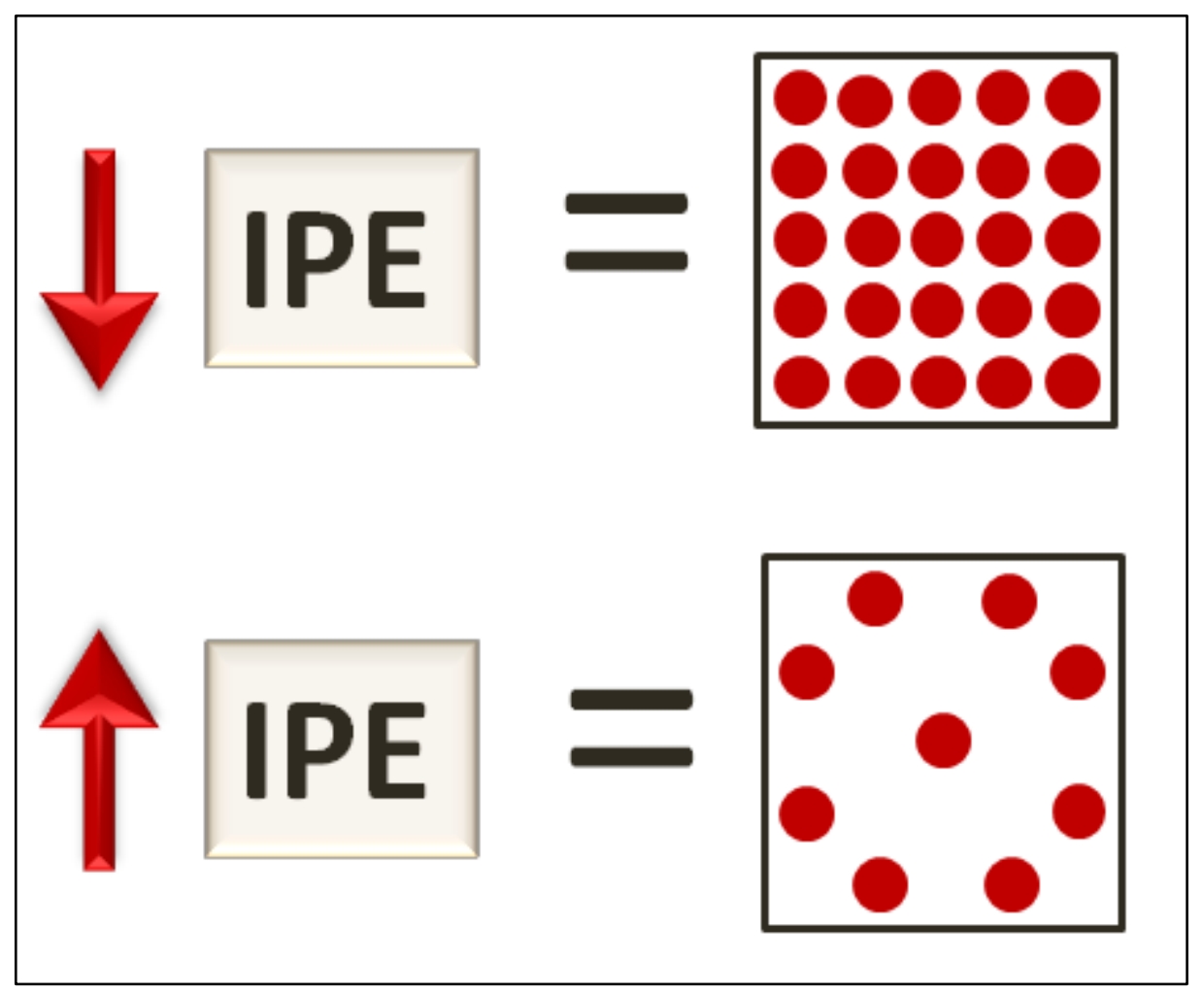

Figura 46: Representação da necessidade de adensamento de estações meteorológicas em função de altos e baixos valores de IPE.

Muitos estudos propuseram avaliar o desing de redes pluviométricas em termos de densidade para entender melhor as suas implicações na modelagem hidrológica. Na China, XU et al. (2013) avaliaram o desempenho de um modelo, sendo que os erros dos índices de precipitação e do escoamento simulado diminuiu progressivamente com o aumento do número de pluviômetros até um limite, para além do qual o desempenho do modelo não mostrou melhorias consideráveis. Na França, ANCTIL et al. (2006) mostraram que o desempenho de modelos hidrológicos diminuiu rapidamente quando a precipitação média foi calculada usando um número de pluviômetros inferior a um determinado limiar, enquanto que algumas combinações de pluviômetros proporcionam melhores previsões do que quando todos os pluviômetros disponíveis foram usados para estimar a precipitação média. Em Taiwan, CHENG, LIN e LIOU (2008) avaliaram, por meio de geoestatística, diferentes configurações de redes de pluviômetros indicando para a rede existente, aqueles que não apresentavam contribuições, os quais poderiam ser removidos ou realocados. No Texas, VIEUX e VIEUX (2005) utilizando conjuntamente dados de radar mostraram diferentes efeitos no escoamento de águas superficiais em relação ao adensamento de pluviômetros, 
concluindo que são necessários menos pluviômetros do que a rede atual apresenta para atingir um dado nível de precisão. GIRONS LOPEZ et al. (2015) avaliaram o efeito da configuração de rede de pluviômetros na interpolação espacial numa bacia hidrográfica no nordeste da Suíça e constataram que a interpolação apresenta menores erros quando usada uma determinada quantidade de pluviômetros para uma determinada área, além dos quais, as melhorias foram insignificantes.

Frequentemente faz-se referência ao adensamento espacial e pouco se versa sobre o adensamento temporal das medidas. Ora, da mesma forma com que a manutenção de um regime de coleta de dados no espaço visa encontrar uma representatividade espacial para o fenômeno, o investimento em manter um adensamento temporal de medidas advém da necessidade da representatividade temporal do mesmo fenômeno. É aqui que nota-se a importância do IPE. Não se trata de utilizar o IPE para calcular um determinado valor de adensamento de coletas no espaço-tempo, visto que o adensamento espacial já é assunto bem abordado, conforme sinalizado na revisão aqui feita, e o adensamento temporal é estruturado com frequências diárias ou horárias (ou superior) e, atualmente, em regime contínuo, automático, autônomo e com distribuição de dados em tempo real. Desta forma, a aplicação do IPE seria mais relacionada a ajustes no desenho espacial de uma rede e na decisão sobre níveis toleráveis na perda de dados, conforme descrito no cenário abaixo:

- Seja uma ampla região de interesse estabelecida, para a qual se planeje um determinado número de pluviômetros (estabelecido por estudos específicos ou por restrições técnicas ou orçamentárias), portanto, com densidade média $D_{\text {media }}$ prevista, sendo também identificados valores mínimo e máximo de tolerância para o adensamento $\left(D_{\min }\right.$ e $\left.D_{\max }\right)$;

- Seja o regime de coleta previsto para numa frequência temporal $f$;

- Sejam os valores de IPE previamente conhecidos para a região, incluindo média $\left(I P E_{\text {médio }}\right)$, valores mínimo $\left(I P E_{\text {min }}\right)$ e máximo $\left(I P E_{\text {max }}\right)$;

Tal cenário poderia ser implementado por meio de um modelo inicial conforme a Figura 47, onde um sistema linear interpolaria todo o domínio numérico das abcissas e ordenadas. Assim: 
- Atribui-se uma densidade $D_{\text {media }}$ para as sub-regiões que possuam o valor de $I P E_{\text {médio}}$;

- Atribui-se uma densidade $D_{\min }$ para as sub-regiões que possuem o valor de $I P E_{\max }$;

- Atribui-se uma densidade $D_{\max }$ para as sub-regiões que possuem o valor de $I P E_{\min }$.

Dessa forma, o planejamento deixa de ser executado exclusivamente em escala (extensão) regional e ganha um aspecto locacional suplementar, onde um local com menor IPE teria um maior adensamento de estações e vice-versa. Assim, seja um usuário que arbitre valores mínimos e máximos de IPE e valores mínimos e máximos possíveis ou desejáveis para a densidade de uma rede meteorológica (estações $/ \mathrm{km}^{2}$ ), a Figura 47 traz a representação algébrica a ser utilizada (Equação 18).

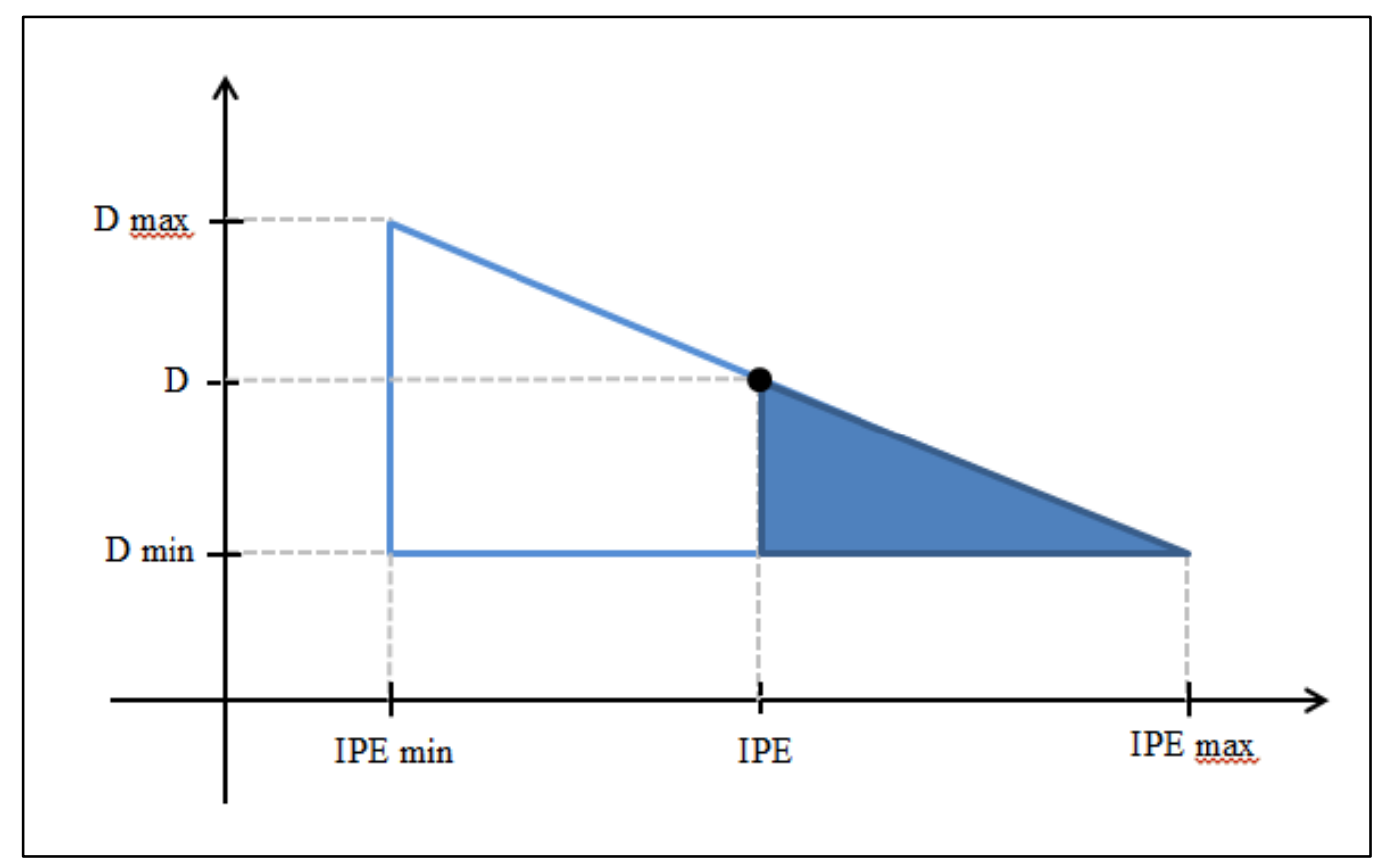

Figura 47: Representação gráfica simplificada de um modelo linear para cálculo do adensamento de estações pluviométricas em um local participante de uma rede regional de estações meteorológicas, dado um valor local de IPE e com base no conhecimento prévio de valores mínimos, máximos e médios da densidade planejada de estações e do IPE. 


$$
D_{(t, e)}=\operatorname{Dmin}_{(t, e)}+\frac{\left(\operatorname{Dmax}_{(t, e)}-\operatorname{Dmin}_{(t, e)}\right) \times\left(\operatorname{IPEmax}_{(t, e)}-I P E_{(t, e)}\right)}{\left(\operatorname{IPEmax}_{(t, e)}-\operatorname{IPEmin}_{(t, e)}\right)}
$$

Equação 19

Onde: $D_{(t, e)}$ : densidade local da rede meteorológica

$\operatorname{Dmin}_{(t, e)}$ : densidade da rede meteorológica mínima desejada

$\operatorname{Dmax}_{(t, e)}$ : densidade da rede meteorológica máxima desejada

$\operatorname{IPEmin}_{(t, e)}$ : valor mínimo de IPE conhecido

$\operatorname{IPEmax}_{(t, e)}$ : valor máximo de IPE conhecido

$I P E_{(t, e)}:$ valor de IPE em local

\section{CONCLUSÃO}

O presente trabalho deu consistência, na medida do possível, a uma extensa série histórica de registros pluviométricos do Brasil, em resolução capaz de expressar identidades regionalizadas, garantindo análises sistemáticas, estrutura multiescalar, passíveis de comparação entre as entidades espaço-temporais, e interação entre diferentes atributos geográficos. Isso foi auxiliado pela existência de softwares livres e dados públicos, compostos por registros, em número superior a 100 milhões de dados diários de chuvas e 20 milhões de dados horários de vento.

A abordagem proposta nesse trabalho possui um caráter nomotético e ideográfico, ao permitir e incentivar análises de amostras relativamente grandes, de caráter genérico, visando o aperfeiçoamento da análise regional, e análises singulares, levando a um conhecimento profundo de terminado local, como sugerido para a disciplina geográfica (MORAES, 1983).

Os resultados obtidos demandaram de um suporte técnico e conceitual, sem os quais, essa abordagem seria inviável, visto o grande volume de dados, os milhares de processamentos executados graças à automação, à necessidade constante de auditorias no banco de dados, além da suscetibilidade a erros, caso fosse executada manualmente. 
Neste contexto, a ciência geográfica necessita aprimoramento de técnicas e conhecimentos de outras áreas que lhe garantam habilidades para explorar os fenômenos geográficos, como já foi destacado por SANT'ANNA NETO (2001), sobre a necessidade de aprimoramento do instrumental geográfico de releitura do fenômeno climático.

Notou-se que a consistência dos dados pluviométricos para fins de análises climatológicas tem uma representação espacial característica, com regiões com consistência a partir da década de 1930, e outras com consistência somente a partir de 1975, como é o caso da região Amazônica. Nesta janela temporal mais restrita (1975 a 2010), pode-se avaliar a abordagem metodológica proposta, seja pela possibilidade de analisar sistemas de tempo diversos, mas, sobretudo, os processos orográficos, seja por identificar sistematicamente mudanças ou oscilações climáticas, em particular com base em tendências.

O trabalho também apontou outras aplicações possíveis, o que remete à estruturação de um programa contínuo de análise de dados meteorológicos estruturados em malhas regulares, a exemplo da aqui empregada, mas que está além dos propósitos desta tese.

Neste sentido, a abordagem aqui proposta demanda certos cuidados no que se refere à aplicação, a exemplo dos aqui tomados. Em primeiro lugar, porque as escalas de tempo (mês) e espaço ( $1^{\circ}$ de arco de latitude/longitude) correspondem a unidades e conceitos diferentes, segundo porque são arbitradas por conveniência do usuário, terceiro porque os meses possuem quantidades de dias diferentes e, quarto, porque o tamanho do quadrante varia com a latitude (um arco de latitude no equador corresponde a uma unidade métrica maior que em outras latitudes). 


\section{REFERÊNCIAS}

AMARANTE, O. A. C.; ZACK, M. B. E. J.; SÁ, A. L. Atlas do Potencial Eólico Brasileiro. p. 45, 2001.

ANA. Agência Nacional de Águas. Disponibilidade e demandas de recursos hídricos no Brasil. Cadernos de Recursos Hídricos, p. 124, 2005.

Agência Nacional de Águas. Orientações para consistência de dados pluviométricos. Superintendência de Gestão da Rede Hidrometeorológica, Brasília, p. 21, 2012.

ANCTIL, F. et al. . Improvement of rainfall-runoff forecasts through mean areal rainfall optimization. Journal of Hydrology, v. 328, n. 3-4, p. 717-725, 2006.

ANDERS, A. M. et al. . Spatial patterns of precipitation and topography in the Himalaya. Geological Society of America, v. 398, p. 39-53, 2006.

ANDRÉ, R. G. B. et al. . Identificação de regiões pluviometricamente homogêneas no estado do Rio de Janeiro utilizando-se valores mensais. Revista Brasileira de Meteorologia, v. 23, n. 4, p. $501-509,2008$.

ARTAXO, P. et al. . Química atmosférica na Amazônia: a floresta e as emissões de quimadas controlando a composição da atmosfera amazônica. Acta Amazonica, v. 35, n. 2, p. 185-196, 2005.

AUSTIN, G. L.; DIRKS, K. N. Topographic Effects on Precipitation. In: ANDERSON, M. G. (Ed.). Encyclopedia of Hydrological Sciences: John Wiley \& Sons, 2005. p.1-7.

ÁVILA, L. F.; DE MELLO, C. R.; VIOLA, M. R. Mapeamento da precipitação mpinima provável para o sul de Minas Gerais. Revista Brasileira de Engenharia Agrícola e Ambiental, v. 13, p. 906-915, 2009.

AYOADE, J. O. Introdução a Climatologia para os Trópicos. $\mathbf{1 6}^{\mathbf{0}}$ ed. Rio de Janeiro: Bertrand, p. 350, 2012.

BACK, A. J. Aplicação de análise estatística para identificação de tendências climáticas. Pesquisa agropecuaria Brasileira, v. 36, n. 5, p. 717-726, 2001.

BARATTO, J.; WOLLMANN, C. A. Perfil topo-oro-pluviométrico do estado do Rio Grande do Sul, Brasil. Interface, v. 10, p. 40-55, 2015.

BARBOSA, R. L. Interação das Perturbações Convectivas Iniciadas na Costa Norte do Brasil com os Distúrbios Ondulatórios de Leste. Dissertação de mestrado. Instituto Nacional de Pesquisas Espaciais, 2005. 
BARGAOUI, Z. K.; CHEBBI, A. Comparison of two kriging interpolation methods applied to spatiotemporal rainfall. Journal of Hydrology, v. 365, n. 1-2, p. 56-73, 2009.

BARROS, A. P.; LETTENMAIER, D. P. Dynamic modeling of orographically induced precipitation. Reviews of Geophysics, v. 32, n. 3, p. 265-284, 1994.

BARRY, R. G.; CHORLEY, A. R. J. Atmosphere, weather, and climate. New York, v. Routledge, n. 9 ed, 2010.

BERBERY, E. H.; COLLINI, E. A. Springtime Precipitation and Water Vapor Flux over Southeastern South America. Monthly Weather Review, v. 128, p. 1328-1345, 2000.

BERNARDO, S. O.; MOLION, L. C. B. Variabilidade espacial e temporal da precipitação sobre a América do Sul Tropical e costa oeste do continente Africano Anais XIII, Congresso Brasileiro de Meteorologia, Fortaleza (CE), 2004.

BERTONI, J. C.; TUCCI, C. E. M. Precipitação. In: TUCCI, C. E. M. Hidrologia: ciência e aplicação. $2^{\circ}$ ed. Porto Alegre: Editora UFRGS, p. 9432001.

BERTRAND, G. Paisagem e geografia física global: esboço metodológico. . RA'E GA - O Espaço Geográfico em Análise, v. 8, p. 141-152, 2004.

BETTS, A. K. et al. . The Amazonian boundary layer and mesoscale circulations. v. 186, p. 163-181, 2009.

BLANCO, C. M. R.; MASSAMBANI, O. Intensificacao orografica e sua relacao com escorregamentos de encostas - o caso de janeiro de 1998. VIII Congresso da Federação Latinoamericana e Ibérica de Meteorologia, 1998.

BRASIL, M., SE. Mapa das isoietas médias anuais do Brasil: série histórica de 1931 a 1988. Brasília, 1993.

BUISHAND, T. A. Some Methods for Testing the Homogeneity of Rainfall Records. Journal of Hydrology, v. 58, p. 11-27, 1982.

BUZZI, A.; FOSCHINI, L. Mesoscale meteorological features associated with heavy precipitation in the southern Alpine region. Meteorology and Atmospheric Physics, v. 72, p. 131-146, 2000.

CÂNDIDO, D. H.; NUNES, L. H. Influência da orografia na precipitação da área entre o vale do rio Tietê e a Serra da Mantiqueira. Espaço e Tempo, v. 24, p. 08-27, 2008.

CARVALHO, L. M. V.; JONES, C.; LIEBMANN, B. Extreme precipitation events in southeastern south america and large-scale convective patterns in the south atlantic convergence zone. Journal of Climate, v. 15, p. 2377-2394, 2002.

CARVALHO, M. A. V.; OYAMA, M. D. Variabilidade da largura e intensidade da Zona de Convergência Intertropical Atlântica: Aspectos observacionais. Revista Brasileira de Meteorologia, v. 28, n. 3, p. 305 - 316, 2013. 
CAVALCANTI, I. F. A.; KOUSKY, V. E. Frentes frias sobre o Brasil. In: CAVALCANTI, IRACEMA FONSECA DE ALBURQUERQUE; FERREIRA, NELSON JESUS; SILVA, MARIA GERTRUDES ALVAREZ JUSTI DA; SILVA DIAS, MARIA ASSUNÇÃo FAUS DA SILVA DIAS (Org.). Tempo e Clima no Brasil. São Paulo: Oficina de Textos, v. 135-147, 2009.

CHAN, S. C. Analysis of easterly wave disturbances over South Atlantic Ocean. Dissertação de mestrado, Instituto Nacional de Pesquisas Espaciais - INPE - 5222 - TDL/437, p. 104, 1990.

CHENG, K. S.; LIN, Y. C.; LIOU, J. J. Rain-gauge network evaluation and augmentation using geostatistics. Hydrological Processes, v. 22, n. 14, p. 2554-2564, 2008.

CLARK, P. J.; EVANS, F. C. Distance to nearest neighbor as a measure of spatial relationships in populations. Ecology, v. 35, p. 445-453, 1954.

CLARK, W. C. Scales of climate impacts. Climatic Change, v. 7, p. 5-27, 1985.

COHEN, J. C. P. et al. . Linhas de Instabilidade na Costa N-NE da America do Sul. n: CAVALCANTI, I.F.A.; FERREIRA, N.J.; SILVA, M.G.A.J.; SILVA DIAS, M.A.F. Tempo e clima do Brasil. 1.ed. São Paulo: Oficina de Textos, p. 75-93, 2009.

COHEN, J. C. P.; SILVA DIAS, M. A. F.; NOBRE, C. A. Aspectos climatológicos das linhas de instabilidade na Amazônia. Climanálise, v. 4, n. 11, p. 34-40, 1989.

CONRAD, V. Methods in climatology. Harvard University Press, Cambridge, MA, 1944.

CONTI, J. B. Um Episódio de Chuva em Território Paulista. Revista Geográfica, v. 81, p. 81-90, 1974.

CORREA, M. G. G. Distribuição espacial e variabilidade da precipitação pluviométrica na bacia do rio Piquiri-PR. Mestrado em Geografia Física, Universidade de São Paulo, 2013.

COUTINHO, E. C.; FISCH, G. Distúrbios Ondulatórios de Leste (DOLs) na região do Centro de Lançamento de Alcântara - MA. Revista Brasileira de Meteorologia, v. 22, n. 2, p. 193 203, 2007.

COX, D. R.; STUART, A. Quick sign tests for trend in location and dispersion. Biometrika, v. 42, p. 80-95, 1955.

CPRM. Serviço Geológico do Brasil. Atlas pluviométrico do Brasil. Isoietas Anuais na escala 1:5.000.000., v. Disponível em: <http://www.cprm.gov.br/publique/Hidrologia/Mapas-ePublicacoes/Atlas-Pluviometrico-do-Brasil-1351.html>, Acesso em 13 de maio, 2014.

DA ROCHA, R. P. et al. . Precipitation diurnal cycle and summer climatology assessment over South America: An evaluation of Regional Climate Model version 3 simulations. Journal of Geophysical Research, v. 114, 2009. 
DATE, C. J. Introdução a sistemas de banco de dados. 8. ed. Rio de Janeiro: Elsevier, 2003.

DAVIDSON, E. A. et al. . The Amazon basin in transition. Nature, v. 481, n. 7381, p. 321$328,2012$.

DELCOURT, H. R.; DELCOURT, P. A.; WEBB, T. Dynamic plant ecology: the spectrum of vegetation change in space and time. Quaternary Science Review, v. 1, p. 153- 175, 1983.

DOUGLAS, E. M.; VOGEL, R. M.; KROLL, C. N. Trends in Floods and Low Flows in the United States: Impact of Spatial Correlation. Journal of Hydrology, v. 240, p. 90-105, 2000.

ELMASRI, R.; NAVATHE, S. B. Sistemas de Banco de Dados. 6. ed. São Paulo: Addison Wesley, 2011.

ELY, D. F. Tendências climáticas e a incidência da dengue em cidades do sul do Brasil: estudo de caso de Londrina, Maringá (PR) e Florianópolis (SC). Revista Brasileira de Climatologia, v. 13, p. 149-163, 2013.

ESCÁRIA, V. A utilização do método XII-ARIMA na dessazonalização de séries de conjuntura. Prospectiva e Planeamento, v. 1, 1995.

ESCOBAR, G. Jatos de Altos Níveis. In: CAVALCANTI et al., Iracema F. A. Tempo e Clima no Brasil. São Paulo: Oficina de Textos, Cap 9, p. 126-134, 2009.

FERREIRA, N. J.; RAMIREZ, M. V.; GAN, M. A. Vórtices ciclônicos de altos níveis que atuam na vizinhança do Nordeste do Brasil. In: CAVALCANTI, I. F. DE A.; FERREIRA, N. J; SILVA, M. G. A. L. J; SILVA DIAS, M. A. F da (Org.). Tempo e clima no Brasil. São Paulo: Oficina de Texto, p. 43-60, 2009.

FETTER, R. et al. . A contribuição da Análise esáço-temporal de dados climáticos. In: BURSZTYN, M. E. R. F., S. (Ed.). O clima em transe: Vulnerabilidade e adaptação da agricultura familiar. 1. Rio de Janeiro: Garamond, 2016. cap. 10, p.219-244.

FORGIARINI, F. R.; VENDRUSCOLO, D. S. Análise de chuvas orográficas no centro do estado do Rio Grande do Sul. Revista Brasileira de Climatologia, v. 13, p. 107-119, 2013.

FREI, C.; SCHAR, C. A precipitation climatology of the Alps from high-resolution raingauge observations. International Journal of Climatology, v. 18, p. 873-900, 1998.

GAN, M. A.; RAO, V. B. Surface cyclogenesis over South America. Monthly Weather Review, v. 119, n. 5, p. 1293-1302, 1991.

GAN, M. A.; SELUCHI, M. E. Parte I - Sistemas meteorológicos que afetam o tempo na América do Sul: Ciclones e ciclogênese. In: CAVALCANTI, Iracema Fonseca de Alburquerque; FERREIRA, Nelson Jesus; SILVA, Maria Gertrudes Alvarez Justi da; SILVA DIAS, Maria Assunação Faus da (Ed.). Para entender tempo e clima. São Paulo: Oficina de Textos, p. 111-125, 2009. 
GIRONS LOPEZ, M. et al. . Location and Density of Rain Gauges for the Estimation of Spatial Varying Precipitation. Geografiska Annaler: Series A, Physical Geography, v. 97, n. 1, p. 167-179, 2015.

GOMES, W. P. A gênese e a distribuição sociespacial das chuvas no município de UbatubaSP. Monografia de Geografia, Universidade Estadual Paulista, 2015.

GREIG-SMITH, P. Pattern in vegetation. Journal of Ecology, v. 67, p. 755-779, 1979.

GRIMM, A. M. Interannual climate variability in South America: impacts on seasonal precipitation, extreme events and possible effects of climate change. Stochastic Environmental Research and Risk Assessment, v. 25, n. 4, p. 537-554, 2011.

GRIMM, A. M.; PAL, J. S.; GIORGI, F. Connection between Spring Conditions and Peak Summer Monsoon Rainfall in South America: Role of Soil Moisture, Surface Temperature, and Topography in Eastern Brazil. Journal of Climate, v. 20, n. 24, p. 5929-5945, 2007.

GRIMM, A. M.; ZILLI, M. T. Interannual variability and seasonal evolution of summer monsoon rainfall in South America. Journal of Climate, v. 22, n. 9, p. 2257-2275, 2009.

GONG, X.; BARNSTON, A. G; WARD, M. N. The Effect of Spatial Aggregation on the Skill of Seasonal Precipitation Forecasts. Journal of Climate, v.16 p. 3059- 3071, 2003.

GUEDES, R. L. et al. . Trajetórias dos sistemas convectivos sobre o continente americano. Anais II, Congresso Brasileiro de Meteorologia, Belo Horizonte-MG, v. 8, n. 77-80, 1994.

GUERRERO, A. M. et al. . Scale Mismatches, Conservation Planning, and the Value of Social-Network Analyses. Conservation Biology, v. 27, n. 1, p. 35-44, 2013.

HAAS, R. Simulações de chuva orográfica associada a um ciclone extratropical, no litoral sul do Brasil. Tese de Doutorado em Meteorologia, 2002.

HABERLANDT, U. Geostatistical interpolation of hourly precipitation from rain gauges and radar for a large-scale extreme rainfall event. Journal of Hydrology, v. 332, n. 1-2, p. 144157, 2007.

HAMED, K. H. Exact distribution of the Mann - Kendall trend test statistic for persistent data. Journal of Hydrology, v. 365, p. 86-94, 2009.

HARRIS, D.; GEORGIOU, E. F. Multiscale Statistical Properties of a High: Resolution Precipitation Forecast. Journal of Hidrometeorology, v. 2, p. 406-418, 2001.

HAYLOCK, M. R. et al. . Trends in total and extreme South American rainfall 1960-2000 and links with sea surface temperature. Journal of Climate, v. 9, p. 1490-1512, 2006.

HYNDMAN, R. J.; ATHANASOPOULOS, G. Forecasting: principles and practice. Disponível em: <http://otexts.org/fpp/>. Acesso em: 2 outubro, 2016, 2016. 
INMET. Instituto Nacional de Meteorologia. Normais Climatológicas do Brasil 1961-1990. v. Disponível em: 〈http://www.inmet.gov.br/portal/index.php?r=clima/normaisClimatologicas>, Acesso em: 13 de maio, 2014.

ISAAKS, E. H.; SRIVASTAVA, R. M. An introduction to applied geostatistics. New York: Oxford University Press, 1989.

JELINSKI, D. E.; J., W. The modifiable areal unit problem and implications for landscape ecology. Landscape Ecology, v. 11, p. 129-140, 1996.

JUNG, Y. et al. . Rain-Gauge Network Evaluations Using Spatiotemporal Correlation Structure for Semi-Mountainous Regions. Terrestrial, Atmospheric and Oceanic Sciences, v. 25, n. 2, p. 267-278, 2014.

KELLER FILHO, T.; ASSAD, E. D.; LIMA, P. R. S. R. Regiões pluviometricamente homogêneas no Brasil. Pesquisa Agropecuária Brasileira, v. 40, n. 4, p. 311-322, 2005.

KENDALL, M. G. Rank Correlation Methods. Charles Griffin: London, v. 4, p. 202, 1975.

KLIMOWSKI, B. A. et al. . The 1995 Arizona Program: toward a better understanding of winter storm precipitation development in mountainous terrain. Bulletin of the American Meteorological Society, v. 79, p. 799-813, 1998.

KOUSKY, V. E. Frontal influences on northeast Brazil. Monthly Weather Review, v. 107, p. 1142-1153, 1979.

KOUTSOYIANNIS, D. Nonstationarity versus Scaling in hydrology. Journal of Hydrology, v. 324, p. 239-254, 2006.

KRIGE, D. G. A statistical approach to some basic mine valuation problems on the Witwatersrand. Journal of the Chemical, Metallurgical and Mining Society of South Africa, v. 52, n. 6, p. 119-139, 1951.

KRUK, N. S. et al. . Modelagem de eventos de precipitação orográfica com o modelo GESIMA: uma aplicação a Serra do Mar SP. XIV Congresso Brasileiro de Meteorologia, 2006.

LAGRANGE, J. P.; RUAS, A. Geographic Information Modeling: GIS and Generalization. In: Waugh, T. C.; Healey, R. G. (eds.) Advances in GIS Research, Vol. 2, London, Taylor \& Francis, 1994.

LANDIM, P. M. B. Sobre Geoestatística e mapas. Terrae Didática, v. 2, n. 1, p. 19-33, 2006.

LEVIN, S. A. The Problem of Pattern and Scale in Ecology: The Robert H. MacArthur Award Lecture. Ecology, v. 73, n. 6, p. 1943-1967, 1992.

LIEBMANN, B.; ALLURED, D. Daily precipitation grids for South America. Bulletin of the American Meteorological Society, v. 86, p. 1567-1570, 2005. 
LIEBMANN, B. et al. . Mechanisms Associated with Large Daily Rainfall Events in Northeast Brazil. Journal of Climate, v. 24, n. 2, p. 376-396, 2011.

LIMA, K. C.; FERNÁNDEZ, J. P. R. A influência das anomalias de temperatura da superficie do mar e da topografia em dois eventos de precipitação intensa ocoridos no sudeste do Brasil. Engenharia Ambiental, v. 8, n. 1, p. 309-319, 2011.

LIU, Y. et al. . Isoprene photochemistry over the Amazon rainforest. Proc Natl Acad Sci U S A, v. 113, n. 22, p. 6125-30, 2016.

LYRA, G. B.; OLIVEIRA-JÚNIOR, J. F.; ZERI, M. Cluster analysis applied to the spatial and temporal variability of monthly rainfall in Alagoas state, Northeast of Brazil. International Journal of Climatology, v. 34, n. 13, p. 3546-3558, 2014.

MACHADO, L. A. T. et al. . Distúrbios ondulatórios de leste. In: CAVALCANTI, I. F. A.; FERREIRA, N. J.; SILVA, M. G. A. J.; DIAS, M. A. F. S. (Orgs.). Tempo e clima no Brasil. São Paulo: Oficina de Textos, p. 61-74, 2009.

MANN, H. B. Non-parametric test against trend, Econometrica. v. 13, p. 245-259, 1945.

MARENGO, J.; HASTERNRATH, S. Cases studies climatic events in Amazon Basin. Journal of Climate, v. 6, p. 617-627, 1993.

MARENGO, J. A. Interdecadal variability and trends of rainfall across the Amazon basin. Theoretical \& Applied Climatology, v. 78, n. 1-3, p. 79-96, 2004.

MARENGO, J. A. The characteristics and variability of the atmospheric water balance in the Amazon basin: Spatial and temporal variability. Climate Dynamics, v. 24, p. 11-22, 2005.

MARTÍNEZ, M. D. et al. . Time trends of daily maximum and minimum temperatures in Catalonia (ne Spain) for the period 1975-2004. International Journal of Climatology, v. 30, p. 267-290, 2010.

MELO, A. B. C.; CAVALCANTI, I. F. A.; SOUZA, P. P. Zona de convergência intertropical do Atlântico. In: CAVALCANTI, I. F. A.; FERREIRA, N. J., SILVA, M. G. A. J.; DIAS, M. A. F. S. Tempo e clima no Brasil. São Paulo: Oficina de Textos, Cap. 2, p. 25-41, 2009.

MELO JÚNIOR, J. C. F. et al. . Distribuição da frequncia de chuvas na região hidrográfica do Atlântico, leste de Minas Gerais. Revista Brasileria de Engenharia Agrícola e Ambiental, v. 10, n. 2, p. 417-425, 2005.

MENDES, D. et al. . On precursors of South American cyclogenesis. Tellus A, v. 59, n. 1, p. 114-121, 2007.

MENDONÇA, F.; DANNI-OLIVEIRA, I. M. Climatologia: noções básicas e climas do Brasil. São Paulo, v. Oficina de Texto, p. 206, 2007. 
MILANESI, M. A.; GALVANI, E. Efeito orográfico na Ilha de São Sebastião (Ilhabela - SP). Revista Brasileira de Climatologia, v. 9, p. 68-79, 2011.

MISHRA, A. K. Effect of rain gauge density over the accuracy of rainfall: a case study over Bangalore India. SpringerPlus, v. 2, n. 311, p. 2-7, 2013.

MOLION, L. C. B.; DAllaROSA, R. L. G. Pluviometria da Amazônia: são os dados confiáveis? Climanálise - Boletim de Monitoramento e Análise Climática, v. 5, n. 3, p. 40 $-42,1990$.

NEGRI, A. J.; ANAGNOSTOU, E. N.; ADLER, R. F. A 10-yr climatology of Amazonian rainfall derived from passive microwave satellite observations. Journal of Applied Meteorology, v. 39, p. 42-56, 2000.

NERY JUNIOR, H.; VANZELA, L. S. Influência do relevo sobre a distribuição espacial da precipitação no município de Caraguatatuba - SP. III Encontro de Pós-Graduação e IX Encontro de Iniciação Científica, 2015.

NIMER, E. Climatologia do Brasil. Rio de Janeiro: IBGE, p. 422, 1979.

NOBRE, C. Amazon and climate. in Proceedings of Climate Conference for latin America and the Caribbean, World Meteorological Organization, Geneva, 1983.

NOBRE, P.; MOURA, A. D.; SUN, L. Dynamical downscaling of seasonal climate prediction over Nordeste Brazil with ECHAM3 and NCEP's regional spectral models at IRI. Bulletin of the American Meteorological Society, v. 82, n. 12, p. 2787-2796, 2001.

NUNES, L. H. Estudo da normalidade da pluviometria no setor serrano de Cubatão e Baixada Santista - SP. Revista do Departamento de Geografia, n. 6, p. 31-43, 1992.

NUNES, L. H.; VICENTE, A. K.; CANDIDO, D. H. Clima da região sudeste do Brasil. In: CAVALCANTI, I. F. A.; FERREIRA, N. J.; JUSTI DA, M. G. A.; SILVA DIAS, M. A. F. Tempo e clima. São Paulo: Oficina de textos v. cap 16, p. 243-256, 2009.

O'NEILL, R. V. et al. . A hierarchical concept of ecosystems. New Jersey: Princeton University Press, p. 257, 1986.

OBREGÓN, G. O.; MARENGO, J. A. Caracterização do clima do século XX no Brtasil: Tendências de chuva e temperaturas médias e extremas. CPTEC/INPE, São Paulo, Brasil, 2007.

OLIVEIRA, A. P. D.; FITZJARRALD, D. R. The Amazon river breeze and the local boundary layer: I - Observations. Boundary Layer Meteorology, v. 63, n. 1-2, p. 141 - 162, 1993.

OLIVEIRA, M. R. P.; GALVANI, E. Avaliação do efeito orográfico na veriação das precipitações no perfil longitudinal Paraty-RJ e Campos do Jordão-SP. Entre-Lugar, v. 11, n. 1, p. 133-151, 2015. 
PELlEGATTI, C. H. G.; GALVANI, E. Avaliação da precipitação na serra do mar-SP em eventos de diferentes intensidade e duração. Espaço e Tempo, v. 27, p. 147-158, 2010.

PEREIRA, T. Influência do relevo na precipitação das regiões hidrográficas do litoral norte de Alagoas. Espaço e Tempo, v. 33, p. 239-253, 2013.

PINHEIRO, A.; GRACIANO, R. L. G.; SEVERO, D. L. Tendência das séries temporais de precipitação da região sul do Brasil. Revista Brasileira de Meteorologia, v. 28, n. 3, p. 281 290, 2013.

PIRES, C. A. L.; PEREIRA, L. S. Predictabilidade Sazonal de Secas Avaliação ao nível regional e agrícola. ISAPRESS, p. 332, 2015.

QUADRO, M. F. L.; ABREU, M. L. Estudos de episódios de Zonas de Convergência do Atlâantico Sul sobre a América do Sul. Anais II, Congresso Brasileiro de Meteorologia, Belo Horizonte-MG, v. 8, p. 620-623, 1994.

QUEIROZ, M. P. ANÁLISE ESPACIAL DOS ACIDENTES DE TRÂNSITO DO MUNICÍPIO DE FORTALEZA. Dissertação de Mestrado apresentada ao Programa de Mestrado em Engenharia de Transportes da Universidade Federal do Ceará, 2003.

RAO, V. B.; HADA, K. Characteristics of rainfall over Brazil: annual variations and connections with the Southern Oscillation. Theoretical and Applied Climatology, v. 42, p. 81-91, 1990.

REINSTORF, F. et al. . Comparative assessment of regionalization methods of monitored atmospheric deposition loads. Atmospheric Environment, v. 39, p. 3661-3674, 2005.

RIEHL, H. Tropical Meteorology. McGraw-Hill Book Company, Inc. Estados Unidos, 1954.

RODRIGUES, M. L. G. Eventos de chuva orografica em Santa Catarina - climatologia e simulações numéricas. Dissertação/Tese em Ciências, Universidade de São Paulo, 2015.

ROE, G. H. Orographic Precipitation. Annual Review of Earth and Planetary Sciences, v. 33, n. 1, p. 645-671, 2005.

ROSA, M. B. et al. . ENERGETICS OF CYCLOGENESIS EVENTS OVER THE SOUTHERN COAST OF BRAZIL. Revista Brasileira de Meteorologia, v. 28, n. 3, p. 231 $245,2013$.

ROTUNNO, R.; HOUZE, R. A. Lessons on orographic precipitation from the Mesoscale Alpine Programme. Quarterly Journal of the Royal Meteorological Society, v. 133, n. 625, p. 811-830, 2007.

RUAS, A.; LAGRANGE, J. P. Data and knowledge modelling for generalization. In: MÜlleR, J. C.; LAGRANGE, J. P.; WEIBEL, R. (Ed.). GIS and Generalization: Methodology and Practice. London: Taylor \& Francis, p. 73-90, 1995. 
RYBSKI, D. et al. . Long-term persistence in climate and the detection problem. Geophysical Research Letters - Wiley Online Library, v. 33, 2006.

SANSIGOLO, C. A.; KAYANO, M. T. Tendências nas temperaturas máximas e mínimas e nas precipitações sazonais do Rio Grande do Sul (1913-2006). In: XII Congresso Brasileiro de Meteorologia, Anais, Belém, 2010.

SANT'ANNA NETO, J. L. Por uma Geografia do Clima Antecedentes históricos, paradigmas contemporâneos e uma nova razão para um novo conhecimento. Terra Livre. n. 17, p. 49-62, 2001.

SATYAMURTI, P.; RAO, V. B. Zona de Convergência do Atlântico Sul. Climanálise v. 3, p. 31-35, 1988.

SCHMIDT, D. M. Dinâmica das configurações de formação e inibição das chuvas no Rio Grande do Norte: caracterização hidrográfica do estado. Tese de doutorado em Ciências Climáticas, 2014.

SELUCHI, M. E.; CALBETE, N. O.; ROZANTE, J. R. Análisis de Un Desarrollo Ciclónico en la Costa Oriental de América Del Sur. Revista Brasileira de Meteorologia, v. 16, n. 1, p. 51-65, 2001.

SELUCHI, M. E.; CHOU, S. C.; GRAMANI, M. A case study of a winter heavy rainfall event over the Serra do Mar in Brazil. Geofísica Internacional, v. 50, n. 1, p. 41-56, 2011.

SERRA, Y. L.; HOUZE, R. A. Observations of variability on synoptic time scales in the east Pacific ITCZ. Journal of the Atmospheric Sciences, v. 59, p. 1723-1743, 2002.

SERVAIN, J.; LUKAS, S. Climatic Atlas of the Tropical Wind Stress and Sea Surface Temperature 1985-1989. Service de la Documentation et des Publications (S.D.P.), Institut Français de Recherch pour l'Exploitation de la Mer, p. 143, 1990.

SESTER, M. Optmization approaches for generalization and data abstraction. International Journal of Geographical Information Systems, v. 19, n. 8-9, p. 871-897, 2005.

SHI, W. et al. . The Annual Cycle and Variability of Precipitation in Brazil. NCEP/Climate Prediction Center Atlas $\mathbf{N}^{\mathbf{0}}$ 9, v. Disponível em: <http://www.cpc.noaa.gov/ products/outreach/research_papers/ncep_cpc_atlas/9>, Acesso em 10 maio, 2000.

SILBERSCHATZ, A.; KORTH, H. F.; SUDARSHAN, S. Sistema de Banco de Dados. 3. ed. São Paulo: Makron Books, p. 778, 1999.

SILVA DIAS, M. A. F.; DA SILVA, M. G. A. J. Para Entender Tempo e Clima. In: Cavalcanti I.D.A., Ferreira N.J., da Silva M.G.A.J., Silva Dias M.A.F. orgs. Tempo e Clima no Brasil. São Paulo: Ofic. Textos, p. 15-21, 2009.

SILVA, E. M. S. et al. . Complexity and predictability of daily precipitation in a semi-arid region - an application to Ceará - Brazil. Nonlinear Processes in Geophysics, v. 13, p. 651659, 2006. 
SILVEIRA, M. H. S. análise termodinâmica dos complexos convectivos de mesoescala atuantes na costa leste do nordeste brasileiro. Mestrado em Meteorologia, Universidade Federal de Alagoas, 2012.

SINCLAIR, M. R. An objective cyclone climatology for the southern hemis. Monthly Weather Review, v. 122, p. 2239-2256, 1994.

SIQUEIRA, J.; MACHADO, L. A. T. Influence of the frontal systems on the day-to-day convection variability over South America. Journal of Climate, 2004.

SKRØVSETH, S.; BELLIKA, J. G.; GODTLIEBSEN, F. Causality in Scale Space as an Approach to Change Detection. PLoS ONE, v. 7, n. 12, 2012.

SMITH, R. B. The Influence of Mountains on the Atmosphere. Advances in Geophysics, v. 21, p. 87-230, 1979.

SOARES, F. S.; FRANCISCO, C. N.; SENNA, M. C. A. Distribuição espaço-temporal da precipitação da região hidrográfica da Baía da Ilha Grande - RJ. Revista Brasileira de Meteorologia, v. 29, n. 1, p. 125 - 138, 2014.

SOUZA, J. O. P.; ALMEIDA, J. D. M.; CORREA, A. C. B. Caracterização e espacialização da precipitação em bacia hidrográfica com relevo complexo - sertão central Pernambucano Bacia do Riacho do Saco. Revista de Geografia, v. 32, n. 2, p. 106-126, 2015.

TORRES, R. Analise e Modelagem dos Distúrbios Ondulatórios de Leste que atuam na Costa Leste do Nordeste do Brasil. Mestrado em Meteorologia - Instituto Nacional de Pesquisas Espaciais, São José dos Campos, 2008.

TURNER, M. G.; DALE, V. H.; GARDNER, R. H. Predicting across scales: Theory development and testing. Landscape Ecology, v. 3, n. 3 e 4, p. 245-252, 1989.

UVO, C. R. B.; NOBRE, C. A. zona de convergência intertropical (ZCIT) e a precipitação no Norte do Nordeste do Brasil. Parte I: a posição da ZCIT no Atlântico Equatorial. Climanálise: Boletim de Monitoramento e Análise Climática, v. 4, n. 7, p. 34-40, 1989.

VEMADO, F.; PEREIRA FILHO, A. J. Severe Weather Caused by Heat Island and Sea Breeze Effects in the Metropolitan Area of São Paulo, Brazil. Advances in Meteorology, v. 2016, p. 1-13, 2016.

VIANELLO, R. L.; ALVES, A. R. Meteorologia básica e aplicações. Viçosa. Imprensa Universitária., p. 449, 1991.

VIEUX, B.; VIEUX, J. Rainfall Accuracy Considerations Using Radar and Rain Gauge Networks for Rainfall-Runoff Monitoring. Journal of Water Management Modeling, p. 333-352, 2005.

VILLARINI, G. et al. . Rainfall and sampling uncertainties: A rain gauge perspective. Journal of Geophysical Research, v. 113, n. D11102, p. 1-12, 2008. 
WIENS, J. A. Spatial scaling in ecology. Functional Ecology, v. 3, p. 385-397, 1989.

WOODWARD, F. I. Climate and Plant Distribution. Cambridge: Cambridge University Press, 1987.

WU, J. Hierarchy and scaling: extrapolating information along a scaling ladder. Canadian Journal of Remote Sensing, v. 25, n. 4, p. 367-380, 1999.

$\mathrm{XU}, \mathrm{H}$. et al. . Assessing the influence of rain gauge density and distribution on hydrological model performance in a humid region of China. Journal of Hydrology, v. 505, p. 1-12, 2013.

XU, Z. X.; TAKEUCHIA, K.; ISHIDAIRAA, H. Monotonic trend and step changes in Japanese precipitation. Journal of Hydrology, v. 279, p. 144-150, 2003.

YEVJEVICH, V. Probability and statistics in hydrology. Fort Collins : Water Resources Publication, p. 276, 1972.

ZAR, J. H. BIOSTATISTICAL ANALYSIS. PRENTICE HALL, 2010.

ZAVATTINI, J. A.; BOIN, M. N. Climatologia grográfica: teoria e prática de pesquisa. Campinas: Editora Alínea, p. 151, 2013. 